ANA CRISTINA FERRARI GUALBERTO

\title{
APLICAÇÃO DA FERRAMENTA DSM - DESIGN STRUCTURE MATRIX AO PLANEJAMENTO DO PROCESSO DE PROJETO DE EDIFICAÇÕES
}


ANA CRISTINA FERRARI GUALBERTO

\section{APLICAÇÃO DA FERRAMENTA DSM - DESIGN STRUCTURE MATRIX AO PLANEJAMENTO DO PROCESSO DE PROJETO DE EDIFICAÇÕES}

Dissertação apresentada a Escola Politécnica da Universidade de São Paulo para obtenção do título de Mestre em Engenharia 
ANA CRISTINA FERRARI GUALBERTO

\section{APLICAÇÃO DA FERRAMENTA DSM - DESIGN STRUCTURE MATRIX AO PLANEJAMENTO DO PROCESSO DE PROJETO DE EDIFICAÇÕES}

Dissertação apresentada a Escola Politécnica da Universidade de São Paulo para obtenção do título de Mestre em Engenharia Área de Concentração: Engenharia Civil e Urbana

Orientador: Prof. Dr. Silvio Melhado 
Este exemplar foi revisado e alterado em relação à versão original, sob responsabilidade única do autor e com a anuência de seu orientador.

São Paulo, 11 de julho de 2012.

Assinatura do autor

Assinatura do orientador

\section{FICHA CATALOGRÁFICA}

Gualberto, Ana Cristina Ferrari

Aplicação da ferramenta DSM - Design Structure Matrix ao planejamento do processo de projeto de edificações / A.C.F. Gualberto. -- ed.rev. -- São Paulo, 2012.

$197 \mathrm{p}$.

Dissertação (Mestrado) - Escola Politécnica da Universidade de São Paulo. Departamento de Engenharia de Construção Civil.

1. Administração de projetos 2. Edificações (Projeto; Processos; Planejamento) 3. Design Structure Matrix I. Universidade de São Paulo. Escola Politécnica. Departamento de Engenharia de Construção Civil II. t. 


\section{DEDICATÓRIA}

Dedico este trabalho aos meus pais, Edmundo e Ana Maria (in memorian), por tanto me incentivarem nos estudos, aos meus irmãos Fernanda e André que me apoiaram e orientaram nesta jornada, ao meu marido Marcelo que sempre me apoiou e entendeu minhas ausências neste período, e à minha amada filha Livia, que tão pequenininha teve que aprender a dividir. 


\section{AGRADECIMENTOS}

A Prof. Silvio B. Melhado, por sua motivação ao desenvolvimento do trabalho e por sua dedicação e atenção na orientação deste.

A todos os professores que tanto contribuíram com informações, textos e comentários.

A todos os colegas pelas preciosas dicas que foram passadas, muitas vezes até inconscientemente.

Aos professores que participaram da minha banca de qualificação: Marcio Fabricio e Francisco Assumpção pelas contribuições e esclarecimentos, tão importantes para continuidade do trabalho.

Aos colegas de profissão Henrique Cambiaghi, Ana Cristina Chalita, Karin Kroner, Ana Liu, Sumaia Sleiman. Marco Manso, Barbara Kelch, Michele Araújo e em particular Leonardo Manzione, pelos comentários enviados que tanto agregaram e contribuíram para o desenvolvimento deste trabalho.

À Bolsa de Imóveis que me incentivou e permitiu que eu dedicasse parte de meu horário de trabalho ao desenvolvimento desta dissertação, e a toda a equipe da empresa, que tanto me auxiliou nos momentos de correria e pelos comentários feitos no texto e pelo suporte técnico tantas vezes prestado.

Às minhas queridas amigas Cintia Vedovello e Cilene Marques, por todos os trabalhos feitos em grupo, pelo apoio, carinho, dedicação, risadas e angústias que dividimos durante todo o período de estudos e principalmente por continuarem a fazer parte da minha vida, não encerrando nossa preciosa amizade junto com este trabalho.

Ao meu marido Marcelo e minha pequena Livia, que tanto me incentivaram e apoiaram durante toda a jornada.

A toda minha família que sempre soube compreender meus momentos de ansiedade, minhas conversas curtas pelo tempo escasso e minhas ausências para finalização deste trabalho. 
A todos que de uma maneira ou de outra se envolveram com este trabalho minha sincera gratidão e um abraço enorme. 


\section{RESUMO}

O presente trabalho apresenta uma análise da aplicação da ferramenta DSM Design Structure Matrix ao planejamento do processo de projeto de edificações.

O objetivo principal desta pesquisa é a análise dos Manuais de Escopo de Projetos e Serviços para a Indústria Imobiliária do ponto de vista do planejamento do processo de projeto, utilizando a ferramenta DSM.

Para desenvolvimento da pesquisa primeiramente foi feita uma revisão bibliográfica, onde selecionou-se a metodologia ADePT para o desenvolvimento do planejamento do processo de projeto.

Em seguida foram aplicadas as duas primeiras etapas da metodologia ADePT definição do processo e otimização do processo, que forneceram material para uma análise da aplicação da ferramenta DSM ao planejamento do processo de projeto e uma análise crítica sobre os Manuais de Escopo de Projetos e Serviços para a Indústria Imobiliária.

O cumprimento das duas primeiras etapas da metodologia ADePT forneceu material com informações que permitiram a observação de algumas incoerências e permitiu a apresentação de críticas e sugestões de alterações em seu conteúdo, como proposta de melhoria à ferramenta-guia que estes se propõem a ser.

Por fim, a partir da validação da DSM como ferramenta para o desenvolvimento do planejamento do processo de projeto e com base nas alterações sugeridas para os manuais, foi proposto um novo modelo de processo de projeto.

Palavras-chave: processo de projeto, planejamento, gestão de projeto, Design Structure Matrix 


\begin{abstract}
This study presentes na analysis of aplication of DSM - Design Struture Matrix to the planning process of building design.

The main objective this study is the analysis of manuals Scope of Projects and Services for the Real State Industry in terms of planning the design process, using the DSM.
\end{abstract}

For development of the study was first done a literature review, where we selected the ADEPT methodology to development planning this process.

When we applied the first two stages of ADEPT methodology - process definition and optimization of the process, which provided material for an analysis of the implementation of DSM planning in the design process and a critical analysis of the Manuals Scope of Projects and Services for Real State Industry.

Compliance with the first two stages of ADEPT methodology provided material with information that allowed the observation of some inconsistencies and allowed the presentation of comments and suggestions for changes in content, as proposed improvements to the tool guide that they purport to be.

Finally, from the validation of the DSM as a tool for development planning and design process based on the suggested changes to the manuals, we proposed a new model of the design process.

Keywords: design process, planning, project management, Design Struture Matrix 


\section{LISTA DE ILUSTRAÇÕES}

Figura 1: representação gráfica da metodologia do trabalho

Figura 2: Evolução do empreendimento e interfaces com as atividades de projeto (ASSUMPÇÃO; FUGAZZA, 2001) .28

Figura 3: Agentes intervenientes na gestão do processo de projeto 34

Figura 4: Ciclo da qualidade do desenvolvimento de projeto no mercado imobiliário

Figura 5: Nível de influência das fases do processo de produção sobre os custos (BARRIE; PAULSON, 1978 apud COVELO, 2003) 36

Figura 6: Elementos que compõem a qualidade do projeto . .36

Figura 7: Agentes atuantes no desenvolvimento do empreendimento. 39

Figura 8: Arranjo multidisciplinar da equipe de projeto (MELHADO, 2005). 40

Figura 9 - O projeto como processo e como produto nos Manuais de Contratação de Projetos e Serviços 46

Figura 10 - Origem das atividades conforme manuais de contratação de projetos e serviços.....

Figura 11 - Projeto como fluxo de informações. .57

Figura 12 - Representação dos subprocessos de gerenciamento de projetos,. .59

Figura 13 - Estrutura dos processos de planejamento de projetos, (PMI, 2000 apud HOFFMEISTER, 2003) 61

Figura 14 - Modelo detalhado do planejamento (VERZUH, 2000) . 62

Figura 15 - Estrutura de projeto integrada. .69

Figura 16 - Representação da relação entre as atividades .71

Figura 17 - Matriz de projeto com representação das dependências de informações .72

Figura 18 - Sequenciamento da metodologia ADePT (WASKETT et al, 2010) .........76

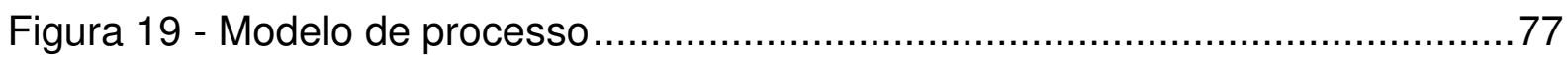

Figura 20 - Visão geral do modelo (AUSTIN et al.,2000) …………………........79

Figura 21 - Estrutura principal do modelo genérico do projeto de arquitetura

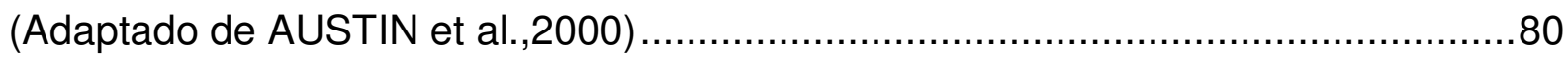

Figura 22 - Convenção para representação da metodologia IDEF0 ….....................83

Figura 23 - Otimização do processo (fonte: www.adeptmanagement.com) ...............84

Figura 24 - O plano de projeto (fonte: www.adeptmanagement.com) …...................85 
Figura 25: Processo de projeto conforme Manuais de Escopo de Contratação de

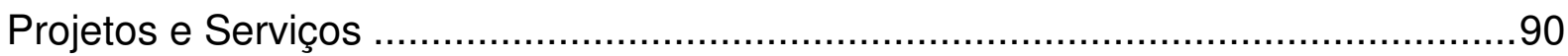

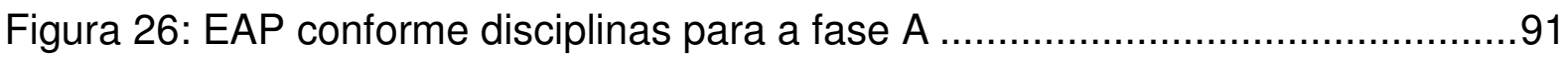

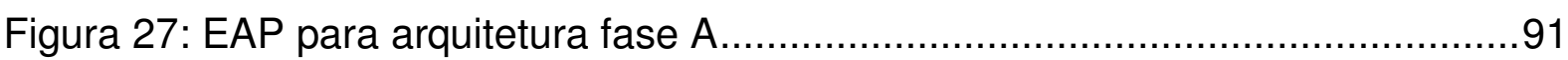

Figura 28: Diagrama de rede conforme Manuais fases A e B ...............................95

Figura 29: Diagrama de rede conforme Manuais fase $C$.......................................96

Figura 30: Diagrama de rede conforme Manuais fase D ....................................97

Figura 31: estruturação da matriz DSM fases A e B .......................................100

Figura 32: estruturação da matriz DSM fase C ...............................................101

Figura 33: estruturação da matriz DSM fase D …...........................................102

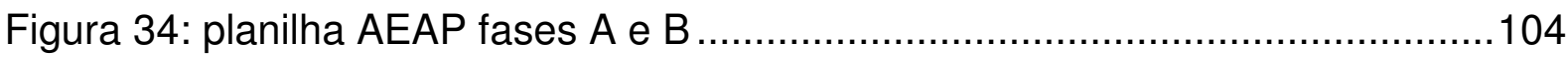

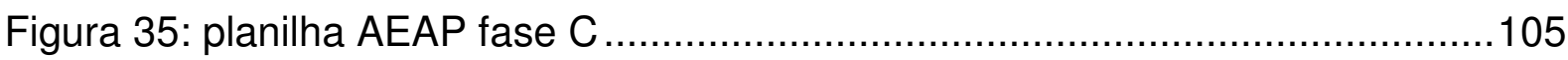

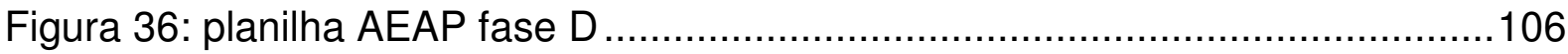

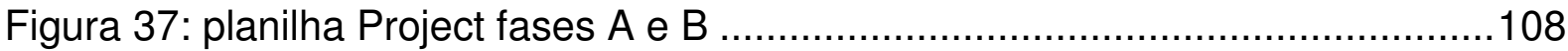

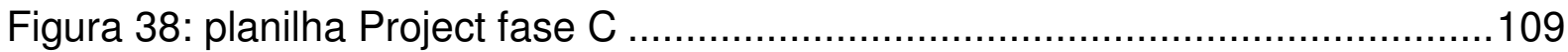

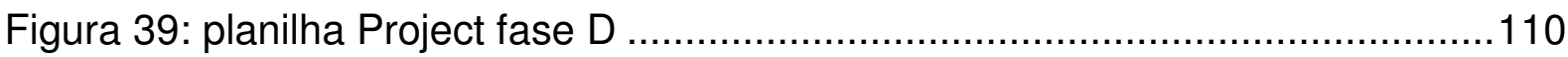

Figura 40: modelo de processo de projeto fases A e B....................................112

Figura 41: modelo de processo de projeto fase C ...........................................113

Figura 42: modelo de processo de projeto fase D...........................................114

Figura 43: estruturação da matriz DSM fases A e B após análise crítica.................119

Figura 44: planilha AEAP fases A e B após análise crítica ..................................120

Figura 45: planilha Project fases A e B após análise crítica.................................121

Figura 46: modelagem do processo de projeto Fases A e B após Análise Crítica..122

Figura 47: estruturação da matriz DSM fase $C$ após análise crítica........................124

Figura 48: planilha AEAP fase $C$ após análise crítica .......................................125

Figura 49: planilha Project fase $C$ após análise crítica .......................................126

Figura 50: modelagem do processo de projeto Fase $C$ após Análise Crítica..........127

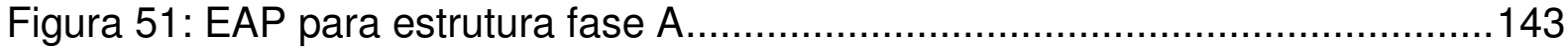

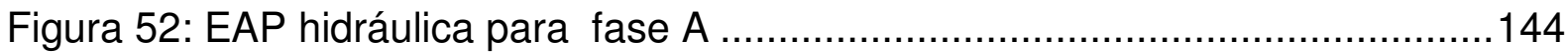

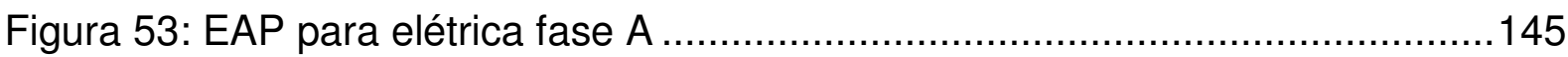

Figura 54: EAP para ar condicionado fase A..................................................146

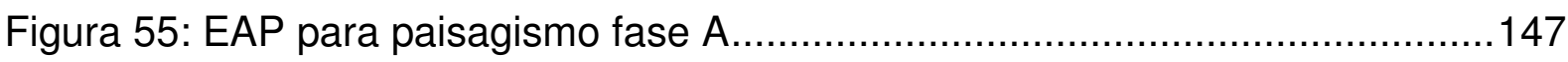

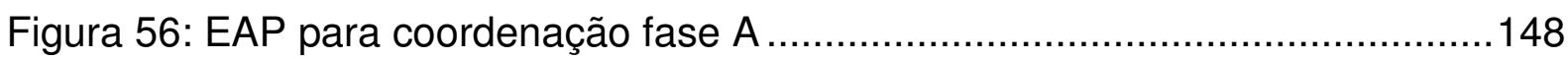

Figura 57: EAP conforme disciplinas para a fase B ..........................................149 


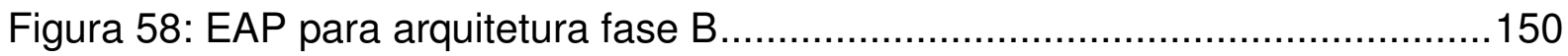

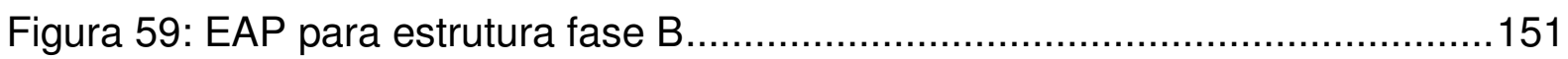

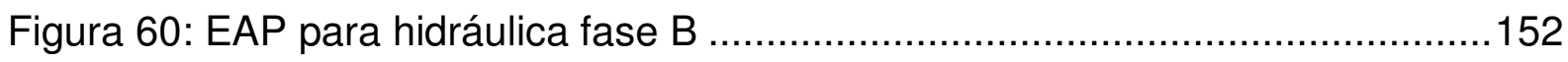

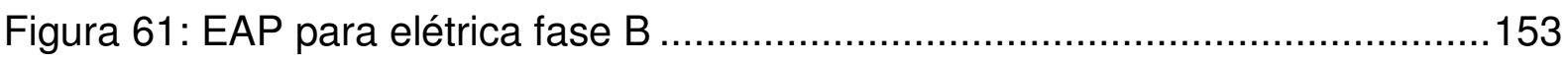

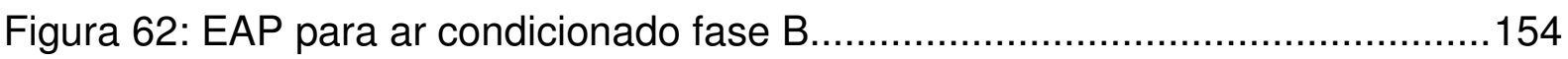

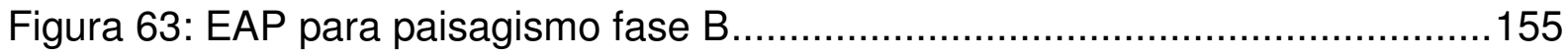

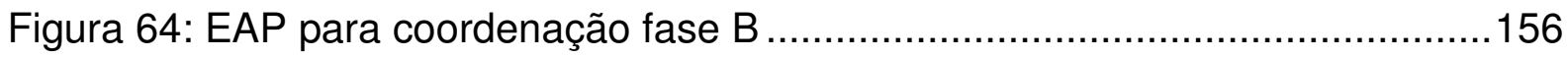

Figura 65: EAP conforme disciplinas para a fase C ......................................157

Figura 66: EAP para arquitetura fase C ...................................................158

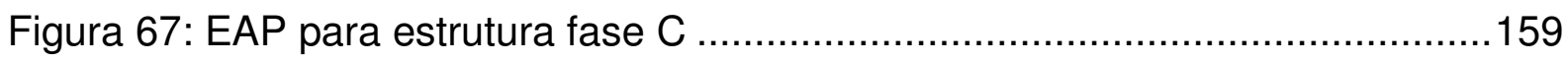

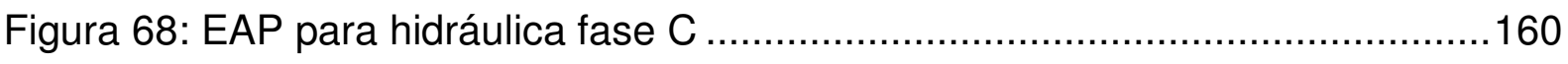

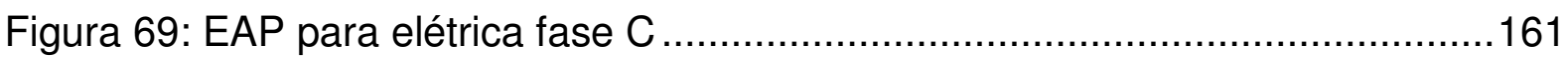

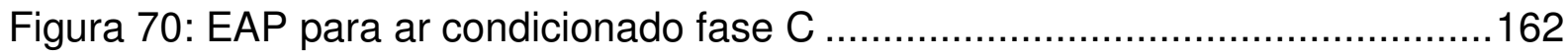

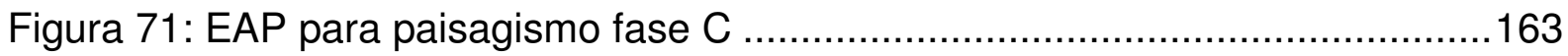

Figura 72: EAP para coordenação fase C ...................................................164

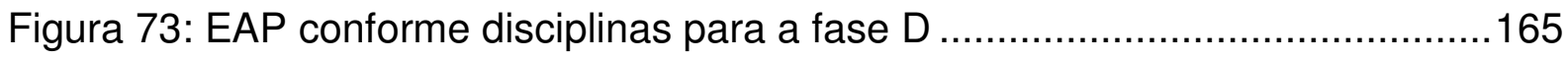

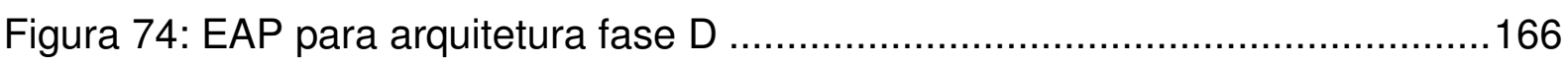

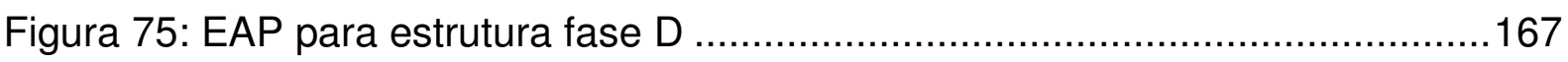

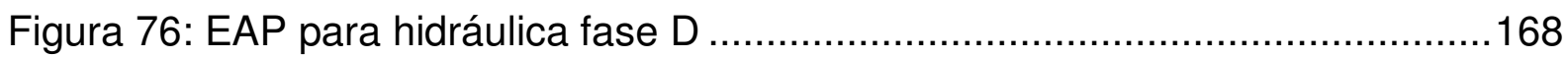

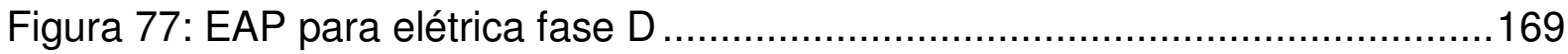

Figura 78: EAP para ar condicionado fase D ……...........................................170

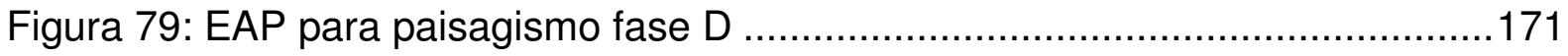

Figura 80: EAP para coordenação fase D .........................................................172 


\section{LISTA DE TABELAS}

Tabela 1: Principais serviços e atividades do processo de projeto de empreendimentos de edificações (FABRICIO, 2002)..........................................27

Tabela 2: Proposta de componentes da qualidade de projeto (PICCHI, 1993) .........29

Tabela 3: Componentes da qualidade do projeto (FABRICIO, 2002) .......................31

Tabela 4: Grupos de projetos e suas tipologias …………...................................

Tabela 5: dados de entrada e análise dos resultados das etapas da DSM...............70

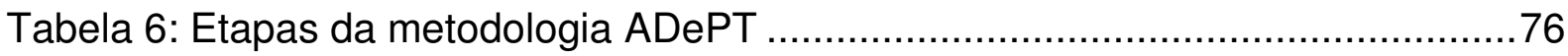

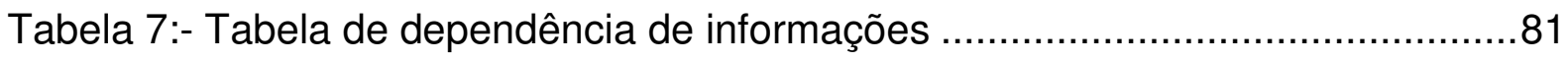

Tabela 8: tabela de dependência de informações fase A ........................................93

Tabela 9: Tabela de dependência de informações fase $B$....................................179

Tabela 10: Tabela de dependência de informações fase $C$.................................185

Tabela 11: Tabela de dependência de informações fase $D$..................................197 


\section{LISTA DE ABREVIATURAS E SIGLAS}

$\begin{array}{ll}\text { ADePT } & \text { Analytical Design and Planning Techniques } \\ \text { ASME } & \text { American Society of Mechanical Engineers } \\ \text { CA } & \text { California } \\ \text { CTE } & \text { Centro de Tecnologia de Edificações } \\ \text { DSM } & \text { Design Structure Matrix } \\ \text { EAP } & \text { Estrutura Analítica de Projeto } \\ \text { IDEF0 } & \text { Integration Definition for Function Modeling } \\ \text { IEEE } & \text { Instituto de Engenheiros Elétricos e Eletrônicos } \\ \text { INCOSE } & \text { The International Council on Systems Engineering } \\ \text { PMI } & \text { Project Management Institute }\end{array}$

Secovi-SP Sindicato das Empresas de Compra, Venda, Locação e Administração de Imóveis Residenciais e Comerciais de São Paulo

UK United Kingdom

USA United States of America

WBS Work Breakdown structure

ABECE Associação Brasileira de Engenharia e Consultoria Estrutural

AsBEA Associação Brasileira de Escritórios de Arquitetura

ABRASIP Associação Brasileira de Engenharia de Sistemas Prediais

SINDUSCON Sindicato da Indústria da Construção Civil do Estado de São Paulo 


\section{SUMÁRIO}

1. INTRODUÇÃO …...............................................................................17

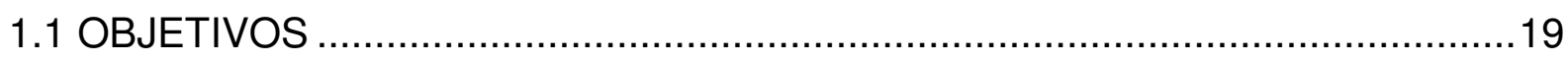

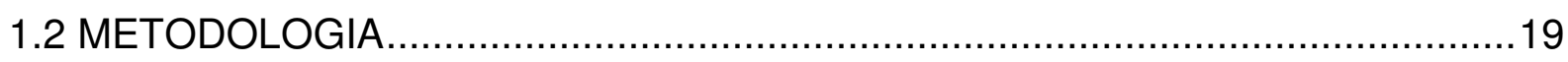

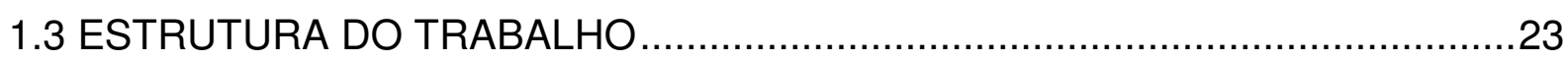

2 REVISÃO BIBLIOGRÁFICA

2.1 A GESTÃO DO PROCESSO DE PROJETO DO EMPREENDIMENTO .............25

2.1.1 O processo de projeto na indústria da construção civil .............................25

2.1.2. A qualidade do processo de projeto ………….........................................28

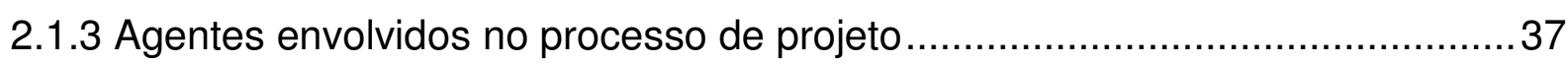

2.1.4 Dificuldades para a gestão do processo de projeto …………....................... 40

2.2 MANUAIS DE ESCOPO DE PROJETOS E SERVIÇOS PARA A INDÚSTRIA

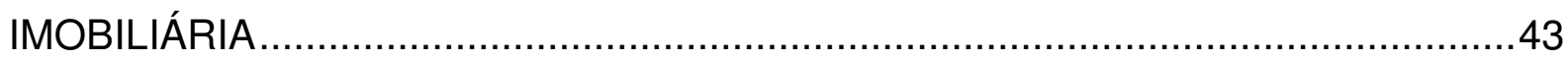

2.2.1 Histórico dos escopos existentes no Brasil ................................................... 47

2.2.2 As Fases dos Manuais de Escopo de Projetos e Serviços para a Indústria

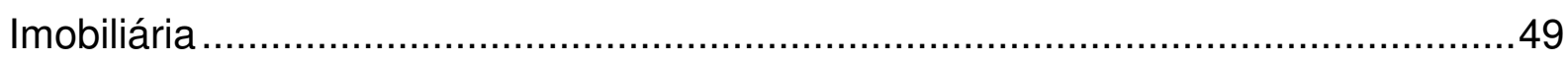

2.3. O PLANEJAMENTO DO PROCESSO DE PROJETO …................................51

2.3.1. A importância do planejamento do processo de projeto...................................51

2.3.2. A importância da modelagem do processo de projeto ……………………....54

2.3.3. Definição das tarefas e o fluxo de informações no processo de projeto ..........55

2.3.4. O planejamento do processo de projeto.....................................................58

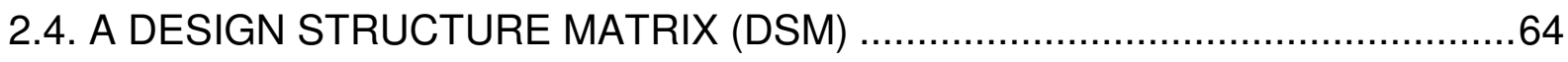

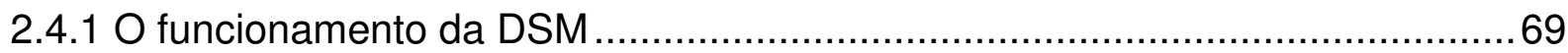

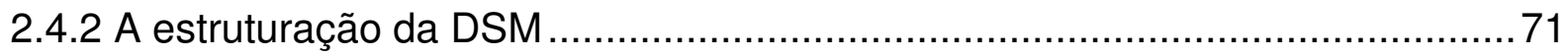

2.5 METODOLOGIA PARA PLANEJAMENTO DE PROJETOS: ANALYTICAL DESIGN PLANNING TECHNIQUES (ADePT) …….........................................74 
2.5.1. Definição do processo

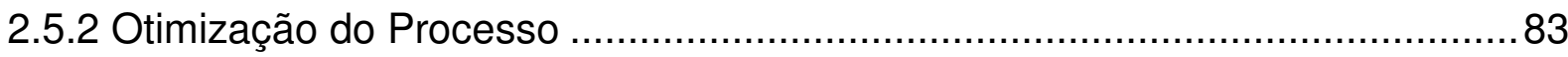

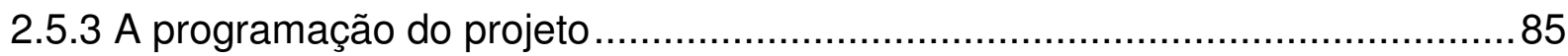

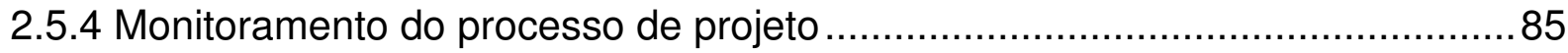

3. MODELAGEM DO PROCESSO DE PROJETO......................................87

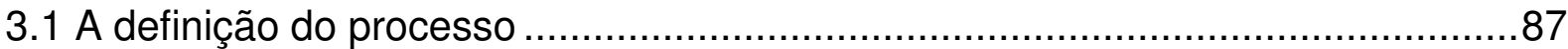

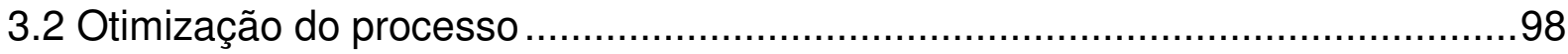

3.3 Conclusões da aplicação da DSM.............................................................115

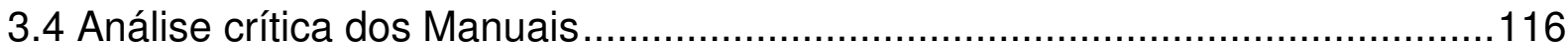

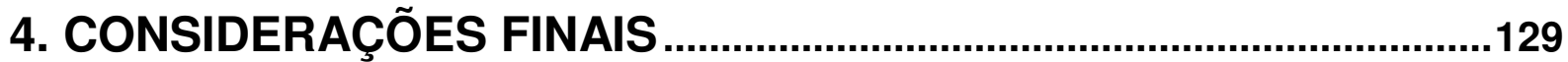

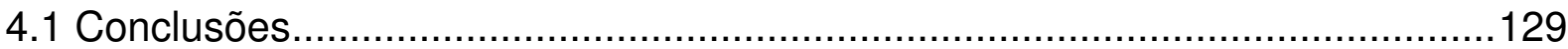

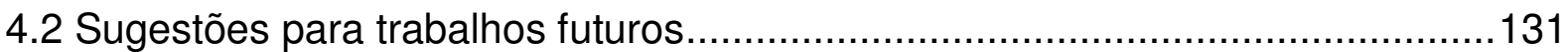

REFERÊNCIAS BIBLIOGRÁFICAS ..................................................132

APÊNDICE A - Listagem das atividades.............................................137

APÊNDICE B - Estrutura das atividades ...........................................142

APÊNDICE C - Tabela de dependência de informações .....................173 


\section{INTRODUÇÃO}

O mercado imobiliário atual apresenta-se estável, retornando aos índices de normalidade, após um período de euforia percebido no ano de 2010. Segundo Petrucci, é consenso no mercado que o setor atingiu um patamar de normalidade com cerca de $40 \%$ do empreendimento vendido no período de lançamento e previsão de venda da quase totalidade em um ano (SECOVI-SP). Esta situação já pode ser observada pelos índices da Região Metropolitana de São Paulo. Inicia-se também um novo ciclo, com a finalização dos empreendimentos lançados entre 2007 e 2008, a abertura de capital de diversas empresas e a facilidade de acesso ao crédito, que gerou uma forte demanda por imóveis.

O fim do ciclo de euforia exigirá do mercado imobiliário uma reestruturação, de forma a atender as novas demandas que estão surgindo e corrigir as falhas identificadas no período anterior, como questões referentes a prazos, custos e qualidade das obras.

O projeto tem papel fundamental na qualidade do empreendimento apresentando-se como o elo da cadeia produtiva. O projeto contempla as definições do produto que interferem nos resultados econômicos do empreendimento, sendo o processo de projeto a etapa mais estratégica com relação aos gastos de produção e agregação de valor ao produto. O projeto deve agregar eficiência e qualidade ao produto e processo construtivo, atendendo aos interesses do empreendedor, projetista, construtor e usuário. (MELHADO, 2005)

No entanto, o cumprimento de prazos e cronogramas de projeto é um problema constante, alvo de reclamações de diversos contratantes e justificativa para atrasos de outros agentes do processo em função do atraso de um, interferindo na produtividade e competitividade do empreendimento.

A Gestão do Processo de Projeto é um assunto já bastante debatido no meio acadêmico, com diversas propostas de ferramentas que auxiliem e viabilizem uma melhora do planejamento do processo de projeto, de forma a se alcançar uma melhoria no fluxo de informações, na integração projeto-obra, na diminuição do ciclo do processo e retrabalhos, e outros fatores que limitam a produtividade do processo.

$\mathrm{Na}$ prática, porém, verifica-se a utilização de métodos obsoletos de modelo de gestão, que valorizam somente o produto final em detrimento do processo, 
controlando contratos e entregas de desenhos sem a valorização da integração entre os diversos agentes envolvidos, a redução de prazos e análise do fluxo de informações. A gestão do processo de projeto ainda é praticada de forma simplista, muitas vezes com projetos sendo trabalhados de forma sequencial e sem a integração dos diversos agentes envolvidos no processo.

Fabrício e Melhado propõem a incorporação de conceitos da Engenharia Simultânea na gestão do processo de projeto, que deve considerar o caráter multidisciplinar do projeto e a interatividade de seu processo de elaboração. A troca de informações é a essência do projeto, e a capacidade do gestor de estruturar o processo de projeto a partir de suas precedências de informações, e não apenas a partir de sequências de entregas de desenhos, é fundamental para um bom andamento do processo e um planejamento efetivo das atividades.

Também são freqüentes as dúvidas sobre o que, quando e como deve ser elaborado, desenvolvido e entregue o projeto. Essas dúvidas se estendem por todas as etapas do projeto, gerando desgastes entre toda a equipe e insatisfação entre contratantes e contratados.

Com o objetivo eliminar as lacunas e dúvidas referentes ao escopo dos projetos a serem contratados, entidades representativas do setor de projetos, com a participação de entidades setoriais representativas dos contratantes de projetos, do setor imobiliário e da construção se uniram, para desenvolver o conjunto de Manuais de Escopo de Projetos e Serviços para a Indústria Imobiliária a fim de oferecer ao mercado uma ferramenta-guia, que esclareça como devem ser desenvolvidos os projetos, percorrendo todas as etapas necessárias, e qual o nível de detalhamento requerido.

Verifica-se assim a necessidade de uma modelagem do processo de projeto que represente a interatividade, reorganize as atividades e reduza os ciclos de retrabalho, de forma a permitir uma visão de todo o conjunto do processo viabilizando um bom planejamento das atividades.

Manzione (2006) propõe o desenvolvimento de uma proposta para modelagem do processo com base as atividades sugeridas pelos Manuais de Escopo de Projetos e Serviços para a Indústria Imobiliária e em seguida a aplicação da Design 
Structure Matrix (DSM). A DSM deverá organizar o fluxo de informações, identificando os ciclos onde ocorrem interações de atividades e entre os agentes envolvidos, com o estabelecimento de precedências para desenvolvimento de outras atividades. A ferramenta também se propõe a minimizar os retrabalhos em função de revisões desnecessárias, acelerando os processos de entrega de etapas e viabilizando a continuidade dos trabalhos dos demais agentes envolvidos nas etapas subseqüentes do empreendimento.

Com base então na proposta apresentada por Manzione foi desenvolvido este trabalho.

\subsection{OBJETIVOS}

O objetivo principal desta pesquisa é a análise da aplicação da ferramenta DSM - Design Structure Matrix ao planejamento do processo de projeto de edificações. O planejamento do processo de projeto foi elaborado utilizando-se como base os Manuais de Escopo de Projetos e Serviços para a Indústria Imobiliária.

Os Manuais de Escopo de Projetos e Serviços para a Indústria Imobiliária representam as boas práticas recomendadas por profissionais, porém não contemplam o processo de projeto e sim fornecem subsídios para que o planejamento seja desenvolvido. Desta forma pode-se considerar que os Manuais apresentam as diretrizes para o planejamento do processo de projeto, e não 0 processo em si. A partir destas considerações os Manuais foram interpretados e as informações transmitidas por estes como produtos gerados foram transformadas em atividades que serviram de base para o planejamento do processo de projeto desenvolvido nesta pesquisa.

Para que o objetivo principal da pesquisa seja atingido será necessária a análise das questões abaixo listadas como objetivos parciais a serem verificados durante 0 desenvolvimento da pesquisa:

- Análise da aplicação da ferramenta DSM ao planejamento do processo de projeto;

- Análise crítica dos Manuais 
O esclarecimento dos objetivos parciais da pesquisa viabilizará o cumprimento do objetivo principal desta, possibilitando a elaboração de um modelo de processo de projeto com base nas diretrizes fornecidas pelos Manuais e na aplicação da ferramenta DSM.

\subsection{METODOLOGIA}

Neste capítulo será descrita a metodologia utilizada para o desenvolvimento da pesquisa. A figura 1 representa graficamente a sequência do processo de trabalho utilizado para obtenção dos objetivos estabelecidos: a análise dos resultados da aplicação prática da ferramenta DSM para o planejamento do processo de projeto e a análise crítica dos Manuais Manuais de Escopo de Projetos e Serviços para a Indústria Imobiliária. 


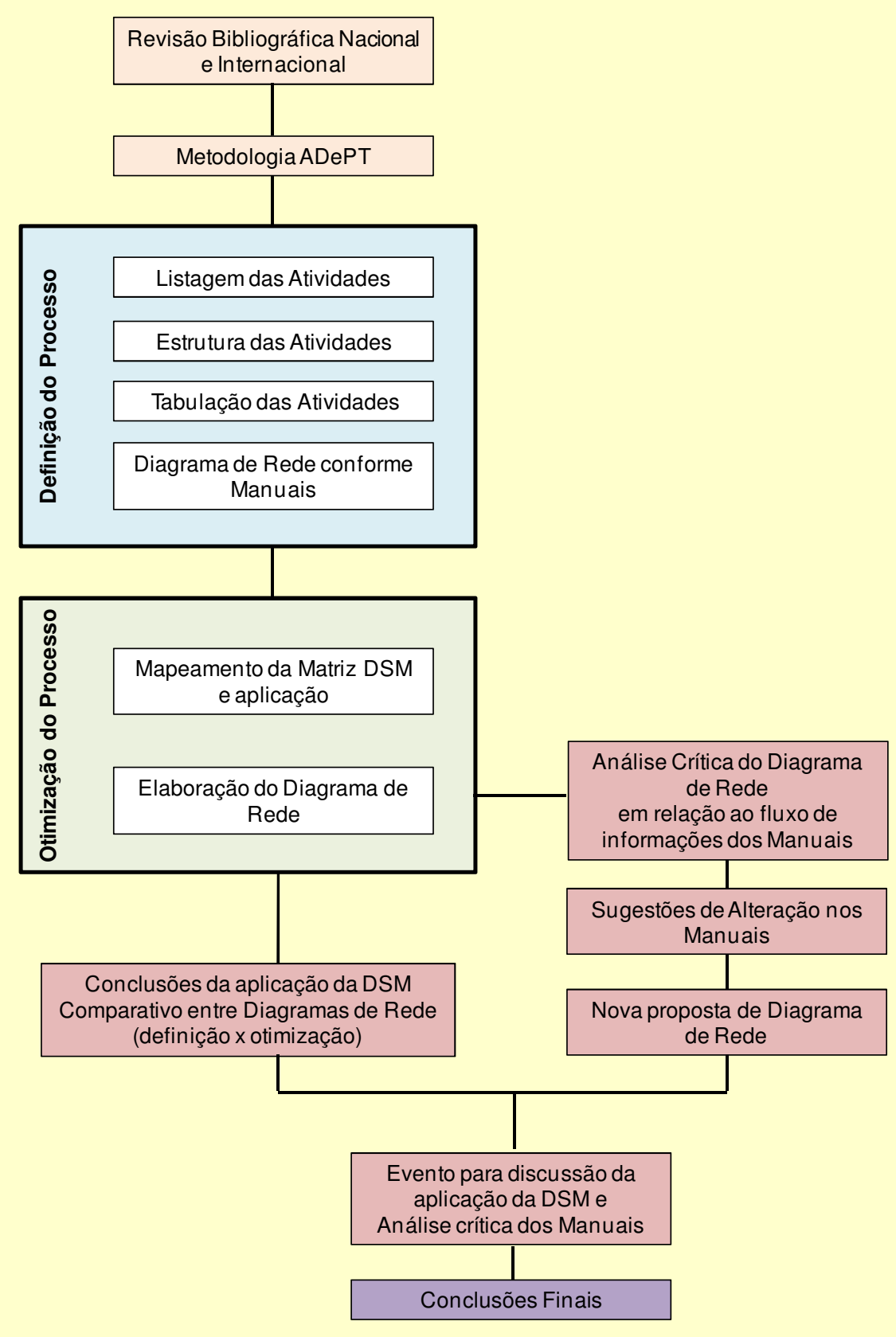

Figura 1: representação gráfica da metodologia do trabalho

A pesquisa foi iniciada a partir de revisão bibliográfica acerca do tema proposto. Para um melhor entendimento do tema foram pesquisados periódicos, livros, teses, dissertações que discorressem sobre o tema planejamento de projeto e Design Structure Matrix (DSM), além de um aprofundamento dos Manuais de Escopo de Projetos e Serviços para a Indústria Imobiliária, bibliografia fundamental para a proposta de aplicação da ferramenta. 
O presente trabalho foi dividido em quatro fases distintas, necessárias ao bom andamento da pesquisa proposta.

$\mathrm{Na}$ primeira fase foi desenvolvida a revisão bibliográfica, com o objetivo de delinear melhor o tema e discorrer sobre as diversas propostas para o planejamento do processo de projeto. A partir da revisão bibliográfica, selecionou-se a metodologia ADePT para o desenvolvimento do planejamento do processo de projeto.

$\mathrm{Na}$ segunda fase foram aplicadas as duas primeiras etapas da metodologia ADePT - definição do processo e otimização do processo.

A etapa de definição do processo obedece ao seguinte seqüenciamento de trabalhos:

1. Listagem das atividades;

2. Estrutura das atividades;

3. Tabulação das atividades;

4. Diagrama de rede.

Para desenvolvimento deste trabalho foram utilizados os Manuais de Escopo de Projetos e Serviços para a Indústria Imobiliária das especialidades de arquitetura, estrutura, hidráulica, elétrica, climatização, paisagismo e coordenação de projetos, limitando os trabalhos às fases $A$ a $D$, e aos serviços essenciais. Apesar da publicação de manuais de outras especialidades, foi feita a opção pelos citados acima e limitado às atividades dos serviços essenciais por se tratarem de especialidades e escopos mais comumente contratados pelo mercado imobiliário, bem como facilitar a visualização da metodologia através da restrição de fases e atividades.

Para o cumprimento da segunda etapa da metodologia, a otimização do processo, as atividades e suas dependências foram representadas através da DSM. Para desenvolvimento da matriz foram utilizadas as tabelas de dependências das fases $A$ e B, C e D como base de dados para sua elaboração e identificação das relações entre as atividades. Para aplicação da DSM foi utilizada a ferramenta computacional DSM@MIT, proposta na dissertação de mestrado “An Integrated Method for Managing Complex Engineering Projects Using the Design Structure Matrix and Advanced Simulation", por Soo-Haeng Cho e Steven D. Eppinger, no MIT - Massachusetts Institute of Technology em junho de 2001 (CHO, 2001). Com base no resultado da planilha AEAP (as early as possible), selecionada entre as outras quatro situações apresentadas pela matriz DSM por se tratar do cenário mais usual 
no mercado imobiliário, e na planilha Project, foi desenvolvido um novo Diagrama de rede.

A terceira fase se inicia a partir da finalização do Diagrama de rede gerado pela aplicação da matriz DSM na etapa de otimização do processo. Este diagrama foi comparado ao Diagrama de rede desenvolvido durante a definição do processo e então foi analisada a aplicação da DSM para verificação do atendimento aos objetivos estabelecidos: análise dos resultados da aplicação prática da ferramenta DSM ao planejamento do processo de projeto.

Ainda na terceira fase, juntamente com a análise da aplicação da matriz DSM, foi desenvolvida a análise crítica dos Manuais de Escopo de Projetos e Serviços para a Indústria Imobiliária. Para esta análise foi utilizado o diagrama de rede desenvolvido durante a otimização do processo, uma vez que este representa fielmente o fluxo de informações proposto pelos manuais, tendo sido apenas otimizado pela aplicação da DSM. O resultado desta análise crítica foi a apresentação de sugestões de alterações nos manuais, sob diversos aspectos como precedências e produtos gerados. Estas sugestões de alterações foram representadas em um terceiro diagrama de rede.

A quarta e última fase da metodologia consistiu na organização de um evento com a participação de nove profissionais atuantes no mercado imobiliário com experiência profissional para discussão acerca do tema. Para o evento estavam finalizadas as três primeiras fases, que foram distribuídas a todos os participantes para um entendimento prévio do trabalho. $O$ evento foi concentrado na apresentação dos diagramas de rede desenvolvidos na definição e otimização do processo, na apresentação das conclusões da aplicação da DSM geradas a partir do comparativo entre os dois diagramas citados acima e na análise crítica dos manuais e sugestões de alteração destes. A discussão do material apresentado ao grupo gerou subsídios para a consolidação do diagrama de rede final, elaborado após a análise crítica dos manuais.

\subsection{ESTRUTURA DO TRABALHO}

Este trabalho está estruturado em quatro amplos capítulos divididos em subcapítulos, de acordo com o assunto a ser desenvolvido. 
O primeiro capítulo (Introdução) apresenta o objeto e o tema da pesquisa, justificando sua escolha, ao mesmo tempo em que esclarece os objetivos do trabalho e a metodologia adotada.

O segundo capítulo (Revisão Bibliográfica) apresenta os debates intelectuais relacionados à gestão do processo de projeto e planejamento do processo de projeto, a descrição da DSM e da metodologia ADePT, bases para 0 desenvolvimento do capítulo 3 .

O terceiro capítulo (Modelagem do processo de projeto) é destinado à aplicação prática da ferramenta DSM e das duas primeiras etapas da metodologia ADePT ao planejamento do processo de projeto. Neste capítulo o planejamento é definido e otimizado, e a aplicação da DSM é avaliada. Também neste capítulo é desenvolvida a análise crítica dos Manuais de Projetos e Serviços para a Indústria Imobiliária.

No quarto, e último, capítulo (Considerações finais) são apresentadas a análise dos resultados obtidos, as críticas e sugestões. 


\section{REVISÃO BIBLIOGRÁFICA}

\subsection{A GESTÃO DO PROCESSO DE PROJETO DO EMPREENDIMENTO}

Os empreendimentos contemporâneos exigem projetos cada vez mais complexos, além de equipes maiores e mais especializadas, que agregam profissionais de diversas áreas do conhecimento. A interação constante entre os membros da equipe é essencial para o bom andamento do projeto. Por outro lado, na prática, são observadas lacunas na escolha e na forma de utilização das ferramentas de planejamento de projeto existentes no mercado, e na integração efetiva de todos os profissionais envolvidos, o que pode ocasionar o não cumprimento dos prazos estipulados, horas de trabalho extra, além de custos não previstos.

Coordenar as partes que compõe esse processo não é tarefa simples. Porém, deve-se levar sempre em conta que o processo de projeto constitui uma etapa fundamental no planejamento do empreendimento, e que sua gestão eficiente influencia diretamente na qualidade do produto final.

\subsubsection{O processo de projeto na indústria da construção civil}

O desenvolvimento de projetos na construção civil envolve tanto aspectos técnicos quanto sociais, além de uma equipe multidisciplinar especializada que atua em todo o processo de desenvolvimento do empreendimento. O processo de produção representa os aspectos técnicos enquanto a equipe multidisciplinar e sua necessidade de interação e integração representam os aspectos sociais do desenvolvimento de projetos (FABRICIO, 2002).

Fabrício (2002) destaca que os projetos contemporâneos de edifícios tem se mostrado extremamente complexos, com equipes cada vez maiores e mais especializadas. Desta forma, nenhum profissional isoladamente é capaz de controlar totalmente o processo de projeto. A evolução do processo de projeto ao longo de seu desenvolvimento limita e dificulta o contato direto entre os vários especialistas. Com isso necessariamente a melhoria da qualidade dos projetos deve passar pela formação de equipes de projeto mais integradas e interativas. 
O processo de projeto envolve todas as decisões e formulações que visam subsidiar a criação e a produção de um empreendimento, indo da montagem da operação imobiliária, passando pela formulação do programa de necessidades e do projeto do produto até o desenvolvimento da produção, o projeto "as built" e a avaliação da satisfação dos usuários com o produto. É importante observar que esse processo engloba não só os projetos de especialidades de produto, mas também a formulação de um negócio, a seleção de um terreno, o desenvolvimento de um programa de necessidades, bem como o detalhamento dos métodos construtivos em projetos para produção e no planejamento da obra. Esse arranjo envolve todos aqueles que tomam decisões relativas à montagem, concepção e planejamento do empreendimento: arquitetos, engenheiros, consultores etc.

O processo de desenvolvimento e projeto se dá a partir da sucessão de diferentes etapas em níveis crescentes de detalhamento de forma que a liberdade de decisões entre alternativas vai sendo substituída pelo amadurecimento e desenvolvimento das soluções adotadas. A gestão eficiente do processo, através da adoção de metodologias adequadas e sistemas colaborativos, deve envolver os projetistas, de forma a proporcionar o fluxo eficiente das informações. Cabe a ela as funções de planejamento, execução e controle do processo, do início ao fim.

O processo de projeto constitui uma das interfaces mais complexas e um dos principais desafios para modernização da indústria da construção. A captura e tradução dos requisitos estabelecidos pelo cliente para o empreendimento podem ser prejudicadas devido ao emprego de técnicas de programação inadequadas (GRILO; MELHADO, 2003). 


\section{Principais Serviços e Atividades do Processo de Projeto}

- Concepção do negócio e desenvolvimento do programa, que envolve a tomada de decisão de lançar um novo empreendimento, a seleção de um terreno, a concepção econômica e financeira do empreendimento e a formulação das características e especificações que o produto deve apresentar;

- Projetos do produto, que compreendem a concepção e o detalhamento do produto edificação por meio dos projetos de arquitetura, paisagismo, acústica, luminotécnica, geotecnia, estruturas, instalações elétricas, hidráulicas, de comunicação, sistemas de ventilação e ar condicionado, etc.;

- Orçamentação, que abarca o levantamento dos custos da obra e do empreendimento;

- Projetos para produção, responsáveis pela seleção da tecnológica construtiva para a realização de determinada parte ou subsistemas da obra, envolve a definição de procedimentos e seqüências de trabalho, bem como dos recursos materiais necessários, maquinas, ferramentas e materiais e componentes necessários;

- Planejamento de obra, responsável pela definição e acompanhamento do cronograma das etapas de obra e pelo fluxo de caixa do empreendimento, afim de cumprir os prazos da obra;

- Projeto "as built", responsável pelo acompanhamento da obra e atualização dos projetos para representar verdadeiramente o que foi construído;

- Serviços associados, acompanhamento de obra pelos projetistas, acompanhamento de problemas de uso e assistência técnica e realização de análises pós-ocupação de forma a avaliar o resultado dos projetos e subsidiar novos empreendimentos.

Tabela 1: Principais serviços e atividades do processo de projeto de empreendimentos de edificações (FABRICIO, 2002)

De acordo com o diagrama proposto por Assumpção e Fugazza (2001), o processo de projeto permeia por diversas etapas do desenvolvimento do empreendimento, iniciando-se nos estudos de massa e finalizando com o desenvolvimento dos desenhos de "as built", que registram as modificações que ocorrem durante a obra. 


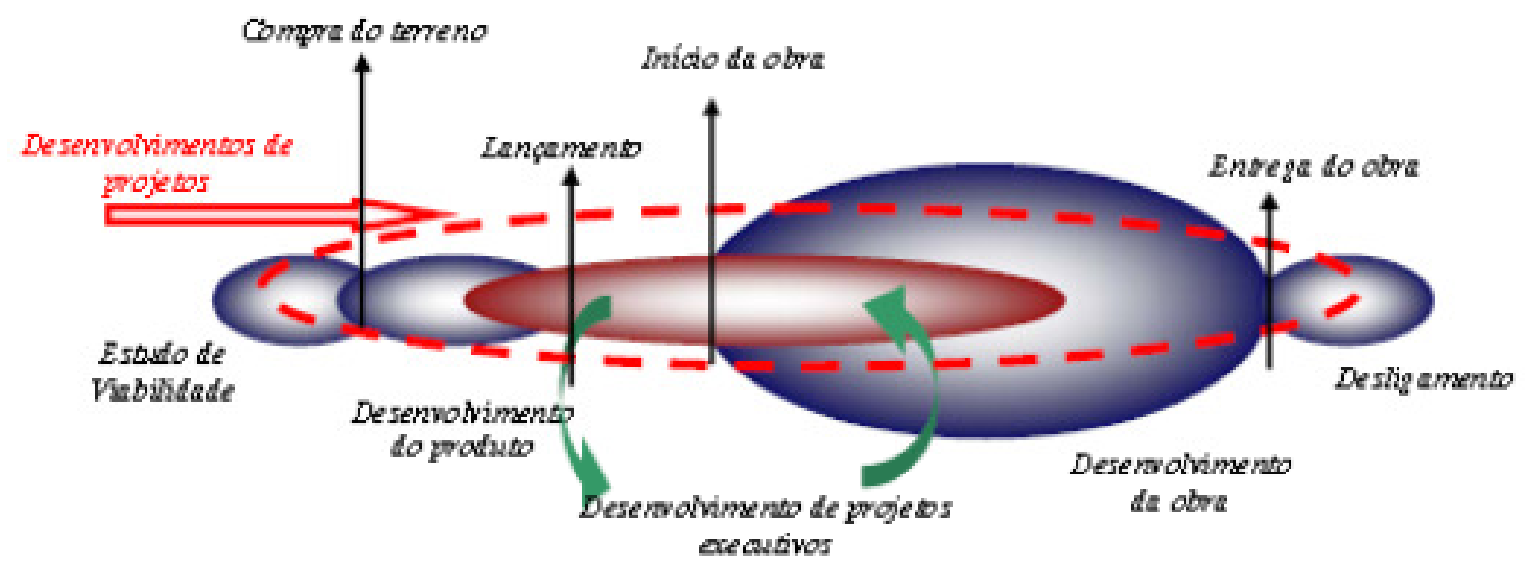

Figura 2: Evolução do empreendimento e interfaces com as atividades de projeto (ASSUMPÇÃO; FUGAZZA, 2001)

Atualmente novas tecnologias estão surgindo como opção para o desenvolvimento dos projetos, o BIM (Building Modeling Information) por exemplo. A chegada destas novas tecnologias não exclui a necessidade de um planejamento do processo de projeto e uma gestão adequada deste. O que pode ocorrer é uma adequação do planejamento pela necessidade de antecipação de informações que, na evolução do detalhamento do modelo, podem ser necessárias porém, estas novas tecnologias não invalidam ou descartam as ferramentas de planejamento do processo de projeto, que devem ser trabalhadas considerando a nova forma de modelar o empreendimento.

\subsubsection{A qualidade do processo de projeto}

A gestão do processo de projeto e a forma de organização dos agentes envolvidos neste são aspectos importantes que influenciam na qualidade global do projeto.

A fase de projeto é fundamental no desenvolvimento do empreendimento, apresentando fortes impactos sobre todas as outras fases subseqüentes do processo de produção. A melhoria da qualidade desta fase é fundamental para o empreendimento, pois representa uma parcela considerável da melhoria do empreendimento como um todo.

Picchi (1993) destaca que a qualidade ao longo do processo de projeto deve ser observada sob quatro aspectos: qualidade do programa; qualidade da solução; qualidade da apresentação; e qualidade do processo de elaboração de projetos. A 
qualidade do projeto como um todo deve balancear os diversos aspectos que a influenciam.

\begin{tabular}{|c|c|c|c|c|}
\hline \multirow{2}{*}{$\begin{array}{l}\text { Componentes da } \\
\text { qualidade de } \\
\text { projeto }\end{array}$} & \multirow[b]{2}{*}{$\begin{array}{l}\text { Sub- } \\
\text { componentes }\end{array}$} & \multirow[b]{2}{*}{$\begin{array}{l}\text { Principais aspectos } \\
\text { relacionados }\end{array}$} & \multicolumn{2}{|c|}{$\begin{array}{l}\text { Origem das } \\
\text { Exigências }\end{array}$} \\
\hline & & & $\begin{array}{l}\text { Cliente } \\
\text { externo }\end{array}$ & $\begin{array}{l}\text { Cliente } \\
\text { interno }\end{array}$ \\
\hline $\begin{array}{l}\text { QUALIDADE DO } \\
\text { PROGRAMA }\end{array}$ & & $\begin{array}{l}\text { Pesquisa de mercado, } \\
\text { correta identificação das } \\
\text { necessidades dos } \\
\text { clientes, antecipação de } \\
\text { tendências }\end{array}$ & $X$ & \\
\hline \multirow{4}{*}{$\begin{array}{l}\text { QUALIDADE DA } \\
\text { SOLUÇÃO }\end{array}$} & $\begin{array}{l}\text { Atendimento } \\
\text { ao programa }\end{array}$ & & $X$ & \\
\hline & $\begin{array}{l}\text { Atendimento a } \\
\text { exigências } \\
\text { psico-sociais }\end{array}$ & $\begin{array}{l}\text { Funcionalidade, estética, } \\
\text { proteção e status }\end{array}$ & $X$ & \\
\hline & $\begin{array}{l}\text { Atendimento a } \\
\text { exigências de } \\
\text { desempenho }\end{array}$ & $\begin{array}{l}\text { Segurança, habilidade, } \\
\text { desempenho no tempo, } \\
\text { economia na utilização }\end{array}$ & $X$ & \\
\hline & $\begin{array}{l}\text { Atendimento a } \\
\text { exigências de } \\
\text { otimização da } \\
\text { execução }\end{array}$ & $\begin{array}{l}\text { Racionalidade, } \\
\text { padronização, facilidade } \\
\text { de construir, integração } \\
\text { entre projetos, custo da } \\
\text { obra }\end{array}$ & & $X$ \\
\hline $\begin{array}{l}\text { QUALIDADE DA } \\
\text { APRESENTAÇÃO }\end{array}$ & & $\begin{array}{l}\text { Clareza de informações, } \\
\text { número de detalhes } \\
\text { suficientes, informações } \\
\text { completas, facilidade de } \\
\text { consulta }\end{array}$ & & $X$ \\
\hline $\begin{array}{l}\text { QUALIDADE DO } \\
\text { PROCESSO DE } \\
\text { ELABORAÇÃO } \\
\text { DE PROJETOS }\end{array}$ & & $\begin{array}{l}\text { Prazo, custo de } \\
\text { elaboração do projeto, } \\
\text { envolvimento das pessoas } \\
\text { relacionadas, } \\
\text { comunicação }\end{array}$ & & $X$ \\
\hline
\end{tabular}

Tabela 2: Proposta de componentes da qualidade de projeto (PICCHI, 1993)

Para Romano (2003), a qualidade do produto-empreendimento é uma decorrência direta da qualidade da definição das necessidades para o produto, da qualidade do projeto do produto, e da interação entre as atividades de 
desenvolvimento do produto e do processo ou seja, para a autora, a qualidade do produto-edificação está vinculada à qualidade do processo de projeto e seu gerenciamento.

Baía e Melhado (1998) vinculam a qualidade do projeto a três aspectos: qualidade da solução, qualidade da apresentação e qualidade da elaboração do projeto.

A qualidade da solução de projeto relaciona-se com a satisfação do usuário, racionalidade da edificação, construtibilidade, funcionalidade da edificação e custo da obra.

A qualidade da apresentação do projeto deve contemplar a clareza e qualidade das informações contidas no projeto, incluindo as especificações do produto e especificações de recursos e estratégias para execução do processo de construção.

Em relação ao processo de elaboração do projeto, a qualidade relaciona-se com: a garantia de um desenvolvimento prévio das atividades considerando-se o tempo e recursos necessários; a eliminação de tempos de espera evitáveis através da manutenção de um fluxo contínuo de atividades; a comunicação e interação entre os diversos agentes envolvidos no processo de projeto; atendimento às necessidades dos clientes internos e externos; confiabilidade e rastreabilidade das decisões feitas através de registros e documentação adequada; controle da qualidade durante o desenvolvimento do processo de projeto com análises críticas ao final de cada etapa; controle da qualidade do projeto no recebimento pelo contratante; validação do projeto pelo cliente; coordenação de projeto que garante as interfaces entre os diversos projetos e entre estes e a produção.

Ceotto (2002) apud Romano (2003) considera que o êxito do projeto traduz-se pela garantia das expectativas do cliente, garantia da construtibilidade, da operacionalidade e da mantenabilidade, garantia da obediência do ambiente regulatório e garantia dos prazos de projeto.

Fabricio (2002) analisa a qualidade e a construtibilidade do projeto em um contexto de geração de empreendimentos complexos, que exigem a participação de equipes de projeto cada vez maiores e conhecimentos mais especializados, 
caracterizando um processo multidisciplinar de desenvolvimento de projeto. Neste cenário o autor atrela a qualidade e a construtibilidade do projeto à capacitação e formação técnica da equipe e à organização e eficácia do projeto. Ele alerta porém que "não basta o conhecimento existir; é necessário que os agentes envolvidos no projeto dominem e utilizem adequadamente tais conhecimentos de forma a equacionar qualidade e custos das soluções."

\begin{tabular}{|c|c|c|c|}
\hline COMPONENTES & \multicolumn{3}{|c|}{ ASPECTOS RELACIONADOS } \\
\hline \multirow{8}{*}{$\begin{array}{l}\text { Qualidade do } \\
\text { programa do } \\
\text { empreendimento }\end{array}$} & \multicolumn{3}{|l|}{ Pesquisas de mercado } \\
\hline & \multicolumn{3}{|l|}{ Necessidades dos clientes } \\
\hline & \multirow[t]{4}{*}{ Seleção e incorporação de terrenos } & \multicolumn{2}{|c|}{ caracterização do entorno urbano } \\
\hline & & \multicolumn{2}{|c|}{ levantamento da legislaçäo construtiva referente à área } \\
\hline & & \multicolumn{2}{|l|}{ levantamentos topográticos } \\
\hline & & \multicolumn{2}{|l|}{ Sondagens do terreno } \\
\hline & \multicolumn{3}{|c|}{ Equacionamentos econômicos, financeiro e comercial } \\
\hline & \multicolumn{3}{|c|}{ Coerência, clareza e exequibilidade das especificaçôes de progranıla } \\
\hline \multirow{26}{*}{$\begin{array}{l}\text { Qualidade das } \\
\text { soluções de } \\
\text { projetuais }\end{array}$} & \multicolumn{3}{|l|}{ Atendimento ao programa } \\
\hline & \multirow{8}{*}{$\begin{array}{l}\text { Atendimento a exigências de } \\
\text { desempenho }\end{array}$} & \multirow[t]{3}{*}{ Segurança } & estrutural \\
\hline & & & ao fogo \\
\hline & & & contra invasores \\
\hline & & \multirow[t]{4}{*}{ Habitabilidade: } & conforto térmico \\
\hline & & & conforto acústico \\
\hline & & & iluminaçăo \\
\hline & & & estanqueidade \\
\hline & & \multicolumn{2}{|c|}{ Durabilidade e desempenho ao longo do tempo } \\
\hline & \multirow[t]{11}{*}{ Sustentabilidade } & \multicolumn{2}{|c|}{ Materias-primas especificadas } \\
\hline & & \multicolumn{2}{|c|}{$\begin{array}{l}\text { Rcjeitos increntes as espceificą̧ócs do projeto } \mathrm{e} \text { ao } \\
\text { processo construtivo adotado }\end{array}$} \\
\hline & & \multicolumn{2}{|c|}{ Consumo de energia na produção } \\
\hline & & \multirow{3}{*}{$\begin{array}{l}\text { Consumo de energia na } \\
\text { utilização }\end{array}$} & luz natural \\
\hline & & & ventilação natural \\
\hline & & & aquecimento de água \\
\hline & & \multirow[t]{3}{*}{ Consumo de água } & bacia sanitária \\
\hline & & & reaproveitamento de água \\
\hline & & & limpeza \\
\hline & & \multicolumn{2}{|c|}{$\begin{array}{l}\text { Disposição de resíduos sólidos (possibilidade de coleta } \\
\text { seletiva) }\end{array}$} \\
\hline & & \multicolumn{2}{|c|}{ Disposição de resídıos líquidos } \\
\hline & Construtibilidade & Racionalização & \\
\hline & & Padronizaçåo & \\
\hline & & Integraçáo e coerência entr & projetos \\
\hline & $\begin{array}{l}\text { Atcndimcnto às cxigências } \\
\text { economia }\end{array}$ & $\begin{array}{l}\text { Custos de exceução } \\
\text { Custos de operação }\end{array}$ & \\
\hline & & Custos de manuteçào & \\
\hline & & Custos de demolição / reco & versão \\
\hline & Clareza de informações & & \\
\hline Qualidade da & Detalhamento adequado & & \\
\hline apresentação & Informaçôes completas & & \\
\hline & Facilidade de consulta & & \\
\hline & Agilidade e cumprimento dos prazo & projeto & \\
\hline & Custo de elaboração de projetos & & \\
\hline Q wandulat dos & Comunicação e envolvimento dos $\mathrm{p}$ & tistas & \\
\hline ao projeto & $\begin{array}{l}\text { Compatibilização entre as disciplina } \\
\text { Acompanllamento do projeto durant }\end{array}$ & $\begin{array}{l}\text { e projeto } \\
\text { obra }\end{array}$ & \\
\hline & Entrega da obra e assistência dos pr & istas durante a utilizacâo do & empreendimento \\
\hline
\end{tabular}


Com base na tabela apresentada por Fabrlcio (2002), Romano (2003) conclui que, para que a qualidade desejada no processo de projeto de edificações seja atingida, são necessárias duas ações integradas de transformação do modelo atual: a reorganização das atividades com aplicação de princípios da Engenharia Simultânea e o gerenciamento efetivo e eficaz do processo como um todo.

Melhado (1994) listou os obstáculos que limitam a qualidade dos projetos:

- o trabalho não sistematizado e descoordenado das diversas equipes de projeto participantes de um empreendimento;

- a ausência de um projeto voltado à produção, com dificuldades de alterar a forma de projetar, muito voltada ao produto;

- a falta de padrões e procedimentos para a contratação de projetistas;

- $\quad$ a realização de uma compatibilização de projetos e não sua real coordenação;

- as falhas no fluxo de informações internas à empresa construtora, prejudicando o processo de retroalimentação de projetos futuros.

Pode-se considerar que de 1994 para os dias atuais, dos itens destacados por Melhado como limitantes para a qualidade dos projetos, houve uma evolução positiva porém, ainda há um longo percurso a ser trilhado para que a qualidade dos projetos seja atingida em todos os seus aspectos.

A participação do coordenador no desenvolvimento do processo de projeto tem aumentado consideravelmente. Entre outras atribuições, cabe a este agente a sistematização e coordenação das equipes participantes do empreendimento. Sua atuação tem se intensificado mas, ainda não se mostrou suficiente e satisfatória.

Os projetos para a produção também tiveram sua participação elevada no desenvolvimento do processo de projeto porém, ainda há deficiências quanto a seu momento de contratação, sua possibilidade de interferência no desenvolvimento do produto e na leitura do projeto pelos demais projetistas.

A falta de padrões e procedimentos para a contratação de projetistas tentou ser sanada pelo desenvolvimento do conjunto de Manuais de Escopo de Projetos e Serviços para a Indústria Imobiliária, desenvolvidos por entidades representativas do setor de projetos, com a participação de entidades setoriais representativas dos contratantes de projetos do setor imobiliário e da construção. Ainda falta, no entanto, 
uma maior divulgação do conjunto de Manuais e a utilização destes por um número maior de agentes envolvidos no processo de projetos, de forma a equalizar as contratações.

Os demais itens citados por Melhado sofreram poucas evoluções ao longo dos anos, mantendo-se como fortes obstáculos para a qualidade dos projetos.

Silva e Souza (2003) consideram que produtos e serviços de qualidade devem estar adequados ao uso de todos os clientes do processo e a satisfação de suas necessidades. A qualidade do projeto é diferente para o incorporador, o construtor, o projetista e o usuário final, uma vez que cada um observa o projeto sob uma ótica diferente.

O processo de desenvolvimento de projeto é composto por um grande número de outros processos sob a responsabilidade de diversos agentes. Mecanismos de gestão e controle da produção do projeto, baseados nas reais necessidades dos agentes envolvidos, devem ser introduzidos no processo, a fim de possibilitar que cada agente garanta a qualidade de sua fração no produto-projeto a ser gerado. A implantação destes mecanismos deve envolver os proprietários do empreendimento, os profissionais responsáveis pela contratação, coordenação e gerenciamento de projeto e contratação da execução da obra, os projetistas e os agentes responsáveis pelo planejamento, execução e controle da obra. 


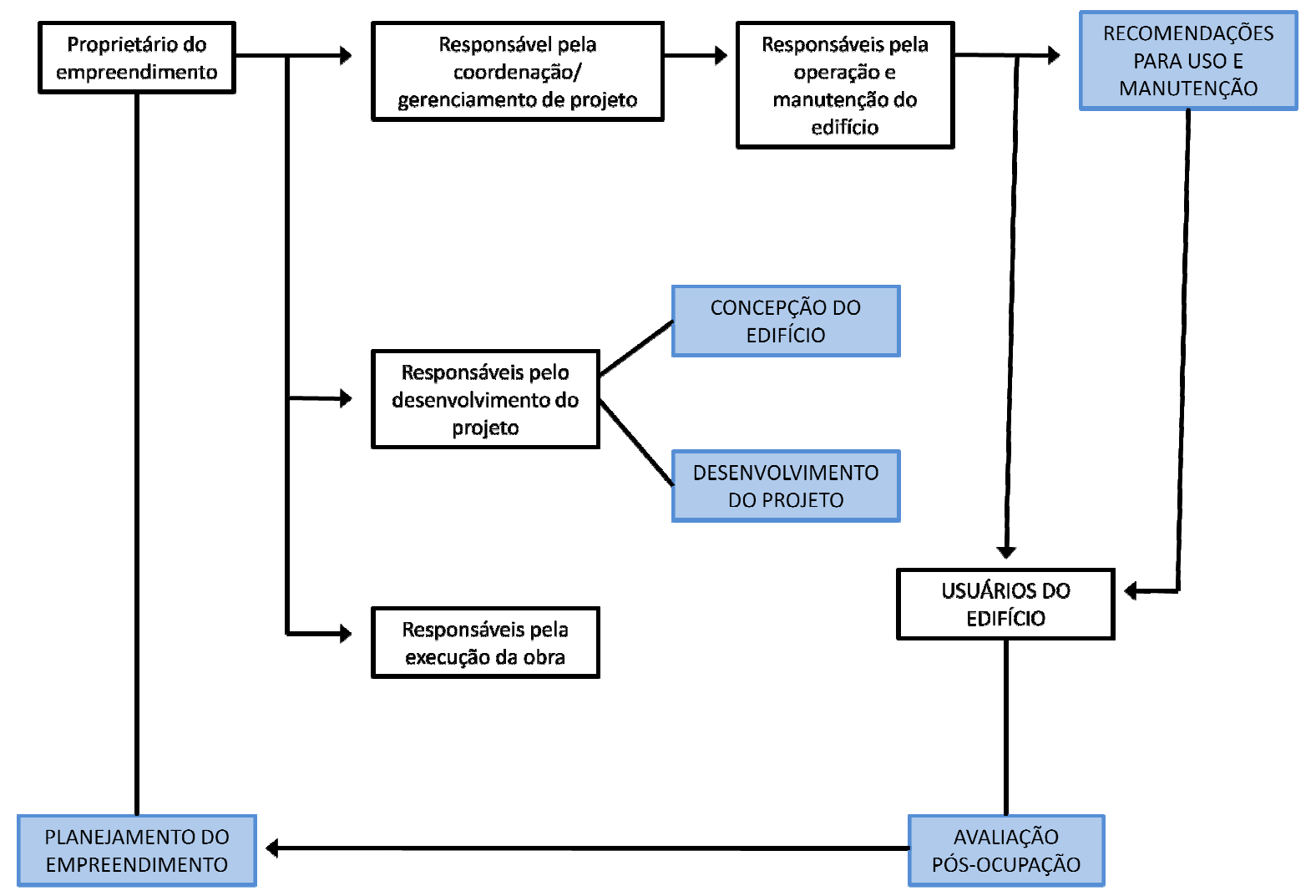

Figura 3: Agentes intervenientes na gestão do processo de projeto

(SILVA; SOUZA, 2003)

"Qualidade no processo de desenvolvimento de projeto é atender às necessidades do próprio processo de produção como forma de atingir a melhor relação possível entre os recursos empregados e resultados obtidos." (SILVA; SOUZA, 2003) 


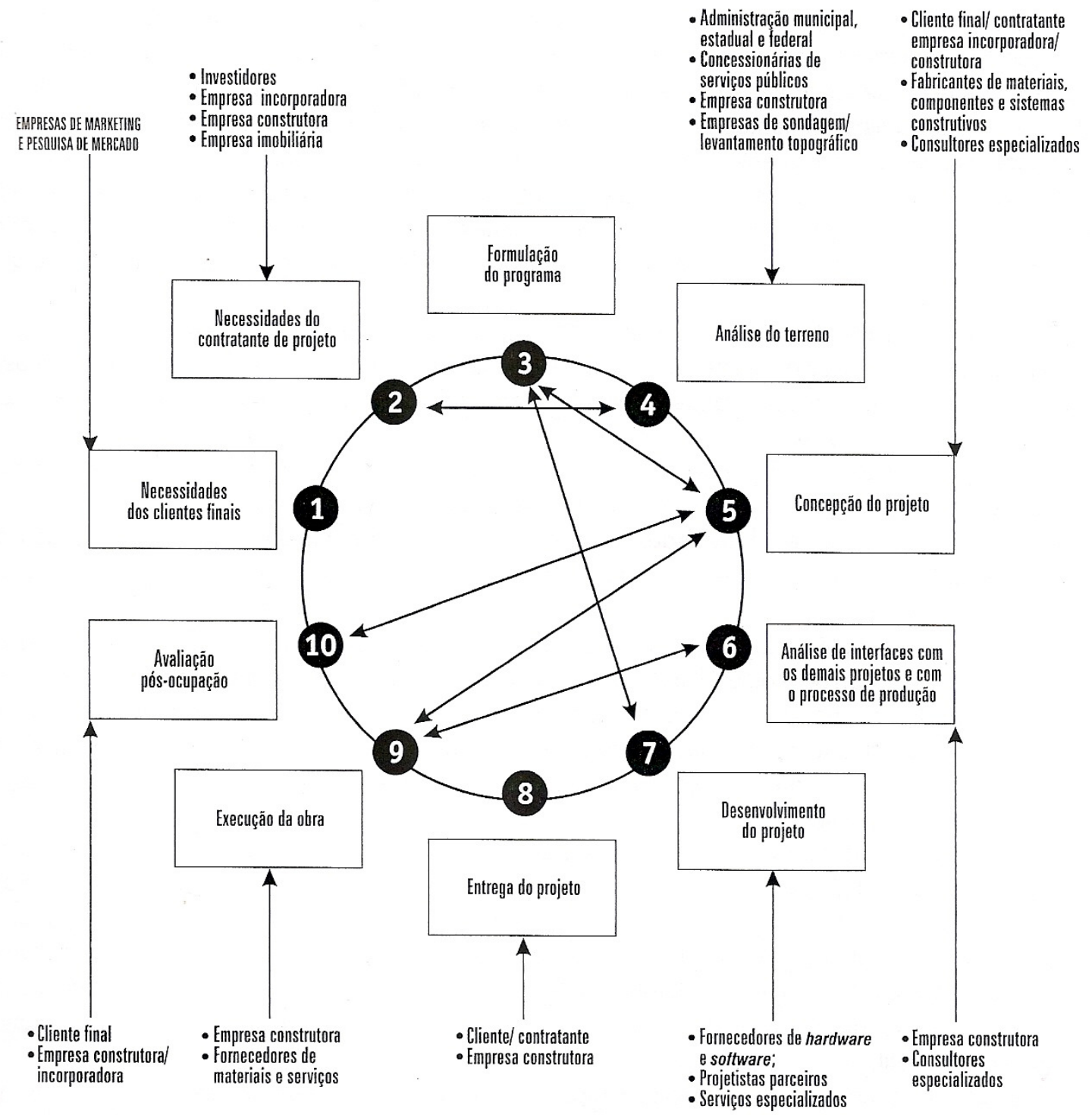

Figura 4: Ciclo da qualidade do desenvolvimento de projeto no mercado imobiliário

(SILVA; SOUZA, 2003) 


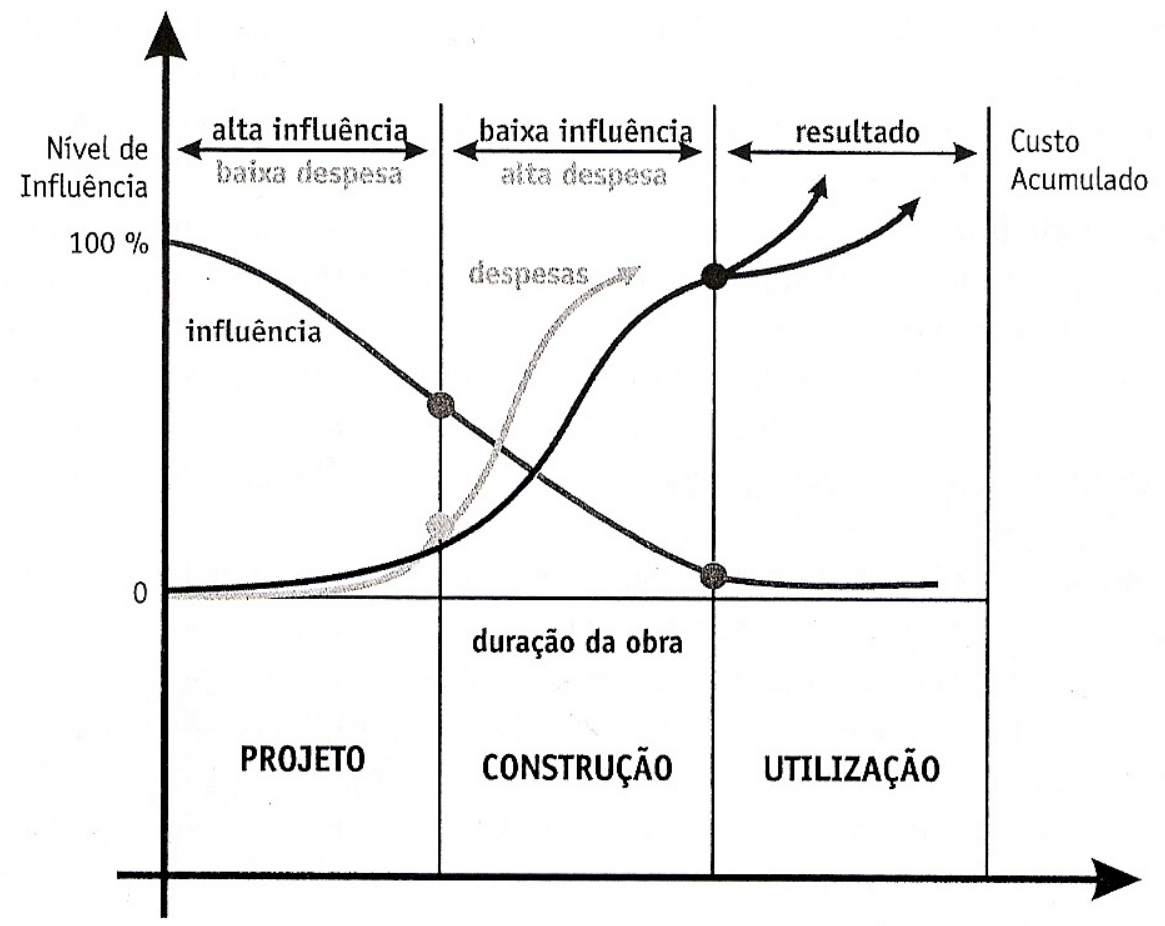

Figura 5: Nível de influência das fases do processo de produção sobre os custos (BARRIE; PAULSON, 1978 apud SILVA; SOUZA, 2003)

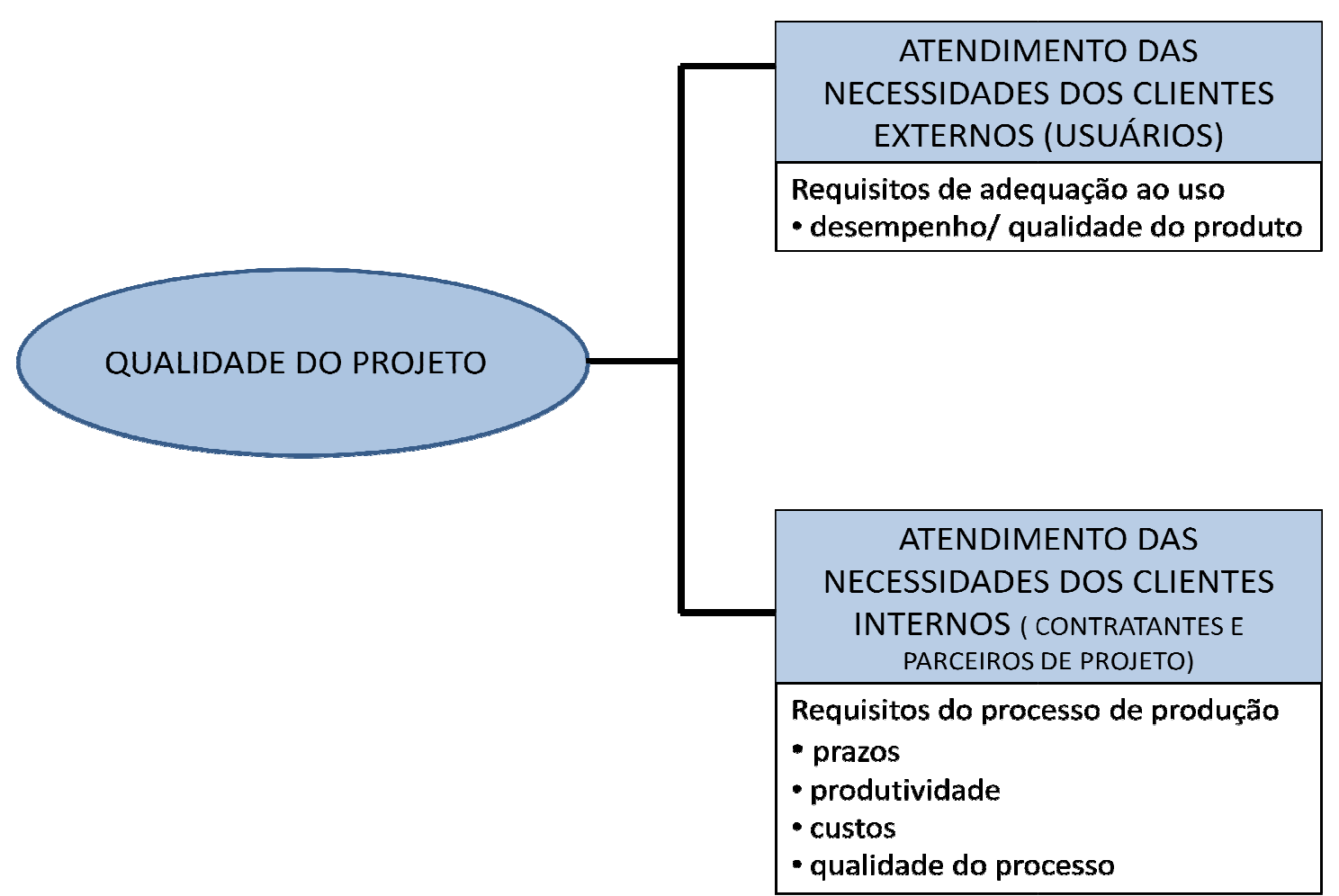

Figura 6: Elementos que compõem a qualidade do projeto 
Assim sendo, a qualidade no processo está relacionada à garantia de:

- planejamento prévio das atividades em termos de tempo e recursos necessários

- manutenção de um fluxo contínuo de atividades sem a incidência de tempos de espera evitáveis

- atendimento às necessidades dos clientes internos

- confiabilidade e rastreabilidade das decisões por meio de registros e documentação adequada

- análise crítica do projeto nos momentos adequados visando a melhor solução possível

- controle da qualidade durante o desenvolvimento

- controle da qualidade no recebimento do projeto pelo contratante

- validação do projeto pelo cliente

Para Romano (2003), a qualidade do produto-edificação está diretamente vinculada à qualidade do processo de projeto e seu gerenciamento, uma vez que a qualidade do produto é decorrente da qualidade da definição das necessidades do produto, da qualidade do projeto do produto e da interação entre as atividades de desenvolvimento do produto e do processo.

\subsubsection{Agentes envolvidos no processo de projeto}

Para Melhado (1998) o processo de projeto, ao longo de seu desenvolvimento, conta com a participação de quatro agentes principais:

Empreendedor - gerador do produto

Projetistas - formaliza o produto

Construtor - executa o produto

Usuário - utiliza o produto

Peralta (2002) destaca a participação mais intensa dos seguintes agentes no processo de projeto: os profissionais de projeto; os profissionais das empresas construtoras; agentes da promoção do empreendimento; empresas incorporadoras; consultores, entre outros.

Fontenelle (2002) salienta que o número de intervenientes envolvidos no processo de projeto sofreu um aumento em função da elevação do número de 
inovações tecnológicas e da necessidade de coerência entre o projeto e os requisitos técnicos e econômicos da produção do edifício.

As equipes de projeto tem se tornado cada vez mais multidisciplinares, mobilizadas temporariamente para o desenvolvimento de um novo produto, com profissionais de diferentes empresas especializadas na prestação de serviços de projeto, que não participam de nenhuma outra fase do empreendimento. As equipes caracterizam-se por uma heterogeneidade dos agentes envolvidos no empreendimento, tanto quanto ao porte econômico quanto ao desenvolvimento cultural e técnico, o que dificulta a integração e cooperação entre os agentes. Neste processo multidisciplinar nenhum profissional detém isoladamente os conhecimento e qualificações necessários para exercer um controle total sobre o processo de projeto como um todo (FABRICIO, 2002).

Assumpção e Fugazza (2001) sugerem que cada projetista tenha como "briefing" de projeto executivo as informações básicas do empreendimento e também um cronograma que mostre como seus produtos se inter-relacionam com o dos demais parceiros como forma de minimizar a complexidade do processo de projeto e suas diferentes especialidades.

Para tanto os autores apresentam uma proposta de classificação das diferentes especialidades e grupos de projetos conforme demonstrado na tabela 4.

\begin{tabular}{|c|c|}
\hline GRUPO & TIPOLOGIA / ESPECIALIDADE \\
\hline $\begin{array}{l}\text { Definição do produto (Definem a forma as } \\
\text { características da edificaçắo) }\end{array}$ & Projeto de Arquitetura \\
\hline $\begin{array}{l}\text { Com plementares I (Necessários ao funcionamento } \\
\text { adequado da edificação) }\end{array}$ & $\begin{array}{l}\text { Estrutura, Fundações e Contençőes, Instalaçôes hidráulicas / elétricas, } \\
\text { Drenagem, Exaustão, Pressurização, Ar Condicionado e Vedaçốes }\end{array}$ \\
\hline Com plementar II (Complementos de instalações) & $\begin{array}{l}\text { Automação Predial, Áudio/ Vídeo/ Sonorização, Detecçăo, Acústica, } \\
\text { Luminotécnica }\end{array}$ \\
\hline Especiais (Valorizaçăo do empreendimento) & $\begin{array}{l}\text { Paisagismo, Decoraçắo, Comunicaçăo Visual, Cozinha Industrial, Cyber room, } \\
\text { Fitness, etc. }\end{array}$ \\
\hline
\end{tabular}

Tabela 4: Grupos de projetos e suas tipologias

Grilo (2002) caracteriza as dificuldades na formação de equipes e na criação de relações de confiança como conseqüência das diferenças na cultura e forma de linguagem dos profissionais, além do caráter temporário do empreendimento. Muitas 
vezes os profissionais participantes de uma equipe de projeto nunca atuaram em conjunto e acabam por focar o trabalho em interesses particulares, em detrimento dos interesses do cliente. A coordenação de projetos deve atuar conduzindo o processo de projeto de maneira profunda e interativa, buscando a convergência dos produtos e serviços gerados pelos diversos participantes da equipe para os objetivos do cliente (ROMANO, 2003).

\section{AGENTES ATUANTES}
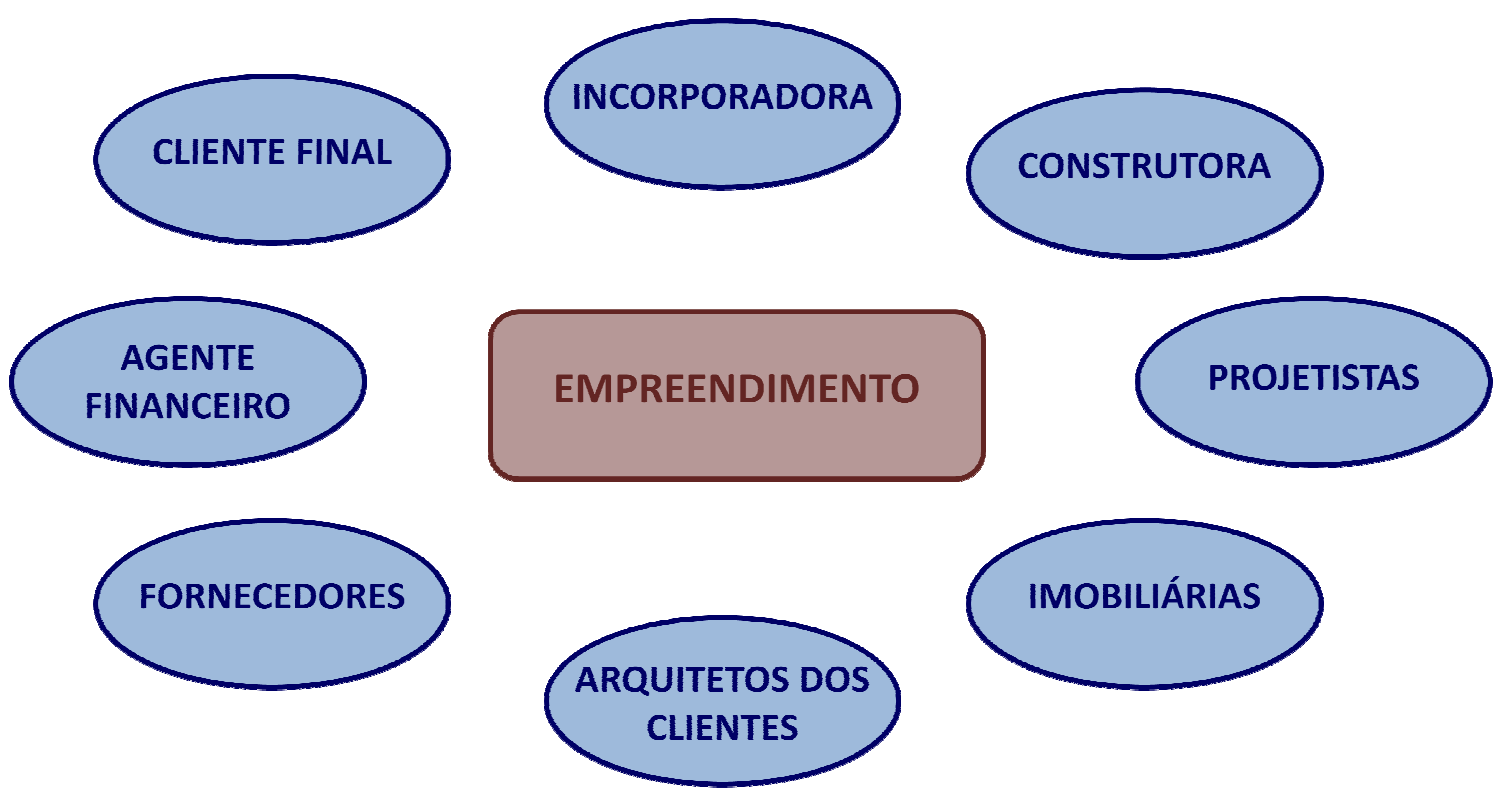

Figura 7: Agentes atuantes no desenvolvimento do empreendimento 


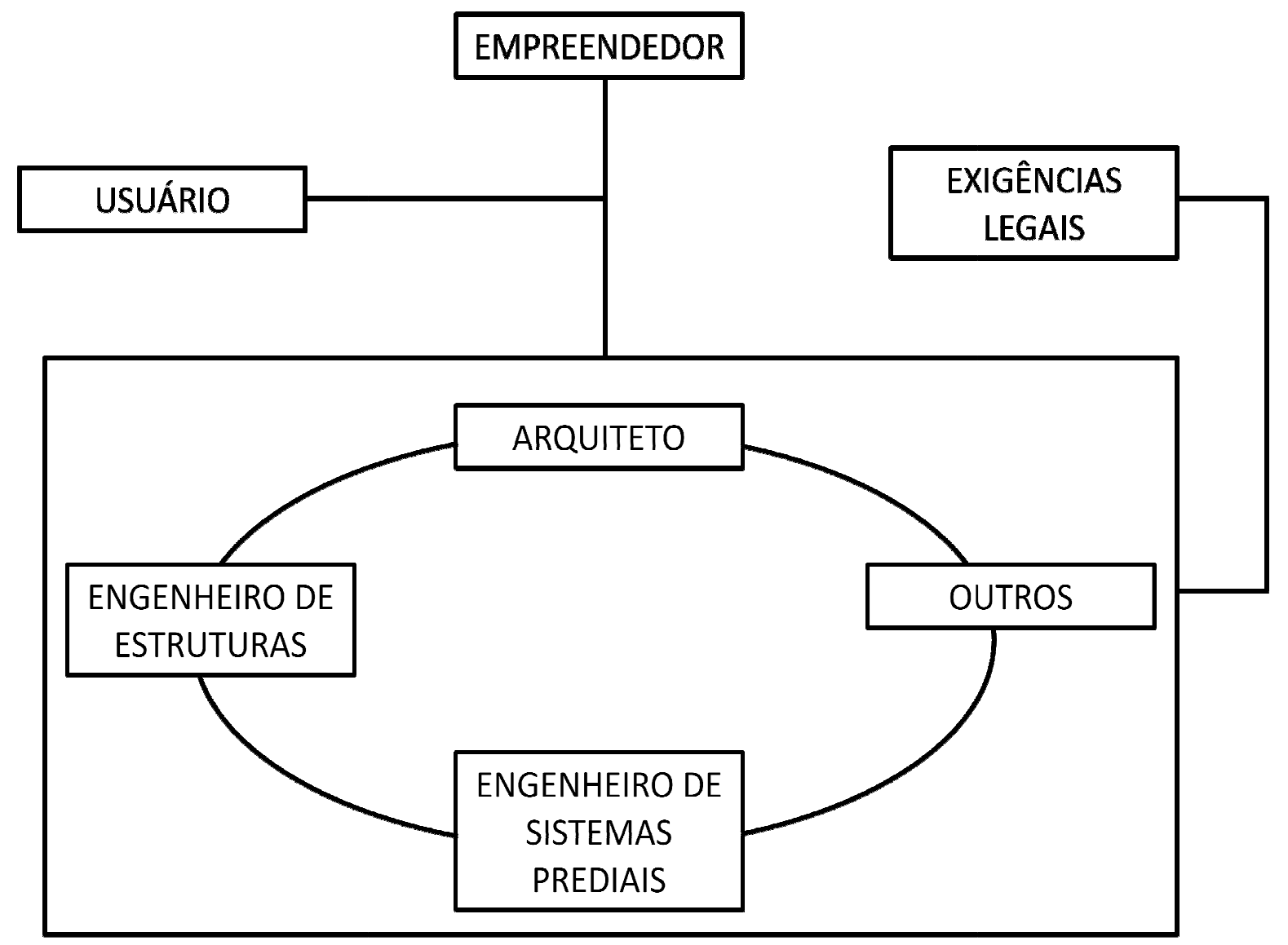

Figura 8: Arranjo multidisciplinar da equipe de projeto (MELHADO, 2005)

\subsubsection{Dificuldades para a gestão do processo de projeto}

Fabrício (2002), em sua avaliação sobre as equipes e organização do projeto, identifica algumas características singulares do processo de projeto na construção civil. O autor avalia que, na construção civil, o vínculo contratual entre os agentes envolvidos normalmente é restrito à duração do empreendimento e ao contrato. As equipes são mobilizadas temporariamente para o desenvolvimento de um novo produto e são compostas por profissionais pertencentes a diferentes empresas especializadas na prestação de serviços de projeto, que não vivenciam nenhuma outra fase do empreendimento além daquela que lhes diz respeito. Disto resulta que a criação de um ambiente de cooperação, baseado na confiança e respeito mútuo entre os agentes do projeto na construção, é mais complexa. A terceirização generalizada dos projetos e empresas que prestam serviços a mais de um contratante e a diferentes projetos simultaneamente é outra característica do setor da construção civil. Nestas condições, um mesmo projetista participa de diferentes 
empreendimentos com equipes de projeto diversas, onde cada equipe e cada empreendimento apresentam condições, demandas e gestão do processo própria. Neste cenário complexo, o planejamento para cada projetista deve levar em consideração seus compromissos nos outros empreendimentos em que participa, uma vez que é comum o início e interrupção momentânea do desenvolvimento do projeto pelo projetista em função de projetos de outros empreendimentos para o qual este foi contratado.

A gestão do tempo e o cumprimento dos prazos de projeto são problemas recorrentes em muitas empresas de projeto. Interferências de agentes externos à empresa como falta de informações e mudanças em programas de necessidades são exemplos de interferências que refletem no desenvolvimento de cada projeto e na gestão do tempo deste. A velocidade no desenvolvimento do projeto também é uma solicitação constante no desenvolvimento dos empreendimentos contemporâneos. Assim, com relação à velocidade, a questão a ser considerada para que não se comprometa a qualidade do projeto seria como manter ou ampliar a agilidade no processo, e ao mesmo tempo obter resultados de maior qualidade e construtibilidade.

Fabrício (2002) conclui assim que, o aumento do volume de produtos gerados, a elevação do fluxo de informações e a necessidade de maior integração e compatibilização entre os intervenientes, em prazos de desenvolvimento global cada vez mais reduzidos, implicaram uma maior demanda e uma maior complexidade na gestão do processo de projeto.

Romano (2003) observa que "a falta ou adiamento de decisões, tanto com relação aos aspectos ligados às características do produto, quanto às definições sobre as tecnologias construtivas a serem adotadas, potencializa uma grande quantidade de erros e retrabalhos para todos os participantes da equipe de projeto $\mathrm{e}$ constitui-se num dos grandes "gargalos" causadores de desperdício, que repercutem negativamente na qualidade dos produtos gerados e na eficiência da construção.". Segundo a autora, para uma gestão eficiente do processo de projeto é necessário que se solucione, ou se crie alternativas, às seguintes dificuldades:

- falta de cultura de planejamento de projeto, com pouca destinação de tempo e esforços para este; 
- falta de investimento em capacitação e aperfeiçoamento dos recursos humanos, informatização, elaboração de metodologias próprias de desenvolvimento do projeto;

- baixo compromisso dos profissionais e empresas de projeto com a estratégia e metas dos contratantes;

- remuneração com enfoque no valor da produção e não com enfoque no valor agregado do projeto ao produto final;

- fixação de prazos curtos para as etapas iniciais do processo de projeto;

- excesso de retrabalhos;

- inexistência de vínculo entre projetistas e construtores;

- elaboração do projeto de forma compartimentada e seqüencial;

- fluxo de informações entre os intervenientes é caótico e desestruturado;

- realização da análise de projeto somente com este já totalmente detalhado;

- falta de desenvolvimento do projeto de forma global com o envolvimento de todas as especialidades necessárias para o desenvolvimento do produto desde o início dos trabalhos;

- falta de definição de diretrizes do produto quanto a custos;

- ausência de metodologias adequadas para o levantamento de necessidades do cliente, investidor e usuário final;

- falta de mecanismos de retroalimentação do projeto a partir da ocupação do empreendimento;

- ausência de projetos para produção;

- falta de mecanismos de retroalimentação do projeto a partir da obra executada;

- falta de padrão de apresentação do projeto ou detalhamento de aspectos construtivos. O projeto em geral representa o que se pretende construir mas não como construir;

- atraso conceitual de características a serem incorporadas no produto que afeta 0 desenvolvimento do projeto;

- ausência de metodologias adequadas para a gestão da qualidade do processo de projeto;

- consideração da fase de projeto como um custo. 
Para muitos empresários, a seguinte citação infelizmente é familiar: "pareceu tudo tão simples: conceba, projete e construa um produto inovativo, novo. Mas durante o desenvolvimento, os problemas se multiplicaram rapidamente: as especificações do projeto mudaram; algumas atividades tiveram que ser abortadas quando outras foram repetidas; a informação dos fornecedores atrasava, era inadequada ou inexistente; a qualidade de trabalho era abaixo das expectativas; as previsões do custo subiram enquanto o potencial dos rendimentos caía; e os prazos de desenvolvimento tiveram que ser alongados repetidamente. As coisas tinham avançado muito para serem interrompidas, da mesma forma que os objetivos do projeto foram degradados. O resultado final foi de atraso, frustrante e oneroso." (PROCESS IMPROVEMENT, 2006)

Neste caso, o prejuízo é compartilhado por toda a cadeia produtiva. Isto ocorre porque a equipe se foca somente nas entregas e não no projeto em sua totalidade, ou seja, no produto final. O projeto muitas vezes também está exageradamente detalhado e freqüentemente a equipe responsável pela sua criação não é capaz de visualizar quanto o processo de projeto pode ser complexo.

O desenvolvimento de um novo empreendimento é um processo complexo, que envolve centenas, às vezes milhares de atividades. O número de interações entre estas atividades também é bastante elevado. A escala e a complexidade do processo de projeto são determinadas pelos inevitáveis retrabalhos, retornos e interações inerentes ao desenvolvimento de qualquer processo. Estas características são frequentemente ignoradas ao se planejar o projeto.

\subsection{MANUAIS DE ESCOPO DE PROJETOS E SERVIÇOS PARA A INDÚSTRIA IMOBILIÁRIA}

A primeira etapa do planejamento do projeto é a definição do objetivo deste, isto é, o resultado final esperado. Este objetivo deve ser claramente definido e acordado entre o cliente e quem vai conduzir o projeto, desde o início, e deve conter escopo, cronograma e custo do projeto.

A definição do escopo dos projetos na construção civil ainda se mostra bastante deficiente, envolvendo diversas dificuldades de ordem técnica e comercial. Há poucos elementos para a definição do conteúdo dos projetos a serem entregues e dos serviços a serem prestados pelos projetistas. Acordos mal-ajustados entre 
contratantes e contratados para o desenvolvimento dos projetos configuram prejuízos para a qualidade do processo e do empreendimento.

São freqüentes as dúvidas sobre o que, quando e como deve ser elaborado, desenvolvido e entregue o projeto. Essas dúvidas se estendem por todas as etapas do projeto, gerando desgastes entre toda a equipe e insatisfação entre contratantes e contratados.

Com o objetivo de eliminar as lacunas e dúvidas referentes ao escopo dos projetos a serem contratados, entidades representativas do setor de projetos, com a participação de entidades setoriais representativas dos contratantes, do setor imobiliário e da construção, se uniram para desenvolver o conjunto de Manuais de Escopo de Projetos e Serviços para a Indústria Imobiliária.

O conjunto de manuais tem como objetivo oferecer ao mercado uma ferramenta-guia, que esclareça como devem ser desenvolvidos os projetos, percorrendo todas as etapas necessárias, e qual o nível de detalhamento requerido. Os Manuais de Escopo de Projetos e Serviços para a Indústria Imobiliária representam as boas práticas recomendadas por profissionais, porém não contemplam o processo de projeto e sim fornecem subsídios para que o planejamento seja desenvolvido. O conjunto de manuais apresenta diretrizes para a definição das responsabilidades no desenvolvimento dos projetos e oferece orientações sobre como identificar os itens envolvidos e suas soluções, atendendo às expectativas dos projetos. Desta forma pode-se considerar que os Manuais apresentam as diretrizes para o planejamento do processo de projeto, e não o processo em si.

A estrutura dos manuais parte de uma sequência de atividades organizadas em fases definidas, que permitem determinar cronogramas, medições e outras etapas. O fluxo de desenvolvimento dos projetos proposto pelos manuais substitui os termos usualmente utilizados no mercado - Estudo Preliminar, Anteprojeto, Projeto Executivo, etc - por Concepção, Definição, Soluções de interfaces do projeto, etc, vinculando-os às fases do desenvolvimento do empreendimento, fazendo com que o processo se altere e a produção de projetos isolados deixe de ocorrer, para ser substituída por projetos pensados como trabalho em equipe. 
O processo de projeto foi dividido em seis fases descritas abaixo:

- Fase A - Concepção do Produto

- Fase B - Definição do Produto

- Fase $\mathrm{C}$ - Identificação e solução de interfaces de projeto

- Fase D - Detalhamento de projetos

- Fase E-Pós-entrega de projetos

- Fase F-Pós-entrega da obra

O projeto de edificações apresenta basicamente duas dimensões, o projeto como processo e o projeto como produto. O projeto como produto compreende a criação e especificação do produto-projeto constituído por representações gráficas e especificações técnicas (FABRICIO, 2002). O projeto como processo consiste na transformação e documentação da informação gerada separadamente pelas diversas especialidades, tornando essencial a integração entre os diversos agentes do projeto (JACQUES, 2002).

As duas dimensões do projeto de edificações podem ser observadas nos Manuais de Escopo de Projetos e Serviços para a Indústria Imobiliária. A divisão do processo de projeto em fases reflete a dimensão do projeto como processo, que ocorre em etapas sucessivas de desenvolvimento, individual e com relação aos agentes envolvidos no processo. A dimensão do projeto como produto pode ser observada na definição dos produtos gerados, descritas em cada um dos manuais para cada serviço contratado. 


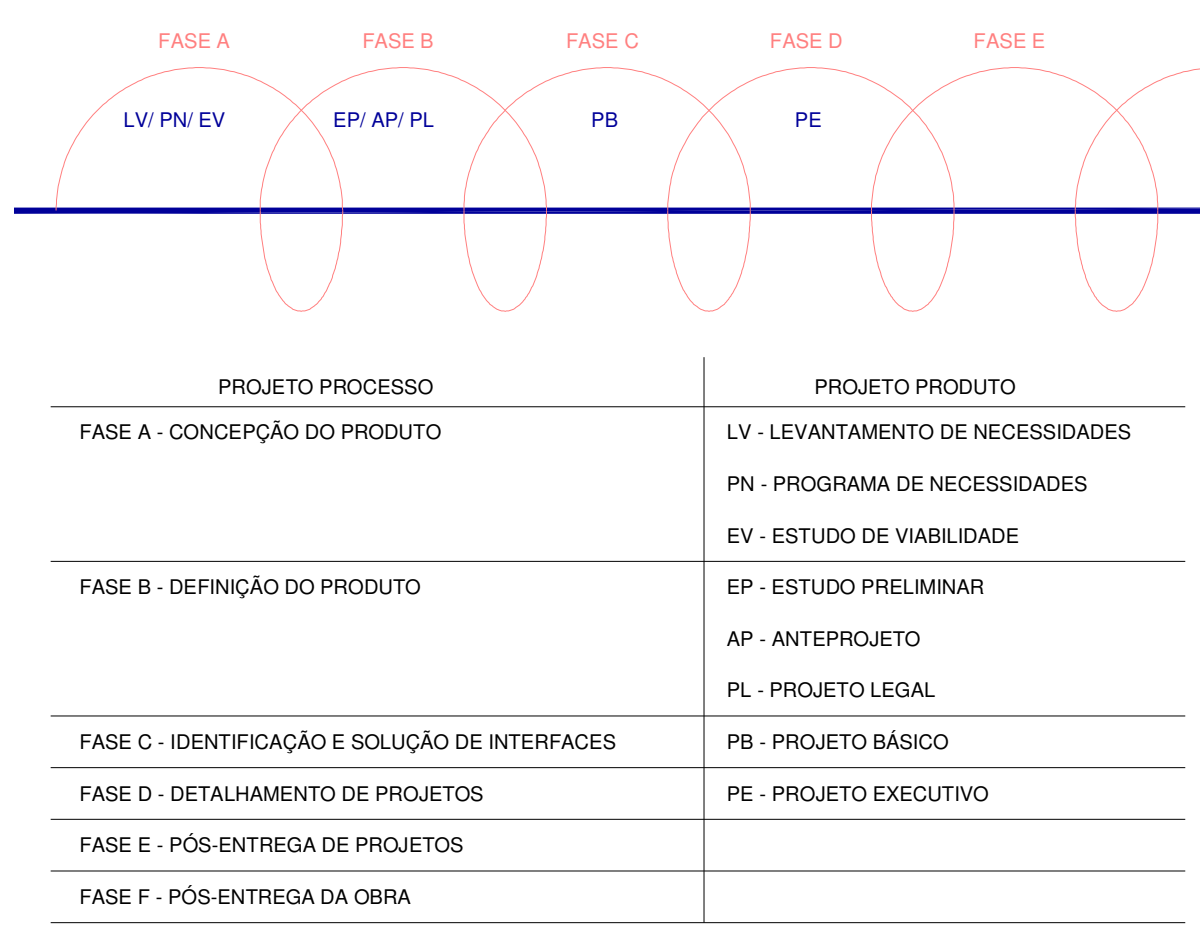

Figura 9 - O projeto como processo e como produto nos Manuais de Contratação de Projetos e Serviços

Os manuais são estruturados a partir de uma sequência de atividades e os serviços foram classificados em:

- serviços essenciais - produtos a serem obrigatoriamente desenvolvidos em cada fase do projeto;

- serviços específicos - produtos complementares que podem ser desenvolvidos mediante contratação específica;

- serviços opcionais - produtos e serviços especializados que podem ser desenvolvidos por alguns escritórios de projeto mediante qualificação e contratação específica.

Os manuais apresentam, para cada fase do projeto, a Descrição das Atividades, relacionando os Dados Necessários e descrevendo os Produtos Gerados. A partir desta estrutura, os Manuais fornecem as informações necessárias para elaboração do projeto bem como o seqüenciamento de atividades e a rede de precedências, tornando-se uma importante fonte para a estruturação do processo de projeto. 


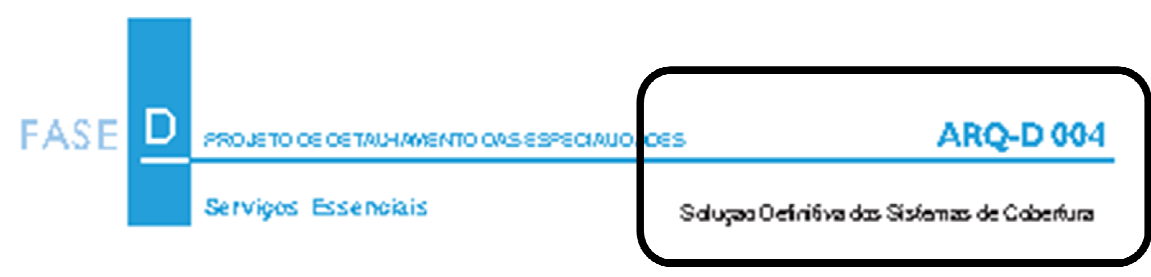

ATIVIDADE

Descriçăo das Arvidades

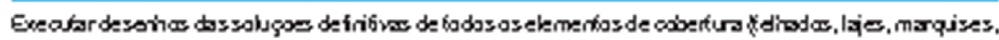

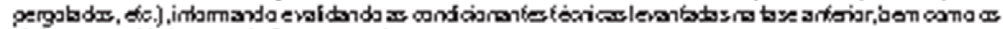

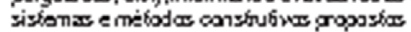

DOdOS NADESTICS

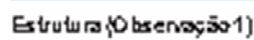

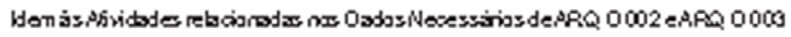

Sistamas prediais Ekltricos e Hid rul licos (Observajōo 2)

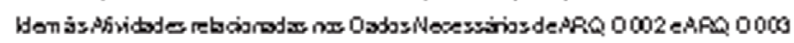

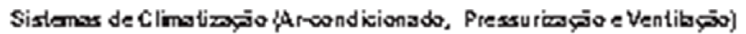

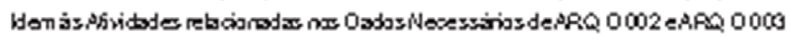

Consultores

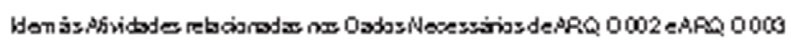

Produns gerados

9lantes daselemertos de coberturs, catoxdanamiima:

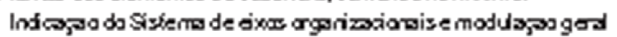

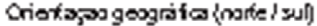

Oimercionameto e epecikaços das 6pdogix da quieto: laje, tehadas, pergdabss, de.

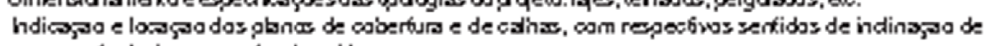

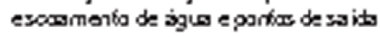

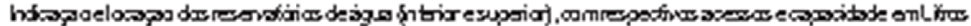
Cortes e sospos graisis nas ealas adequatas

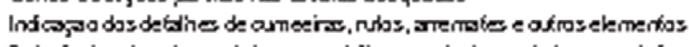

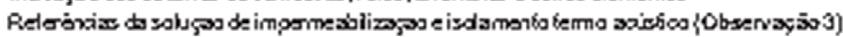

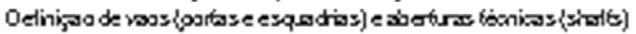

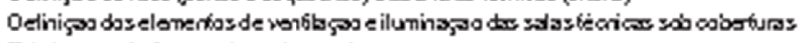

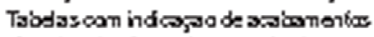

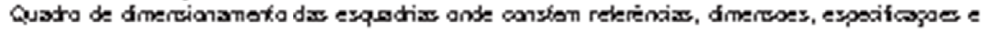
quaridade de coda uma (qanda getinete)

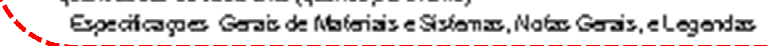

Obsenajöes:

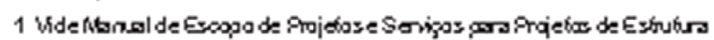

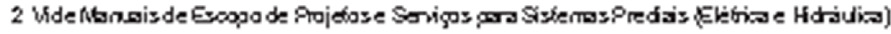

3 Recomentivel Corukikr Expecidieada

Figura 10 - Origem das atividades conforme manuais de contratação de projetos e serviços

\subsubsection{Histórico dos escopos existentes no Brasil}

Melhado (1994), ao analisar quais são as dificuldades para uma melhoria da qualidade do processo de projeto, identifica a falta uma definição dos conteúdos dos projetos e uma melhor definição das atividades a serem desenvolvidas em cada fase do processo como ponto crítico a ser trabalhado. A partir desta observação este propôs um modelo de processo de projeto que foi utilizado em processos isolados mas não chegou a gerar uma discussão setorial. 
Posteriormente, nos anos 2000, iniciaram-se as atividades do grupo de trabalho de projetistas de estruturas filiados à Associação Brasileira de Engenharia e Consultoria Estrutural - ABECE, que estabeleceu uma proposta para o escopo de projetos da especialidade, de forma a contemplar as necessidades típicas de empreendimentos imobiliários. Esse escopo foi, então, debatido em São Paulo, com representantes de outras entidades de projetistas e de contratantes de projetos, AsBEA (Associação Brasileira de Escritórios de Arquitetura); ABRASIP (Associação Brasileira de Engenharia de Sistemas Prediais); SindusCon-SP (Sindicato da Indústria da Construção Civil do Estado de São Paulo); SECOVI-SP (Sindicato da Habitação do Estado de São Paulo). Após uma série de debates, o escopo foi finalizado com uma versão consensual aprovada pelos representantes das entidades envolvidas. Paralelamente iniciou-se a elaboração dos escopos de projetos de sistemas prediais hidráulicos e elétricos por representantes da ABRASIP, que foram desenvolvidos de forma análoga ao escopo para projetos estruturais.

Na sequência a AsBEA utilizou o mesmo procedimento para desenvolvimento dos escopos de projetos de arquitetura e urbanismo e, em 2003, foi proposta a formação de um grupo para conduzir a elaboração de um escopo de serviços para a coordenação de projetos sob liderança da Escola Politécnica da USP e do SECOVISP.

A partir daí iniciou-se, com a mesma metodologia, a elaboração dos escopos para projetos e serviços de: paisagismo, ar-condicionado e ventilação mecânica, automação e segurança e serviços de esportes.

O conjunto de manuais está disponível para download no site www.manuaisdeescopo.com.br. Atualmente encontram-se disponíveis para consulta os seguintes manuais:

- Manual de Escopo de Serviços para Coordenação de Projetos

- Manual de Escopo de Projetos e Serviços de Vedações

- Manual de Escopo de Projetos e Serviços de Revestimento

- Manual de Escopo de Projetos e Serviços de Paisagismo

- Manual de Escopo de Projetos e Serviços de Instalações Prediais - Hidráulica 
- Manual de Escopo de Projetos e Serviços de Instalações Prediais - Elétrica

- Manual de Escopo de Projetos e Serviços de impermeabilização

- Manual de Escopo de Projetos e Serviços de Estrutura

- Manual de Escopo de Projetos e Serviços de Esportes

- Manual de Escopo de Projetos e Serviços de Automação e Segurança

- Manual de Escopo de Projetos e Serviços de Arquitetura

- Manual de Escopo de Projetos e Serviços de Ar Condicionado e Ventilação Mecânica

- Manual de Escopo de Projetos e Serviços de Acústica

Segundo o próprio site, em 10 anos de existência dos Manuais já foram feitos mais de 100 mil downloads por cerca de 20 mil usuários.

\subsubsection{As Fases dos Manuais de Escopo de Projetos e Serviços para a Indústria Imobiliária}

Conforme visto anteriormente, os Manuais foram estruturados obedecendo ao seguinte seqüenciamento de fases:

- Fase A - Concepção do Produto

- Fase B - Definição do Produto

- Fase $\mathrm{C}$ - Identificação e solução de interfaces de projeto

- Fase D - Detalhamento de projetos

- Fase E - Pós-entrega de projetos

- Fase F-Pós-entrega da obra

Cada uma das fases apresenta um escopo e os objetivos gerais, que norteiam o desenvolvimento dos trabalhos. No presente capítulo será feita uma análise do escopo e objetivos gerais propostos para cada uma das fases, em cada uma das especialidades que farão parte do estudo desta dissertação, fases A a $D$ dos manuais de arquitetura, estrutura, hidráulica, elétrica, ventilação mecânica e ar condicionado, paisagismo e coordenação de projetos.

\section{Fase A - Concepção do Produto (Estudo Preliminar conforme NBR 13.531)}

A fase de concepção do produto representa 0 momento em que 0 empreendimento será concebido, levando-se em consideração os aspectos jurídicos, legais, programáticos, mercadológicos e técnicos que nortearão o produto 
imobiliário pretendido. O levantamento destas informações permitirá a caracterização do partido arquitetônico e urbanístico, hidráulico, elétrico, de ventilação mecânica e ar condicionado e paisagismo que serão produtos desta fase para cada uma das especialidades citadas. A estrutura nesta fase prestará o apoio à concepção do produto, apresentando uma análise qualitativa que indique a viabilidade do ponto de vista da estrutura, para o produto proposto.

A fase A está subdividida em três etapas a saber:

LV - Levantamento de Dados

PN - Programa de Necessidades

EV - Estudo de Viabilidade

\section{Fase B - Definição do Produto (Anteprojeto, conforme NBR 13.531)}

A fase de definição do produto utiliza como premissa toda a fase de concepção do produto. A partir da caracterização dos partidos estabelecidos na fase $A$, estes serão agora desenvolvidos. A viabilidade física, legal e econômica do empreendimento deve ser verificada nesta fase, com base na definição e consolidação de todas as informações necessárias para esta análise. O Projeto Legal também deve ser desenvolvido neste momento, utilizando-se das informações desenvolvidas nesta fase. A estrutura deve subsidiar a arquitetura com informações que permitam a correta elaboração do Projeto legal e o empreendedor com índices para elaborção de um orçamento preliminar de viabilidade.

A fase B está subdividida em três etapas a saber:

EP - Estudo Preliminar

AP - Anteprojeto

PL - Projeto Legal

\section{Fase C - Identificação e Solução de Interfaces (Pré-executivo / Projeto Básico, conforme NBR 13.531)}

$\mathrm{Na}$ fase $\mathrm{C}$, a negociação de soluções de interferências entre os sistemas deve ocorrer e ter todas as interfaces resolvidas, de forma a viabilizar uma avaliação 
preliminar de custos, métodos construtivos e prazos de execução. A conclusão desta fase deve permitir, se for necessária, uma licitação da obra. Nesta fase, os ambientes, suas articulações e demais elementos do empreendimento devem estar consolidadas.

O produto gerado nesta fase pode ser chamado de PB - Projeto Básico.

\section{Fase D - Projeto de Detalhamento de Especialidades (Projeto Executivo conforme NBR 13.531)}

O projeto de detalhamento deve refletir, contemplar e caracterizar as obras/ serviços que serão executados e possibilitar a avaliação dos custos, métodos construtivos e prazos de execução.

O produto desta fase deve ser um conjunto de informações técnicas claras e objetivas de todas as especialidades, é o chamado PE - Projeto Executivo.

\subsection{O PLANEJAMENTO DO PROCESSO DE PROJETO}

Como visto, o processo de projeto é interativo e multidisciplinar. Ignorar esta complexidade não é prudente durante seu planejamento, além de não refletir a realidade do desenvolvimento deste. Quando muitos profissionais diferentes trabalham paralelamente em diversas frentes do mesmo projeto, suas entradas precisam ser coordenadas eficazmente e o planejamento deve ser ajustado na medida em que novas informações chegam. "A troca de informação é a seiva do desenvolvimento de produtos [...]. Tais circulações da informação permitem a experimentação e a inovação, e para essa razão, muitas companhias incentivam o feedback e a interação [...]. Mas a interação excessiva pode ter inconvenientes. Um vai e vem contínuo do trabalho inevitavelmente consome tempo e recursos. E muitas das interações podem ser somente um desperdício. ... a lição é clara. A interação deve planejada e controlada cuidadosamente. A boa interação deve ser incentivada e a má interação eliminada. " (EPPINGER, 2001 apud PROCESS IMPROVEMENT, 2006)

\subsubsection{A importância do planejamento do processo de projeto}

A complexidade do processo de projeto de edificações se dá tanto do aspecto técnico quanto gerencial. Estas características se observam por aspectos inerentes 
ao desenvolvimento do empreendimento, que tem apresentado cada vez mais especialistas envolvidos e um aumento da sua complexidade tecnológica, elevando o fluxo de informações e a necessidade de maior integração entre todos os envolvidos (FABRíCIO, 2002).

O processo de projeto envolve um refinamento das soluções à medida que 0 projeto vai se desenvolvendo. Uma gestão adequada deste processo envolve a avaliação e administração do tempo dispendido para este trabalho, além da troca de informações entre todos os agentes e avaliação da qualidade das informações que está sendo transmitida. Fabrício (2002) destaca que a divisão do processo de projeto em etapas facilita o entendimento de cada uma das fases mas alerta sobre a dificuldade em se visualizar o processo como um todo.

Para Fabrício (2002), a complexidade do projeto e da gestão dos agentes envolvidos faz com que muitos empreendimentos ou não tenham um planejamento antecipado do processo de projeto, ou apresentem um planejamento demasiadamente hierárquico e, muitas vezes, ineficaz. Uma boa organização do processo de projeto deve considerar a lógica intelectual de desenvolvimento de projetos e a atuação conjunta e coordenada dos diversos profissionais e interesses envolvidos no desenvolvimento do produto (edifício). O planejamento do processo de projeto deve respeitar esta lógica de desenvolvimento e, principalmente, a interatividade do processo.

CTE (1997) comenta que [...] muitas dificuldades do processo de produção do projeto estão relacionadas à estrutura de atividades e rede de relacionamentos entre elas que se estabeleceram ao longo do tempo.

O processo de projeto é a etapa mais estratégica do empreendimento com relação aos gastos de produção e a agregação de qualidade ao produto porém, o planejamento de projetos ainda não está incorporado às rotinas de gestão de projetos. Sua mais freqüente utilização é como ferramenta de controle de entregas de desenhos, não levando em conta a natureza do processo de projeto, sua complexidade e seu fluxo de informações.

A utilização de modelos inadequados para o planejamento de projeto é freqüente. Usualmente o processo de projetos é planejado com os mesmos métodos utilizados para o planejamento de obras (AUSTIN et al.,2000). Essas técnicas não permitem a representação da multidisciplinaridade e interatividade do processo de 
projeto somente estabelecendo prazos conforme as datas críticas dos empreendimentos imobiliários - lançamento do produto e início de obra. O cronograma é elaborado regressivamente, do fim para o início do processo com base nas datas pré-estipuladas.

Valeriano (1998) considera que o planejamento das atividades de projeto é um processo interativo com o objetivo de propor soluções em detalhamentos sucessivos, determinando os passos a executar e possibilitando a elaboração de um plano que deve ser utilizado como roteiro a ser implementado, controlado e revisado quando necessário.

Fabricio (2002) destaca ainda que o planejamento e a modelagem do processo de projeto na construção de edifícios é uma atividade essencial para compreender o desenvolvimento de produtos (edifícios) e propor melhorias neste processo.

A implementação de qualquer melhoria de um processo exige que primeiramente o processo atual seja levantado e modelado, para que então sejam propostos planejamentos alternativos.

A incerteza, interação e interdependência, características dos projetos de empreendimentos imobiliários, exigem uma metodologia específica para o planejamento do processo de projeto, possibilitando a simulação, controle e retroalimentação (MANZIONE, 2006). A gestão do processo de projeto ainda é praticada de forma simplista, muitas vezes com projetos sendo trabalhados de forma sequencial e sem a integração dos diversos agentes envolvidos no processo. A capacidade do gestor de estruturar o processo de projeto a partir de suas precedências de informações, e não sequências de entregas de desenhos, é fundamental para um bom andamento do processo e um planejamento efetivo das atividades.

Verifica-se assim a necessidade de uma modelagem do processo de projeto para viabilizar um bom planejamento das atividades. Esta modelagem deve representar a interatividade, reorganizar as atividades reduzindo os ciclos de retrabalho, e permitir a visão de todo o conjunto do processo.

Manzione e Melhado (2007) apontam diversas justificativas para o estudo do planejamento do processo de projeto verificadas, entre outros motivos, pelas limitações dos processos de contratação e gestão do projeto, pelo desconhecimento 
dos coordenadores de projeto das ferramentas gerenciais adequadas e dos mecanismos de geração do fluxo de informações dos projetos; pelas deficiências organizacionais das empresas de projeto e na insuficiência de pesquisa acadêmica desenvolvida sobre o tema.

Romano et al. (2001) também apontam razões e justificativas para a modelagem do processo de projeto, que representa de forma abrangente e integrada o processo de desenvolvimento do produto, permitindo a melhoria e redefinição do processo praticado, além da melhoria do gerenciamento do processo:

- compreender o processo de desenvolvimento do produto;

- explicitar o know-how dos profissionais e empresas envolvidas;

- subsidiar a organização do processo;

- dar uma maior eficiência à seleção e treinamento dos agentes do projeto;

- melhorar a interação entre os intervenientes no processo, na medida em que permite racionalizar e garantir o fluxo de informações;

- melhorar o processo de planejamento de novos empreendimentos e projetos (previsão de recursos, de riscos, etc.);

- subsidiar a escolha ou desenvolvimento de sistemas computacionais de suporte ao processo de projeto;

- padronizar as atividades executadas pelos diversos projetistas com o estabelecimento de procedimentos internos mais consistentes com a realidade das áreas envolvidas, facilitando também as atividades de revisão e compatibilização de projetos, bem como a implantação de sistemas de gestão da qualidade e certificação ISO, etc.;

- identificar problemas e promover melhorias no processo de desenvolvimento de produto.

Vargas (2000) afirma que muitos projetos falham ou não atingem as expectativas estipuladas, entre outros motivos, pelo pouco tempo destinado para as estimativas e o planejamento deste.

\subsubsection{A importância da modelagem do processo de projeto}

A grande maioria das empresas atuantes no mercado imobiliário não possui seu processo de projeto modelado, o que dificulta uma visão global deste.

Conforme já verificado anteriormente, a falta de qualidade em edificações é conseqüência, entre outras razões, da falta de qualidade no processo de projeto. $O$ 
processo de projeto ainda tem sido desenvolvido de forma não planejada, segmentada e seqüencial, sem incorporar a necessidade de interação entre os diversos agentes e entre o projeto e execução.

Diversos estudos (FABRICIO, 2002; ROMANO, 2003; entre outros) destacam a importância de uma mudança nas atuais formas de condução do processo de projeto, propondo o desenvolvimento integrado de edificações, com base nos conceitos da Engenharia Simultânea. Mas, para que ocorra uma mudança no desenvolvimento do processo de projeto, é necessário que haja o entendimento de como processo de projeto é executado.

Romano (2003) destaca a modelagem como ferramenta para uma visualização global do processo, permitindo a observação de informações como: o que deve ser feito (projetos, etapas, atividades, tarefas), por quem (os envolvidos, suas funções e responsabilidades, interações), quando (a que tempo e a que hora, relações de precedência), como (informações ou documentos de entrada; procedimentos, ferramentas e/ou tecnologias utilizadas no processamento das informações; informações ou documentos de saída; forma de controle), e onde (em que local, em que tipo de situação, por quais meios).

Tzortzopoulos (1999) destaca a importância da modelagem do processo de projeto, uma vez que permite:

- a implementação de melhorias através da análise e planejamento;

- a visão global do processo por todos os agentes envolvidos e a identificação de seus papéis e responsabilidades, facilitando o intercâmbio de informações;

- a redução do tempo dos projetos, pela definição clara das atividades e das relações de precedências.

\subsubsection{Definição das tarefas e o fluxo de informações no processo de projeto}

De acordo com Fabricio (2002) a sistematização do processo de projeto exige o intercâmbio eficaz de informações entre os profissionais envolvidos, bem como a organização da informação de forma que as premissas, análises críticas, validações, discussões e decisões sejam documentadas e compartilhadas, quando necessário entre os agentes participantes. 
Para Garcia Meseguer (1991), as características mais significativas que influem na eficácia da informação transmitida, são: quantidade de informação; a forma de transmissão; e a confirmação do entendimento do conteúdo da informação.

O intercâmbio de informações entre os agentes participantes no processo de projeto pode ocorrer de duas formas distintas. Na primeira as trocas de informações entre os projetistas são organizadas para serem processadas de forma centralizada na coordenação de projetos através da mediação do coordenador, responsável pelo controle de informações. Na segunda forma, as trocas de informações entre os projetistas circulam livremente entre todos, sendo que o coordenador é mobilizado para solucionar controvérsias ou endossar uma decisão tratada pelos projetistas (MELHADO, 2005). De acordo com Melhado et al. (2005) a solução da centralização das informações no coordenador de projetos, facilita o controle, porém pode significar perda de agilidade na comunicação entre os membros da equipe de projeto e prejudicar a interatividade entre os projetos. A circulação livre das informações, segundo o mesmo autor, pode proporcionar a potencial perda de controle sobre o processo de troca de informações.

A interatividade é uma das características mais importantes e singulares do processo de projeto, e a qualidade do projeto é fortemente influenciada pela qualidade das interações realizadas ao longo do projeto. A fim de respeitar a interatividade e as características do processo de projeto, autores como Austin et al. (1994), Tahon (1997), Formoso et al. (1998), Austin et al. (1999), Baldwin et al. (1999), Romano et al. (2001) destacam técnicas específicas de planejamento de projeto e, em alguns casos, propõem adaptações nestas técnicas para serem utilizadas no planejamento de projetos de construção. Segundo Austin et al. (1999) uma das mais apropriadas técnicas de planejamento de projeto na construção é a metodologia IDEFO e as ferramentas associadas, desenvolvidas inicialmente na indústria aeroespacial nos anos 1970.

Embora tais técnicas sejam poderosas e importantes para o avanço no planejamento de projetos no setor de construção, sua origem em outros setores industriais com culturas e disciplinas de desenvolvimento de produto é bastante diversa. Em geral, são técnicas bastante complexas e rígidas que demandam um conhecimento e uma sistematização do processo que não se compatibilizam com o estágio de desenvolvimento do setor de construção, e com domínio metodológico atual que as empresas de projeto têm sobre seus processos. Por outro lado, como o 
setor trabalha com empreendimentos únicos, muitas vezes, técnicas sofisticadas e laboriosas de planejamento de projeto não são aceitáveis uma vez que o esforço e os gastos para o planejamento não podem ser diluídos em um empreendimento de pequena monta.

Waskett et al (2010) propõem que o processo de projeto seja baseado no fluxo de informações, e suas interações baseadas entre as diversas fases do desenvolvimento do empreendimento e entre os participantes da equipe. A análise e controle do sincronismo das decisões de projeto é fundamental e determinante para controle dos prazos de entrega de projetos. É importante também que a informação possa ser rastreada uma vez que é ela que determina datas macro como a liberação do projeto para a obra.
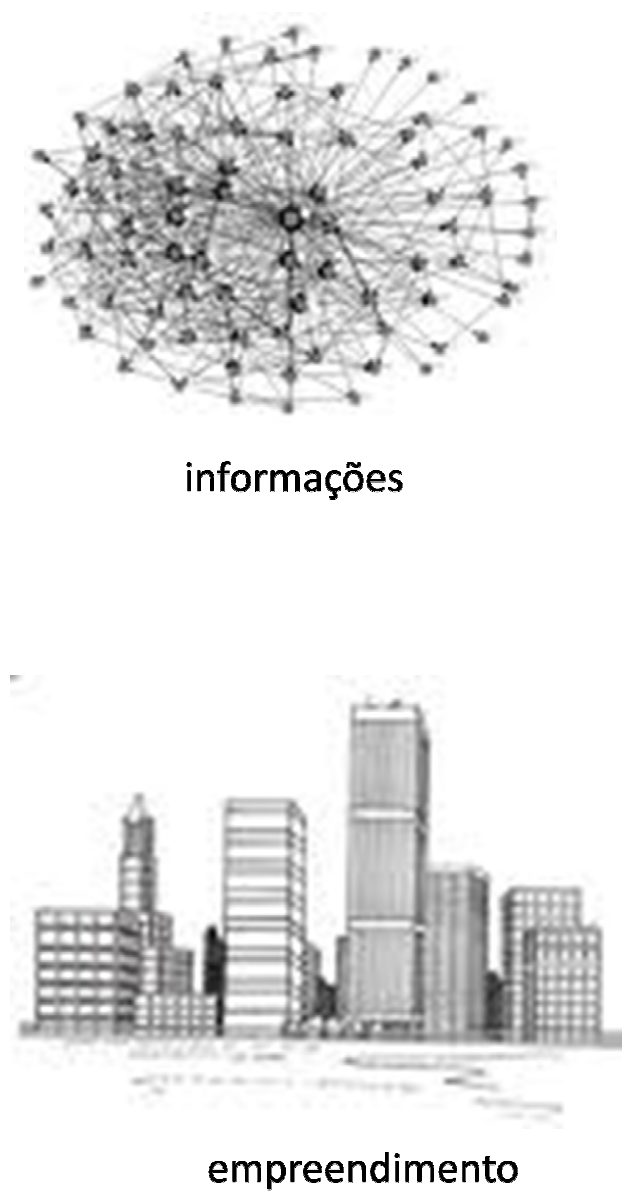
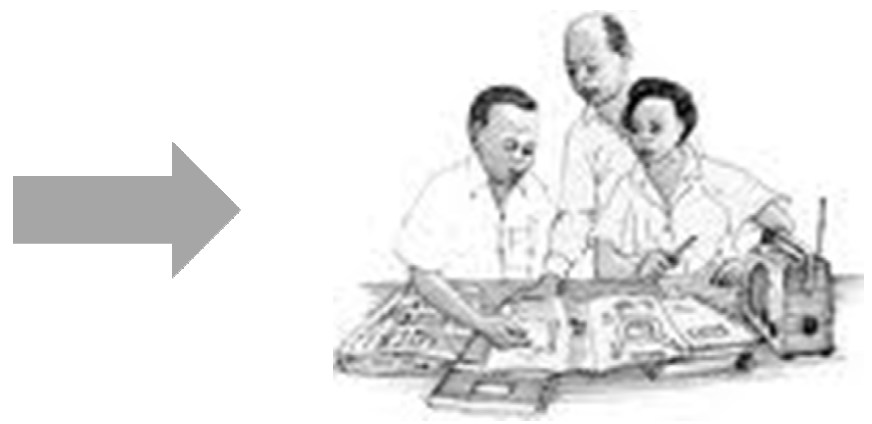

interatividade
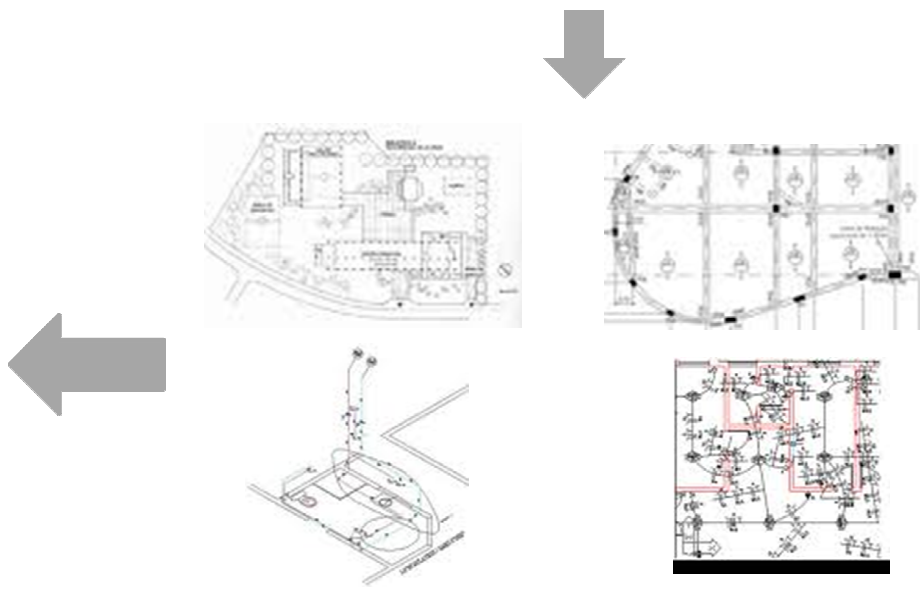

projetos

Figura 11 - Projeto como fluxo de informações 


\subsubsection{O planejamento do processo de projeto}

Todo projeto é constituído e caracterizado por alguns elementos que são diretamente responsáveis pelo seu resultado. Hoffmeister (2003) descreve alguns destes elementos:

- um objetivo: o projeto deve ter um resultado final definido em termos de escopo, custo, tempo e qualidade;

- um certo nível de complexidade: o desenvolvimento do projeto contempla a execução de diversas atividades, algumas delas a serem desempenhadas simultaneamente. O relacionamento entre todas as atividades e seu grau de dependência definem a complexidade do projeto. Quanto mais complexo este for, mais difícil de se atingir seu objetivo;

- sua característica de unicidade: todo projeto é único, nunca um empreendimento é repetido;

- um certo grau de incerteza: apesar de todos os projetos serem planejados antes de executados, é inerente a este o elemento de risco ou incerteza;

- sua natureza temporária: o projeto tem início e fim definidos, com uma concentração temporária de recursos para seu desenvolvimento;

- um ciclo de vida definido: as necessidades relativas a um projeto variam conforme seu ciclo de vida. A divisão do ciclo de vida do projeto em fases permite a alocação adequada de recursos disponíveis, uma vez que estes variam durante sua execução.

Hoffmeister (2003) destaca também que o processo de gerenciamento do projeto subdivide-se em cinco novos conjuntos de processos (subprocessos), que atuam especificamente em cada uma das fases do ciclo de vida deste. Abaixo uma breve descrição de cada um dos subprocessos:

- processo de iniciação: demarca o início do projeto e assegura o comprometimento dos envolvidos com sua execução;

- processo de planejamento: deve garantir o planejamento e a manutenção do trabalho para que os objetivos do projeto sejam atingidos;

- processo de execução: deve coordenar os envolvidos no projeto e outros recursos para que o plano de projeto estabelecido seja alcançado; 
- processo de controle: monitora e avalia o progresso do projeto e estabelece a tomada de ações corretivas quando necessárias, para que os objetivos do projeto sejam atingidos;

- processo de encerramento: formaliza o aceite técnico do projeto e seu fechamento de forma organizada.

Todos os subprocessos se caracterizam por uma interação e iteração entre eles. Desta forma, as saídas de um subprocesso se tornarão entradas do subprocesso seguinte. A figura 12 caracteriza a relação existente entre os subprocessos com base na visão do Project Management Institute sobre este processo.

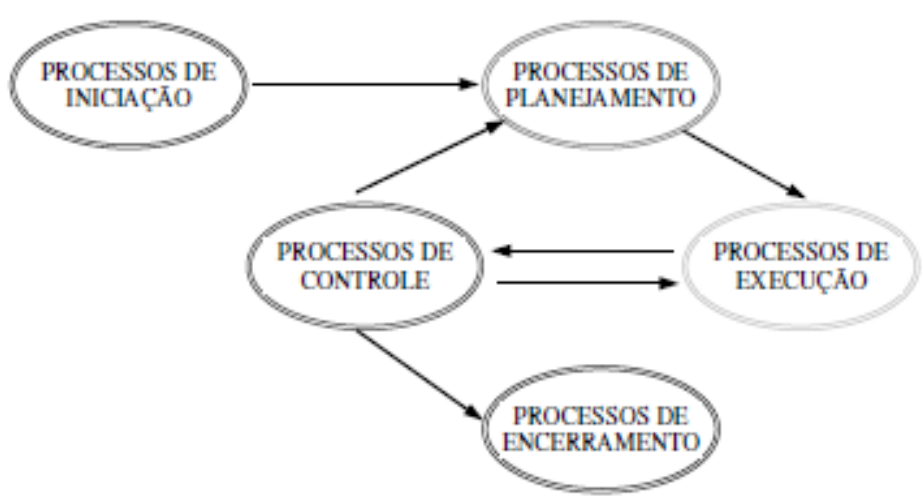

Figura 12 - Representação dos subprocessos de gerenciamento de projetos,

(PMI, 2000 apud HOFFMEISTER, 2003)

Assumpção e Fugazza (2001) consideram que para a estruturação de um modelo de planejamento do processo de projetos é necessário o entendimento do fluxo de desenvolvimento das atividades e produtos decorrentes destas, para que sejam estabelecidas as relações, critérios e parâmetros que delimitem os prazos mínimos necessários na execução dos produtos que devem ser considerados como parte de uma sequência.

Para a elaboração do plano de gerenciamento, os autores propõem que sejam formuladas e respondidas algumas questões como:

- quais as principais etapas do processo de projeto?

- quais os produtos parciais e finais dentro de cada etapa?

- quais os requisitos necessários para se iniciar cada etapa?

- os projetos de instalações devem ser desenvolvidos em conjunto com projetos de arquitetura e estrutura, ou com vedações? 
- em que momento deve-se começar projetos de decoração e paisagismo?

- quando se inicia a consultoria para elevadores (cálculo de trafego, dimensionamento de áreas etc)?

- em que momentos devem ser realizadas reuniões de compatibilização entre os parceiros envolvidos no processo?

A resposta a estas questões leva à caracterização do fluxo do processo de projeto.

Especificamente para o processo de planejamento, foco do trabalho em questão, foram analisadas algumas propostas de estruturação e procedimentos para seu desenvolvimento. Dinsmore (1992), PMI (2009) e Slack et al. (1997).

Para Hoffmeister (2003), com base no trabalho de Dinsmore (1992), o planejamento de projetos pode ser entendido sob dois aspectos, o técnico e o gerencial.

Do ponto de vista técnico, o planejamento de projetos relaciona-se com a execução de uma metodologia, que inclui a definição dos objetivos, a identificação e o seqüenciamento das atividades, a identificação de recursos e a estimativa de tempos para um projeto. Do ponto de vista gerencial, relaciona-se com a coordenação do projeto no dia-a-dia, envolvendo a configuração e gerenciamento da equipe.

Os processos principais são subdivididos em quatro fases conforme descrito a seguir:

- planejamento do escopo do projeto: definição dos objetivos, responsáveis e dos itens de trabalho a serem realizados;

- planejamento das atividades de projeto: definição das etapas ou atividades do plano de projeto e dos recursos necessários para realizá-las;

- planejamento da programação do projeto: seqüenciamento das atividades e estimativa de tempo e custo para execução destas;

- configuração do plano de projeto: organização das informações coletadas nas saídas dos processos anteriores para obtenção do documento plano de projeto, para orientação da equipe durante a execução e controle do processo de desenvolvimento do produto. 


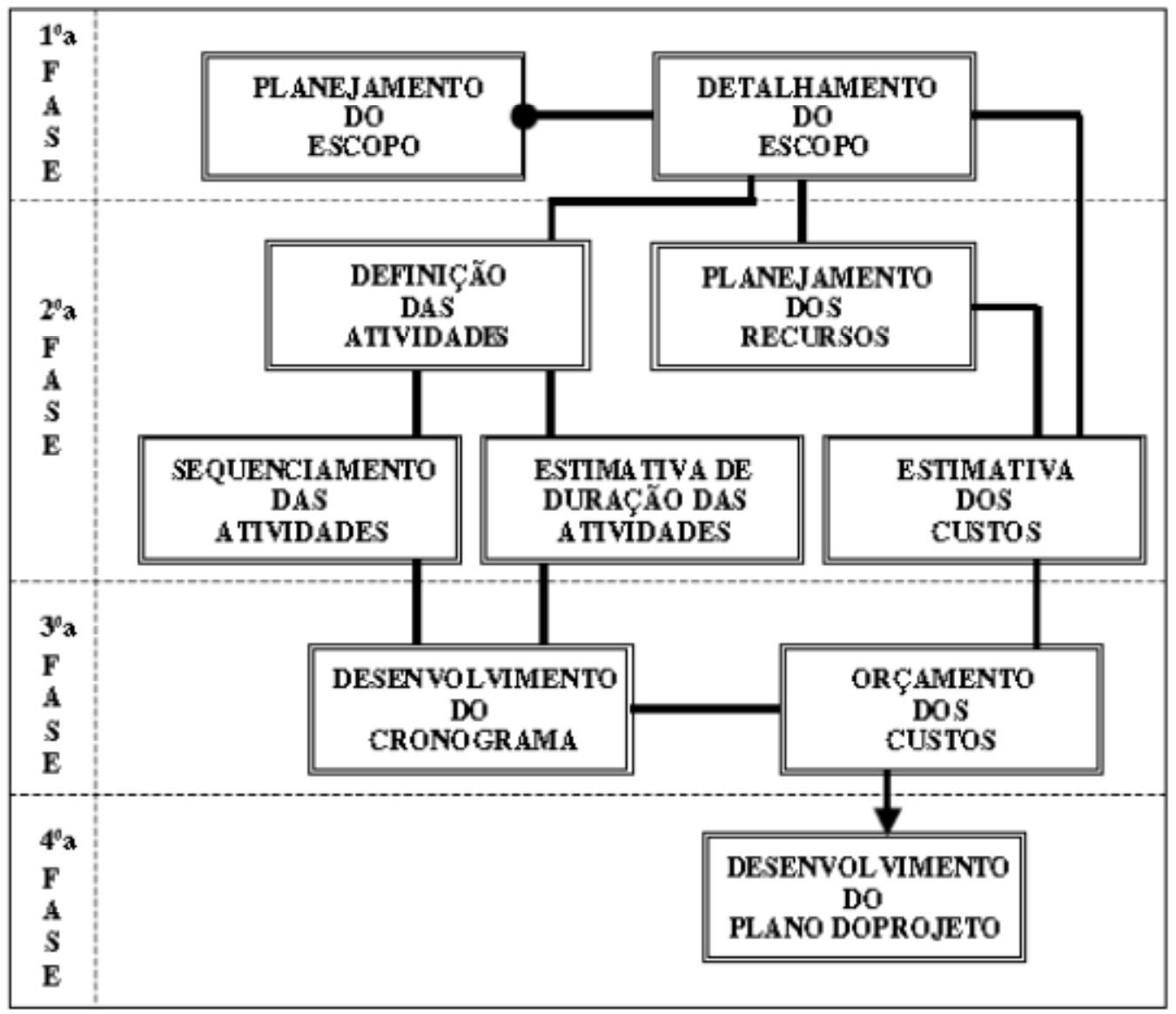

Figura 13 - Estrutura dos processos de planejamento de projetos, (PMI, 2000 apud HOFFMEISTER, 2003)

O Project Management Institute (2009) considera não somente um processo de planejamento de projetos mas, um conjunto de processos divididos em duas categorias, os principais e os facilitadores.

Slack et al. (1997) por sua vez dividiram o processo de planejamento de projetos conforme as seguintes fases:

- identificação das atividades de projeto: as atividades de projeto são desdobradas hierarquicamente até que sejam bem definidas e gerenciáveis;

- estimativa de tempos e recursos: são identificados os requisitos de tempo e recursos para as atividades de projeto;

- identificação das relações e dependências: as atividades de projeto são relacionadas conforme as que podem ser realizadas de forma independente e as que precisam de outras para serem executadas; 
- identificação das limitações de programação: comparação dos requisitos de projeto com os recursos disponíveis;

- preparação da programação: estabelecimento do seqüenciamento das atividades de forma otimizada.

Todas as propostas de estruturação e procedimentos de projeto analisadas apresentam como objetivo o plano de projeto.

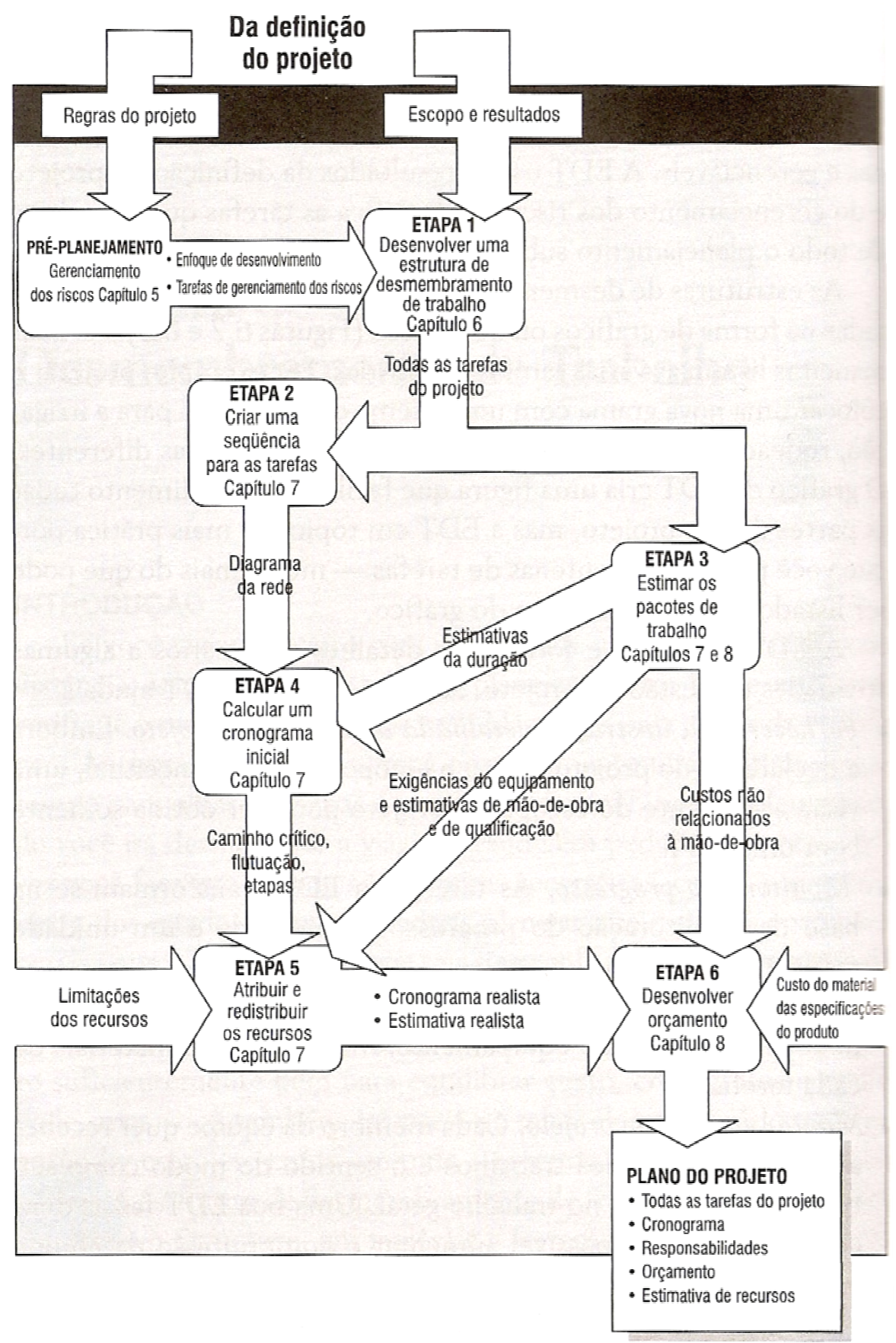

Figura 14 - Modelo detalhado do planejamento (VERZUH, 2000) 
Após a definição do objetivo do projeto, a próxima etapa do planejamento é a determinação de quais elementos de trabalho ou atividades precisam ser conduzidas para o cumprimento do objetivo estabelecido.

As questões de projeto podem ser melhor resolvidas se desmembradas em atividades. A dificuldade está em identificar as atividades do processo de projeto e, para tanto, algumas ferramentas podem ser utilizadas como auxiliares nesta definição.

Gido e Clements (1998) propõem duas direções para a definição das atividades de projeto, a ferramenta brainstorming e a estrutura analítica de projeto (EAP)

Hoffmeister (2003) apresenta um estudo de ferramentas para auxiliar na definição das atividades de projeto, brainstorming, EAP, síntese funcional, técnica de análise funcional de sistemas, definição integrada para modelagem funcional (IDEF0).

Austin et al (2000), discutem a prática atual de planejamento, que não leva em conta a natureza, interdisciplinar e interativa, do processo de projeto, o que compromete a concepção, refletindo em retrabalhos, alongamento de prazos e elevação de custos nas etapas e no produto final. Para superar estas dificuldades foi proposto pelos autores a metodologia ADePT, cuja parte central é a DSM, para elaboração do processo de projeto de empreendimentos imobiliários.

A proposta de utilização da metolodogia ADePT para planejamento do processo de projeto de empreendimentos imobiliários foi feita por Austin et al em sua pesquisa vencedora do prêmio Qualidade e Inovação na Construção de 1999 na Inglaterra. Na pesquisa foi feita uma aplicação prática da metodologia, que tinha como metas e objetivos:

- identificar e definir as necessidades de informação e as dependências durante o desenvolvimento do projeto tanto para o cliente quanto para a construção;

- incorporar as necessidades de informação das organizações e de cada disciplina de projeto em um modelo de projeto genérico; 
- criar uma ferramenta protótipo de software para otimizar o sequenciamento das tarefas de projeto e analisar os efeitos da mudança (tanto no processo de projeto quanto em toda a construção);

- aplicar a técnica em uma série de projetos de empreendimentos imobiliários e investigar os aspectos culturais, organizacionais e problemas de gestão que serão levantados pela sua adoção na indústria da construção.

A metodologia aplicada para desenvolvimento da pesquisa partiu do desenvolvimento do conceito de ADePT e aplicação prática desta. Para o grupo, a utilização da metodologia ADePT para o planejamento do processo de projeto de empreendimentos imobiliários se mostrou viável não só para o planejamento como também para o gerenciamento do processo.

\subsection{A DESIGN STRUCTURE MATRIX (DSM)}

A DSM (Design Structure Matrix) é um método geral para representar e analisar modelos de projetos em diversas áreas de aplicação. A DSM é uma matriz quadrada (ou seja, tem um número igual de linhas e colunas) que mostra as relações entre os elementos de um projeto. Em relação a outros métodos de modelagem do sistema, a DSM tem as seguintes vantagens principais:

- a DSM permite, ao mesmo tempo, uma representação concisa e sistêmica de processos complexos;

- facilita a identificação das dependências existentes no processo;

- descreve o processo de projeto de tal maneira, que o mesmo pode ser analisado e modificado para prover uma prescrição da sua execução, com riscos programados e tempo reduzido;

- consiste em um meio preciso para se gerenciar cronogramas e antecipar riscos, sendo usual representar tempos de projeto na diagonal da DSM;

- demonstra apropriadamente atividades simultâneas;

- consiste em um meio rápido e preciso de se examinar potenciais alterações no seqüenciamento das atividades de projeto e o efeito destas sobre o seu cronograma;

- facilita a organização de recursos, reduzindo iterações no projeto. 
A DSM é uma ferramenta simples para realizar tanto a análise quanto a gestão de sistemas complexos. Ela permite ao usuário modelar, visualizar e analisar as dependências entre as atividades de qualquer projeto e obter sugestões para a melhoria ou a síntese deste.

Como ferramenta para análise de processos de projeto, a DSM fornece uma representação compacta e clara de um processo complexo e um método de captura para as interações / interdependências / interfaces entre os elementos do projeto (ou seja, sub-sistemas e módulos).

Como ferramenta de gestão, a DSM é mais comumente aplicada no gerenciamento de projetos, e fornece uma representação do projeto que permite a visualização das dependências entre as tarefas e um feedback cíclico. Isso é extremamente importante, já que a maioria dos processos de projeto apresenta uma propriedade cíclica. Como tal, esta representação muitas vezes resulta em um cronograma de execução melhorado e mais realista para as atividades de projeto.

A primeira pesquisa sobre a DSM foi publicada por Don Stewart em 1981 e, a partir desta pesquisa, todas as demais se desenvolveram. O site referente aos estudos e desenvolvimento da DSM apresenta uma listagem de institutos de pesquisas, consultorias e sociedades internacionais voltadas ao desenvolvimento do assunto, conforme segue:

Technische Universität München, Institute of Product Development. Munich, Germany. (www.pe.mw.tum.de)

Focada em pesquisa de metodologias para facilitar e apoiar o processo do projeto de engenharia. Como parte do instituto, o grupo de pesquisa em Engenharia de Sistemas tem trabalhado em modelos, métodos e ferramentas para tornar a gestão mais eficiente e de complexidade alcançável.

Massachusetts Institute of Technology. Cambridge, MA, USA.

A pesquisa aborda o gerenciamento de projetos complexos de engenharia, tais como o desenvolvimento de um automóvel, avião ou sistema de telecomunicações utilizando a DSM. 
Loughborough University, Civil and Building Engineering. Loughborough, UK (www.lboro.ac.uk)

O objetivo da pesquisa é desenvolver e testar uma metodologia de planejamento para o projeto de construção detalhado para permitir a concepção de gestão eficiente e reengenharia de processos de construção e engenharia civil.

Texas Christian University. Fort Worth, TX, USA

A pesquisa procura aplicar os critérios da DSM ao produto, processo e projeto de organização e gestão do projeto, concentrada na modelagem e análise de projetos de engenharia complexa, programas e empresas, para aumentar a compreensão de como tais entidades operam. O objetivo é identificar idéias que irão melhorar o planejamento e gestão.

University of lowa, Industrial Engineering. lowa city, lowa, USA.

Focada na engenharia computacional e todos os métodos que são necessários para apoiar o projeto de engenharia eficiente. Os interesses da pesquisa são, entre outros, dados de descoberta de mineração e conhecimento, inteligência computacional, informática médica e da tecnologia, o design de produtos, componentes, processos e sistemas e modelagem de processos.

\section{Engineering Design Center, University of Cambridge. UK (www- edc.eng.cam.ac.uk)}

Concentra suas pesquisas em dois aspectos principais da gestão: a propagação de mudança e melhoria do processo de design.

New England Complex Systems Institute (http://necsi.edu)

Desenvolve pesquisa, sem fins lucrativos, de ensino do desenvolvimento de novos métodos científicos, e aplicação para os desafios da sociedade, principalmente com base na ciência da rede de relacionamentos e as redes que são encontrados em todos os tipos de aspectos da vida cotidiana.

Problematics. Napa, CA, USA. (www.problematics.com)

Trata-se de um software de gerenciamento de empresa para consultoria em desenvolvimento de forma que os clientes possam implementar métodos de DSM 
para gerir os negócios e odesenvolvimento de produtos através de uma visão sistêmica.

Axiomatic Design Solutions. Boston, MA, USA. (www.axiod.com)

Oferece treinamento e serviços de processos de concepção axiomática. A tecnologia de processo de projeto ajuda as equipes de concepção e desenvolvimento de produtos e sistemas.

Teseon GmbH. Garching, Germany. (www.teseon.com)

Vê a gestão da complexidade como uma fonte de vantagem competitiva. Oferece assistência ao acesso, compreensão e em tirar proveito da complexidade por meio de consultoria e desenvolvimento de ferramentas de software

RedTeam. Ljungsbro, Sweden. (www.redteam.se)

Oferece apoio na resolução de problemas e gestão da incerteza no desenvolvimento de produtos com relação à organização do projeto, modularização de sistemas, concepção de produtos, modelagem e processo de desenvolvimento do produto.

Adept Management Ltd. Coventry, UK. (www.adeptmanagement.com)

Implanta sua metodologia, que compreende a modelagem de processos, análise de DSM, programação e controle de etapas do processo de projeto, em projetos em construção, engenharia civil e defesa.

\section{AML Technologies. Carlsbad, CA, USA.}

Especializados em programação e controle de projetos complexos e projetos de engenharia, utilizando a metodologia ADEPT que tem na DSM seu foco. Os consultores tem experiência na implementação de DSM em projetos de US \$3 milhões a US \$1,5 bilhão.

EOY- New Business Development. Talheim, Germany. (www.orbach-yliruka.de)

Apoia os clientes na gestão da inovação e coordenação do projeto se concentrando na melhoria da compreensão, o desenvolvimento do conhecimento e tomada de decisão. Enfoca especialmente a fase de concepção e projeto de 
desenvolvimento e projetos complexos de engenharia. A abordagem da questão é facilitada pela metodologia AdePT com experiência em saúde, indústria automobilística e desenvolvimento de plantas.

- Sociedades internacionais

The Design Society, Special Interest Group "Managing Structural Complexity". Fundada para contribuir com uma ampla compreensão e estabelecimento do desenvolvimento e design, e promover a utilização dos resultados e conhecimento das pesquisas sobre o projeto de engenharia para o bem da humanidade. Como parte deste trabalho, foi criado o Grupo de Interesse Especial "Gerenciando complexidade estrutural" para mediar áreas de competência no que respeita à gestão da complexidade estrutural em todos os aspectos do desenvolvimento do produto através de uma análise de pontos de vista diferentes em um sistema, seus elementos e interdependências, e sua evolução e dinâmica.

\section{The International Council on Systems Engineering (INCOSE).}

Associação sem finsl lucrativos fundada para avançar o estado da arte e da prática da engenharia de sistemas na indústria, pesquisa e governo promovendo a interdisciplinaridade e abordagens para produzir soluções tecnologicamente adequadas e que atendam às necessidades da sociedade.The American Society of Mechanical Engineers (ASME).

Organização sem fins lucrativos que promove a arte, a ciência ea prática da engenharia mecânica e multidisciplinar e ciências afins em todo o mundo.

\section{IEEE}

Organização sem fins lucrativos originária do Instituto de Engenheiros Elétricos e Eletrônicos, Inc., focada no apoio ao avanço da tecnologia em todo o mundo.

Com base na análise dos focos de pesquisa das instituições e consultorias optou-se por desenvolver este trabalho com referência nas pesquisas desenvolvidas pela Loughborough University através do Prof. Simon Austin e Adept Management Ltd via Paul Waskett, por se tratarem de trabalhos voltados para a indústria da construção civil. 


\subsubsection{O funcionamento da DSM}

O método de planejamento integrado do projeto, DSM, simplifica e controla o processo de desenvolvimento de projetos utilizando três módulos: estruturação, modelagem e programação, como ilustrado na figura 15.

No módulo de estruturação, a matriz é utilizada para estruturar os fluxos de informação e identificar as interações entre as atividades. Os vários tipos de dependências de informação são classificados e as redundâncias são removidas para a modelagem e programação.

No módulo de modelagem, um modelo de processo calcula a probabilidade de distribuição de tempo necessário para desenvolvimento das atividades e identifica os caminhos críticos em um projeto interativo e com recursos limitados.

Usando os resultados das análises dos módulos de estruturação e modelagem, um cronograma no formato gráfico Pert ou Gantt é desenvolvido no módulo programação. A programação é usada como base para o monitoramento e controle do projeto.

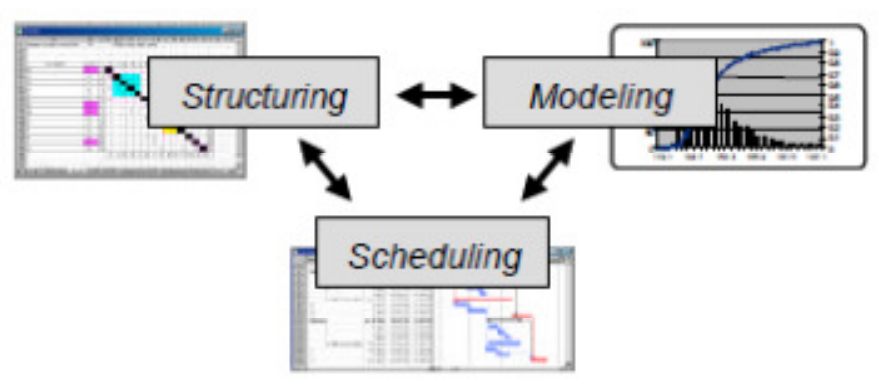

FIGURE 1. ANINIEGRATE PROIECT MANAGEMENT FRAMETORK

Figura 15 - Estrutura de projeto integrada

O objetivo principal do trabalho com a DSM é desenvolver um método integrado de gerenciamento de projeto que orienta esforços pela melhoria da eficácia e previsibilidade de processos complexos. O método pode também ser usado para identificar pontos de alavancagem para a melhoria dos processos e avaliação de alternativas estratégicas de planejamento e execução. Um melhor gerenciamento de projetos acabará por resultar em um produto de melhor qualidade com entrega adequada aos clientes. 
A estruturação e modelagem são implementadas através de um suplemento do Microsoft Excel. A análise dos resultados podem ser exportadas para 0 Microsoft Project. A Tabela 5 resume as entradas e análise dos resultados de cada módulo.

\begin{tabular}{|c|c|c|}
\hline & Dados de entrada & Análise dos resultados \\
\hline Estruturação & $\begin{array}{l}\text { - } \text { Lista de tarefas } \\
\text { - } \text { Fluxo de informação entre as } \\
\text { tarefas } \\
\text { - Padronização do fluxo de } \\
\text { informações }\end{array}$ & 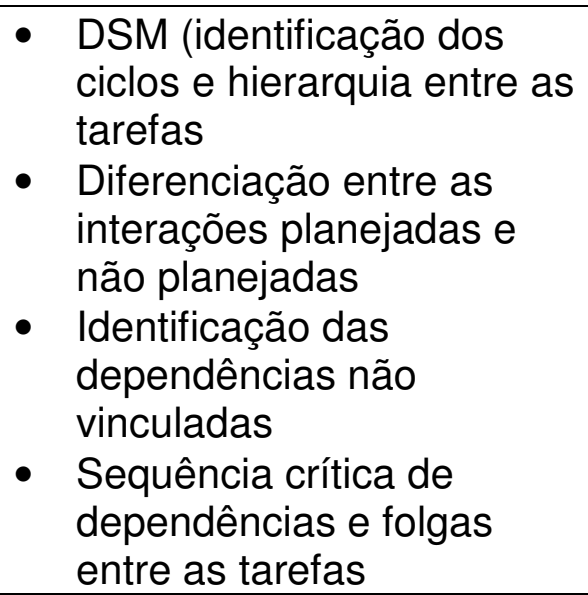 \\
\hline Modelagem & $\begin{array}{l}\text { - Duração estimada das } \\
\text { tarefas } \\
\text { - Recursos necessários para } \\
\text { as tarefas e capacidade do } \\
\text { projeto } \\
\text { - Características de } \\
\text { sobreposição e } \\
\text { seqüenciamento das } \\
\text { interações } \\
\text { - Tolerância para o risco de } \\
\text { retrabalho }\end{array}$ & 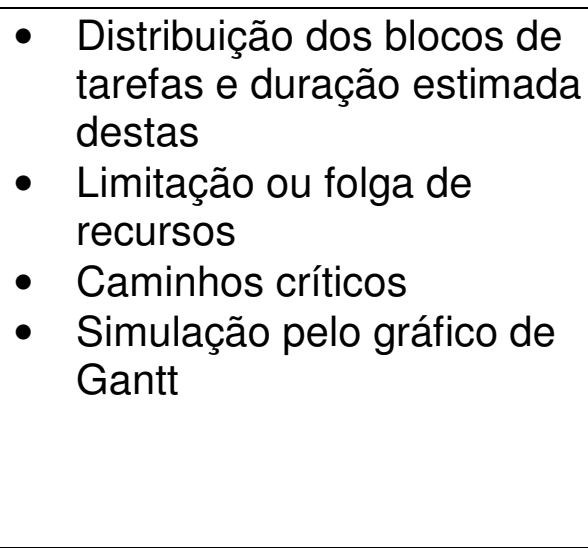 \\
\hline programação & 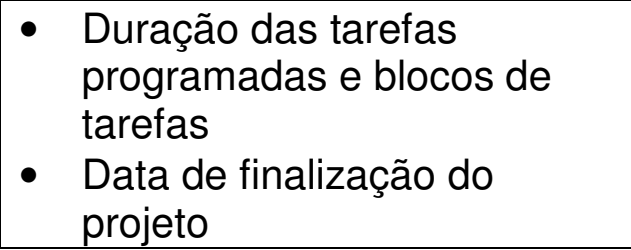 & $\begin{array}{l}\text { - } \\
\text { - AnRT ou grise de risco de não } \\
\text { finalização do projeto na } \\
\text { data programada }\end{array}$ \\
\hline
\end{tabular}

Tabela 5: dados de entrada e análise dos resultados das etapas da DSM

(Guia do usuário da DSM)

A macro escrita para o Microsoft Excel foi desenvolvida por Cho Soo-Haeng em sua tese "An integrated method for managing complex engineering projects using the design structure matrix and advanced simulation" no Massachusetts Institute of Technology em junho de 2000 e está disponibilizada no site de estudos da DSM. Esta macro será utilizada para desenvolvimento do modelo de processo de projeto a ser desenvolvido nesta dissertação de mestrado. 
Há três maneiras básicas para representar a relação entre as atividades: em paralelo, sequencial ou interdependente, conforme representado na figura 16.

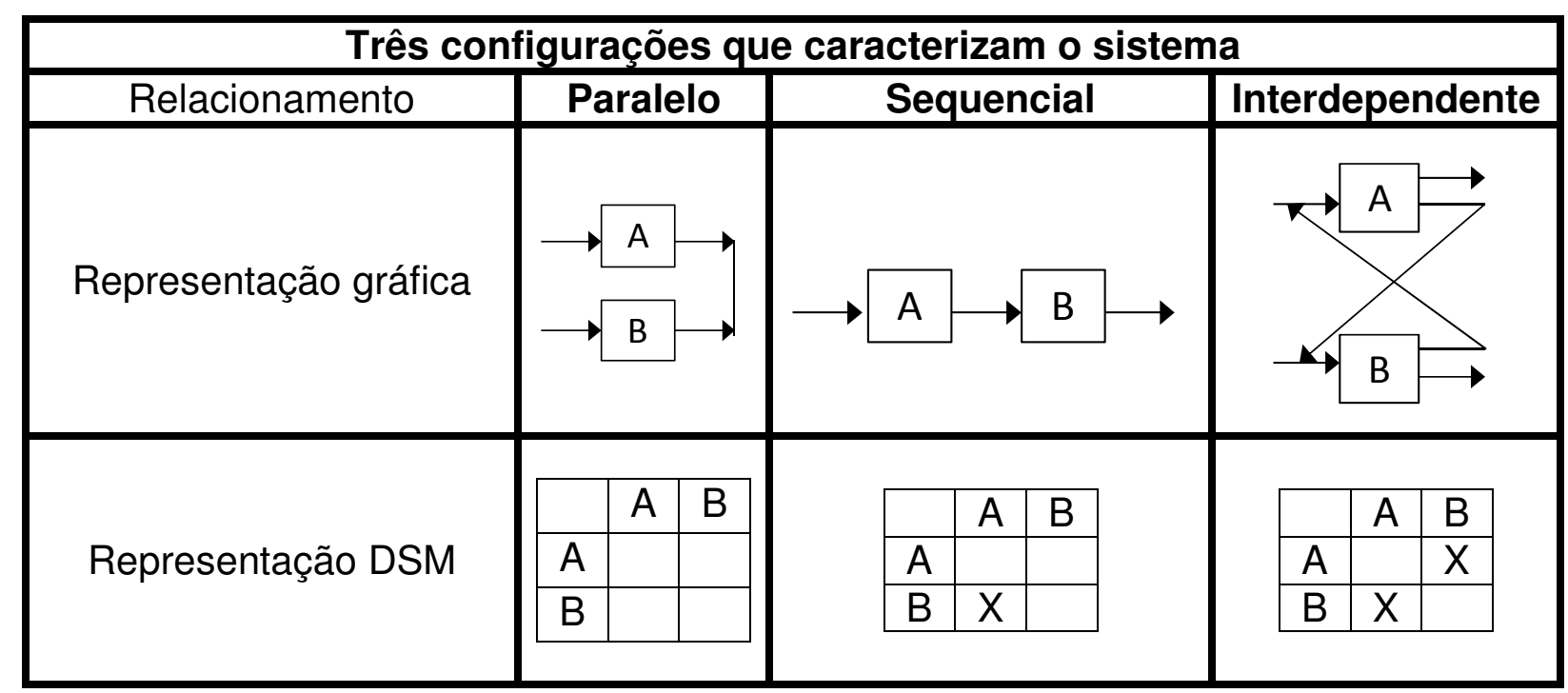

Figura 16 - Representação da relação entre as atividades

(Adaptado do site www.dsmweb.org)

Na configuração paralela, os elementos do sistema não interagem uns com os outros. A atividade B é independente da atividade $\mathbf{A}$ e não é necessária uma troca de informações entre as atividades.

Na configuração seqüencial, um elemento influencia o comportamento ou a decisão de outro elemento de uma forma unidirecional, ou seja, os parâmetros da atividade $\mathbf{B}$ são selecionados com base nos parâmetros da atividade A. Para a programação de projeto, a tarefa $\mathbf{A}$ deve estar finalizada para início da tarefa $\mathbf{B}$.

Na configuração interdependente, as informações são interligadas. A tarefa A interfere na tarefa $\mathbf{B}$ e vice-versa.

\subsubsection{A estruturação da DSM}

A DSM é representada por uma matriz de projeto, que deve ser preenchida com uma lista de todas as atividades, indicadas em linhas e colunas respectivas. Após o preenchimento da listagem de atividades, as trocas de informações e dependências devem ser preenchidas na matriz com os padrões correspondentes. 


\begin{tabular}{|c|r|r|r|r|r|r|r|}
\hline NOME DA ATIVIDADE & & $\mathrm{A}$ & $\mathrm{C}$ & $\mathrm{D}$ & $\mathrm{E}$ & $\mathrm{B}$ & $\mathrm{F}$ \\
\hline $\mathrm{A}$ & 1 & & & & & & \\
\hline C & 2 & 1 & & 2 & & 1 & \\
\hline D & 3 & 1 & 2 & & & 1 & \\
\hline E & 4 & 1 & 1 & 1 & & 1 & \\
\hline B & 5 & 1 & & & & & \\
\hline F & 6 & 1 & 1 & 1 & 1 & 1 \\
\hline
\end{tabular}

Figura 17 - Matriz de projeto com representação das dependências de informações para o desenvolvimento do projeto

A linha corresponde a uma atividade e nesta são selecionadas as outras atividades das quais esta depende, atividades estas indicadas nas colunas. A leitura da linha permite identificar quais atividades são necessárias para o desenvolvimento da atividade e a leitura da coluna identifica quais atividades recebem as informações desta. A DSM permite representar quais tarefas são seqüenciais, paralelas e interdependentes.

Por exemplo, se considerarmos a atividade $C$ da matriz acima verificamos que, na leitura em linha, esta necessita das atividades $A$ e $B$ para ser desenvolvida e interage ou é paralela à atividade $D$. Na leitura em coluna, a atividade $C$ é predecessora das atividades E e F, ou seja, é necessária para a produção destas atividades, e igualmente interage ou é paralela à atividade $\mathrm{D}$.

De forma genérica pode-se considerar que, as indicações abaixo da diagonal principal representam a dependência da atividade da linha em relação à da coluna (atividades anteriores da matriz), enquanto uma marca acima da diagonal principal representa a dependência da atividade da coluna (de atividades posteriores da matriz).

O sucesso do método DSM é determinado por uma identificação adequada das atividades e a correta relação de dependência entre estas.

Após a identificação das atividades, estas são listadas na DSM nas linhas e colunas e suas relações indicadas devem seguir o seguinte padrão:

1 - deve ser utilizada para casos em que a atividade necessita terminar para início da atividade seguinte (atividades sequenciais) 
2 - deve ser utilizada para casos em que a atividade pode iniciar sem que a anterior tenha sido concluída (atividades paralelas ou simultâneas)

Abaixo uma sugestão de sequência básica extraída do site de estudos da DSM para seqüenciamento das atividades.

- entrevista com engenheiros e gerentes;

- verificar se as possíveis fontes de dados podem ser analisadas ou exportadas para uma DSM;

- determinar a lista de atividades do projeto;

- perguntar sobre entradas, saídas, interações, etc entre as atividades

- indicar as interações na matriz;

- recolher os comentários que explicam cada atividade e cada dependência (para posterior entendimento e interpretação);

- solicitar aos engenheiros e gerentes a análise da DSM;

- refinar o modelo ao longo do tempo, assimilando o aprendizado organizacional.

A execução da macro na análise da DSM fornece os resultados em cinco diferentes planilhas: AEAP (as early as possible), ALAP (as late as possible), AEAP Colapso, ALAP Colapso e a relação de precedências para a programação e monitoramento utilizando o MS- PROJECT.

A planilha AEAP apresenta a reordenação das atividades identificando o sequenciamento das tarefas e suas interações, de forma que as atividades devam começar o mais cedo possível.

A planilha ALAP reorganiza as atividades de forma que estas possam ser iniciadas o mais tarde possível. As planilhas AEAP Colapso e ALAP Colapso representam as planilhas AEAP e ALAP respectivamente de forma reduzida, onde os blocos contendo as atividades colapsadas são representados como uma única atividade "bloco".

A partir do resultado da estruturação e modelagem da DSM é possível a construção do Gráfico de Gantt no MS- PROJECT para programação do processo. 


\subsection{METODOLOGIA PARA PLANEJAMENTO DE PROJETOS: ANALYTICAL DESIGN PLANNING TECHNIQUES (ADePT)}

Conforme visto no capítulo 2.1, item 2.1.4, muitas dificuldades para a gestão do processo de projeto se concentram na complexidade deste. Em função de sua complexidade e da multidisciplinaridade da equipe, os participantes se focam principalmente nas entregas e não no processo envolvido no desenvolvimento do empreendimento, muitas vezes por não conseguirem visualizar o processo completo.

O desenvolvimento de um novo empreendimento é um processo complexo, que envolve centenas, às vezes milhares de atividades. O número de interações entre estas atividades também é bastante elevado. A escala e a complexidade do processo de projeto é determinada pelos inevitáveis retrabalhos, retornos e interações inerentes ao desenvolvimento de qualquer processo. Estas características são frequentemente ignoradas no planejamento do processo de projeto. As ferramentas tradicionais de planejamento de projeto são incapazes de representar ou resolver principalmente os problemas de interação entre os agentes e o fluxo de informações. A metodologia ADePT se propõe a solucionar estes problemas (WASKETT et al 2010).

A metodologia ADePT sugere um processo que represente uma melhoria para o processo de projetos, identificando as relações entre as atividades e facilitando sua gestão. Este processo pode ser aplicado no desenvolvimento de projetos internos às empresas e, também, em projetos que envolvam uma equipe multidisciplinar, caso dos projetos de empreendimentos imobiliários.

Otimizar os processos de projetos leva a melhorias significativas no desempenho e qualidade do produto. A identificação e análise das atividades envolvidas no desenvolvimento do projeto faz com que as atividades desnecessárias e improdutivas sejam destacadas e possam ser removidas, e as atividades efetivamente produtivas possam ser refinadas e integradas.

A metodologia ADePT oferece uma abordagem para planejamento e controle de processos de projeto mais eficaz do que as demais abordagens usualmente utilizadas (WASKETT et al, 2010). A proposta permite que a ineficiência da equipe 
seja minimizada e a coodenação do projeto seja baseada no fluxo de informações, através da captura e gerência das relações entre as atividades.

A aplicação prática envolve uma abordagem estruturada e facilitada, que proporciona oportunidades para estabelecer a melhor seqüência do processo e compreender a interface entre projeto e construção. A etapa de workflow permite que o processo de projeto possa ser monitorado e controlado de forma eficaz.

A metodologia identifica as prováveis interações dentro do processo de projeto e fornece ferramentas de controle, redução ou eliminação das atividades, conforme as necessidades produto final. Além de ser uma ferramenta de planejamento e tomada de decisão, o ADePT pode ser utilizado também como uma ferramenta de identificação e controle dos riscos. Sinalizando as datas chaves à equipe, a metodologia fornece a esta uma maior compreensão do processo e das interações existentes.

A metodologia é composta por um software que permite que a equipe de projeto, em particular os gestores e planejadores, definam eficiente e eficazmente $o$ planejamento e monitoramente dos processos e dos conceitos. Como resultados positivos que a metodologia propõe pode-se observar:

- redução de níveis de trabalho;

- redução do risco de descontrole dos custos;

- redução dos custos de projeto;

- redução dos prazos de entrega do projeto.

A metodologia ADePT é dividida em quatro etapas a serem cumpridas, para que o planejamento do processo de projeto seja efetivado, conforme mostrado na figura 18 e tabela 6. Na primeira etapa, são definidos os objetivos do projeto e as dependências entre as atividades são definidas. Na segunda, a seqüência do processo é determinada com base nas dependências entre as atividades e interação dentro do processo. A terceira, envolve a representação do processo de projeto na forma de uma programação, permitindo a integração do processo de projeto com a construção. É na quarta etapa que o processo de projeto é monitorado e o fluxo de trabalho controlado. 


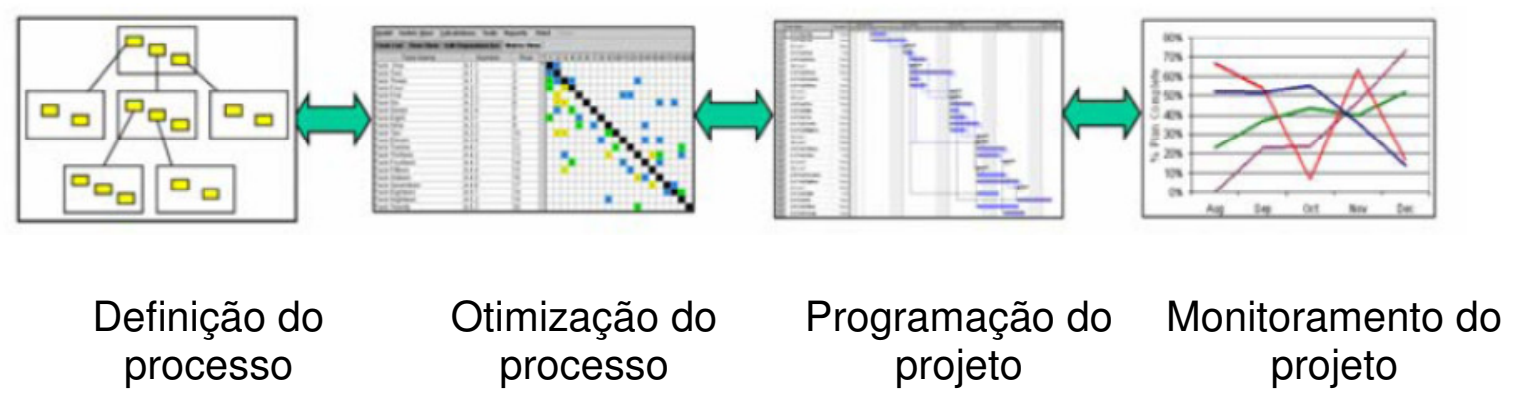

Figura 18 - Sequenciamento da metodologia ADePT (WASKETT et al, 2010)

\begin{tabular}{|c|c|l||}
\hline \multicolumn{3}{|c|}{ Etapas da metodologia ADePT } \\
\hline & Etapa & \multicolumn{1}{|c|}{ Processo } \\
\hline \hline 1 & Definição do processo & $\begin{array}{l}\text { elaboração do modelo do processo de } \\
\text { projeto com identificação das atividades e } \\
\text { suas interações }\end{array}$ \\
\hline 2 & Otimização do processo & $\begin{array}{l}\text { mapeamento das atividades e suas } \\
\text { relações de na matriz DSM para otimização } \\
\text { e ordenação destas }\end{array}$ \\
\hline 3 & Programação do projeto & $\begin{array}{l}\text { programação do projeto em forma de } \\
\text { cronograma baseado na otimização e } \\
\text { ordenação gerada pela DSM }\end{array}$ \\
\hline 4 & Monitoramento do & $\begin{array}{l}\text { monitoramento através de relatórios e } \\
\text { acompanhamento do modelo gerado nas } \\
\text { etapas anteriores }\end{array}$ \\
\hline
\end{tabular}

Tabela 6: Etapas da metodologia ADePT

\subsubsection{Definição do processo}

A primeira etapa a ser desenvolvida é a elaboração do modelo do processo de projeto, que pode ser baseado em um modelo geral já desenvolvido e adequado à necessidade específica do projeto, ou ser elaborado um modelo novo para o projeto em questão. Cada atividade a ser executada deve ser identificada, para que seja parte integrante do modelo.

A metodologia para elaboração do modelo do processo, através da identificação dos dados de entrada e saída, permite que todos os participantes tenham ciência dos fluxos de informações e dependências entre as diferentes disciplinas. 


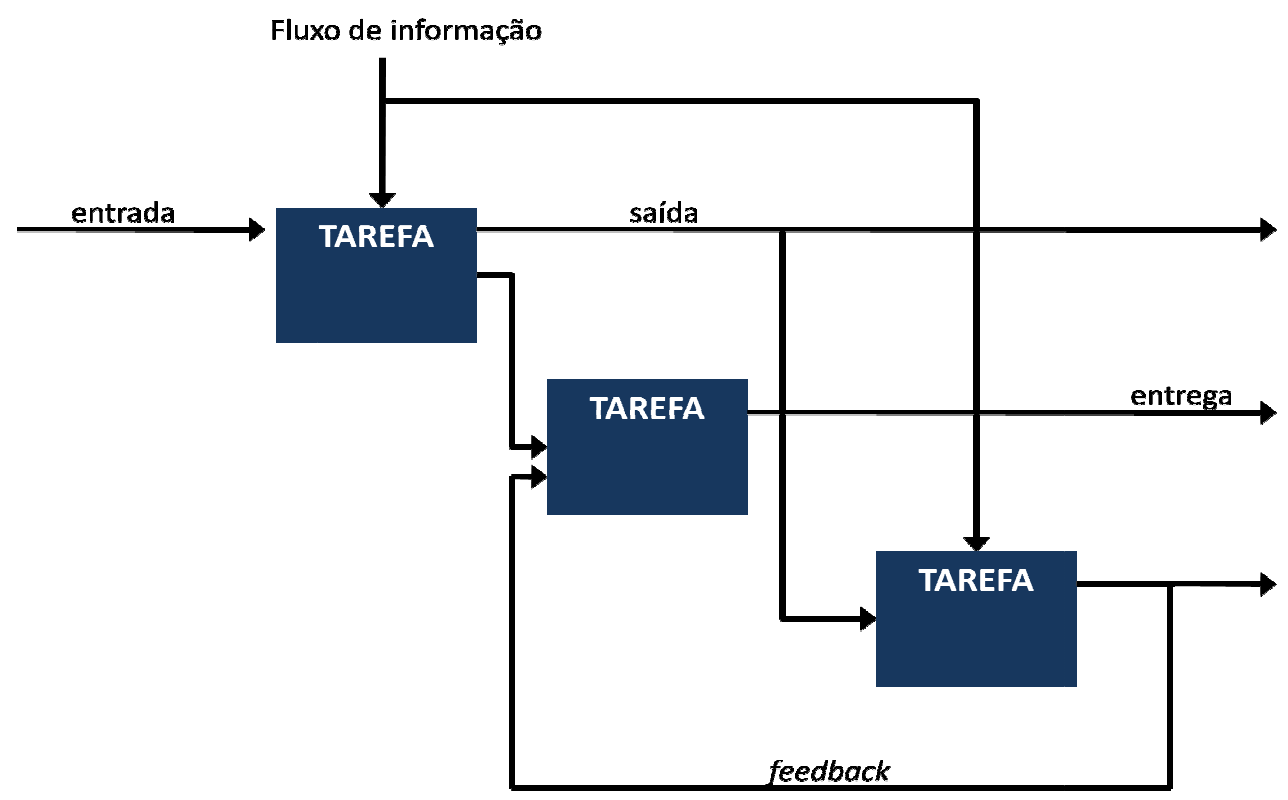

Figura 19 - Modelo de processo

Definir o escopo do projeto com a listagem de atividades necessárias e as dependências entre elas é um processo demorado. Egan (1998) apud Waskett et all (2010) propõe que seja definido um modelo genérico que vá sendo ampliado continuamente, à medida que mais projetos sejam planejados e, consequentemente, mais partes do processo sejam adicionadas.

Especificamente para o desenvolvimento de um modelo de processo de projeto adequado à realidade nacional, Manzione (2006) propõe a utilização dos Manuais de Escopo de Projetos e Serviços para a Indústria Imobiliária. Estes manuais relacionam as informações necessárias para as tarefas de projeto conforme os padrões brasileiros, e podem ser um ponto de partida para a identificação das atividades de projeto bem como suas interdependências.

\section{Estrutura Analítica de Projeto (EAP)}

As atividades identificadas na etapa anterior serão utilizadas para a elaboração da EAP. As atividades devem ser listadas em uma estrutura hierárquica, que define as dependências entre as atividades. Uma vez que o processo está completo, a seqüência das atividades é reorganizada com o objetivo de minimizar a quantidade de interação dentro do processo. 
EAP, também conhecido com Work Breakdown Structure (WBS) é uma estrutura hierárquica na qual o projeto é dividido em atividades cada vez menores e mais simples, até chegar ao nível de tarefas executáveis (pacotes de trabalho).

Gido e Clements (1998) comparam o resultado da EAP a uma "árvore hierárquica" de itens a serem executados e/ou produzidos pela equipe durante 0 processo de projeto. Para a elaboração da EAP, sugere-se que as atividades sejam desdobradas até que se possa mensurá-la em termos de custo, tempo, escopo e qualidade.

Verzuh (2000) propõe como diretrizes para elaboração da EAP três etapas a serem cumpridas:

- começar por cima desmembrando o projeto em níveis descendentes de detalhe, dando nome a todas as tarefas necessárias para que os objetivos do projeto sejam atingidos;

- nomear as tarefas: o nome de uma tarefa descreve uma atividade que gera um produto e, para tanto, deve ser precedida de um verbo;

- organizar a EAP.

A EAP também pode ser uma ferramenta auxiliar na gestão do processo de projeto para fornecer uma ilustração detalhada do escopo do projeto, monitorar o progresso, criar estimativas precisas de custos e cronogramas e montar equipes de projeto (Verzuh, 2000)

A EAP pode ser representada também em forma de lista de atividades e não somente no formato de "árvore hierárquica".

No processo de projeto de empreendimentos imobiliários, a definição das tarefas pode se tornar uma ação complexa pois, mais do que o simples desenvolvimento da tarefa e finalização do produto, é fundamental que o resultado final seja de qualidade e contenha todas as informações necessárias para que os agentes do processo que se utilizarão deste produto não incorram em má interpretação ou tenham retrabalhos por falta de informação ou informação incorreta.

Assim, o projeto de arquitetura de um empreendimento, por exemplo, deve contemplar mais do que a entrega dos produtos plantas, cortes, fachadas, 
detalhamento e/ou quaisquer outros itens acordados entre contratante e contratado. O projeto deve contemplar as informações relevantes para o desenvolvimento do empreendimento. Essas informações, que devem ser incorporadas no projeto, podem ser definidas como tarefas a serem desenvolvidas.

A EAP deve ser modelada com início nas disciplinas de projeto, que serão decompostas hierarquicamente até o nível elementar das tarefas específicas de cada projeto. Este procedimento permite a visão sistêmica do empreendimento (MANZIONE, 2006).

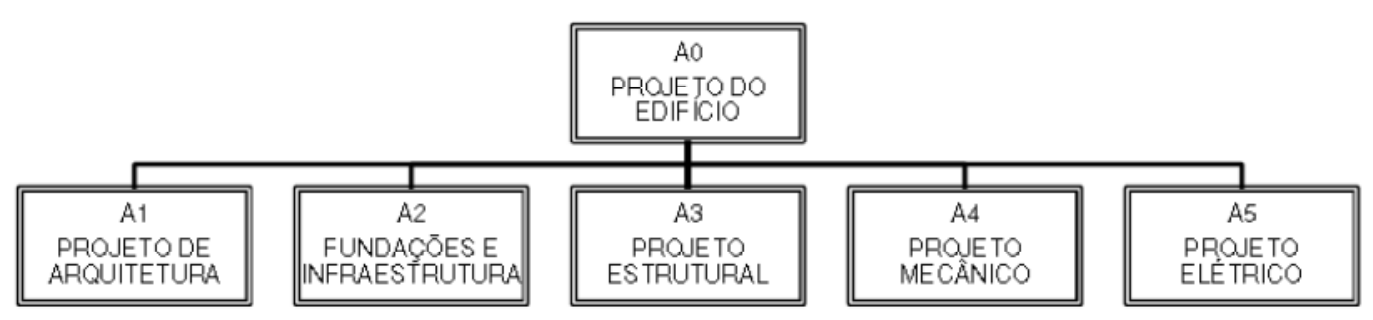

Figura 20 - Visão geral do modelo (AUSTIN et al.,2000) 


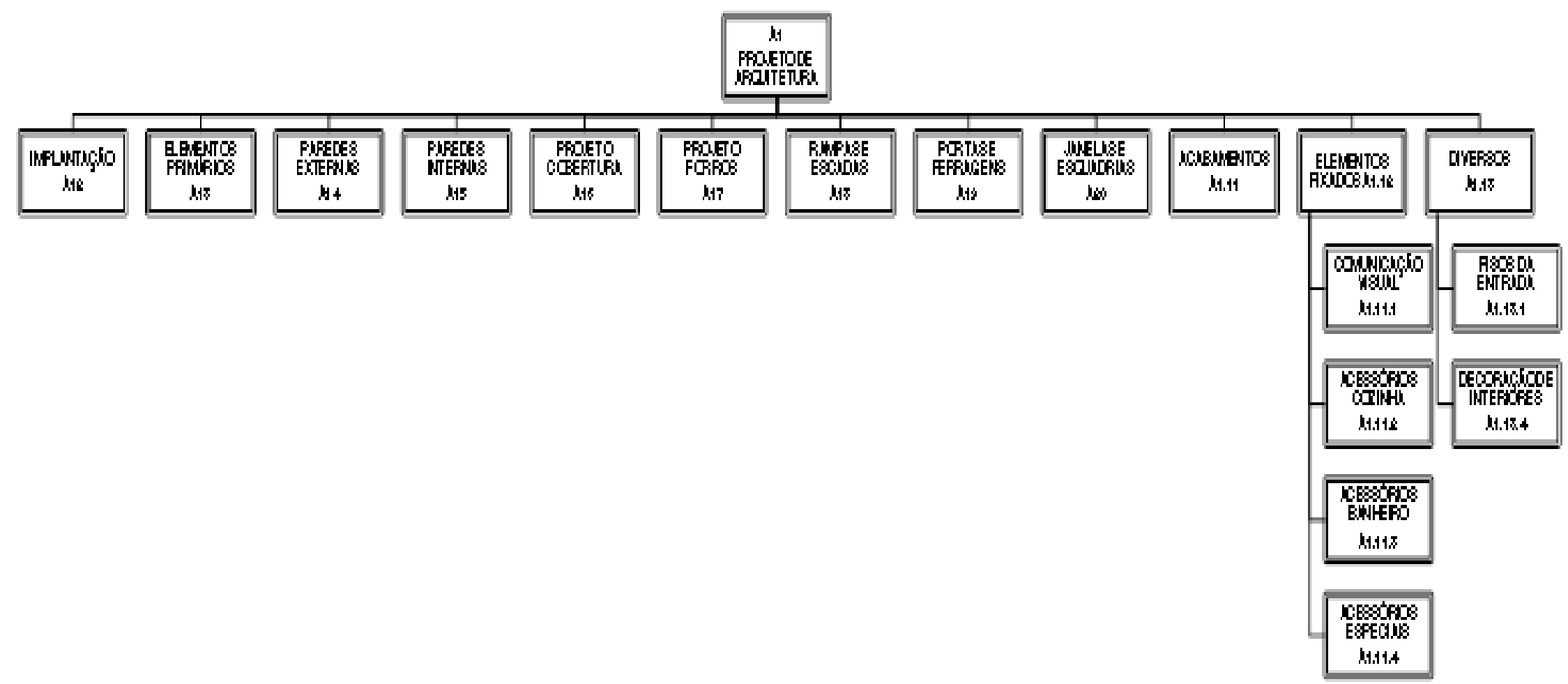

Figura 21 - Estrutura principal do modelo genérico do projeto de arquitetura (Adaptado de AUSTIN et al.,2000) 
As figuras 20 e 21 representam exemplos de EAP para modelos desenvolvidos fora do Brasil. Os modelos nacionais apresentem outra configuração, em função da forma de projetar tipicamente utilizada em nosso país.

\section{Tabela de Dependência de Informações}

As interações entre as atividades são definidas pelas dependências de informações e não pela sequência temporal. As ligações entre as atividades se estabelecem nos dois sentidos, vertical e horizontal. No sentido vertical as ligações se dão pelo aprofundamento dos detalhes na própria disciplina, e no sentido horizontal pelas ligações interdisciplinares. Austin et al (1998) apud Manzione (2006) propõem a elaboração de uma tabela de dependência de informações onde todas as atividades devem ser relacionadas, as informações necessárias para que estas sejam desenvolvidas e as atividades de origem destas informações. As atividades de origem devem ser complementadas por uma classificação de grau de importância, sendo A a dependência mais crítica, $\mathbf{B}$ a intermediária e $\mathbf{C}$ a menos crítica.

\begin{tabular}{|c|c|c|c|c|c|}
\hline \multicolumn{6}{|c|}{ Tabela de dependência de informações } \\
\hline \multicolumn{2}{|c|}{ Atividade } & \multicolumn{4}{|c|}{ Informação requerida } \\
\hline Número & Nome & Nome & $\begin{array}{c}\text { Atividade de } \\
\text { origem }\end{array}$ & Classificação & Obs. \\
\hline $\begin{array}{l}\text { Número } \\
\text { de } \\
\text { ordem } \\
\text { dado no } \\
\text { diagrama } \\
\text { IDEFO }\end{array}$ & $\begin{array}{l}\text { Nome da } \\
\text { atividade }\end{array}$ & $\begin{array}{c}\text { Informações } \\
\text { necessárias } \\
\text { para a } \\
\text { atividade }\end{array}$ & $\begin{array}{c}\text { Atividades que } \\
\text { originam as } \\
\text { informações }\end{array}$ & $\begin{array}{c}\text { Grau de } \\
\text { importância da } \\
\text { informação (A, } \\
\text { B ou C) }\end{array}$ & \\
\hline
\end{tabular}

Tabela 7:- Tabela de dependência de informações

(AUSTIN et al.,1998 apud MANZIONE, 2006)

\section{Desenho dos diagramas do processo}

A representação gráfica do modelo do processo de projeto deve ser baseada na técnica de modelagem IDEF0. 
Segundo Hoffmeister (2003) as técnicas IDEF foram desenvolvidas de forma orientada para auxiliar na análise e comunicação de processos de manufatura, dando suporte à modelagem de diversos elementos característicos deste sistema.

Embora a IDEF0 tenha sido desenvolvida para suportar processos de manufatura, esta ferramenta pode ser utilizada atualmente para modelar qualquer tipo de processo, sob diferentes pontos de vista. 
A modelagem IDEF0 representa as entradas e saídas das atividades porém não representa o processo de transformação por que as informações passam.

Abaixo as convenções para a representação da modelagem:

- a atividade é representada dentro de uma caixa;

- as entradas de informações intra-disciplinares ocorrem pelo lado esquerdo da atividade;

- as entradas de informações inter-disciplinares ocorrem por cima da atividade;

- as entradas de informações externas ocorrem por baixo da atividade;

- as saídas de informações ocorrem pela direita da atividade.

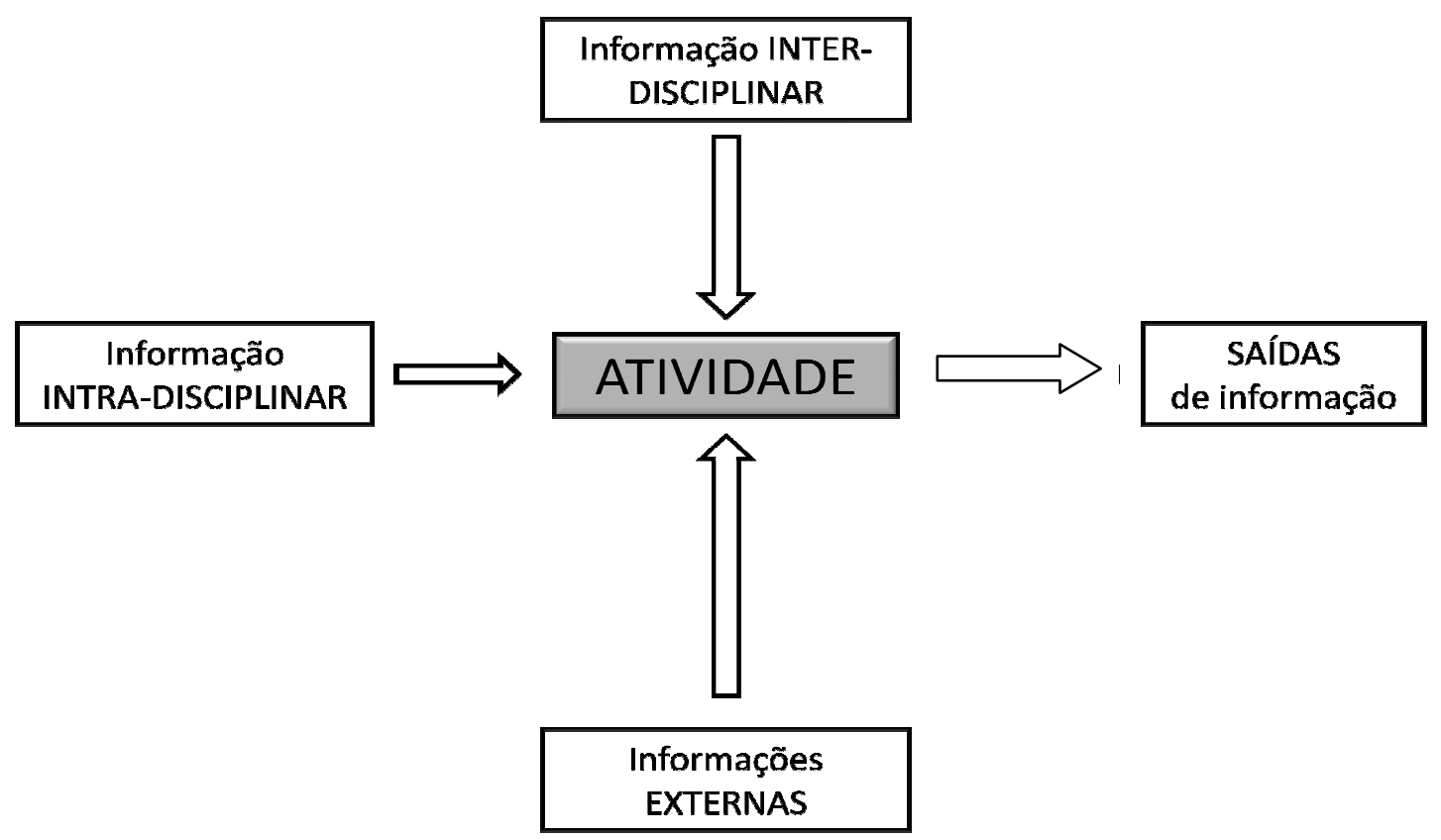

Figura 22 - Convenção para representação da metodologia IDEF0

\subsubsection{Otimização do Processo}

Nesta etapa as atividades e suas dependências são representadas através da DSM. As tarefas são listadas em linhas e colunas, dando forma a esta matriz. Por se tratar de uma matriz quadrada, cada linha representa as entradas necessárias para a finalização da tarefa, e cada coluna as saídas de informação a serem fornecidas para outras tarefas ou o contrário, conforme a estruturação feita durante a montagem da matriz. 
A otimização do processo tem como objetivo ordenar melhor as atividades no processo de projeto para limitar as interdependências, simplificar o planejamento e agrupar as atividades, que após a otimização serão representadas em blocos que facilitam a visualização do gestor para uma ação mais efetiva em sua gestão.

A matriz destaca quais trocas de informações envolvem interação e as que não envolvem. Algumas interações podem ser eliminadas, outras minimizadas, de modo que o processo seja o mais eficiente possível.

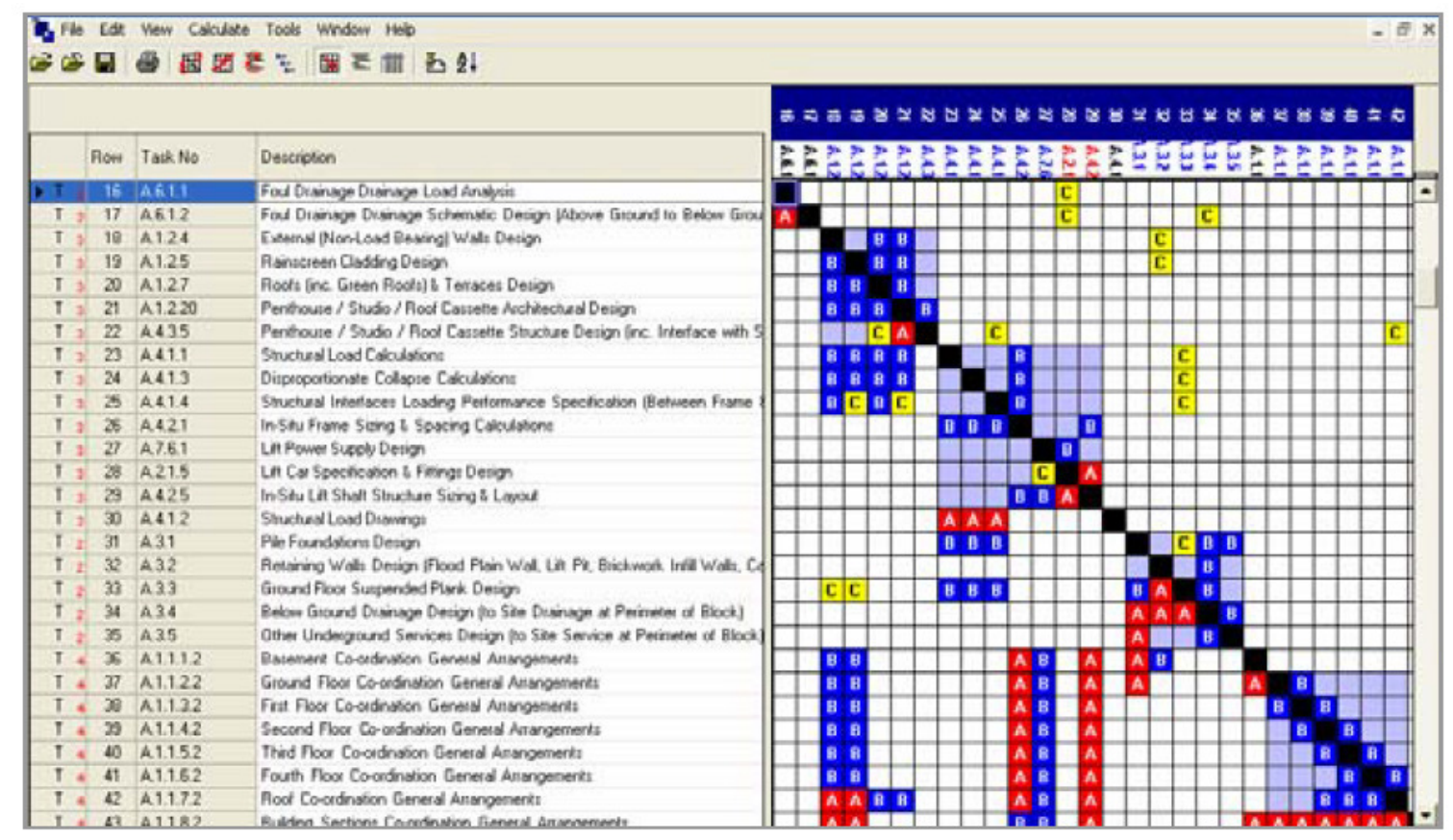

Figura 23 - Otimização do processo (fonte: www.adeptmanagement.com)

A seqüência de atividades é calculada com o objetivo de maximizar a interação no processo de projeto e assegurar que todas as atividades a serem desenvolvidas pela equipe sejam aquelas que possam ser feitas com confiança. Isto é conseguido através da ponderação das dependências entre as atividades em uma escala de três pontos; crítica, importante ou interessante de constar. O cálculo de uma seqüência, incluindo conjuntos de tarefas inter-relacionadas, prioriza a disponibilidade de saídas associadas com as dependências mais críticas. 
Os pontos de interação identificados na matriz representam momentos em que a equipe de projeto deve trabalhar em conjunto, para resolver o problema das interdependências. Normalmente, eles também representam elementos da construção e, portanto, da produção do projeto, que exigem coordenação.

\subsubsection{A programação do projeto}

A matriz aperfeiçoada é exportada para ser aplicada em um software de programação de projeto como o MS Project, o Primavera ou o PowerProject. Esta programação pode então ser revista e integrada a outros projetos relacionados. Se as mudanças forem necessárias, podem ser simuladas com o ADePT e a programação revisada, integrada com o projeto a ser produzido, destacando pontos críticos de decisão e riscos potenciais.

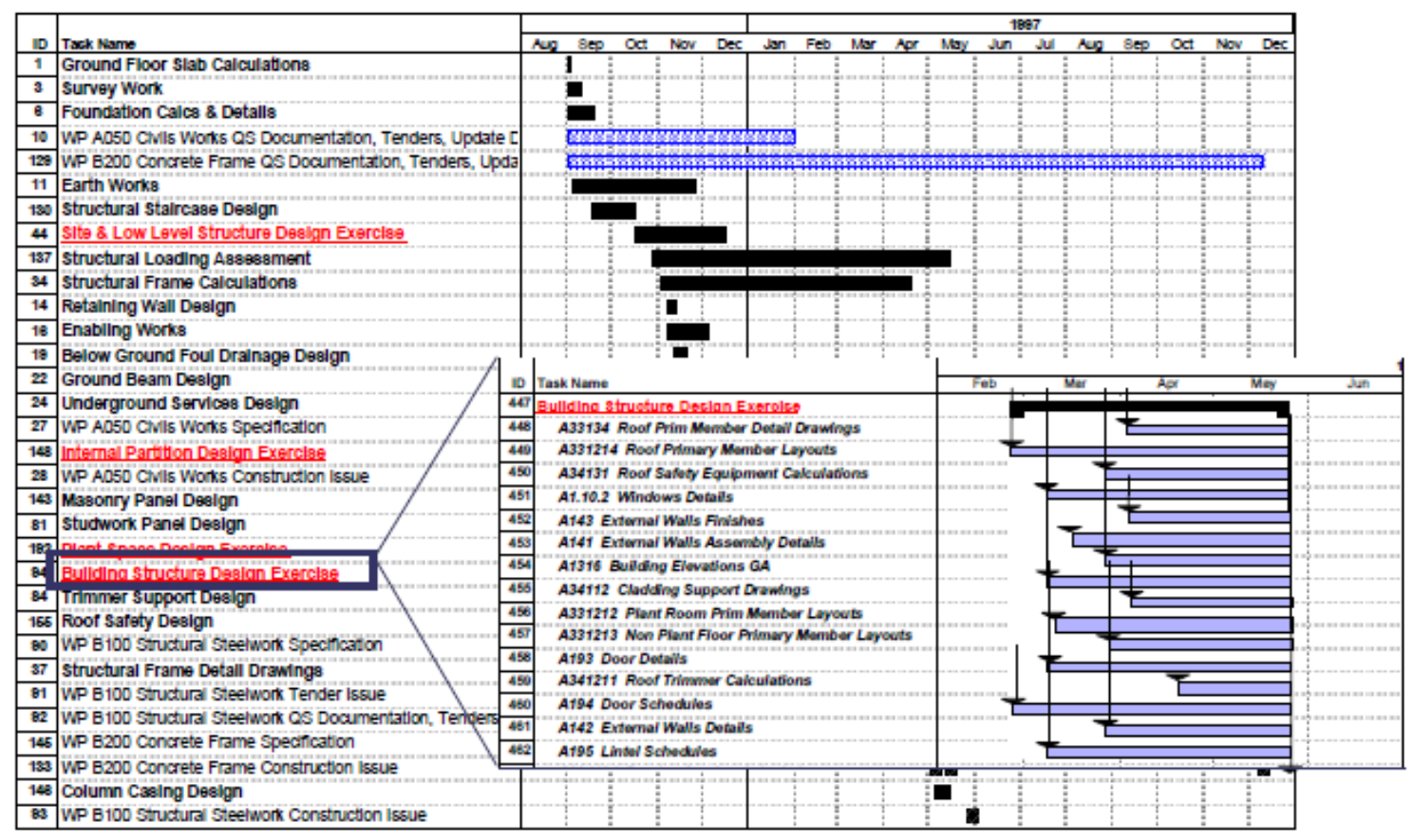

Figura 24 - O plano de projeto (fonte: www.adeptmanagement.com)

\subsubsection{Monitoramento do processo de projeto}

A ADePT pode ser utilizada durante todo o desenvolvimento do projeto para monitorar seu progresso, através de relatórios de conclusão e relatórios intermediários, em períodos definidos como ao final de cada etapa do processo de projeto, por exemplo. A programação é atualizada no fim de cada etapa, permitindo que os membros da equipe avaliem o impacto das alterações (por exemplo: as 
alterações de especificação, ou a conclusão atrasada das atividades) e tomem decisões que devem ser informadas a toda a equipe. Os desvios de projeto também podem facilmente ser identificados de modo que ações corretivas possam ser tomadas. 


\section{MODELAGEM DO PROCESSO DE PROJETO}

Conforme visto no capítulo 2.5, a metodologia ADePT sugere um processo que represente uma melhoria para o processo de projetos, identificando as relações entre as atividades e facilitando sua gestão.

Otimizar os processos de projetos leva a melhorias significativas no desempenho e qualidade do produto. A identificação e análise das atividades envolvidas no desenvolvimento do projeto faz com que as atividades desnecessárias e improdutivas sejam destacadas e possam ser removidas, e as atividades efetivamente produtivas possam ser refinadas e integradas.

A metodologia ADePT é dividida em quatro etapas a serem cumpridas, para que o planejamento do processo de projeto seja efetivado, a saber:

- Definição do processo;

- Otimização do processo;

- Programação do projeto;

- Monitoramento do projeto.

Neste capítulo serão estudadas as duas primeiras etapas, a definição e otimização do processo, com base nas atividades sugeridas pelos Manuais de Escopo de Projetos e Serviços para a Indústria Imobiliária e na aplicação da DSM para otimização da modelagem sugerida por estes.

\subsection{A definição do processo}

Conforme visto no item 2.5 do capítulo 2, referente à metodologia ADePT, a etapa de definição do processo obedece ao seguinte seqüenciamento de trabalhos:

- Listagem das atividades;

- Estrutura das atividades;

- Tabulação das atividades;

- Diagrama de rede.

Para o desenvolvimento do presente trabalho todos os passos para a definição do processo, sugeridos pela metodologia foram percorridos. 


\section{Listagem das atividades}

Para o levantamento das atividades foram utilizados os Manuais de Escopo de Projetos e Serviços para a Indústria Imobiliária das especialidades de arquitetura, estrutura, hidráulica, elétrica, climatização, paisagismo e coordenação de projetos, limitando os trabalhos às fases $A$ a $D$, e aos serviços essenciais. O escopo da pesquisa foi limitado às atividades e serviços acima citados por se tratarem de especialidades e escopos mais comumente contratados pelo mercado imobiliário, bem como para facilitar a visualização da metodologia através da restrição de fases e atividades.

A listagem de atividades foi desenvolvida considerando-se fase a fase e especialidade a especialidade. Abaixo encontra-se representada a listagem das atividades referentes à fase $A$, as demais listagens encontram-se no apêndice $A$ deste trabalho.

\section{Arquitetura}

\begin{tabular}{|l|l|}
\hline ARQ-A 001 & Levantamento de Dados / Restrições Físicas e Legais \\
\hline ARQ-A 002 & Quantificação do potencial construtivo do Empreendimento \\
\hline ARQ-A 003 & $\begin{array}{l}\text { Concepção e análise de viabilidade de Implantação do } \\
\text { Empreendimento }\end{array}$ \\
\hline ARQ-A 004 & $\begin{array}{l}\text { Concepção e análise de viabilidade das Unidades / Pavimentos Tipo } \\
\text { do Empreendimento }\end{array}$ \\
\hline
\end{tabular}

\section{Estrutura}

STR-A 001 Relatório de viabilidade estrutural da proposta arquitetônica

\section{Hidráulica}

HID-A 001 Análise das condicionantes locais

\section{Elétrica}

\begin{tabular}{|l|l}
\hline ELE-A 001 & Análise das condicionantes locais
\end{tabular}

\section{Ar Condicionado e Ventilação}




\section{Paisagismo}

\begin{tabular}{|l|l|}
\hline PSG-A001 & $\begin{array}{l}\text { Identificação das Restrições Legais e análise do potencial } \\
\text { paisagístico, concepção }\end{array}$ \\
\hline PSG-A002 & $\begin{array}{l}\text { Análise das restrições de legislação nas esferas Municipal, Estadual e } \\
\text { Federal }\end{array}$ \\
\hline
\end{tabular}

\section{Coordenação de Projetos}

\begin{tabular}{|c|l|}
\hline A001 & $\begin{array}{l}\text { Contato inicial com o empreendedor, definição do escopo de } \\
\text { coordenação e formulação do Programa de Necessidades (briefing) } \\
\text { geral do empreendimento }\end{array}$ \\
\hline A002 & $\begin{array}{l}\text { Ciência e análise das restrições legais de uso e ocupação para o } \\
\text { terreno em estudo }\end{array}$ \\
\hline A003 & $\begin{array}{l}\text { Identificação das especialidades, qualificações e escopos de projeto a } \\
\text { contratar }\end{array}$ \\
\hline A004 & Estimativa dos recursos necessários ao desenvolvimento dos projetos \\
\hline A005 & $\begin{array}{l}\text { Organização, realização e registro de reuniões de coordenação de } \\
\text { projetos }\end{array}$ \\
\hline A006 & $\begin{array}{l}\text { Controle do processo quanto ao tempo e demais recursos, incluindo } \\
\text { as ações corretivas necessárias }\end{array}$ \\
\hline
\end{tabular}

\section{Estrutura das atividades}

Após a listagem de todas as atividades referentes a cada uma das fases selecionadas para o trabalho, foi desenvolvida a estrutura destas.

A EAP foi modelada com início nas disciplinas de projeto, que foram decompostas hierarquicamente até o nível elementar das tarefas específicas de cada especialidade de forma a permitir uma visão sistêmica do empreendimento.

A elaboração da EAP permite uma visualização completa do escopo integrante do processo de projeto em questão, permitindo que os agentes do processo que se utilizarão deste produto não incorram em má interpretação ou tenham retrabalhos por falta de informação ou informação incorreta. 


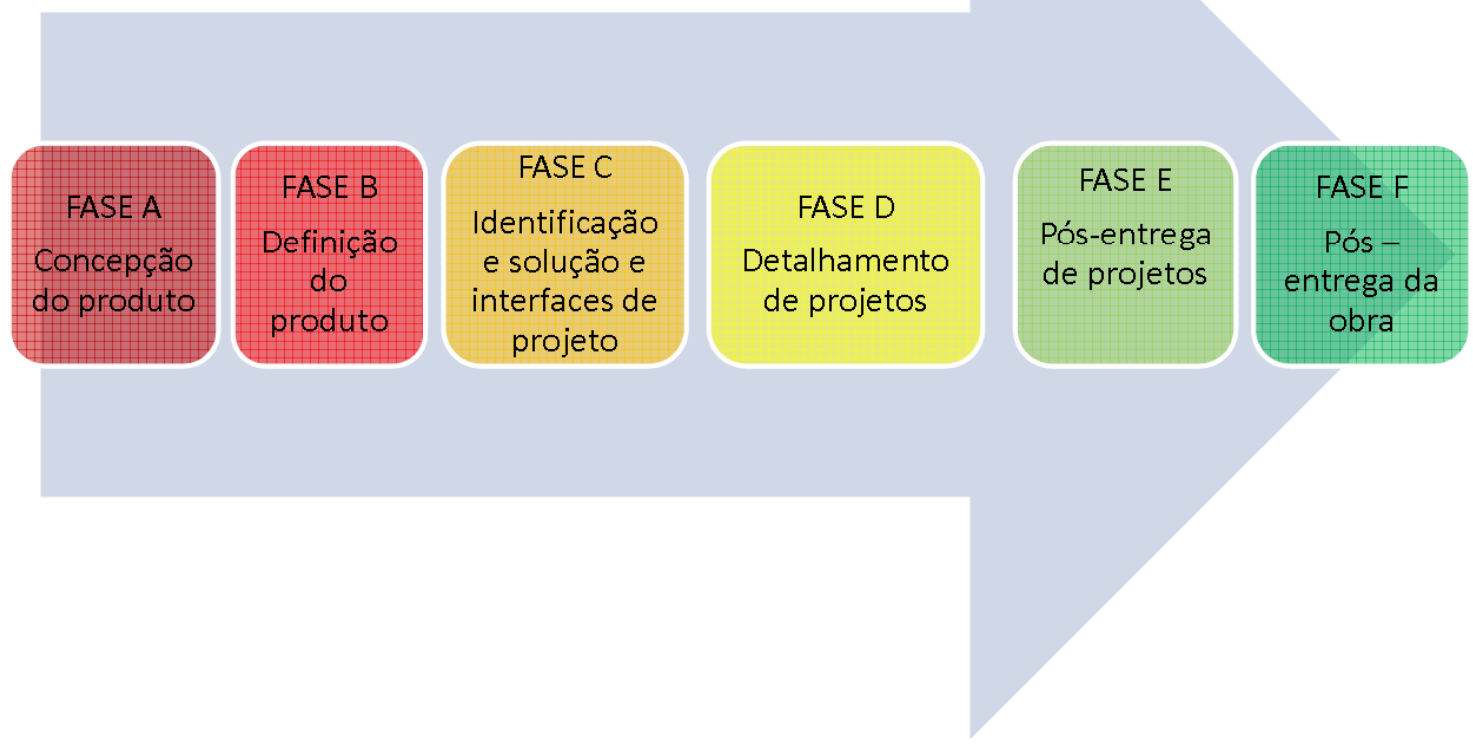

Figura 25: Processo de projeto conforme Manuais de Escopo de Contratação de Projetos e Serviços

A figura 25 representa o processo de projeto conforme os Manuais de Escopo de Projetos e Serviços para a Indústria Imobiliária. Com base neste processo foram selecionadas as atividades referentes aos serviços essenciais das fases $A$ a $D$, Concepção do produto a Detalhamento de projetos.

A partir do processo de projeto, a estrutura foi decomposta considerando-se as especialidades envolvidas em cada fase e uma nova decomposição com as atividades de cada especialidade. A figura 26 representa a decomposição da fase $A$ em cada uma das especialidades inseridas no processo e a figura 27 a decomposição de cada uma das atividades referentes à especialidade arquitetura na mesma fase. As estruturas desenvolvidas para cada uma das fases e atividades encontram-se no apêndice $B$ deste trabalho. 


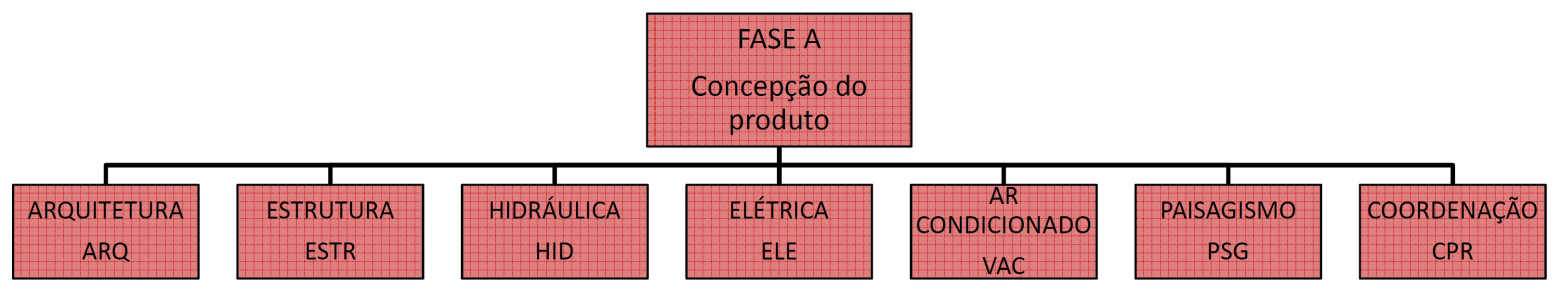

Figura 26: EAP conforme disciplinas para a fase $\mathrm{A}$

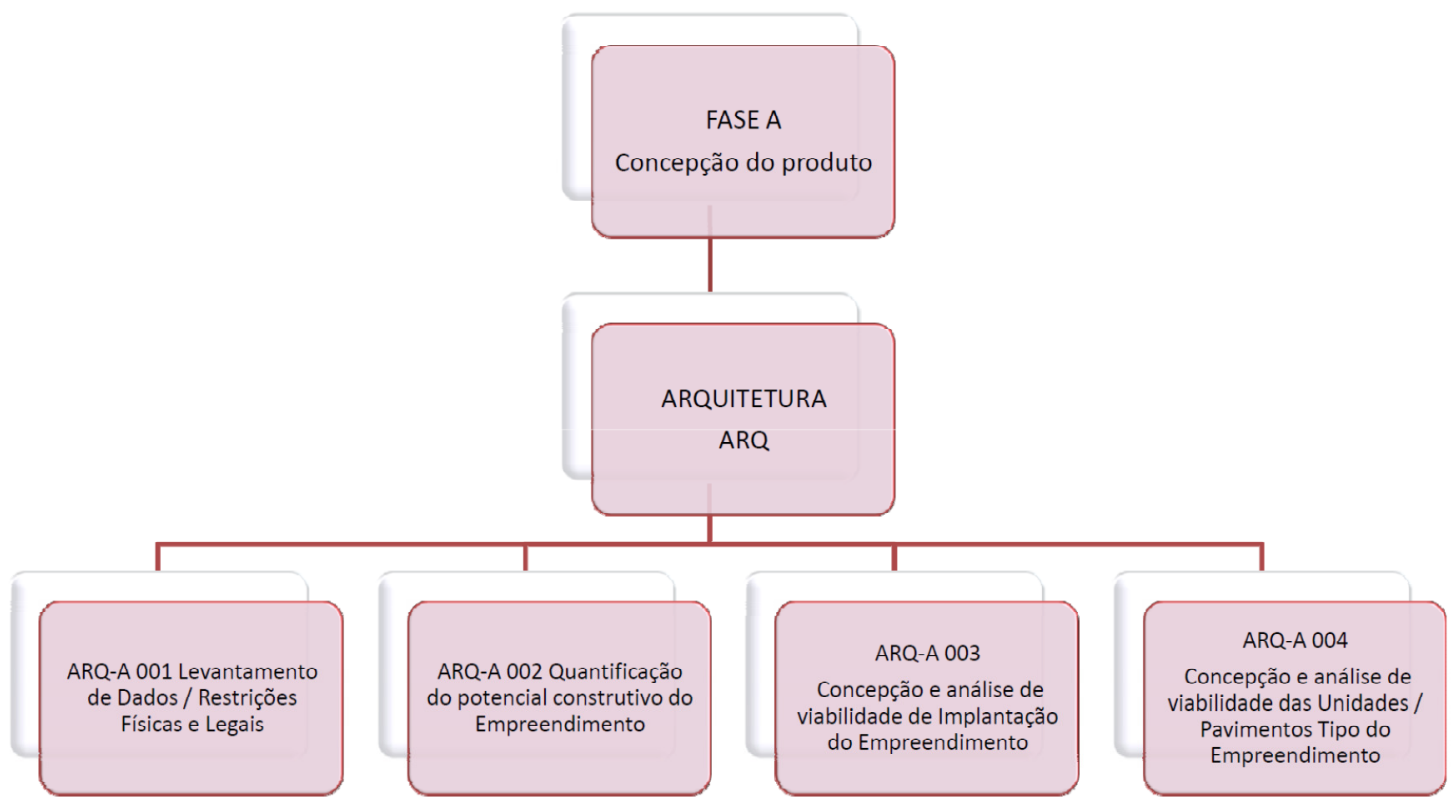

Figura 27: EAP para arquitetura fase A

\section{Tabelas de dependência de informações}

Com base na listagem de atividades e na EAP, foi desenvolvida a tabulação das atividades considerando-se a dependência das informações e não o seqüenciamento dos trabalhos. A dependência das informações foi obtida a partir do item "dados necessários" constante de cada um dos Manuais.

A tabela 8 representa a tabela de dependência de informações para a fase A, as demais tabelas estão incluídas no apêndice $\mathrm{C}$ deste trabalho. 
FASE A CONCEPÇÃO DO PRODUTO

\begin{tabular}{|c|c|c|c|c|c|c|c|}
\hline \multirow{2}{*}{\multicolumn{3}{|c|}{ Atividade de projeto }} & \multicolumn{5}{|c|}{ DU } \\
\hline & & & nome & atividade $\mathrm{d}$ & origem & classificicação & \multirow[b]{3}{*}{$\begin{array}{l}\text { Relatório preliminar de restrições legais, contendo todos itens de legislação } \\
\text { pertinentes abordados na atividade } \\
\text { Alertar sobre eventuais restrições não verificadas }\end{array}$} \\
\hline \multirow[t]{2}{*}{1} & ARQ-A 001 & $\begin{array}{l}\text { Levantamento de Dados } \\
\text { /Restrições Físicas e } \\
\text { Legais }\end{array}$ & & & & & \\
\hline & & & 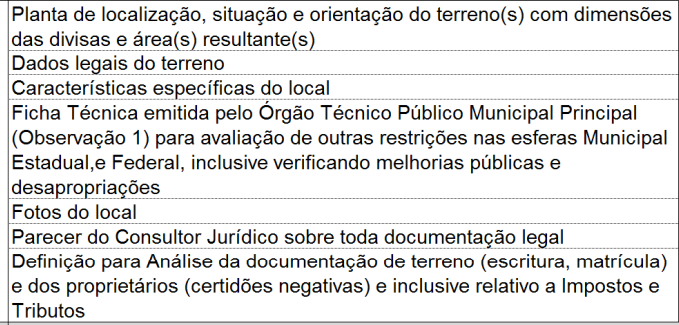 & Empreendedor & & & \\
\hline \multirow[t]{2}{*}{2} & ARQ-A 002 & $\begin{array}{l}\text { Quantificacąão do } \\
\text { Potencial Construtivo do } \\
\text { Empreendimento }\end{array}$ & & & & & \\
\hline & & & 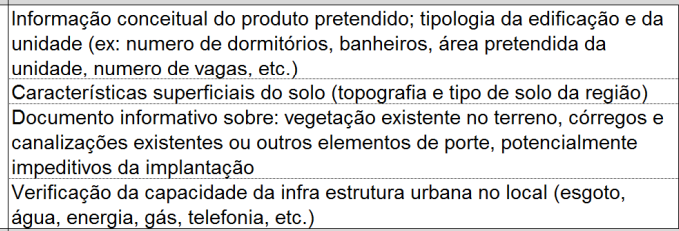 & Empreendedor & & & Quadros de áreas analíticos das áreas das unidades e totais do Empreendimento \\
\hline \multirow[t]{2}{*}{3} & ARQ-A 003 & $\begin{array}{l}\text { Conceppção e Análise de } \\
\text { Viabiliade da } \\
\text { Implantação do } \\
\text { Empreendimento }\end{array}$ & & & & & \\
\hline & & & $\begin{array}{l}\text { Informações preliminares sobre a disponibilidade e caracteristicas de } \\
\text { atendimento do Empreendimento pelos serviços públicos de infra- } \\
\text { estrutura urbana local }\end{array}$ & $\begin{array}{l}\text { Sistemas } \\
\text { Prediais - } \\
\text { Elétricose e } \\
\text { Hidráulicos }\end{array}$ & $\begin{array}{l}\text { HID-A001/ } \\
\text { ELE- A001 }\end{array}$ & & Croquis esquemático de implantação geral do Empreendimento \\
\hline \multirow[t]{6}{*}{4} & ARQ-A 004 & $\begin{array}{l}\text { Conceppção e Análise de } \\
\text { Viabilidade das Unidades } \\
\text { / Pavimentos, Tipo do } \\
\text { Empreendimento }\end{array}$ & & & & & \\
\hline & & & $\begin{array}{l}\text { Aprovacãoo das atividades anteriores } \\
\text { Informação sobre recursos técnicos e tecnológicos disponiveis ou } \\
\text { pretendidos }\end{array}$ & \multirow{2}{*}{ Empreendedor } & \multirow{2}{*}{$\begin{array}{l}\text { ARQ-A A001/ } \\
\text { ARQ-A 002/ } \\
\text { ARQ-A } 003\end{array}$} & & \multirow{5}{*}{$\begin{array}{l}\text { Planta(s) baixa(s) esquemática(s) do(s) pavimento(s) / unidade(s) tipo } \\
\text { Planta esquemática do pavimento / unidades / blocos-tipo } \\
\text { Quadro preliminar completo das áreas do empreendimento } \\
\text { Implantação geral esquemática com indicaçãa Norte-Sul, vias de acesso e locação } \\
\text { do(s) bloco(s) }\end{array}$} \\
\hline & & & $\begin{array}{l}\text { Informação sobre sistemas construtivos e niveis de acabamentos } \\
\text { pretendidos }\end{array}$ & & & & \\
\hline & & & levantamento topográfico & Topografia & & & \\
\hline & & & $\begin{array}{l}\text { relatório de sondagem } \\
\text { Comentários e recomendaçōes preliminares sobre a ligação do } \\
\text { Empreendimento aos serviços públicos e necessidade de } \\
\text { complementacãa de infra-estrutura urbana (tratamento esgoto, rede de } \\
\text { gás, etc.) }\end{array}$ & $\begin{array}{l}\text { Geotécnica } \\
\text { Sistemas } \\
\text { prediais - } \\
\text { Elétricos e } \\
\text { Hidráulicos }\end{array}$ & $\begin{array}{l}\text { HID-A } 001 / \\
\text { ELE-A } 001\end{array}$ & & \\
\hline & & & pareceres especificos & $\begin{array}{l}\text { consultores } \\
\text { especializados }\end{array}$ & & & \\
\hline
\end{tabular}




\begin{tabular}{|c|c|c|c|c|c|c|}
\hline \multirow[t]{4}{*}{5} & STR-A 001 & $\begin{array}{l}\text { Relatório de viabilidade } \\
\text { estrutural da proposta } \\
\text { arquitetônica }\end{array}$ & & \multirow{4}{*}{ Arquitetura } & \multirow{4}{*}{ ARQ-A 004} & \multirow{4}{*}{$\begin{array}{l}\text { Relatório escrito com croquis de lançamento de pilares se for considerado essencial } \\
\text { pelo projetista estrutural }\end{array}$} \\
\hline & & & Croquis do Terreno; & & & \\
\hline & & & Planta do pavimento tipo; & & & \\
\hline & & & Caracteristicas do Empreendimento: (número de pavimentos e subsolos). & & & \\
\hline \multirow[t]{2}{*}{6} & HID-A 001 & $\begin{array}{l}\text { Análise dos } \\
\text { Condicionantes Locais }\end{array}$ & & & & \\
\hline & & & $\begin{array}{l}\text { Dados gerais do empreendimento (áreas, número de pavimentos, tipo de } \\
\text { ocupacaco, tec.) } \\
\text { Cropuis do tereno com dadosos preliminiares de niveis } \\
\text { Planta de situacāo }\end{array}$ & Arquitetura & ARQ-A 002 & Relatớrio preliminar de condicionantes locais \\
\hline \multirow[t]{2}{*}{7} & HID-A 002 & $\begin{array}{l}\text { Consulta a } \\
\text { Concessionárias de } \\
\text { Servicos Públicos }\end{array}$ & & & & \\
\hline & & & $\begin{array}{l}\text { Cópias do projetto para aprovacăo na prefeitura, em versão preliminar } \\
\text { Cronograma fisico da construçăo }\end{array}$ & Arquitetura & ARQ-B 008 & $\begin{array}{l}\text { Diretrizes / respostas às consultas junto às concessionárias locais de água, esgoto, } \\
\text { gás combustivel e energia elétrica }\end{array}$ \\
\hline \multirow[t]{2}{*}{8} & ELE-A 001 & $\begin{array}{l}\text { Análise dos } \\
\text { Condicionantes Locais }\end{array}$ & & & & \\
\hline & & & 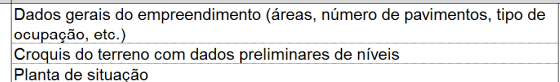 & Arquitetura & ARQ-A 002 & Relatório preliminar de condicionantes locais \\
\hline \multirow[t]{2}{*}{9} & ELE-A 002 & $\begin{array}{l}\text { Quantificacăão do } \\
\text { Potencial Construtivo do } \\
\text { Empreendimento }\end{array}$ & & & & \\
\hline & & & $\begin{array}{l}\text { Cópias do projeto para aprovacăão na prefeitura, em versão preliminar } \\
\text { Cronograma físico da construçăo }\end{array}$ & Arquitetura & ARQ-B 008 & $\begin{array}{l}\text { Diretrizes / respostas às consultas junto às concessionárias locais de água, esgototo, } \\
\text { gás combustivel e energia elétrica }\end{array}$ \\
\hline \multirow[t]{2}{*}{10} & VAC-A001 & $\begin{array}{l}\text { Estudo de implantação } \\
\text { do empreendimento }\end{array}$ & & & & \\
\hline & & & 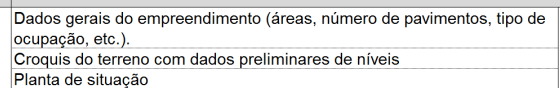 & Arquitetura & ARQ-A 004 & Relatório preliminar de condicionantes locais \\
\hline \multirow[t]{4}{*}{11} & PSG-A001 & 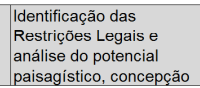 & & & & \\
\hline & & & Levantamento planialtimétrico cadastral & & & $\begin{array}{l}\text { Desenho técnico e/ou artistico em escala adequada permitindo a clara compreensão } \\
\text { da proposta paisagistica }\end{array}$ \\
\hline & & & $\begin{array}{l}\text { Levantamento Arbóreo quando houver vegetação significativa no terreno } \\
\text { Estuddos preliminares ou projetos existentes } \\
\text { Programa } \\
\text { Consulturia da area de vendas. } \\
\text { Parecereres de consultores especificos }\end{array}$ & Empreendedor & ARQ-A 004 & \\
\hline & & & Diretrizes e restriçōes legais & Órgãos Públicos & & \\
\hline \multirow[t]{2}{*}{12} & PSG-A002 & 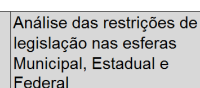 & & & & \\
\hline & & & 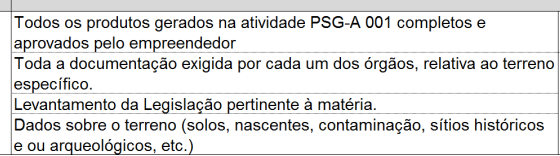 & Empreendedor & PSG-A 001 & Relatório preliminar de condicionantes locais \\
\hline
\end{tabular}

Tabela 8: tabela de dependência de informações fase A 


\section{Diagrama de rede}

Nesta etapa foi desenvolvido o diagrama de rede com base nas informações indicadas nas tabelas de dependências de informações. Os diagramas de rede foram elaborados considerando-se o nome da atividade porém é importante ressaltar que cada atividade fornece e necessita de uma série de informações. Com base nesta análise entende-se que cada atividade só poderá ser considerada como cumprida desde que observadas suas entradas e saídas, que devem ter sido integralmente cumpridas. O não cumprimento de todas as informações poderá implicar em retrabalhos em função do recebimento de informações tardias. 


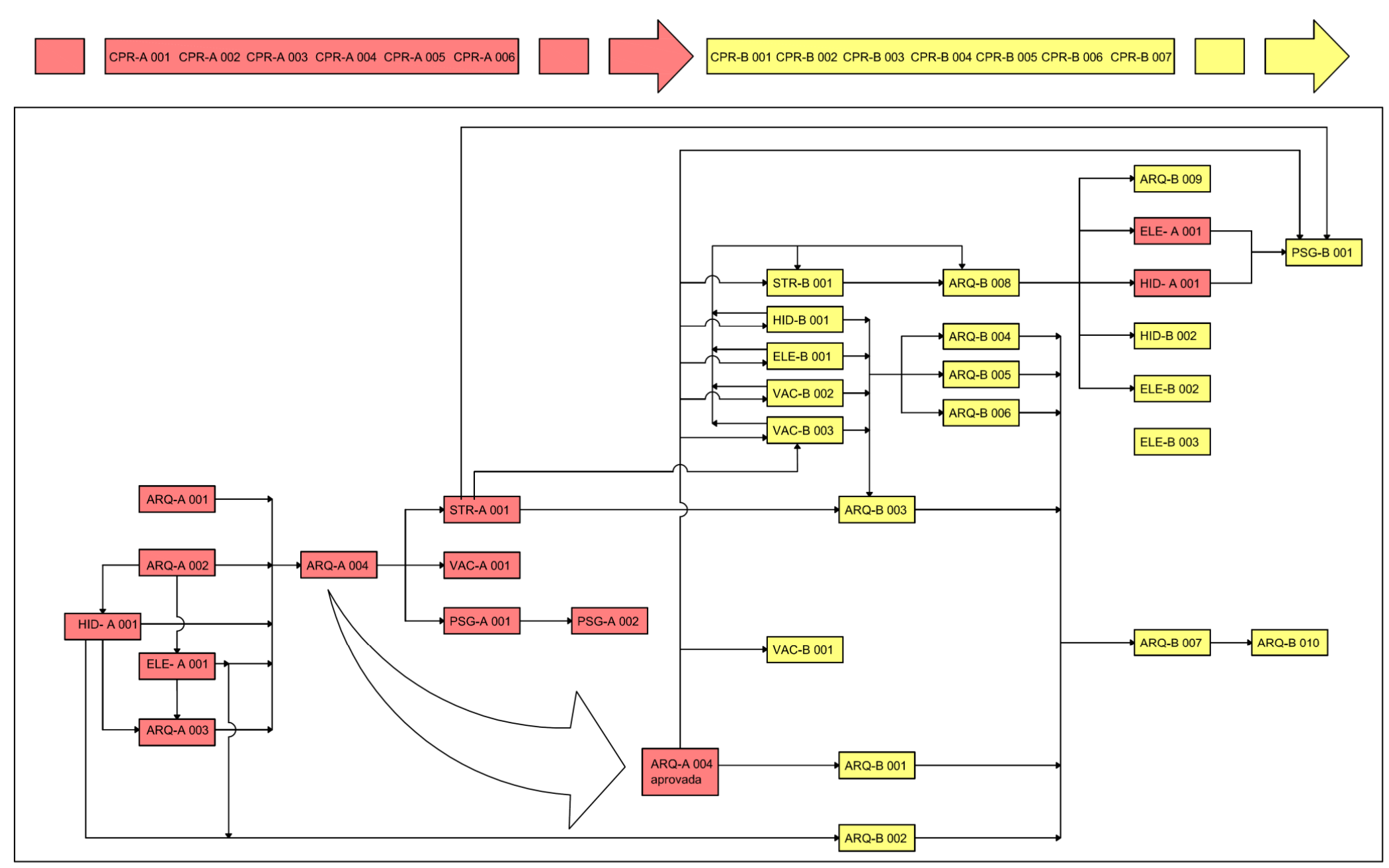

$\square$ ATIVIDADE FASE A

$\square$ ATIVIDADE FASE B

Figura 28: Diagrama de rede conforme Manuais fases A e B 


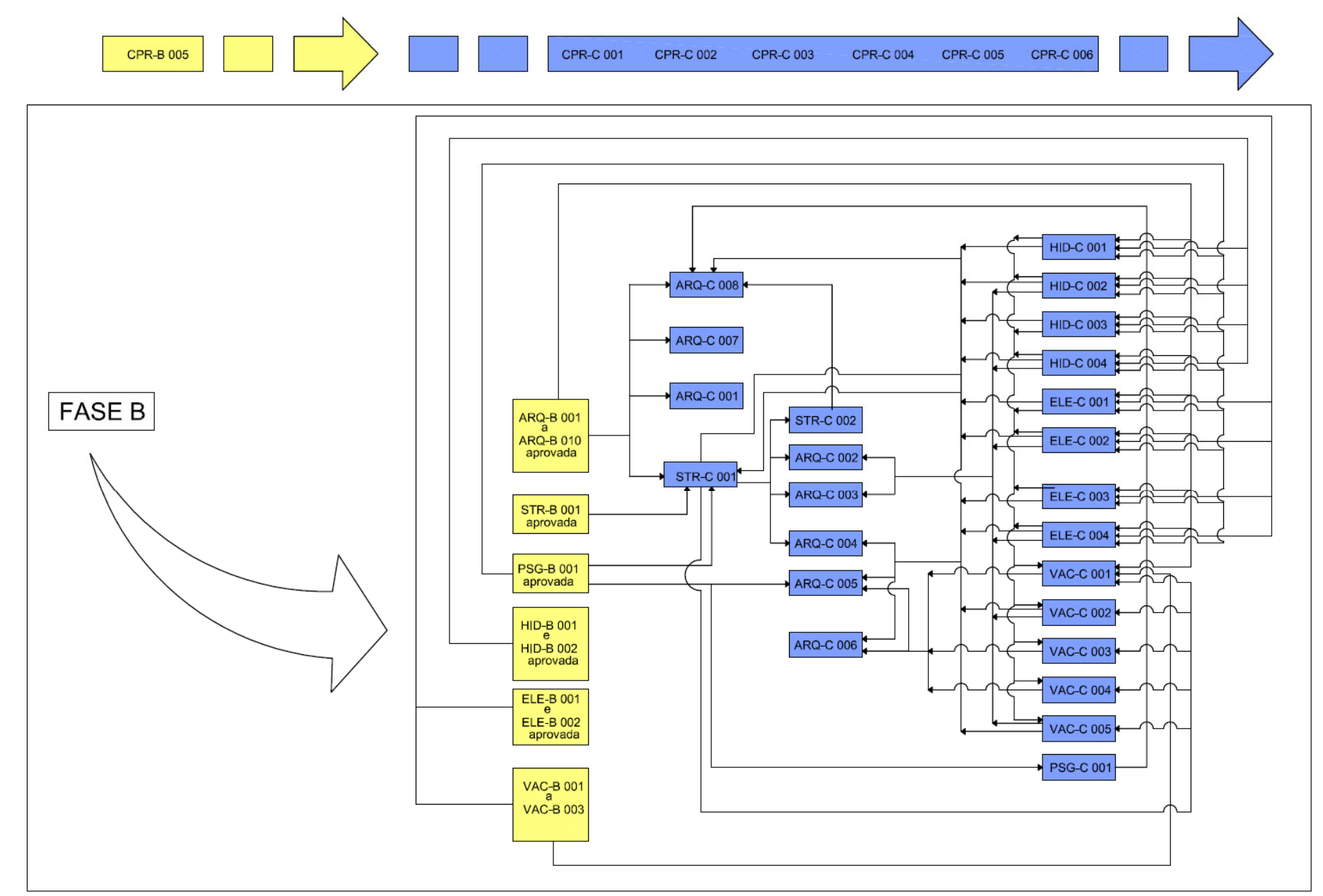

$\square$ ATIVIDADE FASE B

$\square$ ATIVIDADE FASE C

Figura 29: Diagrama de rede conforme Manuais fase $\mathrm{C}$ 


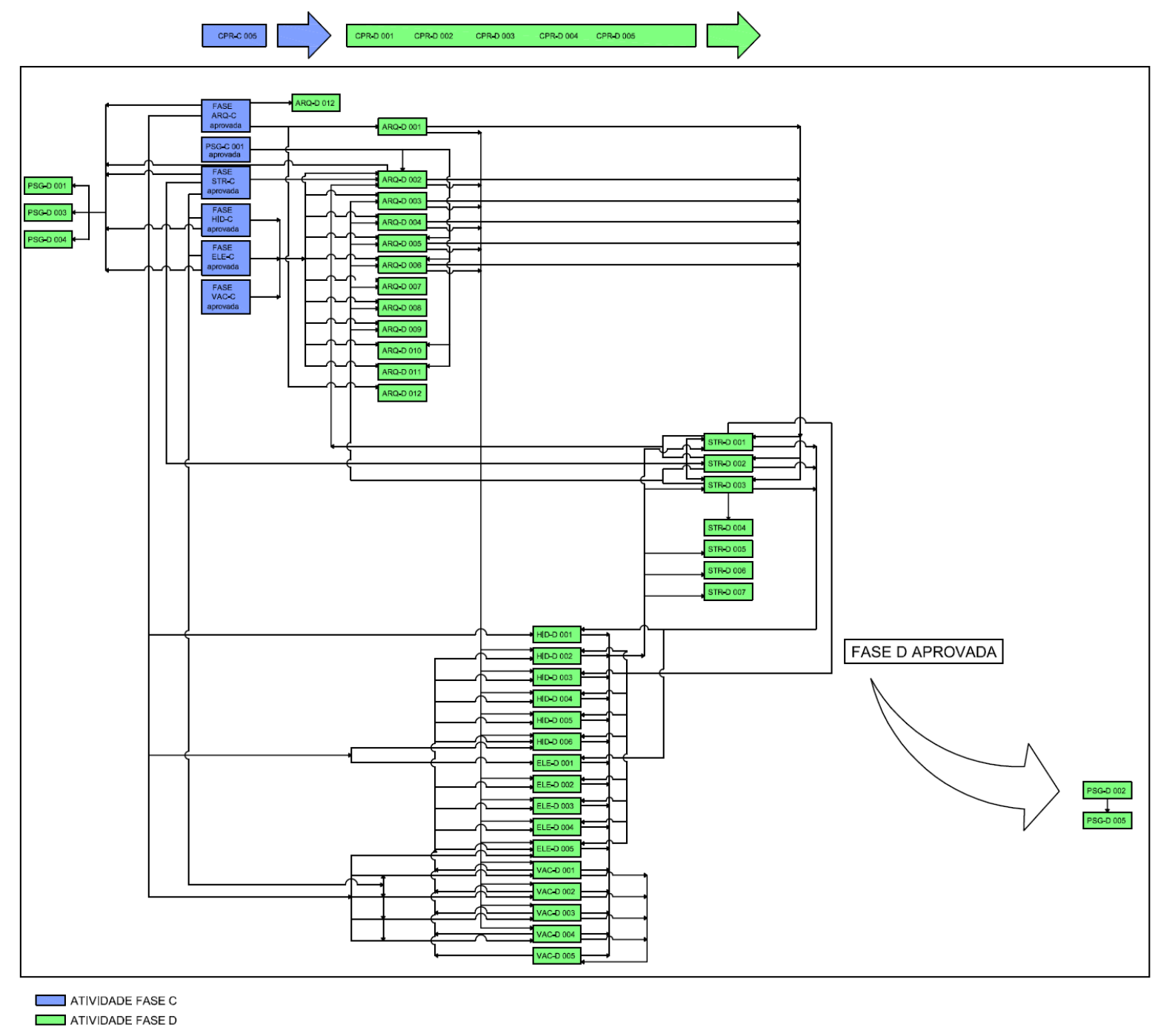

Figura 30: Diagrama de rede conforme Manuais fase $D$ 


\subsection{Otimização do processo}

Para que a otimização do processo fosse desenvolvida estabeleceu-se o seguinte seqüenciamento de trabalho:

- Estruturação da DSM;

- Análise da DSM;

- Elaboração do modelo de processo de projeto.

A análise da DSM foi feita com base no resultado da planilha AEAP (as early as possible), selecionada entre as outras quatro situações apresentadas pela matriz DSM para facilitar o entendimento e a análise da aplicação da matriz. Nos modelos de processo de projeto do mercado imobiliário deve-se levar em conta e selecionar a planilha mais adequada ao planejamento daquele empreendimento especificamente e/ou daquela fase, pois podem ocorrer situações em que ocorra a necessidade de desenvolvimento de algumas atividades com o máximo de antecedência ou o mais tarde possível.

O modelo de processo de projeto foi desenvolvido baseando-se na planilha Project, fornecida pela própria ferramenta.

\section{Estruturação da DSM}

Nesta etapa as atividades e suas dependências foram representadas através da DSM. Para desenvolvimento da matriz foram utilizadas as tabelas de dependências de informações das fases $A$ e $B, C$ e $D$ como base de dados para sua elaboração e identificação das relações entre as atividades. Para aplicação da DSM foi utilizada a ferramenta computacional DSM@MIT, proposta na dissertação de mestrado "An Integrated Method for Managing Complex Engineering Projects Using the Design Structure Matrix and Advanced Simulation", por Soo-Haeng Cho e Steven D. Eppinger, no MIT - Massachusetts Institute of Technology em junho de 2001 (CHO, 2001).

As atividades foram indicadas nas linhas da matriz conforme a listagem de atividades desenvolvida na etapa anterior. A dependência entre estas atividades foi estabelecida com base nas tabelas de dependências de informações, que foram geradas a partir das informações fornecidas pelos próprios Manuais. 
As relações entre cada uma das atividades foi indicada conforme o seguinte padrão:

1 - utilizada para casos em que a atividade necessita terminar para início da atividade seguinte (atividades sequenciais)

2 - utilizada para casos em que a atividade pode iniciar sem que a anterior tenha sido concluída (atividades paralelas ou simultâneas)

Os módulos de estrutura e modelagem da DSM são suplementos do Microsoft Excel. A execução destes suplementos fornece os resultados em cinco planilhas: AEAP (as early as possible), ALAP (as late as possible), AEAP Colapso e ALAP Colapso, além da relação de precedências para controle do processo utilizando-se o MS-Project. Especificamente para o presente trabalho foram analisadas as planilhas AEAP e a planilha Project.

O planejamento do processo de projeto não é estático e as planilhas devem ser analisadas separadamente ou em conjunto, conforme a necessidade do empreendimento e o momento em que este se encontra. Em algumas ocasiões pode ser interessante que a atividade se inicie o mais cedo possível e em outras o mais tarde possível, devendo ser ponderada esta necessidade para o planejamento do processo de projeto.

Para uma melhor análise do processo de projeto a matriz DSM foi elaborada separando-se as atividades das fases $A$ e $B$ das fases $C$ e $D$ sendo que as duas primeiras foram analisadas em conjunto e as duas últimas separadamente. As figuras 31,32 e 33 representam a estruturação da matriz para cada uma das fases.

É importante salientar que, apesar das análises terem sido desenvolvidas separadamente há uma interface entre cada uma das fases, interface esta bem destacada, explicada e controlada pelas atividades da especialidade coordenação. 
FASES A e B

DSM Input

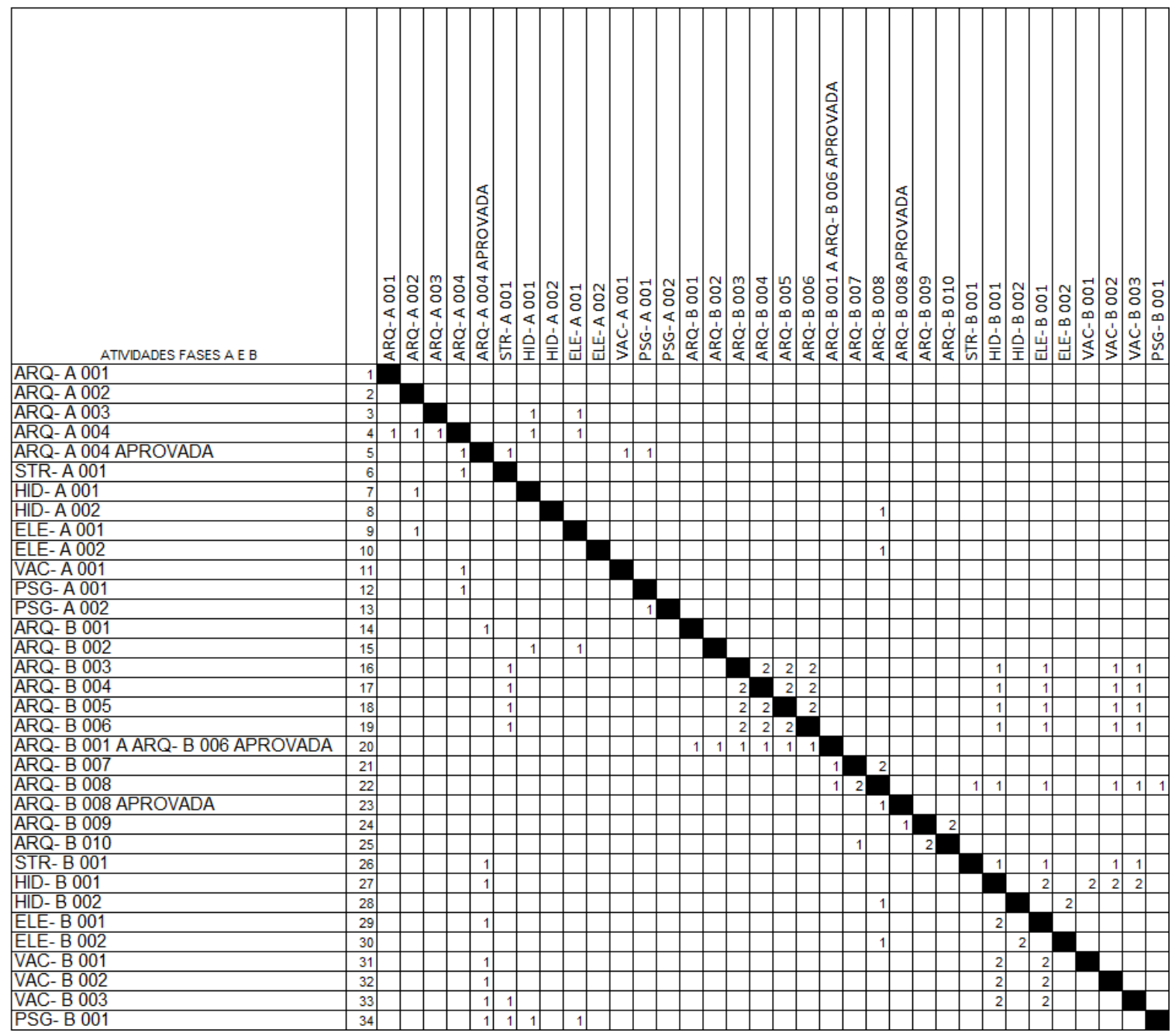

Figura 31: estruturação da matriz DSM fases A e B 
FASE C

DSM Input

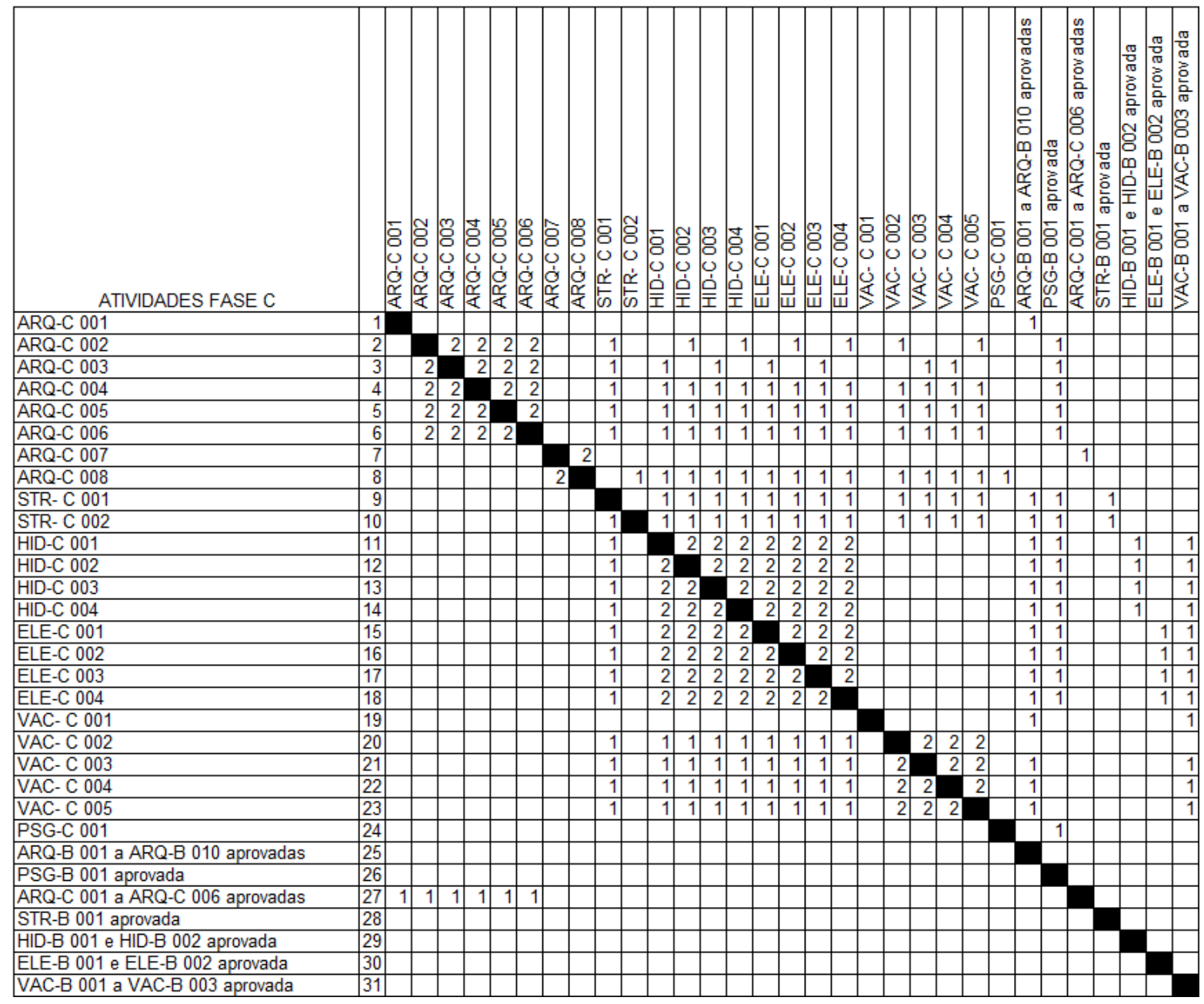

Figura 32: estruturação da matriz DSM fase C 
FASE D

DSM Input

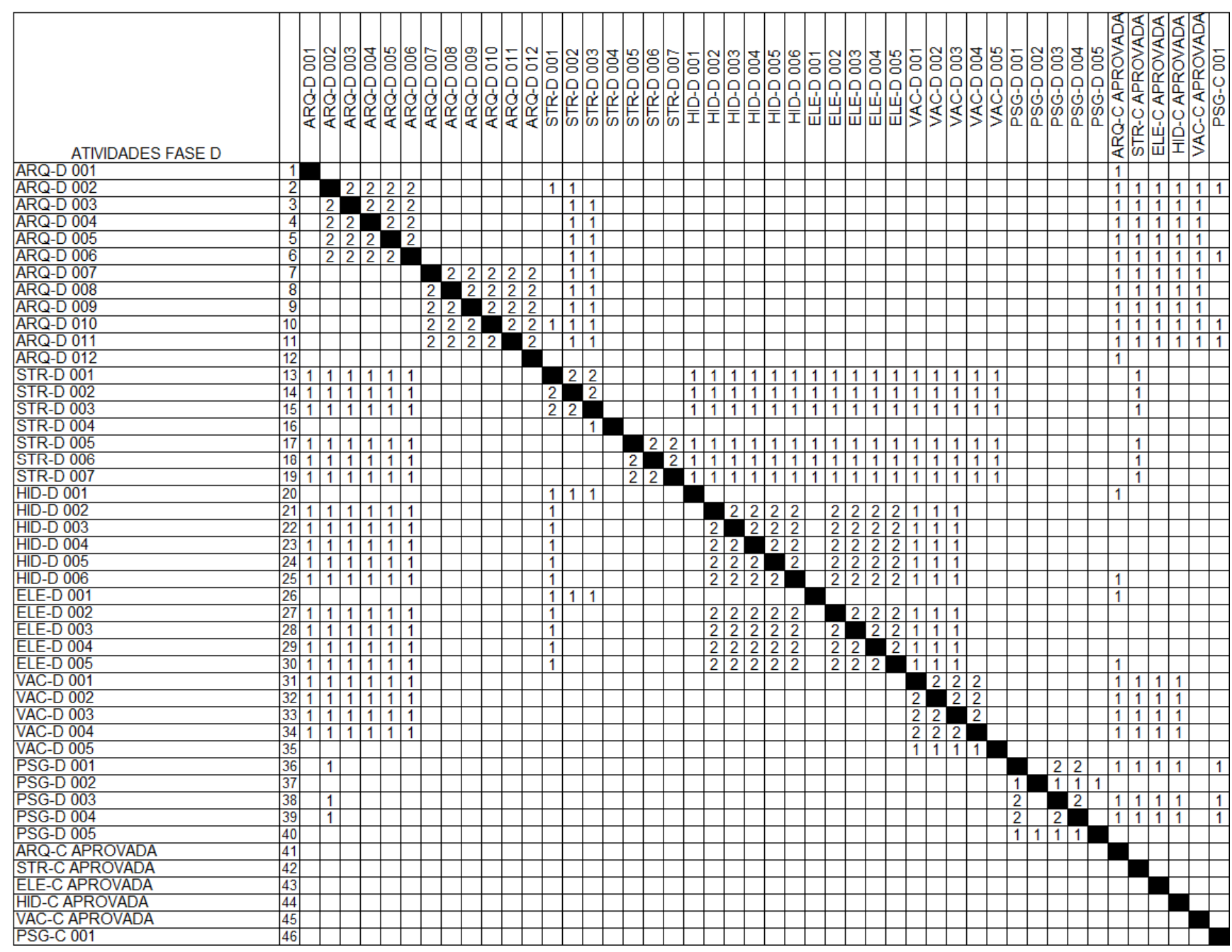

Figura 33: estruturação da matriz DSM fase D 


\section{Análise da DSM}

A estruturação das matrizes de cada fase e a análise desenvolvida pela própria ferramenta gerou as planilhas AEAP e Project.

A figura 34 representa a planilha AEAP das fases A e B. Nesta planilha a própria ferramenta indicou os blocos de interações que ocorreram entre as atividades, representados pelas cores ciano (block 1), amarela (block2), verde (block 3) e cinza (block 4). As interações ocorrem onde há um paralelismo ou simultaneidade de desenvolvimento das atividades, representado pelo número 2 na planilha de estruturação da DSM. As indicações dos blocos na planilha facilita a visualização do gestor e sua ação sobre o processo. Os pontos de interação exigem uma ação mais forte do gestor e uma interferência deste auxiliando na troca de informações e controle dos prazos. Com estas informações o gestor do processo também pode solicitar o início de atividades que possam ocorrer paralelamente, reduzindo prazos de desenvolvimento dos trabalhos.

As figuras 35 e 36 representam as planilhas AEAP das fases $C$ e D respectivamente e podem ser analisadas de forma análoga às fases $A$ e $B$. 
ATIVIDADES FASES A E B Level

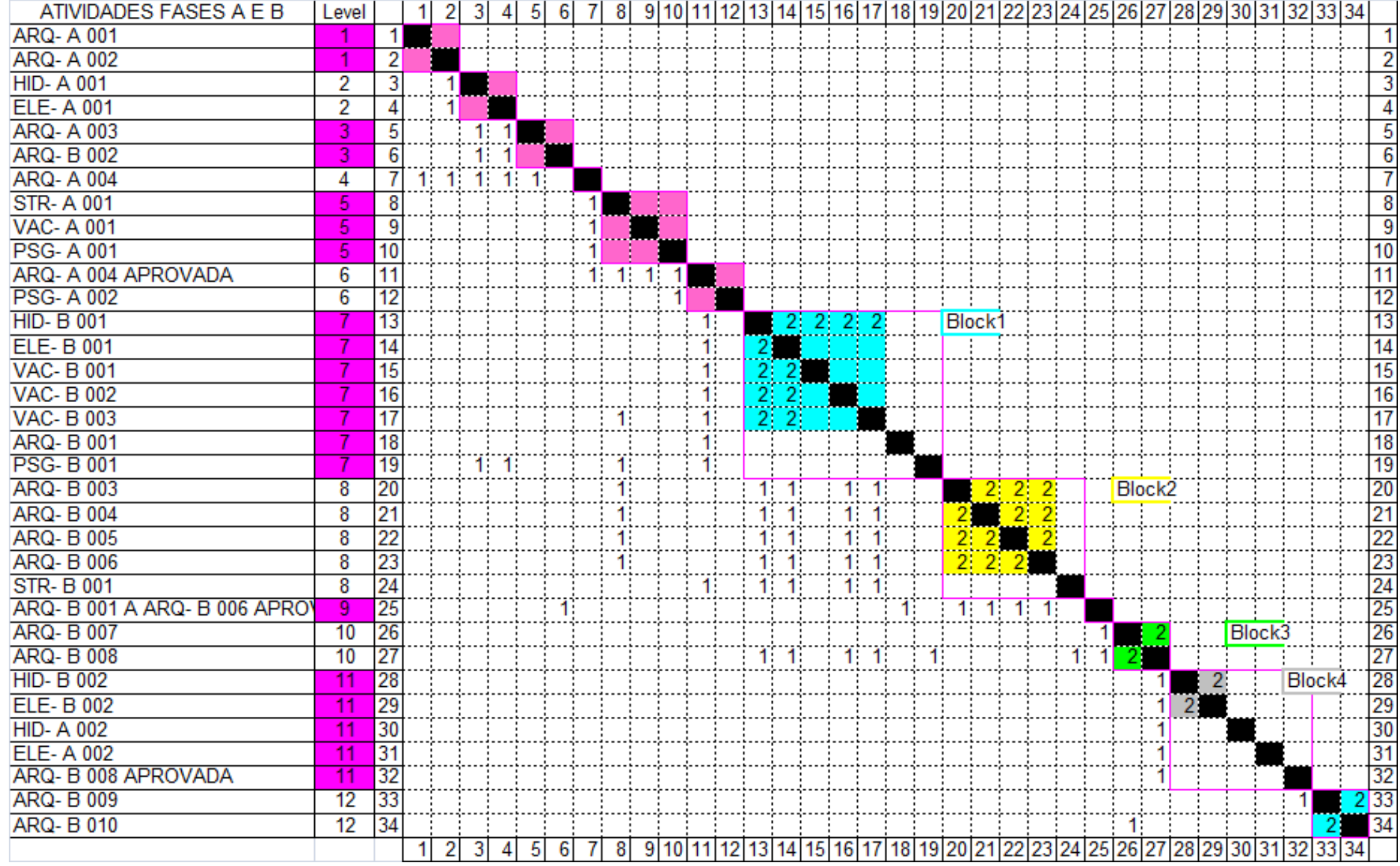

Figura 34: planilha AEAP fases A e B 
ATMIDADES FASE $C$

Level

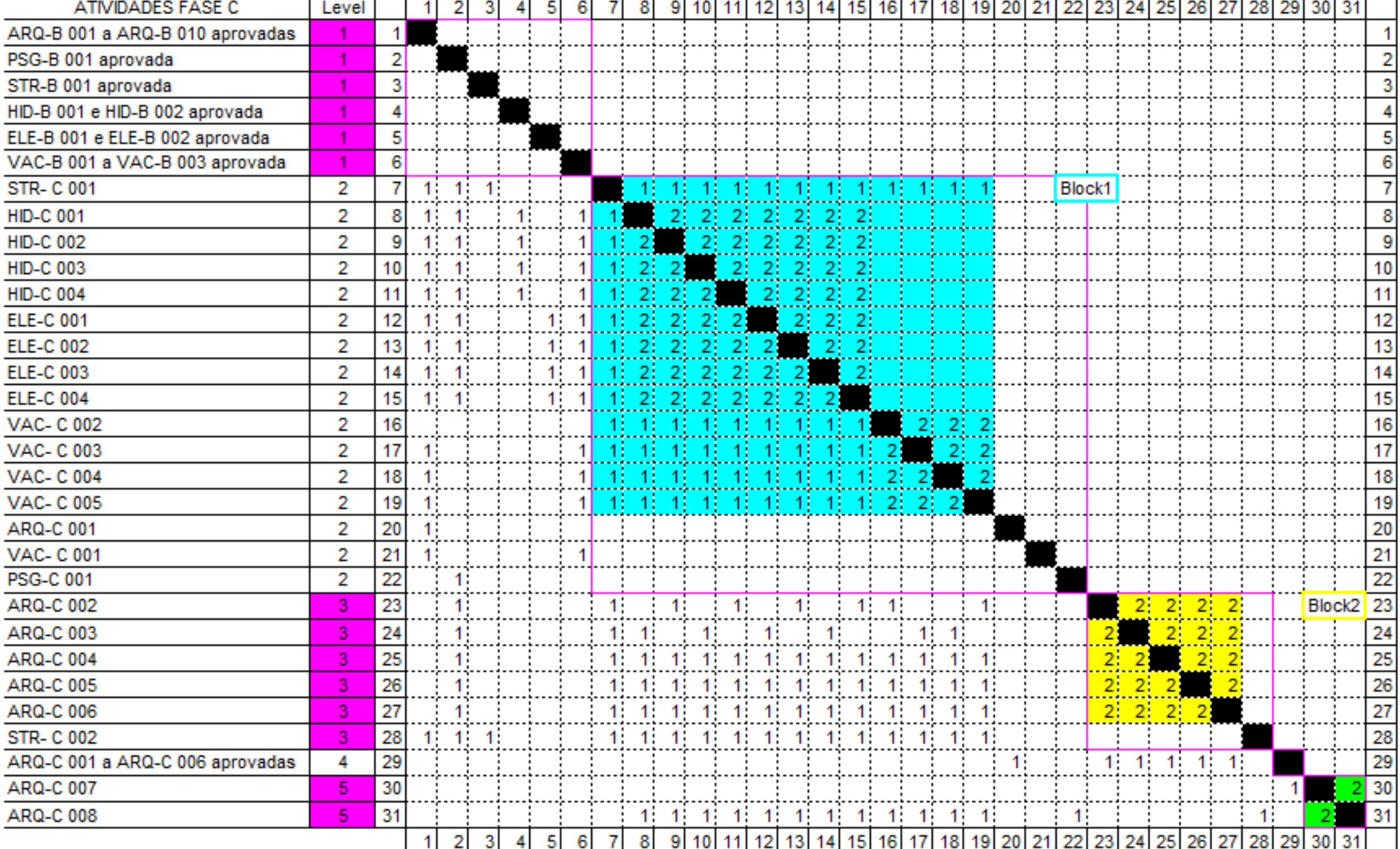

Figura 35: planilha AEAP fase $C$ 




Figura 36: planilha AEAP fase $D$ 
As figuras 37, 38 e 39 representam a planilha Project, geradas pela própria ferramenta a partir da estruturação e análise da matriz DSM. A partir desta planilha é possível modelar o processo de projeto otimizado, uma vez que as precedências e os blocos de interações já foram fornecidos.

Para desenvolvimento do presente trabalho foram utilizadas as planilhas Project das fases A e B, C e D e gerados os modelos de processo de projeto otimizado para cada uma delas. 


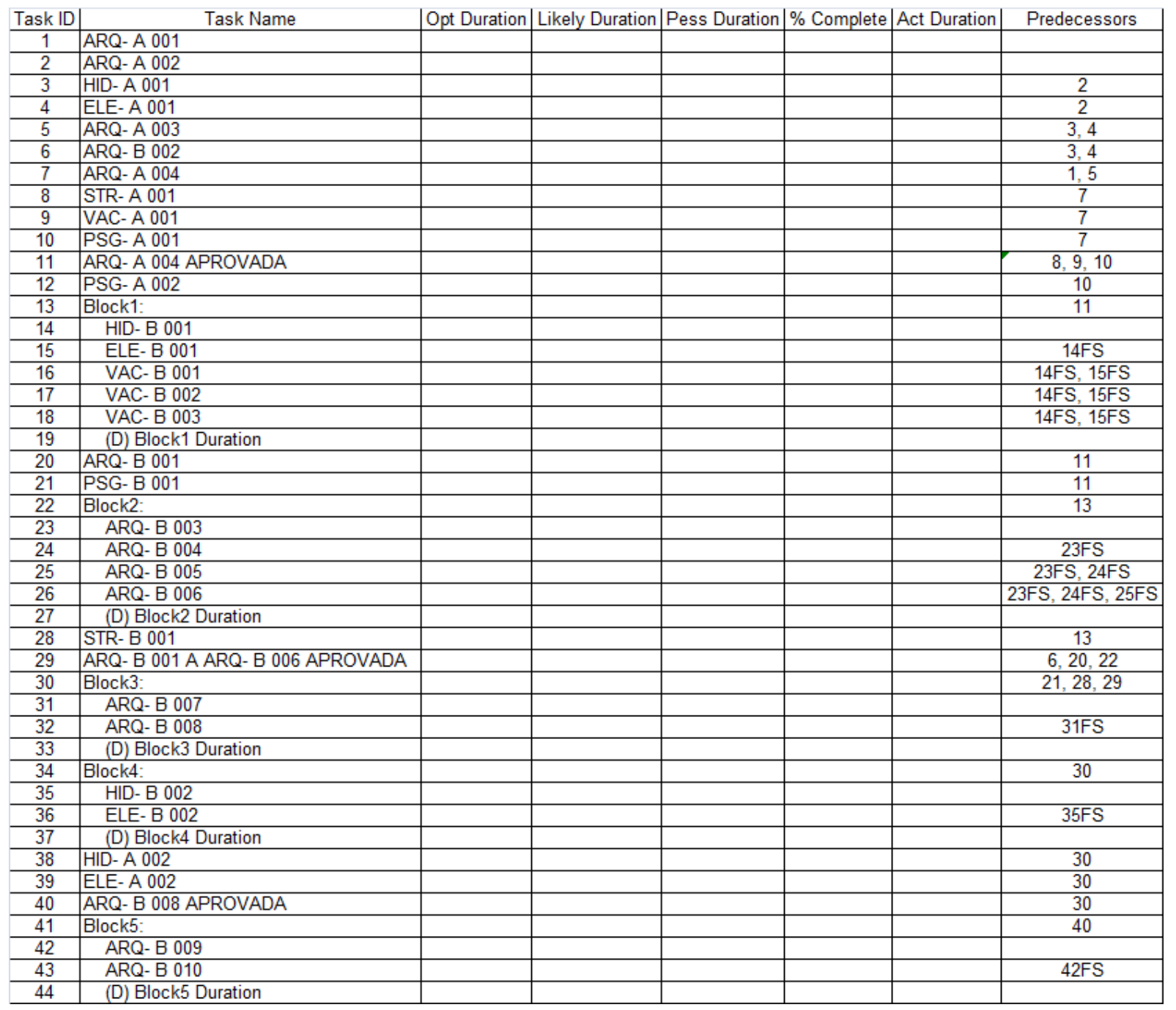

Figura 37: planilha Project fases A e B 


\begin{tabular}{|c|c|c|c|c|c|c|c|}
\hline Task ID & Task Name & Opt Duration & Likely Duration & \begin{tabular}{|l|} 
Pess Duration \\
\end{tabular} & $\%$ Complete & Act Duration & Predecessors \\
\hline 1 & ARQ-B 001 a ARQ-B 010 aprovadas & & & & & & \\
\hline 2 & PSG-B 001 aprovada & & & & & & \\
\hline 3 & STR-B 001 aprovada & & & & & & \\
\hline 4 & HID-B 001 e HID-B 002 aprovada & & & & & & \\
\hline 5 & ELE-B 001 e ELE-B 002 aprovada & & & & & & \\
\hline 6 & VAC-B 001 a VAC-B 003 aprovada & & & & & & \\
\hline 7 & Block1: & & & & & & $1,2,3,4,5,6$ \\
\hline 8 & STR-C 001 & & & & & & \\
\hline 9 & HID-C 001 & & & & & & 8 \\
\hline 10 & HID-C 002 & & & & & & $8,9 \mathrm{FS}$ \\
\hline 11 & HID-C 003 & & & & & & $8,9 \mathrm{FS}, 10 \mathrm{FS}$ \\
\hline 12 & HID-C 004 & & & & & & $8,9 \mathrm{FS}, 10 \mathrm{FS}, 11 \mathrm{FS}$ \\
\hline 13 & ELE-C 001 & & & & & & $8,9 \mathrm{FS}, 10 \mathrm{FS}, 11 \mathrm{FS}, 12 \mathrm{FS}$ \\
\hline 14 & ELE-C 002 & & & & & & $8,9 \mathrm{FS}, 10 \mathrm{FS}, 11 \mathrm{FS}, 12 \mathrm{FS}, 13 \mathrm{FS}$ \\
\hline 15 & ELE-C 003 & & & & & & $8,9 \mathrm{FS}, 10 \mathrm{FS}, 11 \mathrm{FS}, 12 \mathrm{FS}, 13 \mathrm{FS}, 14 \mathrm{FS}$ \\
\hline 16 & ELE-C 004 & & & & & & $8,9 \mathrm{FS}, 10 \mathrm{FS}, 11 \mathrm{FS}, 12 \mathrm{FS}, 13 \mathrm{FS}, 14 \mathrm{FS}, 15 \mathrm{FS}$ \\
\hline 17 & VAC-C 002 & & & & & & $8,9,10,11,12,13,14,15,16$ \\
\hline 18 & VAC-C 003 & & & & & & $8,9,10,11,12,13,14,15,16,17 \mathrm{FS}$ \\
\hline 19 & VAC-C 004 & & & & & & $8,9,10,11,12,13,14,15,16,17 \mathrm{FS}, 18 \mathrm{FS}$ \\
\hline 20 & VAC-C 005 & & & & & & $8,9,10,11,12,13,14,15,16,17 \mathrm{FS}, 18 \mathrm{FS}, 19 \mathrm{FS}$ \\
\hline 21 & (D) Block1 Duration & & & & & & \\
\hline 22 & ARQ-C 001 & & & & & & 1 \\
\hline 23 & VAC-C 001 & & & & & & 1,6 \\
\hline 24 & PSG-C 001 & & & & & & 2 \\
\hline 25 & Block2: & & & & & & 7 \\
\hline 26 & ARQ-C 002 & & & & & & \\
\hline 27 & ARQ-C 003 & & & & & & $26 \mathrm{FS}$ \\
\hline 28 & ARQ-C 004 & & & & & & $26 \mathrm{FS}, 27 \mathrm{FS}$ \\
\hline 29 & ARQ-C 005 & & & & & & $26 \mathrm{FS}, 27 \mathrm{FS}, 28 \mathrm{FS}$ \\
\hline 30 & ARQ-C 006 & & & & & & $26 \mathrm{FS}, 27 \mathrm{FS}, 28 \mathrm{FS}, 29 \mathrm{FS}$ \\
\hline 31 & (D) Block2 Duration & & & & & & \\
\hline 32 & STR-C 002 & & & & & & 7 \\
\hline 33 & ARQ-C 001 a ARQ-C 006 aprovadas & & & & & & 22,25 \\
\hline 34 & Block3: & & & & & & $24,32,33$ \\
\hline 35 & ARQ-C 007 & & & & & & \\
\hline 36 & ARQ-C 008 & & & & & & $35 \mathrm{FS}$ \\
\hline 37 & (D) Block3 Duration & & & & & & \\
\hline
\end{tabular}

Figura 38: planilha Project fase C 


\begin{tabular}{|c|c|c|c|c|c|c|c|}
\hline Task ID & Task Name & Opt Duration & |Likely Duration & Pess Duration & $\%$ Complete & Act Duration & Predecessors \\
\hline 1 & ARQ-C APROVADA & & & & & & \\
\hline 2 & STR-C APROVADA & & & & & & \\
\hline 3 & ELE-C APROVADA & & & & & & \\
\hline 4 & HID-C APROVADA & & & & & & \\
\hline 5 & VAC-C APROVADA & & & & & & \\
\hline 6 & PSG-C 001 & & & & & & \\
\hline 7 & ARQ-D 001 & & & & & & 1 \\
\hline 8 & ARQ-D 012 & & & & & & 1 \\
\hline 9 & Block1: & & & & & & $2,3,4,5,6,7$ \\
\hline 10 & ARQ-D 002 & & & & & & \\
\hline 11 & ARQ-D 003 & & & & & & 10FS \\
\hline 12 & ARQ-D 004 & & & & & & 10FS, 11FS \\
\hline 13 & ARQ-D 005 & & & & & & 10FS, 11FS, 12FS \\
\hline 14 & ARQ-D 006 & & & & & & 10FS, 11FS, 12FS, 13FS \\
\hline 15 & STR-D 001 & & & & & & $10,11,12,13,14$ \\
\hline 16 & STR-D 002 & & & & & & $10,11,12,13,14,15 \mathrm{FS}$ \\
\hline 17 & STR-D 003 & & & & & & $10,11,12,13,14,15 \mathrm{FS}, 16 \mathrm{FS}$ \\
\hline 18 & HID-D 001 & & & & & & $15,16,17$ \\
\hline 19 & HID-D 002 & & & & & & $10,11,12,13,14,15$ \\
\hline 20 & HID-D 003 & & & & & & $10,11,12,13,14,15,19 \mathrm{FS}$ \\
\hline 21 & HID-D 004 & & & & & & $10,11,12,13,14,15,19 \mathrm{FS}, 20 \mathrm{FS}$ \\
\hline 22 & HID-D 005 & & & & & & $10,11,12,13,14,15,19 \mathrm{FS}, 20 \mathrm{FS}, 21 \mathrm{FS}$ \\
\hline 23 & HID-D 006 & & & & & & $10,11,12,13,14,15,19 \mathrm{FS}, 20 \mathrm{FS}, 21 \mathrm{FS}, 22 \mathrm{FS}$ \\
\hline 24 & ELE-D 001 & & & & & & $15,16,17$ \\
\hline 25 & ELE-D 002 & & & & & & $10,11,12,13,14,15,19 \mathrm{FS}, 20 \mathrm{FS}, 21 \mathrm{FS}, 22 \mathrm{FS}, 23 \mathrm{FS}$ \\
\hline 26 & ELE-D 003 & & & & & & $10,11,12,13,14,15,19 \mathrm{FS}, 20 \mathrm{FS}, 21 \mathrm{FS}, 22 \mathrm{FS}, 23 \mathrm{FS}, 25 \mathrm{FS}$ \\
\hline 27 & ELE-D 004 & & & & & & $10,11,12,13,14,15,19 \mathrm{FS}, 20 \mathrm{FS}, 21 \mathrm{FS}, 22 \mathrm{FS}, 23 \mathrm{FS}, 25 \mathrm{FS}, 26 \mathrm{FS}$ \\
\hline 28 & ELE-D 005 & & & & & & $10,11,12,13,14,15,19 \mathrm{FS}, 20 \mathrm{FS}, 21 \mathrm{FS}, 22 \mathrm{FS}, 23 \mathrm{FS}, 25 \mathrm{FS}, 26 \mathrm{FS}, 27 \mathrm{FS}$ \\
\hline 29 & VAC-D 001 & & & & & & $10,11,12,13,14$ \\
\hline 30 & VAC-D 002 & & & & & & $10,11,12,13,14,29 \mathrm{FS}$ \\
\hline 31 & VAC-D 003 & & & & & & $10,11,12,13,14,29 \mathrm{FS}, 30 \mathrm{FS}$ \\
\hline 32 & VAC-D 004 & & & & & & $10,11,12,13,14,29 \mathrm{FS}, 30 \mathrm{FS}, 31 \mathrm{FS}$ \\
\hline 33 & VAC-D 005 & & & & & & $29,30,31,32$ \\
\hline 34 & (D) Block1 Duration & & & & & & \\
\hline 35 & Block2: & & & & & & 8,9 \\
\hline 36 & ARQ-D 007 & & & & & & \\
\hline 37 & ARQ-D 008 & & & & & & $36 \mathrm{FS}$ \\
\hline 38 & ARQ-D 009 & & & & & & $36 \mathrm{FS}, 37 \mathrm{FS}$ \\
\hline 39 & ARQ-D 010 & & & & & & $36 \mathrm{FS}, 37 \mathrm{FS}, 38 \mathrm{FS}$ \\
\hline 40 & ARQ-D 011 & & & & & & $36 \mathrm{FS}, 37 \mathrm{FS}, 38 \mathrm{FS}, 39 \mathrm{FS}$ \\
\hline 41 & (D) Block2 Duration & & & & & & \\
\hline 42 & Block3: & & & & & & 9 \\
\hline 43 & STR-D 005 & & & & & & \\
\hline 44 & STR-D 006 & & & & & & $43 \mathrm{FS}$ \\
\hline 45 & STR-D 007 & & & & & & $43 \mathrm{FS}, 44 \mathrm{FS}$ \\
\hline 46 & (D) Block3 Duration & & & & & & \\
\hline 47 & Block4: & & & & & & 9 \\
\hline 48 & PSG-D 001 & & & & & & \\
\hline 49 & PSG-D 003 & & & & & & $48 \mathrm{FS}$ \\
\hline 50 & PSG-D 004 & & & & & & $48 \mathrm{FS}, 49 \mathrm{FS}$ \\
\hline 51 & (D) Block4 Duration & & & & & & \\
\hline 52 & STR-D 004 & & & & & & 9 \\
\hline 53 & Block5: & & & & & & 47 \\
\hline 54 & PSG-D 002 & & & & & & \\
\hline 55 & PSG-D 005 & & & & & & 54 \\
\hline 56 & (D) Block5 Duration & & & & & & \\
\hline
\end{tabular}

Figura 39: planilha Project fase $D$ 


\section{Modelo de processo de projeto}

Com base nas planilhas Project fornecidas pela ferramenta DSM foram elaborados os modelos de processo de projeto para as fases A e B, C e D. O modelos de processo gerado consideram a otimização que a própria ferramenta apresenta permitindo uma análise comparativa com os diagramas de rede gerados na etapa de definição do processo e a análise da aplicação da DSM ao planejamento do processo de projeto, detalhada a seguir no capítulo 3.3. 


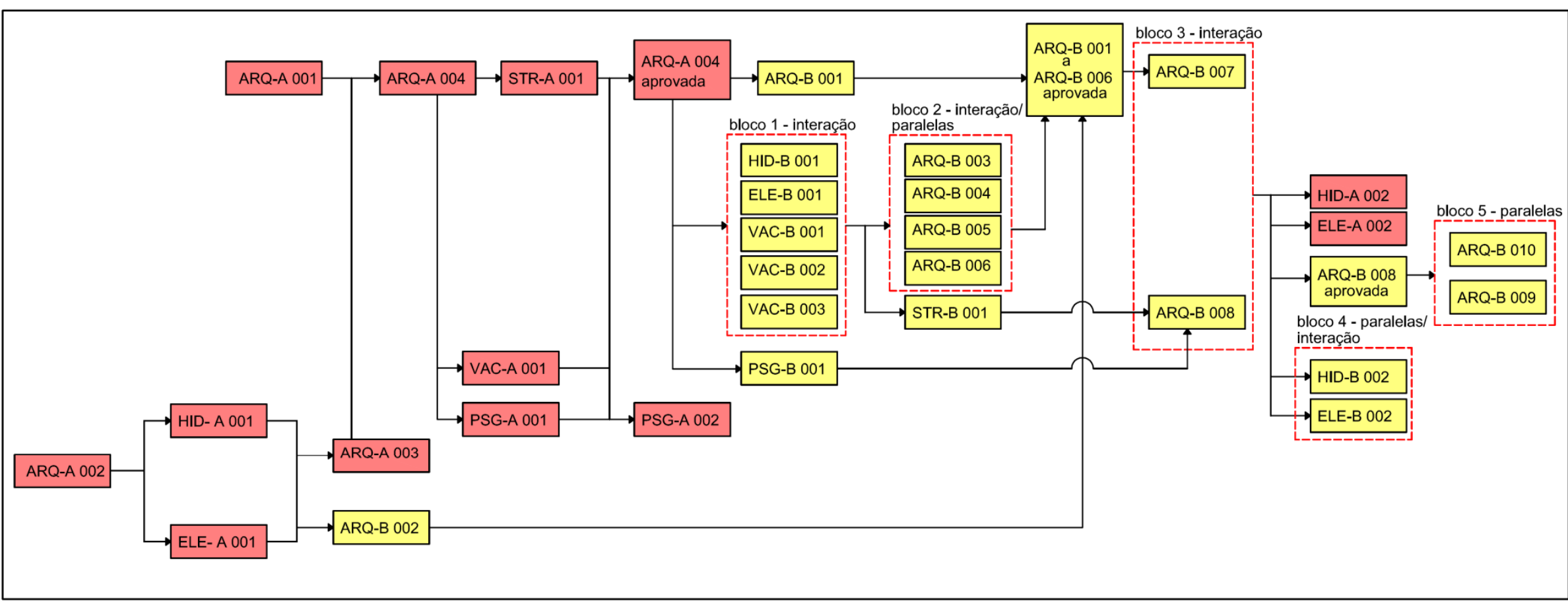

ATIVIDADE FASE A

ATIVIDADE FASE B

Figura 40: modelo de processo de projeto fases A e B 


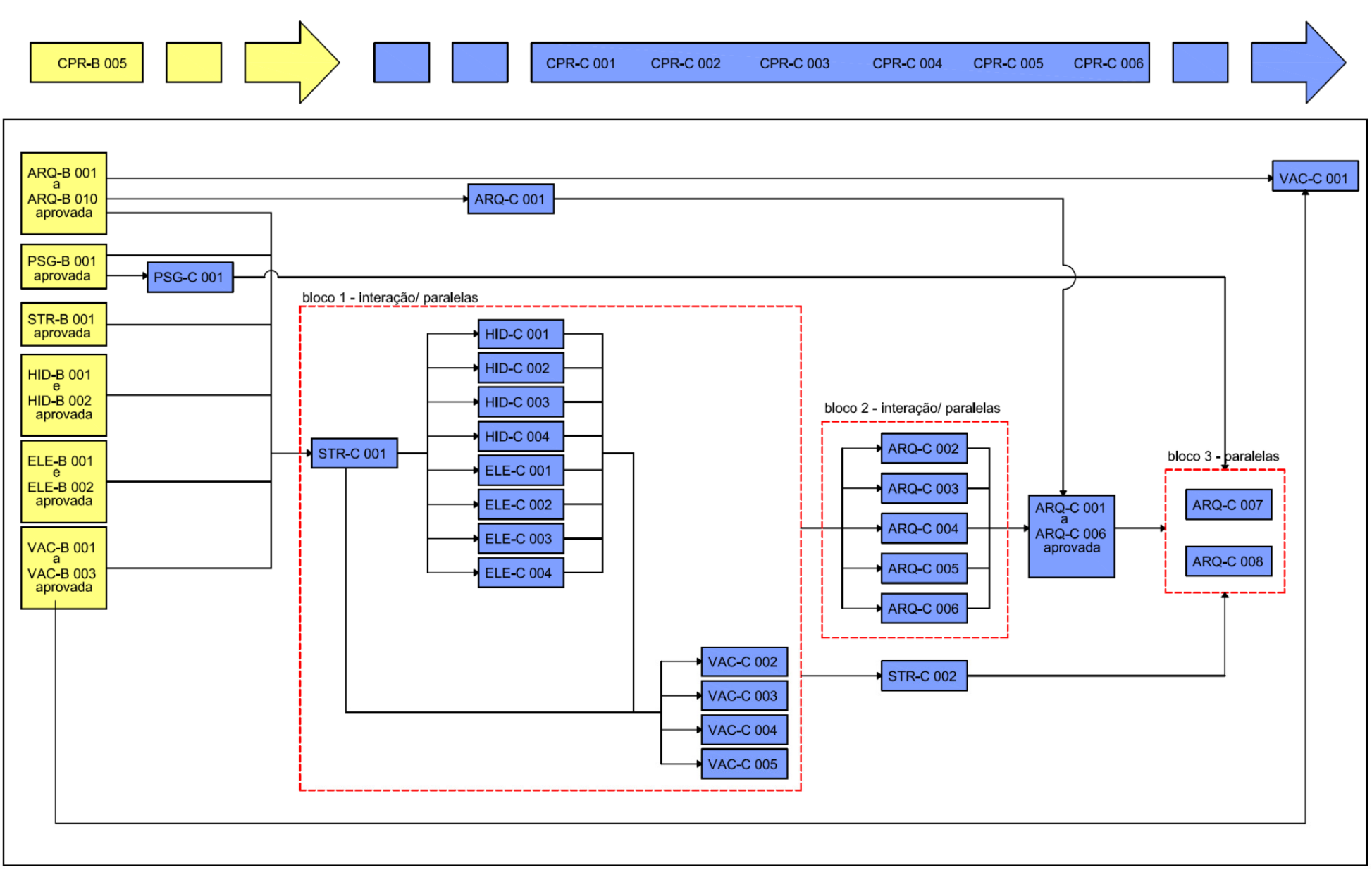

$\square$ ATIVIDADE FASE B

$\square$ ATIVIDADE FASE C

Figura 41: modelo de processo de projeto fase C 

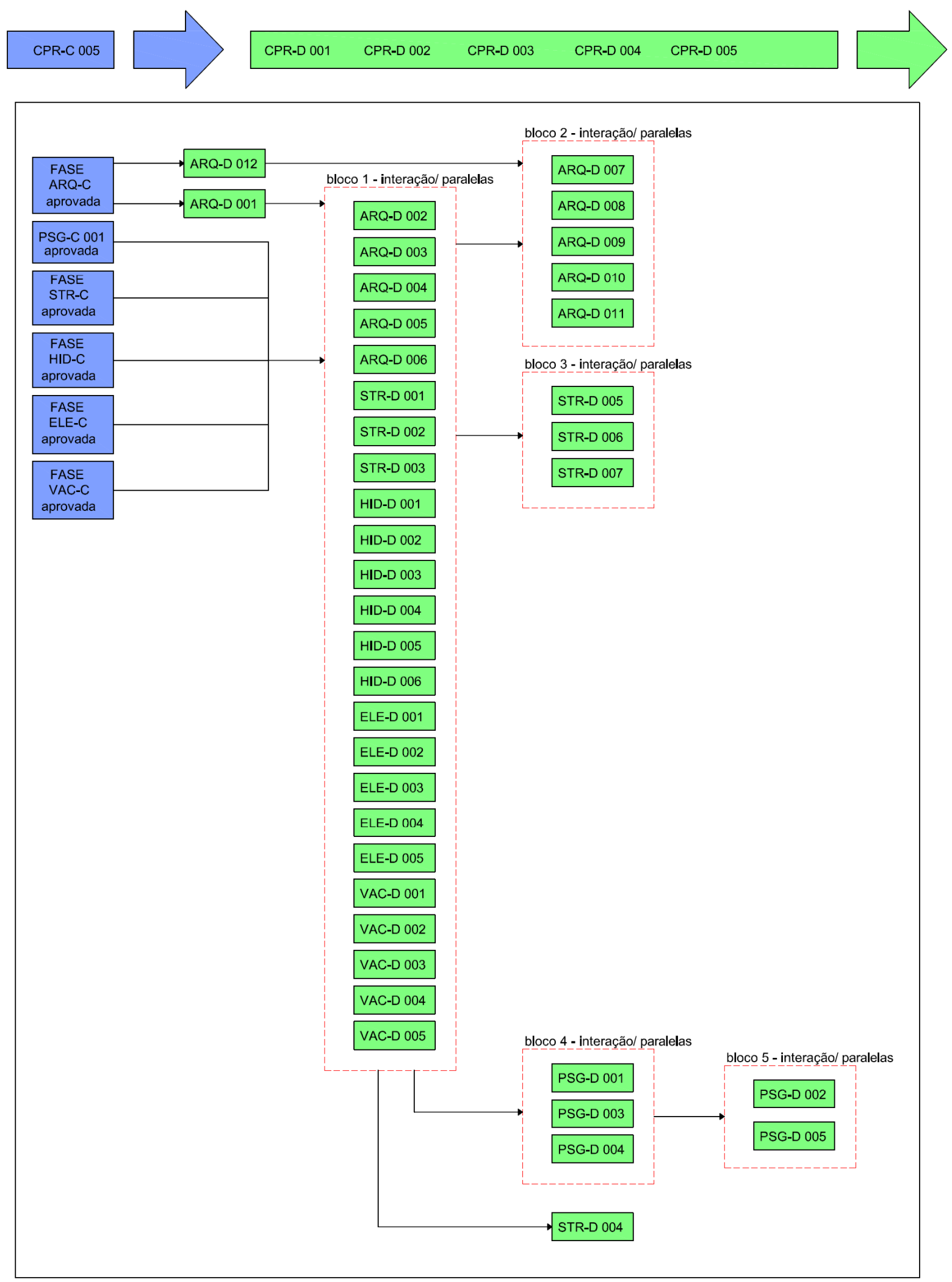

ATIVIDADE FASE C

ATIVIDADE FASE D

Figura 42: modelo de processo de projeto fase $D$ 


\subsection{Conclusões da aplicação da DSM}

A presente pesquisa tem como objetivo analisar a aplicação prática da ferramenta DSM ao planejamento do processo de projeto. Uma análise comparativa entre os diagramas de rede gerados na etapa de definição do processo e a aplicação da DSM na etapa otimização do processo permitem que esta análise seja desenvolvida, bem como a avaliação do cumprimento do objetivo proposto pelo trabalho.

Um comparativo entre os dois diagramas de rede demonstra a capacidade de simplificação e otimização da aplicação da DSM. Os primeiros diagramas, elaborados durante a definição do processo, apresentam um fluxo de leitura mais complexa, com a representação das ligações entre as atividades feitas uma a uma. A otimização do processo apresenta os blocos de interações e paralelismos entre as atividades, permitindo uma leitura mais fluida do processo, facilitando seu entendimento tanto por parte do gestor quanto por todos os agentes envolvidos.

A representação dos blocos de interações e paralelismos entre as atividades permite que o gestor tenha uma atuação mais forte nestas etapas, auxiliando e incentivando o aumento da interação entre os diversos agentes envolvidos e do fluxo de informações, minimizando os retrabalhos, acelerando os processos de entrega de etapas e viabilizando a continuidade dos trabalhos dos demais agentes envolvidos nas etapas subseqüentes do empreendimento. Esta representação também permite a antecipação de tomada de decisões, uma vez que a visualização simplificada do processo como um todo facilita o entendimento deste, e permite que decisões que anteriormente eram tomadas mais tarde possam ser antecipadas sem prejuízo de informações ou falta destas.

O planejamento do processo de projeto também deve ser alterado em relação à forma convencional. A capacidade de uma visão global do processo e a ênfase na troca de informações que os Manuais e a DSM propõem, exigem do gestor uma nova forma de planejamento, considerando a importância do conteúdo das entregas em detrimento ao simples cumprimento de etapas. É importante que o gestor, nesta nova forma de planejamento, entenda que, para que uma atividade seja considerada finalizada, esta deve conter todas as informações que se propõe a fornecer. Para 
que isto ocorra, a ação do gestor durante a troca de informações entre os agentes do processo, principalmente nos momentos em que ocorrem os blocos de interações e paralelismos das atividades, seja efetiva, este deve ser ativo e não passivo na gestão do processo.

\subsection{Análise crítica dos Manuais}

O desenvolvimento dos diagramas de rede conforme as precedências estabelecidas pelos Manuais de Escopo de Projetos e Serviços para a Indústria Imobiliária permite observar que a relação entre algumas atividades ainda se mostra falha.

Neste item será apresentada uma análise crítica sobre os Manuais de Escopo de Projetos e Serviços para a Indústria Imobiliária, com o objetivo de sugerir alterações, sejam nos dados necessários para cada atividade, nos produtos gerados e outros itens que possam propor melhorias para o usuário deste material.

A análise crítica será desenvolvida separadamente para as fases $A$ e $B, C$ e $D$, da mesma forma que foram desenvolvidos os diagramas de rede.

\section{Análise crítica para as Fases A e B}

Conforme visto no item 2.2 do capítulo 2, na fase A os partidos de cada uma das especialidades devem ser caracterizados, para então, na fase B, serem definidos. Ao final da fase $\mathrm{B}$, o empreendedor deve ter material suficiente para analisar a viabilidade física, legal e econômica do empreendimento bem como o Projeto Legal deve estar finalizado, com base nas informações desenvolvidas nestas duas fases.

Uma análise crítica das tabelas de dependência de informações, da tabela AEAP da DSM e da rede de precedências desenvolvidos para estas duas fases permite observar algumas incoerências e sugerir alterações no fluxo de atividades proposto pelos Manuais:

a. na fase $A$, há uma incoerência na solicitação das premissas para as atividades HID- A 002 e ELE- A 002 - Consulta às Concessionárias de Serviços Públicos. Estas duas atividades solicitam como dado de entrada a atividade ARQ- B 008 Documentos Legais Gráficos Preliminares - atividade esta que será gerada 
somente na próxima fase com base também em informações geradas na fase B. Por se tratar de uma consulta formal às concessionárias estas atividades devem ser concluídas o quanto antes, para que não ocorram prejuízos ao projeto pela chegada de informações tardias. Desta forma sugere-se a alteração dos dados necessários para o desenvolvimento destas atividades, trocando-se a atividade ARQ-B 008 pela atividade ARQ-A 002, que fornece dados suficientes para 0 desenvolvimento destas.

b. a atividade ARQ-A 003 deve incluir como dado de entrada a atividade VAC-A 001 uma vez que as condicionantes locais de instalações hidráulicas e elétricas (HIDA 001 e ELE-A 001) já estão sendo incorporadas à atividade neste momento;

c. a atividade STR- A 001 deve gerar os croquis de lançamento dos pilares e incluir a locação das vigas pois, com estas informações disponibilizadas, as atividades HID-B 001, ELE-B 001, VAC-B 002 e VAC-B 003 podem ser desenvolvidas já verificando uma prévia da compatibilização estrutural, minimizando retrabalhos em função de interferências estruturais;

d. a atividade VAC-A 001 deve alterar a atividade ARQ-A 004 pela atividade ARQ-A 002 como dado de entrada. Desta forma a informação fornecida pela atividade VAC-A 001 pode ser antecipada para a arquitetura, assim como já ocorre nas atividades HID-A 001 e ELE-A 001;

e. a atividade ARQ-B 002 deve incluir PSG-A 001 como dado de entrada, pois neste momento está sendo desenvolvida a solução preliminar de implantação, da qual o paisagismo é atividade fundamental. Sugere-se também alterar as atividades HID-A 001 e ELE-A 001 pela atividade ARQ-A 004 aprovada, pois as atividades de instalações já foram premissa para a arquitetura, que deve ter incorporado suas considerações. As atividades HID-B 001, ELE-B 001, VAC-B 002, VAC- B 003 e STR-B 001 também devem ser contempladas como dado de entrada, do contrário a arquitetura não contemplará os espaços técnicos necessários para o desenvolvimento da implantação e não considerará adequadamente as interferências estruturais que podem ocorrer, gerando futuros retrabalhos;

f. as atividades ARQ-B 003 a ARQ-B 006 devem alterar a atividade STR-A 001 para a STR-B 001, uma vez que esta já estará finalizada e mais evoluída que na fase $A$, quando a arquitetura iniciar seus trabalhos da fase $B$; 
g. as atividades HID-B 001, ELE-B 001, VAC-B 002 e VAC-B 003 devem incluir a atividade STR-A 001 como dado de entrada, para que neste momento já ocorra uma primeira compatibilização estrutural.

A partir das observações e sugestões listadas acima, foi desenvolvida uma nova matriz, com o objetivo de otimizar o modelo de processo de projeto para as fases $\mathrm{A}$ e B. 
FASES A e B

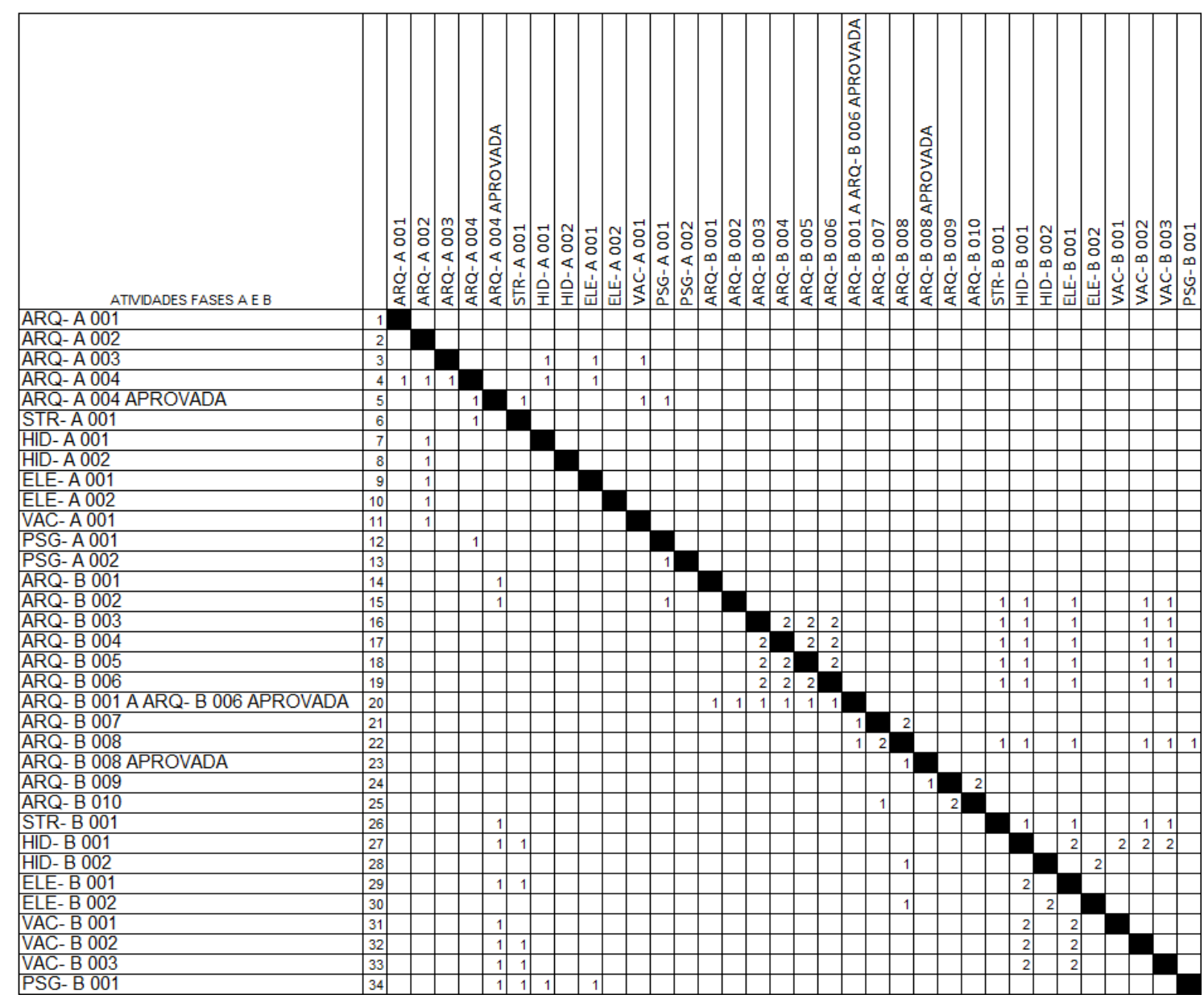

Figura 43: estruturação da matriz DSM fases A e B após análise crítica 


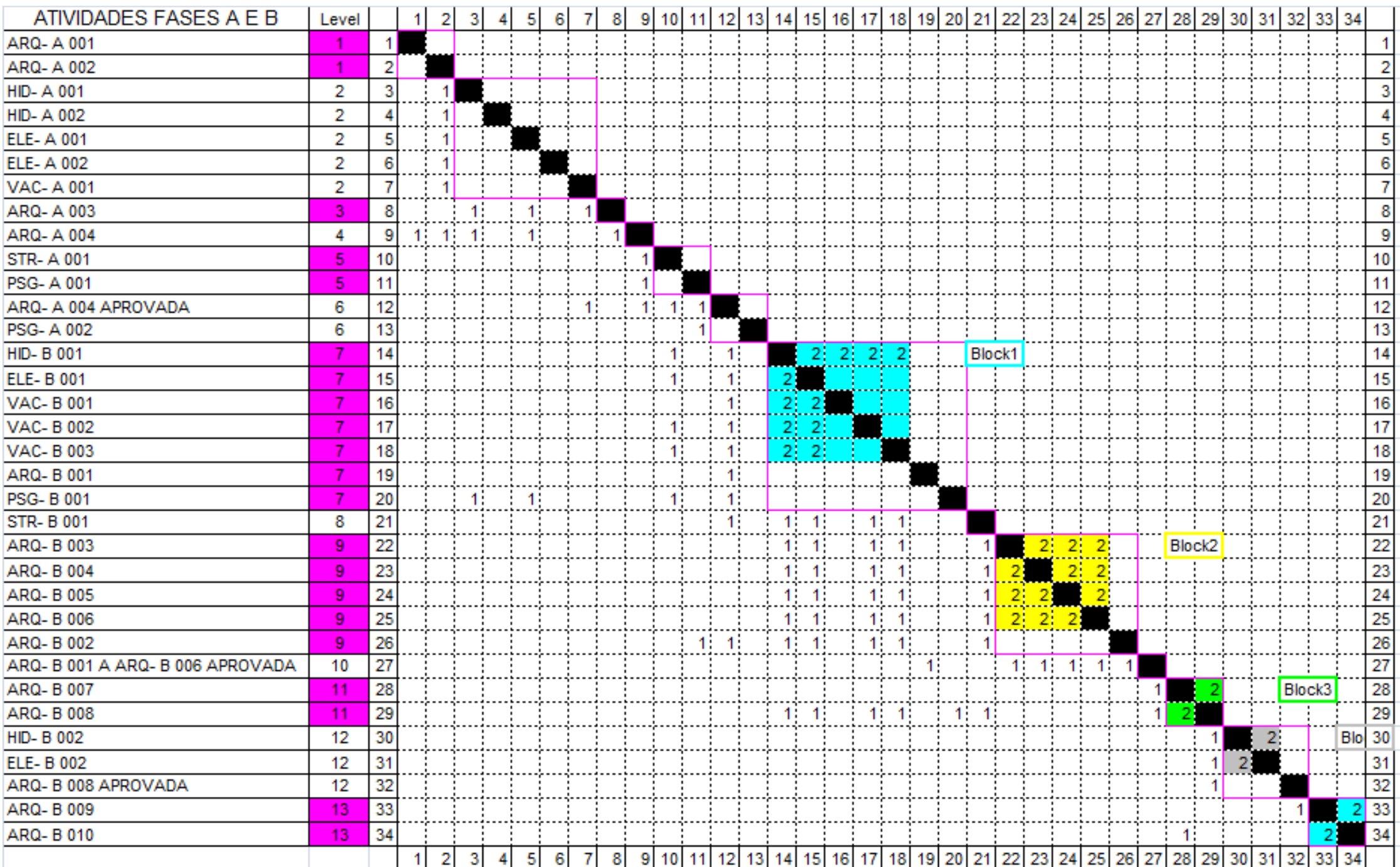

Figura 44: planilha AEAP fases A e B após análise crítica 


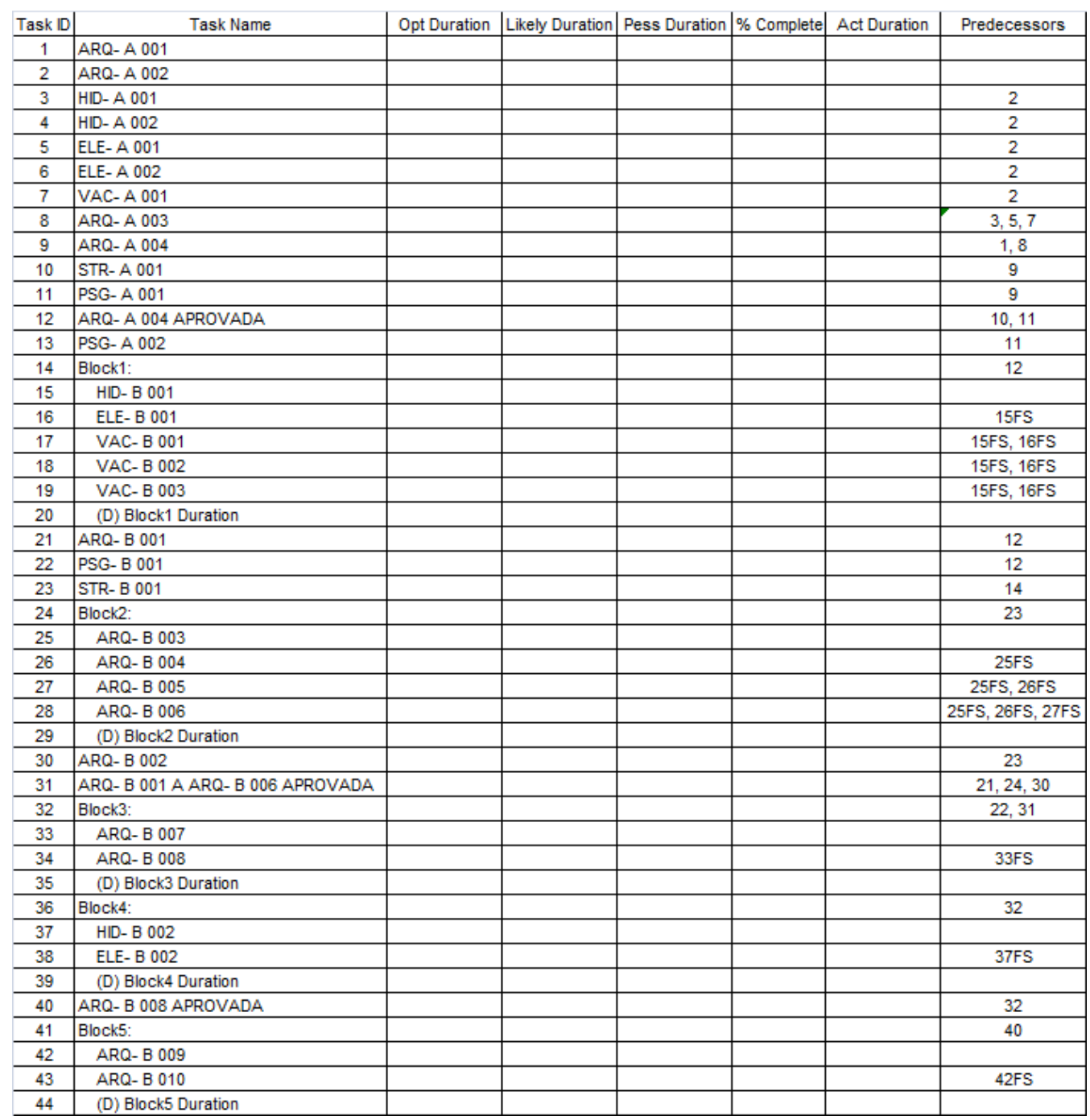

Figura 45: planilha Project fases A e B após análise crítica 


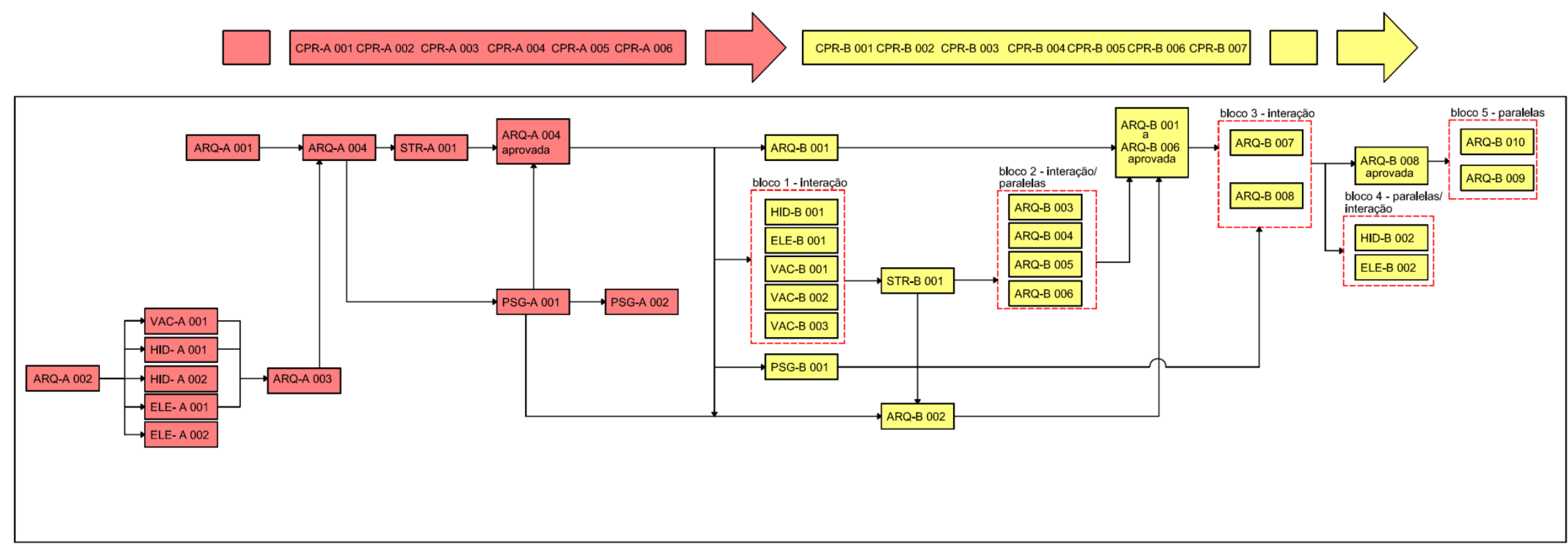

$\square$ ATIVIDADE FASE A

$\square$ ATIVIDADE FASE B

Figura 46: modelagem do processo de projeto Fases A e B após Análise Crítica 


\section{Análise crítica para a Fase C}

Conforme visto no item 2.2 do capítulo 2 , na fase $C$ a negociação de soluções de interferências entre os sistemas deve ocorrer e ter todas as interfaces resolvidas, de forma a viabilizar uma avaliação preliminar de custos, métodos construtivos e prazos de execução. A conclusão desta fase deve permitir, se for necessária, uma licitação da obra. Nesta fase, os ambientes, suas articulações e demais elementos do empreendimento devem estar consolidadas.

Uma análise crítica das tabelas de dependência de informações, da tabela AEAP da DSM e da rede de precedências desenvolvidos para esta fase permite observar algumas incoerências e sugerir alterações no fluxo de atividades proposto pelos Manuais:

a. a atividade PSG-C 001 utiliza como atividade predecessora somente PSG-B 001. Desta forma a atividade não incorpora todas as informações geradas ao longo das fases B e C (notar que a atividade PSG-B 001 tem como predecessora somente a atividade ARQ-A 004). Sugere-se aqui que a atividade PSG-C 001 seja postergada e incorpore como premissa para desenvolvimento de seus trabalhos as atividades ARQ-C 002, ARQ-C 008, STR-C 002, HID-C001 a HID-C 004, ELE-C 001 a ELE-C 004 e VAC-C 002 a VAC-C 005.

b. As atividades VAC-C 002 a VAC-C 005 utilizam como premissa para desenvolvimento de seus trabalhos as atividades HID-C e ELE-C. Sugere-se aqui que, assim como as atividades de instalações da fase $C$, as atividades VAC-C 002 a VAC-C 005 sejam adiantadas e tomem como premissas as atividades da fase $B$. Desta forma elimina-se a necessidade de finalização das atividades de instalações fase $C$ para início das atividades VAC-C, estas passam a serem desenvolvidas paralelamente e interagem entre si durante seu desenvolvimento. 
FASE C

DSM Input

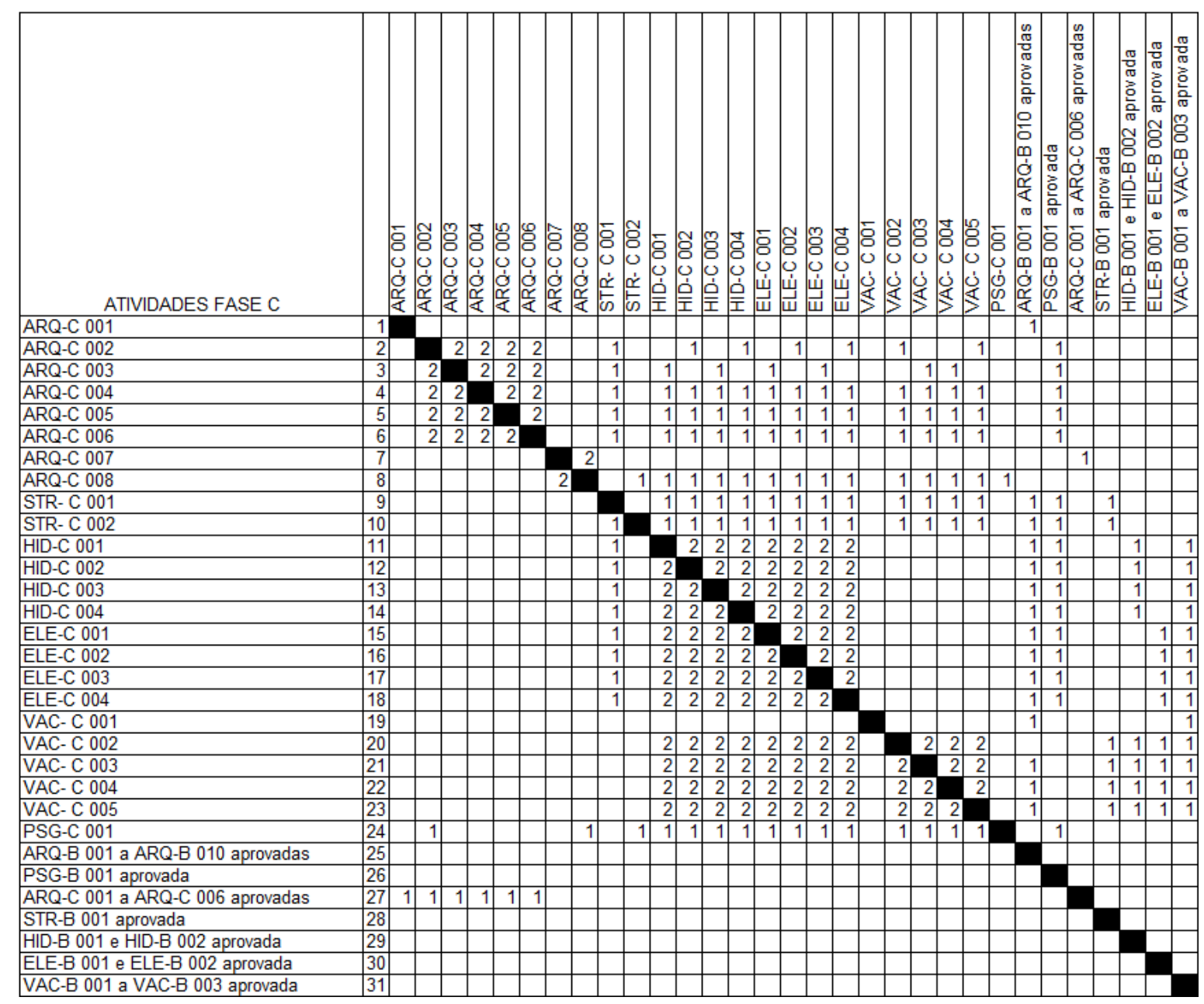

Figura 47: estruturação da matriz DSM fase C após análise crítica 
ATIVIDADES FASE C

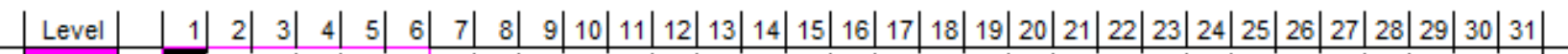

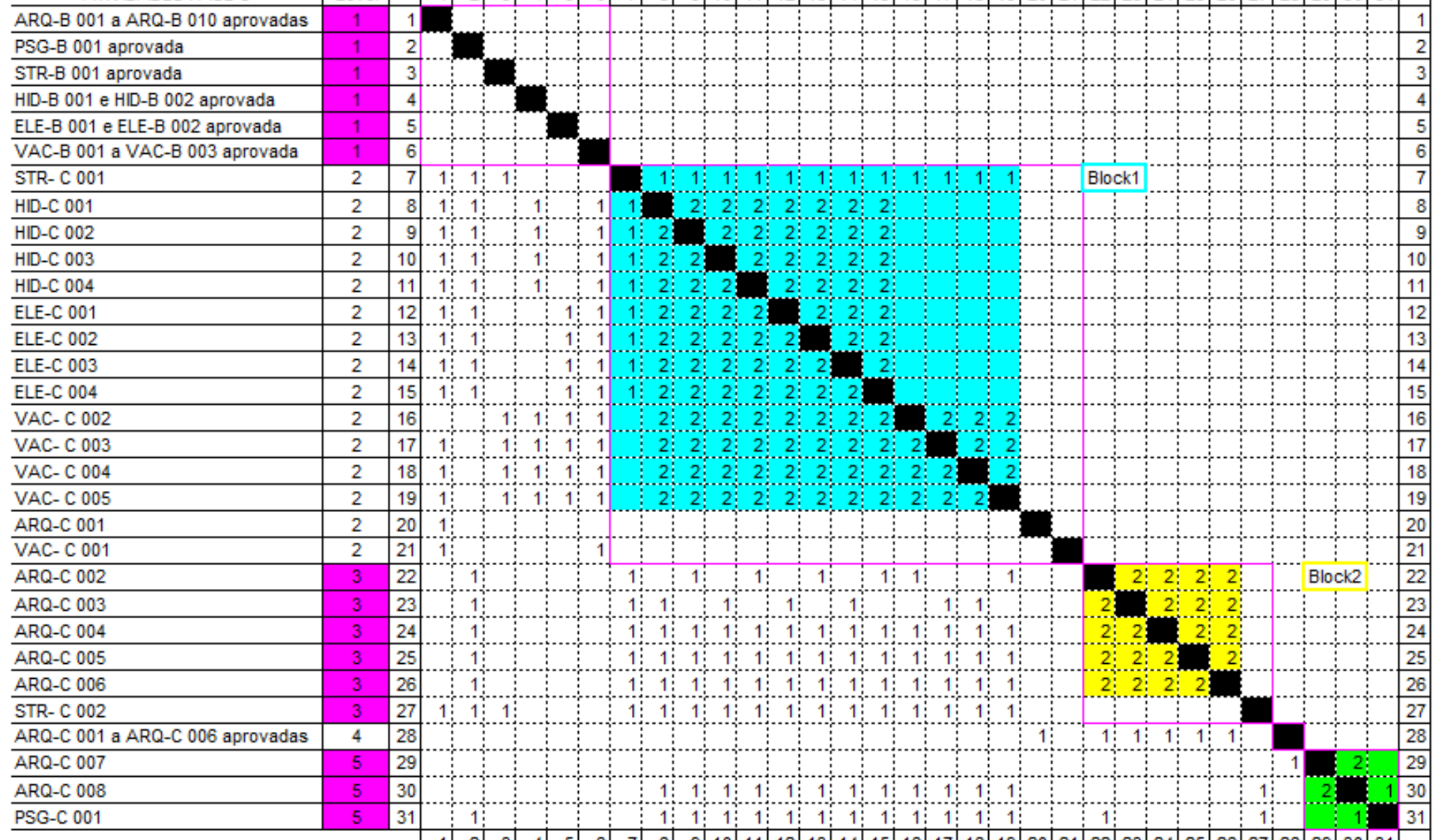

Figura 48: planilha AEAP fase $\mathrm{C}$ após análise crítica 


\begin{tabular}{|c|c|c|c|c|c|c|c|}
\hline Task ID & Task Name & Opt Duration & Likely Duration & Pess Duration & $\%$ Complete & Act Duration & Predecessors \\
\hline 1 & ARQ-B 001 a ARQ-B 010 aprovadas & & & & & & \\
\hline 2 & PSG-B 001 aprovada & & & & & & \\
\hline 3 & STR-B 001 aprovada & & & & & & \\
\hline 4 & HID-B 001 e HID-B 002 aprovada & & & & & & \\
\hline 5 & ELE-B 001 e ELE-B 002 aprovada & & & & & & \\
\hline 6 & VAC-B 001 a VAC-B 003 aprovada & & & & & & \\
\hline 7 & Block1: & & & & & & $1,2,3,4,5,6$ \\
\hline 8 & STR-C 001 & & & & & & \\
\hline 9 & HID-C 001 & & & & & & 8 \\
\hline 10 & HID-C 002 & & & & & & $8,9 \mathrm{FS}$ \\
\hline 11 & HID-C 003 & & & & & & $8,9 \mathrm{FS}, 10 \mathrm{FS}$ \\
\hline 12 & HID-C 004 & & & & & & $8,9 \mathrm{FS}, 10 \mathrm{FS}, 11 \mathrm{FS}$ \\
\hline 13 & ELE-C 001 & & & & & & $8,9 \mathrm{FS}, 10 \mathrm{FS}, 11 \mathrm{FS}, 12 \mathrm{FS}$ \\
\hline 14 & ELE-C 002 & & & & & & $8,9 \mathrm{FS}, 10 \mathrm{FS}, 11 \mathrm{FS}, 12 \mathrm{FS}, 13 \mathrm{FS}$ \\
\hline 15 & ELE-C 003 & & & & & & $8,9 \mathrm{FS}, 10 \mathrm{FS}, 11 \mathrm{FS}, 12 \mathrm{FS}, 13 \mathrm{FS}, 14 \mathrm{FS}$ \\
\hline 16 & ELE-C 004 & & & & & & $8,9 \mathrm{FS}, 10 \mathrm{FS}, 11 \mathrm{FS}, 12 \mathrm{FS}, 13 \mathrm{FS}, 14 \mathrm{FS}, 15 \mathrm{FS}$ \\
\hline 17 & VAC- C 002 & & & & & & $9 \mathrm{FS}, 10 \mathrm{FS}, 11 \mathrm{FS}, 12 \mathrm{FS}, 13 \mathrm{FS}, 14 \mathrm{FS}, 15 \mathrm{FS}, 16 \mathrm{FS}$ \\
\hline 18 & VAC- C 003 & & & & & & 9FS, 10FS, 11FS, 12FS, 13FS, 14FS, 15FS, 16FS, 17FS \\
\hline 19 & VAC-C 004 & & & & & & 9FS, 10FS, 11FS, 12FS, 13FS, 14FS, 15FS, 16FS, 17FS, 18FS \\
\hline 20 & VAC-C 005 & & & & & & $9 \mathrm{FS}, 10 \mathrm{FS}, 11 \mathrm{FS}, 12 \mathrm{FS}, 13 \mathrm{FS}, 14 \mathrm{FS}, 15 \mathrm{FS}, 16 \mathrm{FS}, 17 \mathrm{FS}, 18 \mathrm{FS}$, 19FS \\
\hline 21 & (D) Block1 Duration & & & & & & \\
\hline 22 & ARQ-C 001 & & & & & & 1 \\
\hline 23 & VAC-C 001 & & & & & & 1,6 \\
\hline 24 & Block2: & & & & & & 7 \\
\hline 25 & ARQ-C 002 & & & & & & \\
\hline 26 & ARQ-C 003 & & & & & & $25 \mathrm{FS}$ \\
\hline 27 & ARQ-C 004 & & & & & & $25 \mathrm{FS}, 26 \mathrm{FS}$ \\
\hline 28 & ARQ-C 005 & & & & & & $25 \mathrm{FS}, 26 \mathrm{FS}, 27 \mathrm{FS}$ \\
\hline 29 & ARQ-C 006 & & & & & & $25 \mathrm{FS}, 26 \mathrm{FS}, 27 \mathrm{FS}, 28 \mathrm{FS}$ \\
\hline 30 & (D) Block2 Duration & & & & & & \\
\hline 31 & STR- C 002 & & & & & & 7 \\
\hline 32 & ARQ-C 001 a ARQ-C 006 aprovadas & & & & & & 22,24 \\
\hline 33 & Block3: & & & & & & 31,32 \\
\hline 34 & ARQ-C 007 & & & & & & \\
\hline 35 & ARQ-C 008 & & & & & & $34 \mathrm{FS}$ \\
\hline 36 & PSG-C 001 & & & & & & 35 \\
\hline 37 & (D) Block3 Duration & & & & & & \\
\hline
\end{tabular}

Figura 49: planilha Project fase $C$ após análise crítica 


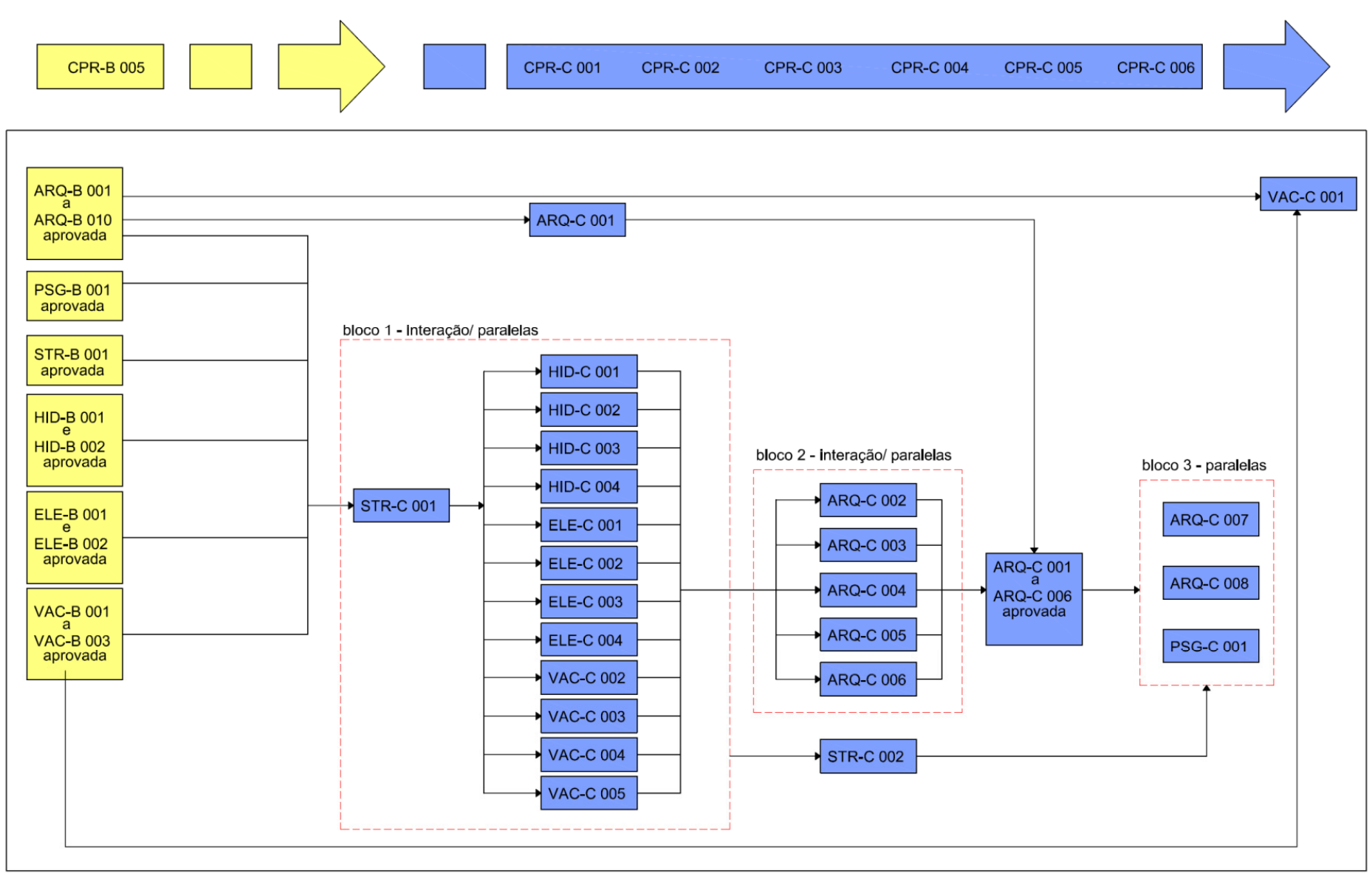

$\square$ ATIVIDADE FASE B

ATIVIDADE FASE C

Figura 50: modelagem do processo de projeto Fase C após Análise Crítica 


\section{Análise crítica para a Fase D}

Conforme visto no item 2.2 do capítulo 2, na fase D o projeto de detalhamento deve refletir, contemplar e caracterizar as obras/ serviços que serão executados e possibilitar a avaliação dos custos, métodos construtivos e prazos de execução. Uma análise crítica das tabelas de dependência de informações, da tabela AEAP da DSM e da rede de precedências desenvolvidos para esta fase permite observar que esta fase apresenta-se coerente em seu fluxo de informações, não havendo para esta a sugestão de alterações. 


\section{CONSIDERAÇÕES FINAIS}

Neste capítulo serão discutidas as considerações finais acerca da pesquisa apresentada, e o atendimento aos objetivos propostos. Serão apresentadas também sugestões para futuras pesquisas sobre o tema planejamento do processo de projeto e aplicação da ferramenta DSM para este fim.

\subsection{Conclusões}

No capítulo introdutório desta pesquisa discutiu-se a necessidade de reestruturação do mercado imobiliário a fim de atender as novas demandas que estão surgindo e corrigir as falhas que este apresenta como questões referentes a prazos, custos e qualidade das obras.

O projeto já foi amplamente discutido como de fundamental importância para o empreendimento, porém ainda se mostra uma etapa deficiente em todo o processo, com excesso de atrasos e faltas de informações, muitas vezes por não se considerar o caráter multidisciplinar do projeto e a interatividade de seu processo de elaboração.

Identificou-se então a necessidade de uma modelagem do processo de projeto que represente a interatividade, reorganize as atividades e reduza os ciclos de retrabalho, de forma a permitir uma visão de todo o conjunto do processo viabilizando um bom planejamento das atividades. A presente pesquisa propôs a utilização da ferramenta DSM para elaboração deste planejamento.

O objetivo principal proposto nesta pesquisa foi analisar a aplicação da ferramenta DSM ao planejamento do processo de projeto de edificações utilizandose como base os Manuais de Escopo de Projetos e Serviços para a Indústria Imobiliária.

Para que o objetivo principal da pesquisa fosse atingido foi necessária a análise das questões abaixo listadas como objetivos parciais que foram verificados durante o desenvolvimento desta:

- Análise da aplicação da ferramenta DSM ao planejamento do processo de projeto; 
- Análise crítica dos Manuais

No item 3.3 do capítulo 3 da presente dissertação, conclusões da aplicação da DSM, foi desenvolvida a análise da aplicação da ferramenta ao planejamento do processo de projeto, limitando-se a desenvolver um comparativo entre o diagrama de rede gerado pelas diretrizes fornecidas pelos Manuais de Escopo de Projetos e Serviços para a Indústria Imobiliária e o diagrama de rede gerado pela otimização fornecida pela aplicação da ferramenta DSM.

A elaboração do diagrama de rede conforme a rede de precedências dos Manuais de Escopo de Projetos e Serviços e a aplicação da ferramenta DSM com elaboração de novo diagrama de rede permitiu uma análise comparativa entre os dois diagramas, que demonstrou a capacidade de simplificação e otimização que a ferramenta se propõe a fornecer. A ferramenta também representa os blocos de interações e paralelismos entre as atividades, demonstrando a capacidade de representação das interações e reorganização das atividades, auxiliando na visão de todo o conjunto do processo. Este comparativo consolidou a análise e demonstrou a viabilidade da utilização da ferramenta para o desenvolvimento de modelos de processos de projetos para a indústria imobiliária.

A aplicação da ferramenta DSM e da metodologia ADePT exige do planejador o cumprimento de quatro etapas:

- Definição do processo;

- Otimização do processo;

- Programação do projeto;

- Monitoramento do projeto

A presente pesquisa aplicou a metodologia nas duas primeiras etapas e, para tal, necessitou desenvolver uma série de atividades, a saber:

- Listagem das atividades;

- Estrutura das atividades;

- Tabulação das atividades;

- Diagrama de rede;

- Estruturação da DSM; 
- Análise da DSM.

Para que todas as atividades fossem cumpridas verificou-se a necessidade da identificação das interações entre os agentes envolvidos, com estabelecimento de precedências para desenvolvimento de outras atividades e a organização das atividades de projeto com ênfase na troca de informações considerando a importância do conteúdo das entregas em detrimento ao simples cumprimento de etapas.

O cumprimento das duas primeiras etapas da metodologia ADePT forneceu material com informações que permitiram a observação de algumas incoerências e sugerir alterações no fluxo de atividades proposto pelos Manuais, análise apresentada no item 3.4 do capítulo 3 da presente dissertação, análise crítica dos manuais. Neste item foram apresentados os comentários referentes às diretrizes fornecidas pelos manuais, com críticas e sugestões de alterações em seu conteúdo, como proposta de melhoria à ferramenta-guia que estes se propõem a ser.

Por fim, a partir da confirmação da viabilidade de utilização da DSM como ferramenta para o desenvolvimento do planejamento do processo de projeto e com base nas alterações sugeridas para os manuais, foi proposto um novo modelo de processo de projeto.

\subsection{Sugestões para trabalhos futuros}

O desenvolvimento desta pesquisa propicia a sugestão de temas para trabalhos futuros, relativos ao planejamento do processo de projeto e a aplicação da DSM como ferramenta para tal:

- Aplicação do modelo de processo de projeto final em um projeto real como estudo de caso, com o objetivo de validar o processo e analisar possíveis alterações que possam ser sugeridas;

- Transferir todo o modelo de processo de projeto para um ambiente informatizado, criando uma ferramenta de gestão que permite uma análise crítica das entregas com base nas informações necessárias para conclusão destas, uma validação e um controle do processo. Com esta ferramenta poder-se-á controlar o real avanço do projeto. 


\section{REFERÊNCIAS BIBLIOGRÁFICAS}

ASSUMPÇÃO, J. F. P.; FUGAZZA, A. E. C. Coordenação de projetos de edifícios : um sistema para programação e controle do fluxo de atividades do processo de projetos. São Carlos, 2001.

Workshop Nacional Gestão do Processo de Projeto na Construção de Edifícios. São Carlos, 2001.

AUSTIN, S., BALDWIN, A., LI, B. \& WASKETT, P. Analytical Design Planning Technique (ADePT): A Dependency Structure Matrix Tool to Schedule the Building Design Process. Construction Management and Economics, vol 18, pp 173-182, 2000.

The Analytical Design Planning Technique (ADePT) Projects: Design Information Methodology and Tools for the Management of Detailed Building Design and Link IDAC100 ADePT Technology Transfer Project. Department of Civil \& Building Engineering Loughborough University, Mar. 2000.

BAÍA, J. L.; MELHADO, S. B. Processo de implantação de um sistema de gestão da qualidade em empresas de projeto. In: Simpósio Brasileiro de Gestão da Qualidade e Organização do Trabalho, 1, 1998, Recife. Anais... Recife: GEQUACIL/DPE/DEC/POLI/UPE, 1998.

BORDIN, L. Caracterização do processo e modelagem de rede deprecedências das atividades geradoras de informações no desenvolvimento deprojetos de edifícios residenciais multifamiliares. 2003. Dissertação (Mestrado) - Programa de Pós-Graduação em Engenharia Civil, UFRGS,Porto Alegre, 2003.

FABRICIO, M. M.; ORNSTEIN, S. W. Qualidade no Projeto de Edifícios. RIMA, 2010. 261p.

FABRICIO, M. M. Projeto Simultâneo na construção de edifícios. 2002. $329 f$. Tese (doutorado) - Escola Politécnica, Universidade de São Paulo, São Paulo, 2002.

FONTENELLE, E.C. Estudos de casos sobre a gestão do projeto em empresas de incorporação e construção. 2002. Dissertação (Mestrado) - Escola Politécnica, Universidade de São Paulo, 2002.

CLEMENTS, J. P.; GIDO, J. Gestão de Projetos. Thomson, 2007. 472p.

GARCIA MESEGUER, A. Controle e garantia da qualidade na construção. São Paulo, SINDUSCON-SP, 1991. 
GRILO, L. M. Gestão do processo de projeto no segmento de construção de edifícios por encomenda. 2002. 391 f. Dissertação (Pós-graduação) - Escola Politécnica, Universidade de São Paulo, São Paulo, 2002.

GRILO, L. M.; MELHADO, S. B. Alternativas para a melhoria na gestão do processo de projeto na indústria da construção de edifícios. In: III Workshop Brasileiro de Gestão do Processo de Projeto na Construção de Edifícios, 3, 2003, Belo Horizonte. Anais... Belo Horizonte, [s.n.], 2003. 8 p.

HOFFMEISTER, A. Sistematização do Processo de Planejamento de Projetos: Definição e Seqüenciamento das Atividades para o Desenvolvimento de Produtos Industriais. Dissertação (Mestrado) - Universidade Federal de Santa Catarina, Florianópolis, Santa Catarina, 2003.

KORTLER, S.; HELMS B.; BERKOVICH M.; LINDEMANN U.; SHEA K.; LEIMEISTER, J. M.; KRCMAR H. Using MDM-Methods in Order to Improve Managing of Iterations in Design Processes. In: 12th International DSM Conference, Cambridge: Matthias Kreimeyer David Wynn, Jul. 2010. Munich: Hanser, 2010.

MANZIONE, L. Estudo de métodos de planejamento do processo de projeto de edifícios. 2006. 250f. Dissertação (Mestrado) - Universidade de São Paulo, São Paulo, 2006.

MANZIONE, L.; MELHADO, S. B. Porque os projetos atrasam? Uma análise crítica da eficácia do planejamento de projetos adotada no mercado imobiliário de São Paulo. III Encontro de Tecnologia de Informação e Comunicação na Construção Civil. Porto Alegre, Jul. 2007.

MELHADO, S. B. Qualidade do projeto na construção de edifícios: aplicação ao caso das empresas de incorporação e construção. 1994. Tese (Doutorado) Escola Politécnica, Universidade de São Paulo, São Paulo,1994.

MELHADO, S. B. et al. Coordenação de projetos de edificações. São Paulo: O Nome da Rosa, 2005. 115p.

PERALTA, A.C. Um modelo do processo de projeto de edificações, baseado na engenharia simultânea, em empresas construtoras incorporadoras de pequeno porte. 2002. 143f. Dissertação (mestrado) - Universidade Federal de Santa Catarina, Florianópolis, 2002.

PICCHI, F. A. - Sistemas da qualidade: uso em empresas de construção de edifícios. 1993. Dissertação (doutorado) - Universidade de São Paulo, Escola Politécnica, São Paulo, 1993.

PROCESS IMPROVEMENT (2006). Disponível em www.adeptmanagement.com. 
PROJECT MANAGEMENT INSTITUTE. Um Guia do Conjunto de Conhecimentos em Gerenciamento de Projetos - Guia PMBOK. Project Management Institute, Inc: Pennsylvania, EUA, 2009. 4ª. Ed. 388p.

ROMANO, F. V. Modelo de referência para o gerenciamento do processo de projeto integrado de edificações. 2003. 381f. Tese (doutorado) - Universidade Federal de Santa Catarina, Florianópolis,2003.

SILVA, M. V. M. F. P. As atividades de coordenação e a gestão do conhecimento nos projetos de edificações. 2004. 202 f. Dissertação (Mestrado) Universidade Federal de São Carlos, São Paulo, 2004.

SILVA, M. A.; SOUZA, R. Gestão do processo de projeto de edificações. São Paulo: O Nome da Rosa, 2003. 181p.

SOUZA. R. et al. Sistemas de gestão para empresas de incorporação imobiliária. São Paulo: O Nome da Rosa, 216p.

VERZUH, E. MBA Compacto, Gestão de Projetos. Editora Campus: Rio de Janeiro, 2000.

WASKETT, P.; NEWTON, A.; STEELE, J.; CAHILL, M.; BEAUMONT, J. (2010). Achieving Reliable Delivery of Design Information for Procurement and Construction. Disponível em www.adeptmanagement.com.

ASSOCIAÇÃO BRASILEIRA DE ARQUITETOS PAISAGISTAS; SINDICATO DAS EMPRESAS DE COMPRA, VENDA, LOCAÇÃO E ADMINISTRAÇÃO DE IMÓVEIS RESIDENCIAIS E COMERCIAIS DE SÃO PAULO; SINDICATO DA INDÚSTRIA DA CONSTRUÇÃO CIVIL DO ESTADO DE SÃO PAULO. Manual de escopo de projetos e serviços de paisagismo. São Paulo, 2005. 65p.

ASSOCIAÇÃO BRASILEIRA DE ENGENHARIA E CONSULTORIA ESTRUTURAL; SINDICATO DAS EMPRESAS DE COMPRA, VENDA, LOCAÇÃO E ADMINISTRAÇÃO DE IMÓVEIS RESIDENCIAIS E COMERCIAIS DE SÃO PAULO; SINDICATO DA INDÚSTRIA DA CONSTRUÇÃO CIVIL DO ESTADO DE SÃO PAULO. Manual de escopo de projetos e serviços de estrutura. São Paulo, 2005. $60 \mathrm{p}$.

ASSOCIAÇÃO BRASILEIRA DE ENGENHARIA DE SISTEMAS PREDIAIS; SINDICATO DAS EMPRESAS DE COMPRA, VENDA, LOCAÇÃO E ADMINISTRAÇÃO DE IMÓVEIS RESIDENCIAIS E COMERCIAIS DE SÃO PAULO; SINDICATO DA INDÚSTRIA DA CONSTRUÇÃO CIVIL DO ESTADO DE SÃO PAULO. Manual de escopo de projetos e serviços de elétrica e hidráulica. São Paulo, 2005. 58p.

ASSOCIAÇÃO BRASILEIRA DE ENGENHARIA DE SISTEMAS PREDIAIS; SINDICATO DAS EMPRESAS DE COMPRA, VENDA, LOCAÇÃO E ADMINISTRAÇÃO DE IMÓVEIS RESIDENCIAIS E COMERCIAIS DE SÃO PAULO; SINDICATO DA INDÚSTRIA DA CONSTRUÇÃO CIVIL DO ESTADO DE SÃO 
PAULO. Manual de escopo de projetos e serviços de automação e segurança. São Paulo, 2005. 57p.

ASSOCIAÇÃO BRASILEIRA DOS GESTORES E COORDENADORES DE PROJETO; SINDICATO DAS EMPRESAS DE COMPRA, VENDA, LOCAÇÃO E ADMINISTRAÇÃO DE IMÓVEIS RESIDENCIAIS E COMERCIAIS DE SÃO PAULO; SINDICATO DA INDÚSTRIA DA CONSTRUÇÃO CIVIL DO ESTADO DE SÃO PAULO. Manual de escopo de serviços de coordenação de projetos. São Paulo, 2005. 105p.

ASSOCIAÇÃO BRASILEIRA DE REFRIGERAÇÃO, AR CONDICIONADO, VENTILAÇÃO, AR CONDICIONADO; SINDICATO DAS EMPRESAS DE COMPRA, VENDA, LOCAÇÃO E ADMINISTRAÇÃO DE IMÓVEIS RESIDENCIAIS E COMERCIAIS DE SÃO PAULO; SINDICATO DA INDÚSTRIA DA CONSTRUÇÃO CIVIL DO ESTADO DE SÃO PAULO. Manual de escopo de projetos e serviços de ar condicionado e ventilação. São Paulo, 2005. 58p.

SINDICATO DAS EMPRESAS DE COMPRA, VENDA, LOCAÇÃO E ADMINISTRAÇÃO DE IMÓVEIS RESIDENCIAIS E COMERCIAIS DE SÃO PAULO; SINDICATO DA INDÚSTRIA DA CONSTRUÇÃO CIVIL DO ESTADO DE SÃO PAULO. Manual de escopo de projetos e serviços de arquitetura. São Paulo, 2005. 132p.

User Guide. Disponível em www.dsmweb.org.

MELHADO, S. B. et al. Escopo de serviços para coordenação de projetos, In: WORKSHOP Brasileiro de gestão do processo de projeto na construção de edifícios. 2004

\section{Bibliografia Consultada}

AUSTIN, S. Barriers and Opportunities - The ADePT Experience in UK Construction. In: 2nd Design Structure Matrix Workshop, Cambridge, MA: A. Yassine, S. Eppinger and D. Whitney, Set. 2000. Cambridge, MA: Massachusetts Institute of Technology, 2000.

CHEN J. J.; LI S. Matrix-Based Change Management: a Case Study in a Construction Project. In: 12th International DSM Conference, Cambridge: Matthias Kreimeyer David Wynn, Jul. 2010. Munich: Hanser, 2010.

EPPINGER S. Integrating the Product, Process, and Organization Views of Complex System Development. In: 11th International Design Structure Matrix Conference, Greenville, SC: M. Kreimeyer, J. Maier, G. Fadel and U. Lindemann. Munich: Hanser, 2009.

NEDERVEEN, S.; BEHESHTI, R.; RIDDER, H. Supplier-Driven Integrated Design. Revista Architectural Engineering and Design Management, v. 6, p. 241-253, 2006. Edição especial. 
NEWTON, A. Defining the Benefits of Deploying ADePT. In: 8th International Design Structure Matrix Conference, Seattle: [s.n.]. Seattle: The Boeing Company, 2006.

NEWTON A.; STEELE J.; WASKETT P. Engineering Project Planning and Control Software to Enable the 'Adept' Technique. In: 10th International DSM Conference, Stockholm: M. Kreimeyer, U. Lindemann and M. Danilovic, Nov. 2008. Munich: Hanser, 2008.

NEWTON A.; STEELE J.; AUSTIN, S.; WASKETT P. Benefits Derived from Use of DSM as Part of the ADePT Approach to Managing Engineering Projects.

In: 9th International DSM Conference, Munich: U. Lindemann, M. Danilovic, F. Deubzer, M. Maurer and M. Kreimeyer, Out. 2007. Aachen: Shaker, 2007.

PEKTAS, S. T. The Complementary Use of the Parameter-Based Design Structure Matrix and the IFC Process Models for Integration in the Construction Industry In: 12th International DSM Conference, Cambridge: Matthias Kreimeyer David Wynn, Jul. 2010. Munich: Hanser, 2010.

POWELL, C. Design Management for Architects. Revista Architectural Engineering and Design Management, v. 3, n. 2, p. 143-144(2), 2007.

SEBASTIAN, R. Evaluating a Proposed Approach for Managing Collaborative Design in the Conceptual Design Phase. Revista Architectural Engineering and Design Management, v. 2, n. 3, p. 216-224(9), 2006.

SENTHILKUMAR, V.; VARGHESE, K. Structured Methodology to Formulate Drawing Dependency Structure Matrix for Construction Design. Revista Architectural Engineering and Design Management, v.5, n. 4, p. 225-248, 2009.

Drawing DSM Implementation in Construction Design - Discussions on Applicability. In: 11th International Design Structure Matrix Conference, Greenville, SC: M. Kreimeyer, J. Maier, G. Fadel and U. Lindemann. Munich: Hanser, 2009.

SOUTO, R. G. Gestão do Processo de Planejamento da Produção em Empresas Construtoras de Edifícios: estudos de caso. 2006. Dissertação (mestrado) Universidade de São Paulo, Escola Politécnica, 2006.

TZORTZOPOULOS, P.; COOPER, R. Design Management from a Contractor's Perspective: The Need for Clarity. Revista Architectural Engineering and Design Management, v. 3, n.1, p. 17-28(12), 2007.

WASKETT P.; NEWTON A.; STEELE J.; HAMMOND J. Practical Ways of Dealing with Progress in a DSM Tool. In: 12th International DSM Conference, Cambridge: Matthias Kreimeyer David Wynn, Jul. 2010. Munich: Hanser, 2010. 


\section{APÊNDICE A - Listagem das atividades}

Neste apêndice serão apresentadas as listagem das atividades fases B, C e D para uma melhor compreensão do desenvolvimento do trabalho.

\section{Fase B}

\section{Arquitetura}

\begin{tabular}{|c|l|}
\hline ARQ-B 001 & $\begin{array}{l}\text { Consolidação da quantificação do potencial construtivo das áreas e } \\
\text { número total de Unidades }\end{array}$ \\
\hline ARQ-B 002 & Solução preliminar de Implantação \\
\hline ARQ-B 003 & Solução preliminar Pavimentos / Unidades \\
\hline ARQ-B 004 & Solução preliminar dos Elementos de Cobertura \\
\hline ARQ-B 005 & Solução preliminar dos Cortes \\
\hline ARQ-B 006 & Solução preliminar das Fachadas \\
\hline ARQ-B 007 & $\begin{array}{l}\text { Solução preliminar dos Sistemas, Métodos Construtivos e Materiais } \\
\text { de Acabamento }\end{array}$ \\
\hline ARQ-B 008 & Consolidação nos documentos arquitetônicos gerados nesta fase \\
\hline ARQ-B 009 & Documentação Gráfica do Projeto Legal Municipal (Principal) \\
\hline ARQ-B 010 & Memoriais Descritivos exigidos pela Legislação Municipal (Principal) \\
\hline
\end{tabular}

\section{Estrutura}

STR-B 001 Definição sumária de solução construtiva

\section{Hidráulica}

HID-B 001

Definição de ambientes e espaços técnicos

HID-B 002 Consulta às concessionárias de serviços públicos

\section{Elétrica}

ELE-B 001 Definição de ambientes e espaços técnicos

ELE-B 002 Consulta às concessionárias de serviços públicos

\section{Ar Condicionado e Ventilação}

\begin{tabular}{|c|l|}
\hline VAC-B 001 & Cálculos de carga térmica e de vazões de ar \\
\hline VAC-B 002 & $\begin{array}{l}\text { Definição de compartimentos e espaços técnicos, acesso de } \\
\text { equipamentos, estimativas de pesos, consumos de energia e água }\end{array}$ \\
\hline VAC-B 003 & $\begin{array}{l}\text { Dimensionamento de dutos e tubulações principais para identificação } \\
\text { preliminar de interferências }\end{array}$ \\
\hline
\end{tabular}

\section{Paisagismo}

PSG-B 001

Solução preliminar de Implantação do paisagismo no

empreendimento 


\section{Coordenação de Projetos}

\begin{tabular}{|c|c|}
\hline B001 & $\begin{array}{l}\text { Identificação e planejamento das etapas de desenvolvimento dos } \\
\text { projetos }\end{array}$ \\
\hline B002 & Coordenação do fluxo de informações entre os agentes envolvidos \\
\hline B003 & Identificação e análise crítica das interfaces técnicas dos projetos \\
\hline B004 & $\begin{array}{l}\text { Organização, realização e registro de reuniões de coordenação de } \\
\text { projetos }\end{array}$ \\
\hline B005 & $\begin{array}{l}\text { Validação do produto e liberação para início das etapas } \\
\text { subseqüentes dos projetos }\end{array}$ \\
\hline B006 & $\begin{array}{l}\text { Análise crítica e validação de memoriais e desenhos de venda, } \\
\text { estande de vendas, maquetes e unidade modelo }\end{array}$ \\
\hline B007 & $\begin{array}{l}\text { Controle do processo quanto ao tempo e demais recursos, incluindo } \\
\text { as accoos corretivas necessárias }\end{array}$ \\
\hline
\end{tabular}

\section{Fase C}

\section{Arquitetura}

\begin{tabular}{|c|l|}
\hline ARQ-C 001 & $\begin{array}{l}\text { Solução consolidada dos sistemas, métodos construtivos e } \\
\text { materiais de acabamento }\end{array}$ \\
\hline ARQ-C 002 & Solução consolidada de Implantação \\
\hline ARQ-C 003 & $\begin{array}{l}\text { Solução consolidada de todos os ambientes, de todos os } \\
\text { pavimentos / unidades }\end{array}$ \\
\hline ARQ-C 004 & Solução consolidada dos elementos de cobertura \\
\hline ARQ-C 005 & Solução consolidada de todos os Cortes \\
\hline ARQ-C 006 & Solução consolidada de todas as Fachadas \\
\hline ARQ-C 007 & $\begin{array}{l}\text { Atendimento de eventuais comunicações e Correções na } \\
\text { Documentação Legal para o Órgão Técnico Público Municipal } \\
\text { Principal }\end{array}$ \\
\hline ARQ-C 008 & $\begin{array}{l}\text { Compatibilização formal dos documentos arquitetônicos gerados } \\
\text { nesta fase com as demais Especialidades e Consultorias }\end{array}$ \\
\hline
\end{tabular}

\section{Estrutura}

STR-C 001 Pré-formas de todos os pavimentos

STR-C 002 Formas de todos os pavimentos

\section{Hidráulica}

\begin{tabular}{|l|l|}
\hline HID-C 001 & Posicionamento de dispositivos e componentes hidráulicos \\
\hline HID-C 002 & Definição e layout de salas técnicas \\
\hline HID-C 003 & Traçado de tubulações hidráulicas principais \\
\hline
\end{tabular}




\section{Elétrica}

\begin{tabular}{|c|l|}
\hline ELE-C 001 & Posicionamento de pontos elétricos \\
\hline ELE-C 002 & Definição e lay-out de salas técnicas \\
\hline ELE-C 003 & Traçado de linhas elétricas principais \\
\hline ELE-C 004 & Definição e lay-out de shafts verticais \\
\hline
\end{tabular}

\section{Ar Condicionado e Ventilação}

\begin{tabular}{|c|l|}
\hline VAC-C 001 & Consolidação dos cálculos anteriores e seleção de equipamentos \\
\hline VAC-C 002 & Definição e layout de casas de máquinas \\
\hline VAC-C 003 & Definição e layout de forros \\
\hline VAC-C 004 & $\begin{array}{l}\text { Definição do dimensionamento e caminhamento da rede de dutos } \\
\text { e tubulações, em formato unifilar }\end{array}$ \\
\hline VAC-C 005 & Definição e layout de furações verticais e horizontais \\
\hline
\end{tabular}

\section{Paisagismo}

PSG-C 001 materiais de acabamento e projeto apresentado sob a forma de desenhos e memoriais

\section{Coordenação de Projetos}

\begin{tabular}{|c|l|}
\hline C001 & Coordenação do fluxo de informações entre os agentes envolvidos \\
\hline C002 & $\begin{array}{l}\text { Análise crítica e tomada de decisões sobre as necessidades de } \\
\text { integração das soluções }\end{array}$ \\
\hline C003 & Análise das soluções técnicas e do grau de solução global atingida \\
\hline C004 & $\begin{array}{l}\text { Organização, realização e registro de reuniões de coordenação de } \\
\text { projetos }\end{array}$ \\
\hline C005 & $\begin{array}{l}\text { Validação de produtos intermediários e liberação para início das } \\
\text { etapas subseqüentes do projeto }\end{array}$ \\
\hline C006 & $\begin{array}{l}\text { Controle do processo quanto ao tempo e demais recursos, } \\
\text { incluindo as ações corretivas necessárias }\end{array}$ \\
\hline
\end{tabular}


Fase D

\section{Arquitetura}

\begin{tabular}{|c|l|}
\hline ARQ-D 001 & $\begin{array}{l}\text { Solução definitiva de todos Métodos Construtivos e Materiais de } \\
\text { Acabamento }\end{array}$ \\
\hline ARQ-D 002 & Solução definitiva de Implantação \\
\hline ARQ-D 003 & $\begin{array}{l}\text { Solução definitiva de todos os Ambientes, em todos os Pavimentos / } \\
\text { Unidades }\end{array}$ \\
\hline ARQ-D 004 & Solução definitiva dos sistemas de Coberturas \\
\hline ARQ-D 005 & Solução definitiva de todos os Cortes \\
\hline ARQ-D 006 & Solução definitiva de todas as Fachadas \\
\hline ARQ-D 007 & Detalhamento de Áreas Molhadas \\
\hline ARQ-D 008 & Detalhamento de Escadas e Rampas \\
\hline ARQ-D 009 & Detalhamento Construtivo Específico (Horizontal e Vertical) \\
\hline ARQ-D 010 & $\begin{array}{l}\text { Detalhamento Básico de Esquadrias e Elementos de Ferro, Alumínio, } \\
\text { Madeira e Vidro }\end{array}$ \\
\hline ARQ-D 011 & $\begin{array}{l}\text { Detalhamento Básico de Muros de Divisa, Piscinas, e Elementos de } \\
\text { Água }\end{array}$ \\
\hline ARQ-D 012 & Tabelas de Acabamentos \\
\hline
\end{tabular}

\section{Estrutura}

\begin{tabular}{|l|l|}
\hline STR-D 001 & Locação de apoios, pilares e cargas \\
\hline STR-D 002 & Forma da Fundação \\
\hline STR-D 003 & Projeto estrutural dos elementos estruturais de fundação \\
\hline STR-D 004 & Projeto de contenções internas e externas à edificação \\
\hline STR-D 005 & Projeto estrutural com formas, armações, detalhes construtivos \\
\hline STR-D 006 & Plano de cimbramento \\
\hline STR-D 007 & $\begin{array}{l}\text { Quantitativos de área de forma, volume de concreto e consumo de } \\
\text { aço }\end{array}$ \\
\hline
\end{tabular}

\section{Hidráulica}

\begin{tabular}{|l|l|}
\hline HID-D 001 & Dimensionamentos hidráulicos gerais \\
\hline HID-D 002 & Projeto e detalhamento de instalações localizadas \\
\hline HID-D 003 & Plantas de distribuição hidráulica \\
\hline HID-D 004 & Preparação de esquemas verticais da instalação \\
\hline HID-D 005 & Detalhamento de ambientes e centrais técnicas \\
\hline HID-D 006 & Elaboração de memoriais e especificações \\
\hline
\end{tabular}




\section{Elétrica}

\begin{tabular}{|l|l|}
\hline ELE-D 001 & $\begin{array}{l}\text { Definição de circuitos, dimensionamentos elétricos gerais e projeto de } \\
\text { quadros e painéis elétricos }\end{array}$ \\
\hline ELE-D 002 & Plantas de distribuição elétrica \\
\hline ELE-D 003 & Preparação de esquemas verticais da instalação \\
\hline ELE-D 004 & Detalhamento de ambientes e centrais técnicas \\
\hline ELE-D 005 & Elaboração de memoriais e especificações \\
\hline
\end{tabular}

\section{Ar Condicionado e Ventilação}

\begin{tabular}{|l|l|}
\hline VAC-D 001 & Detalhamento das instalações em planta \\
\hline VAC-D 002 & Desenho de cortes localizados \\
\hline VAC-D 003 & Detalhamento de casas de máquinas \\
\hline VAC-D 004 & Elaboração de diagramas de alimentação elétrica \\
\hline VAC-D 005 & Elaboração de memoriais descritivos e especificações técnicas \\
\hline
\end{tabular}

\section{Paisagismo}

\begin{tabular}{|l|l|}
\hline PSG-D 001 & $\begin{array}{l}\text { Solução definitiva de implantação, detalhamento e materiais de } \\
\text { acabamento }\end{array}$ \\
\hline PSG-D 002 & Memoriais Descritivos de Especificações de materiais \\
\hline PSG-D 003 & Detalhamento de pisos e pavimentações \\
\hline PSG-D 004 & $\begin{array}{l}\text { Detalhamento de muros de divisa, piscinas, elementos de água e } \\
\text { elementos construidos }\end{array}$ \\
\hline PSG-D 005 & Solução definitiva do projeto de vegetação - plantio \\
\hline
\end{tabular}

\section{Coordenação de Projetos}

\begin{tabular}{|c|l|}
\hline D001 & Coordenação do fluxo de informações entre os agentes envolvidos \\
\hline D002 & $\begin{array}{l}\text { Análise crítica do detalhamento de projetos e ações corretivas } \\
\text { necessárias }\end{array}$ \\
\hline D003 & $\begin{array}{l}\text { Controle do processo quanto ao tempo e demais recursos, incluindo } \\
\text { as ações corretivas necessárias }\end{array}$ \\
\hline D004 & $\begin{array}{l}\text { Organização, realização e registro de reuniões de coordenação de } \\
\text { projetos }\end{array}$ \\
\hline D005 & $\begin{array}{l}\text { Validação de produtos finais e liberação para início das etapas } \\
\text { subseqüentes ao término dos projetos }\end{array}$ \\
\hline
\end{tabular}




\section{APÊNDICE B - Estrutura das atividades}

Neste apêndice serão apresentadas as estruturas das atividades fases A, B, C e D para uma melhor compreensão do desenvolvimento do trabalho. 


\section{Fase A}

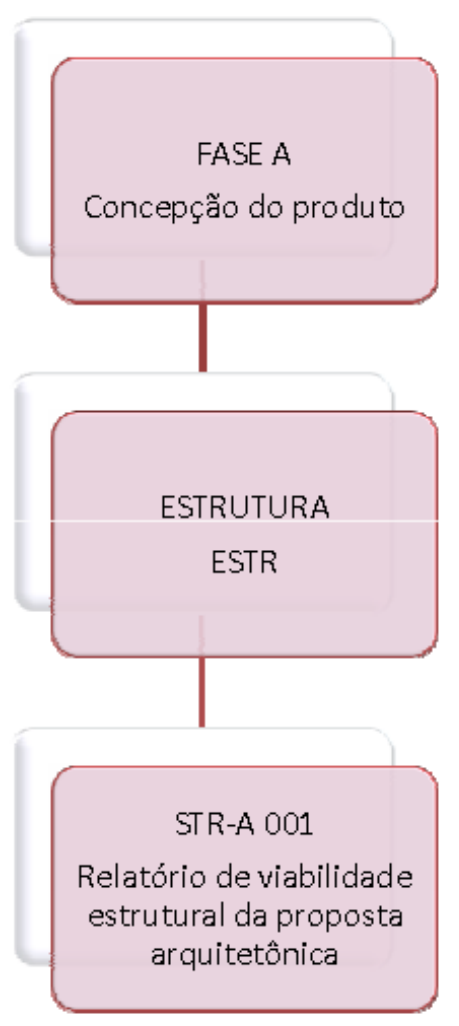

Figura 51: EAP para estrutura fase $A$ 


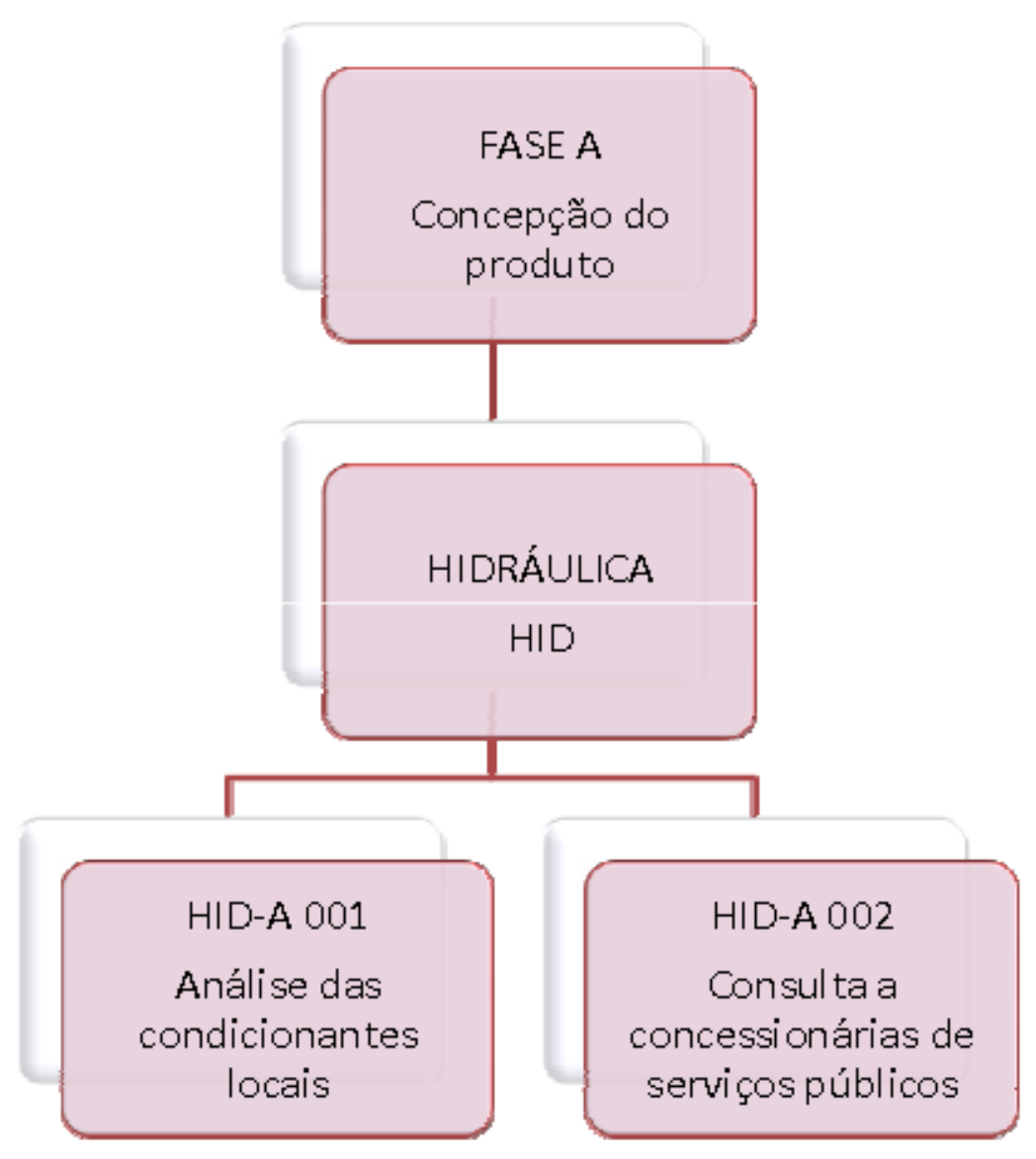

Figura 52: EAP hidráulica para fase A 


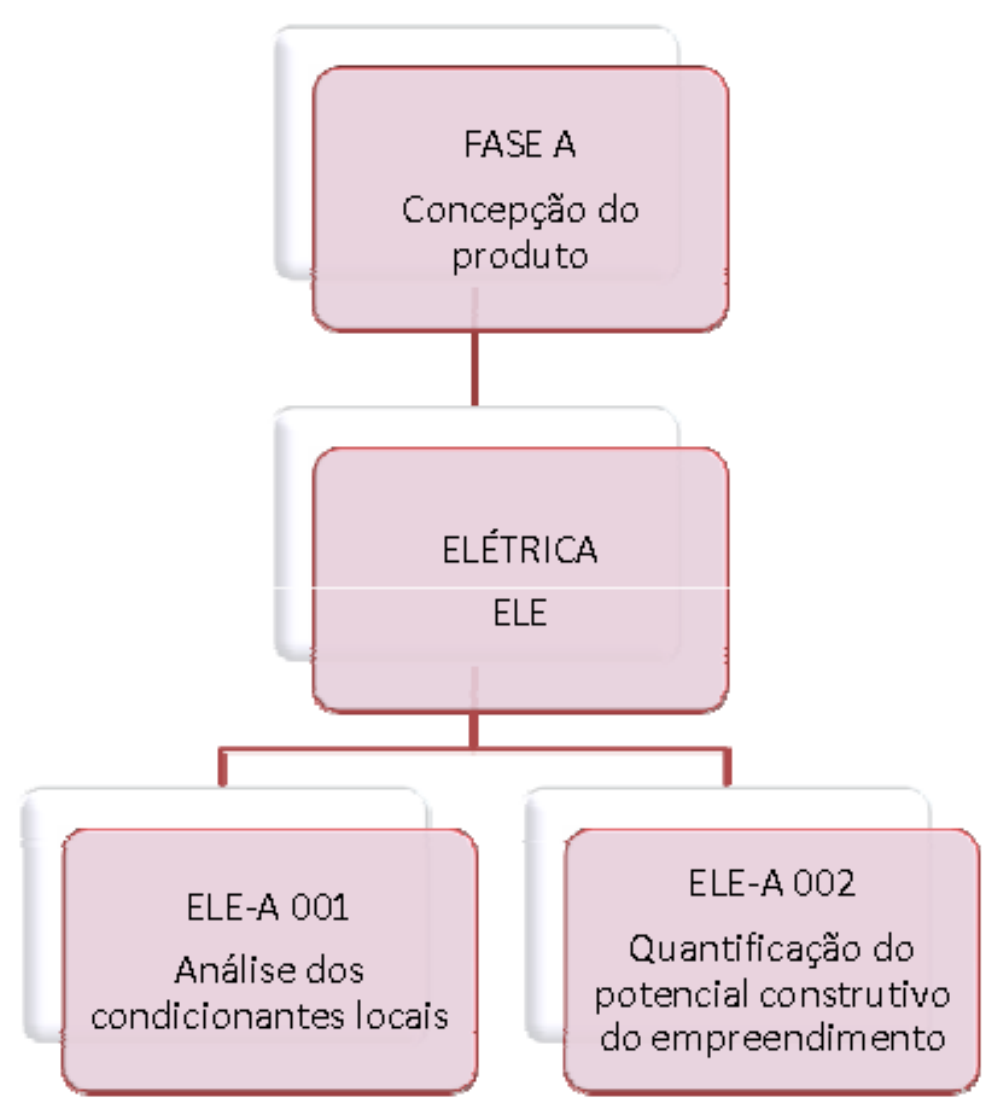

Figura 53: EAP para elétrica fase $A$ 


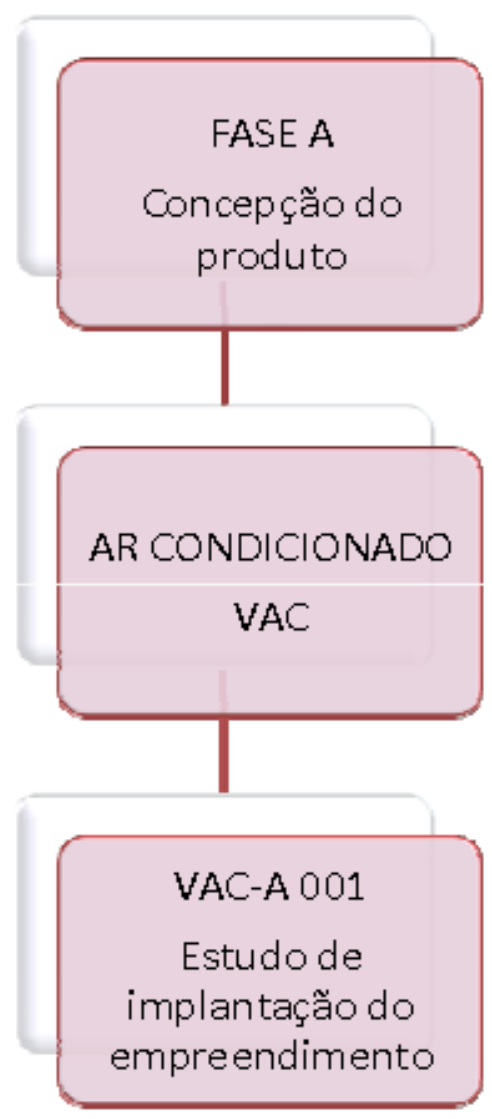

Figura 54: EAP para ar condicionado fase A 


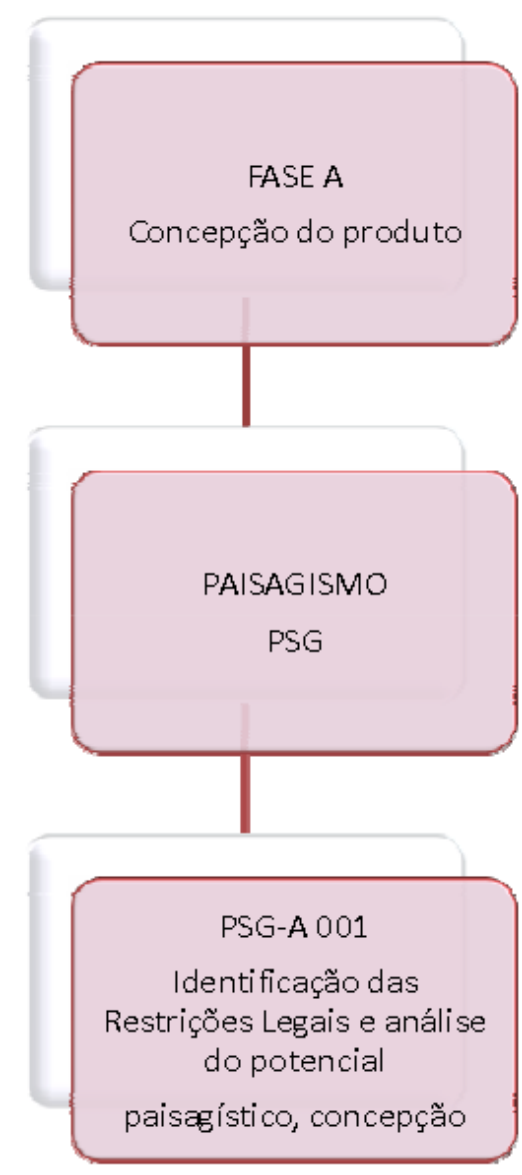

Figura 55: EAP para paisagismo fase $\mathrm{A}$ 


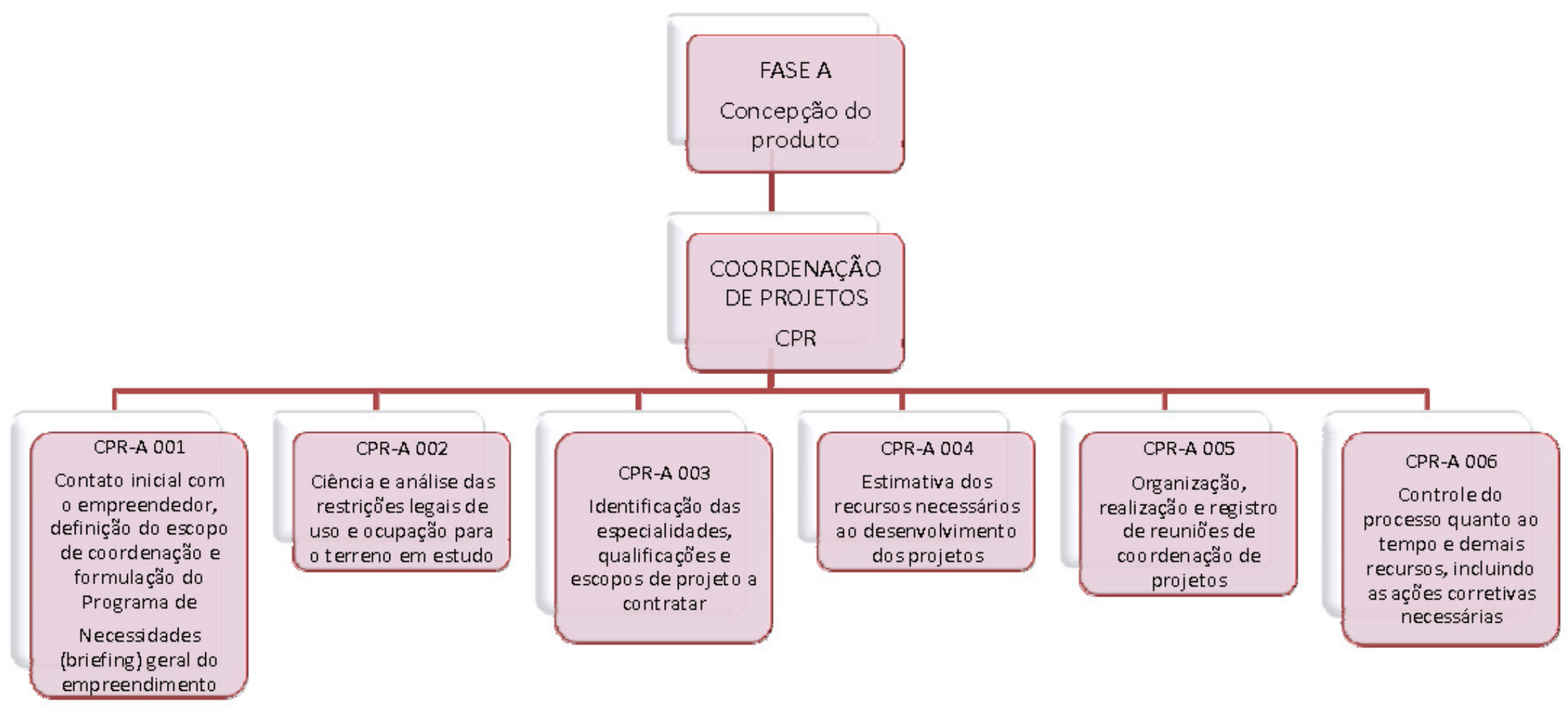

Figura 56: EAP para coordenação fase A 
Fase B

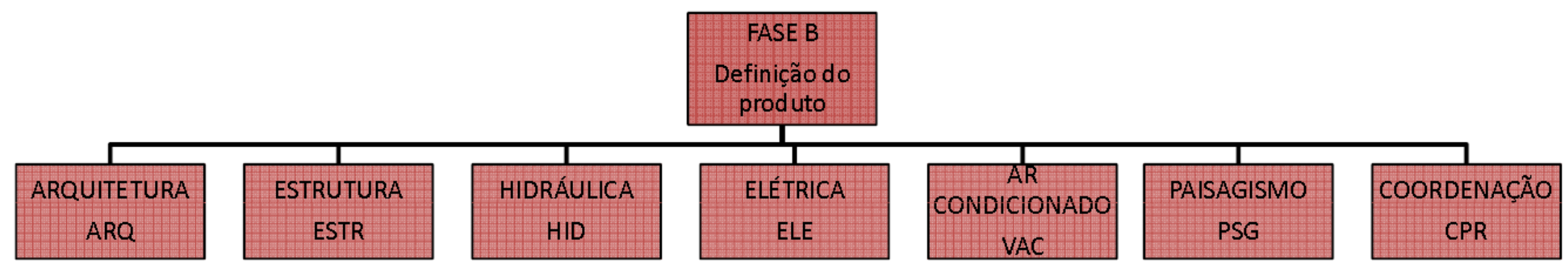

Figura 57: EAP conforme disciplinas para a fase B 


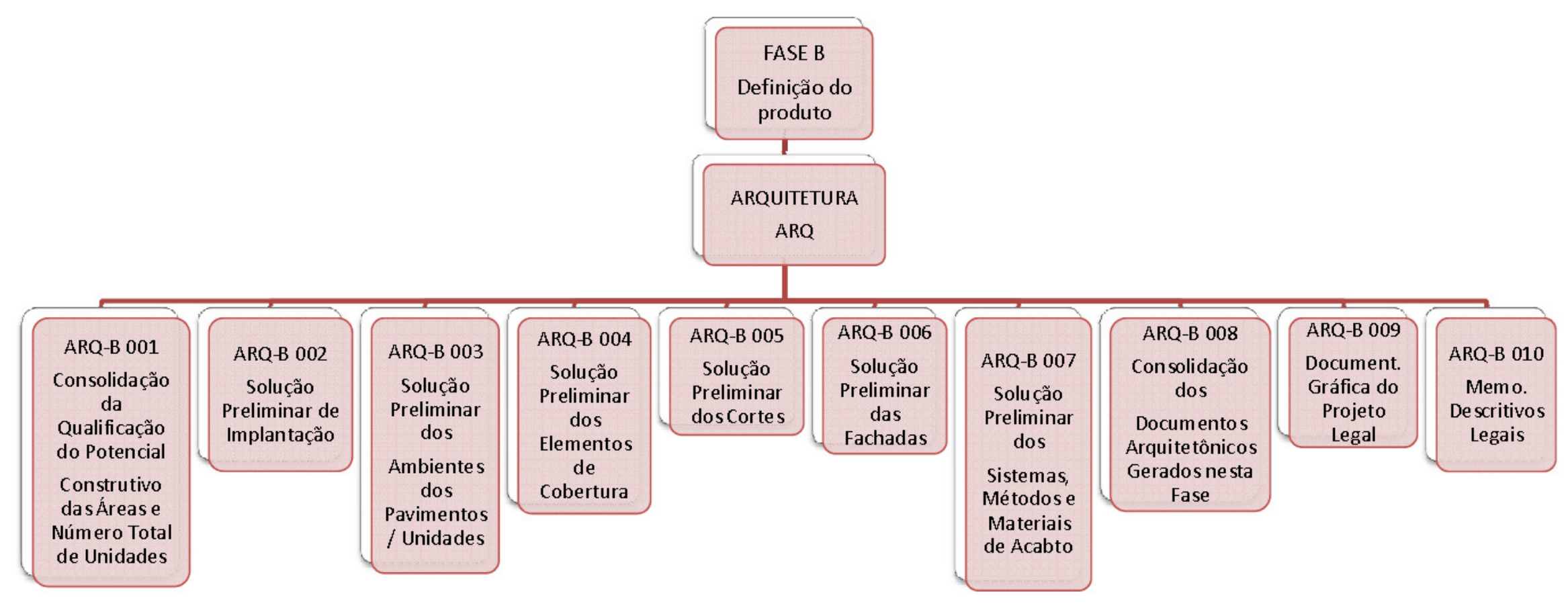

Figura 58: EAP para arquitetura fase $B$ 


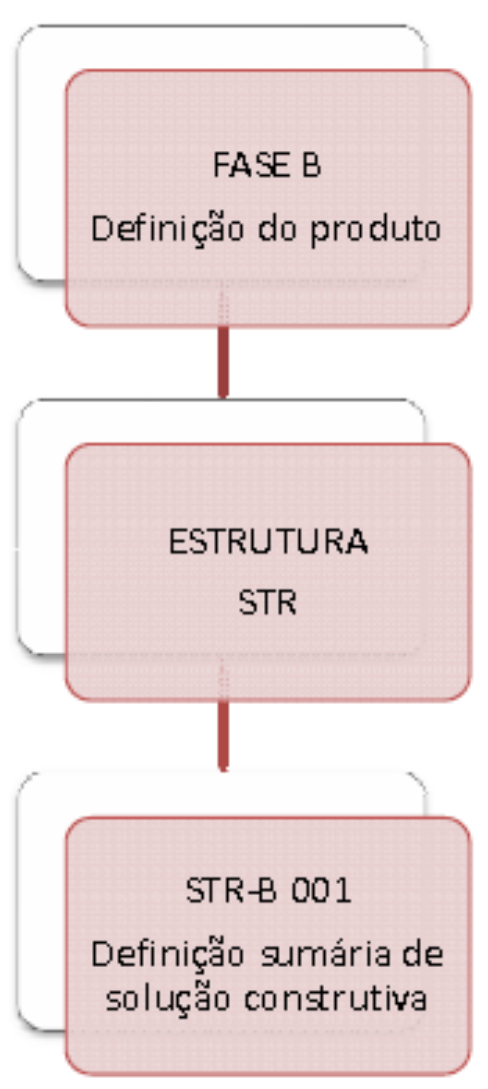

Figura 59: EAP para estrutura fase $B$ 


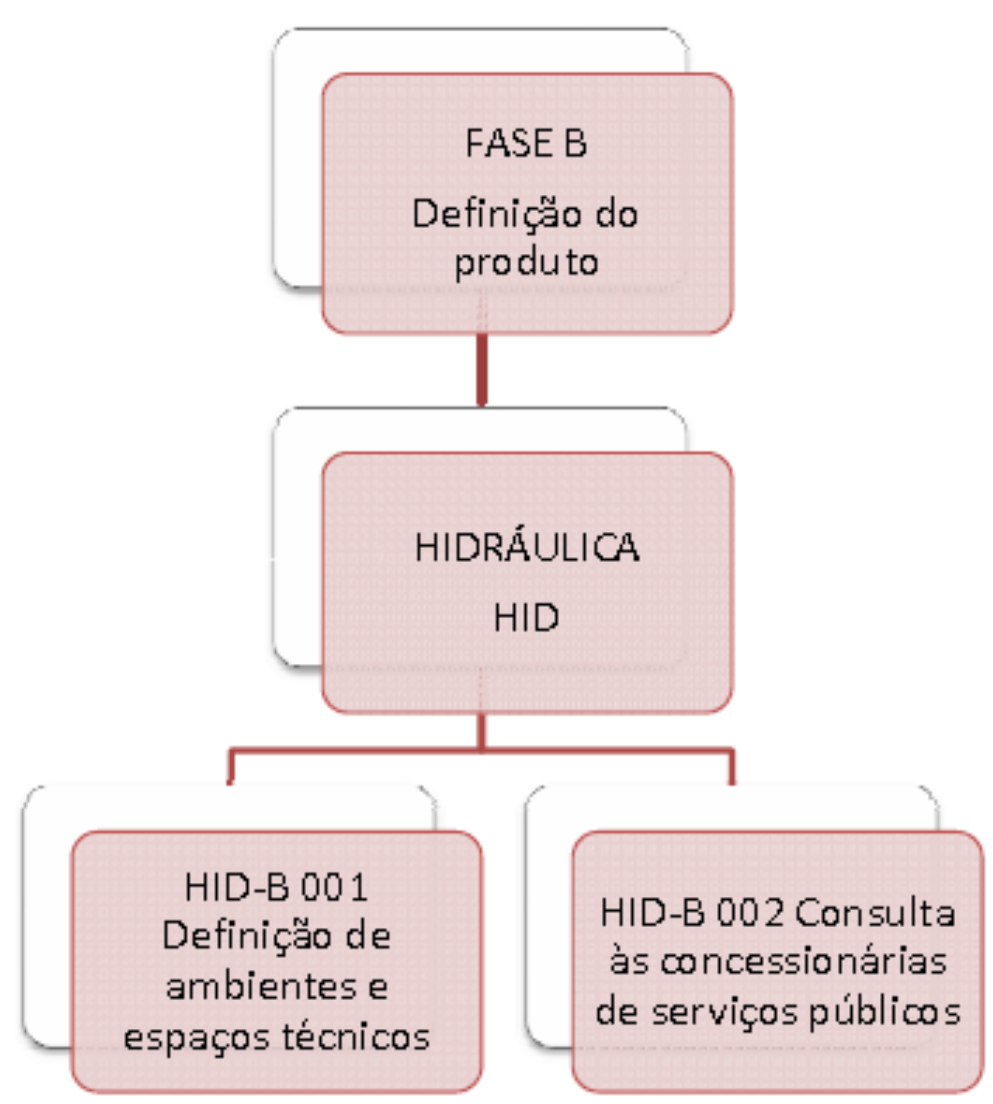

Figura 60: EAP para hidráulica fase B 


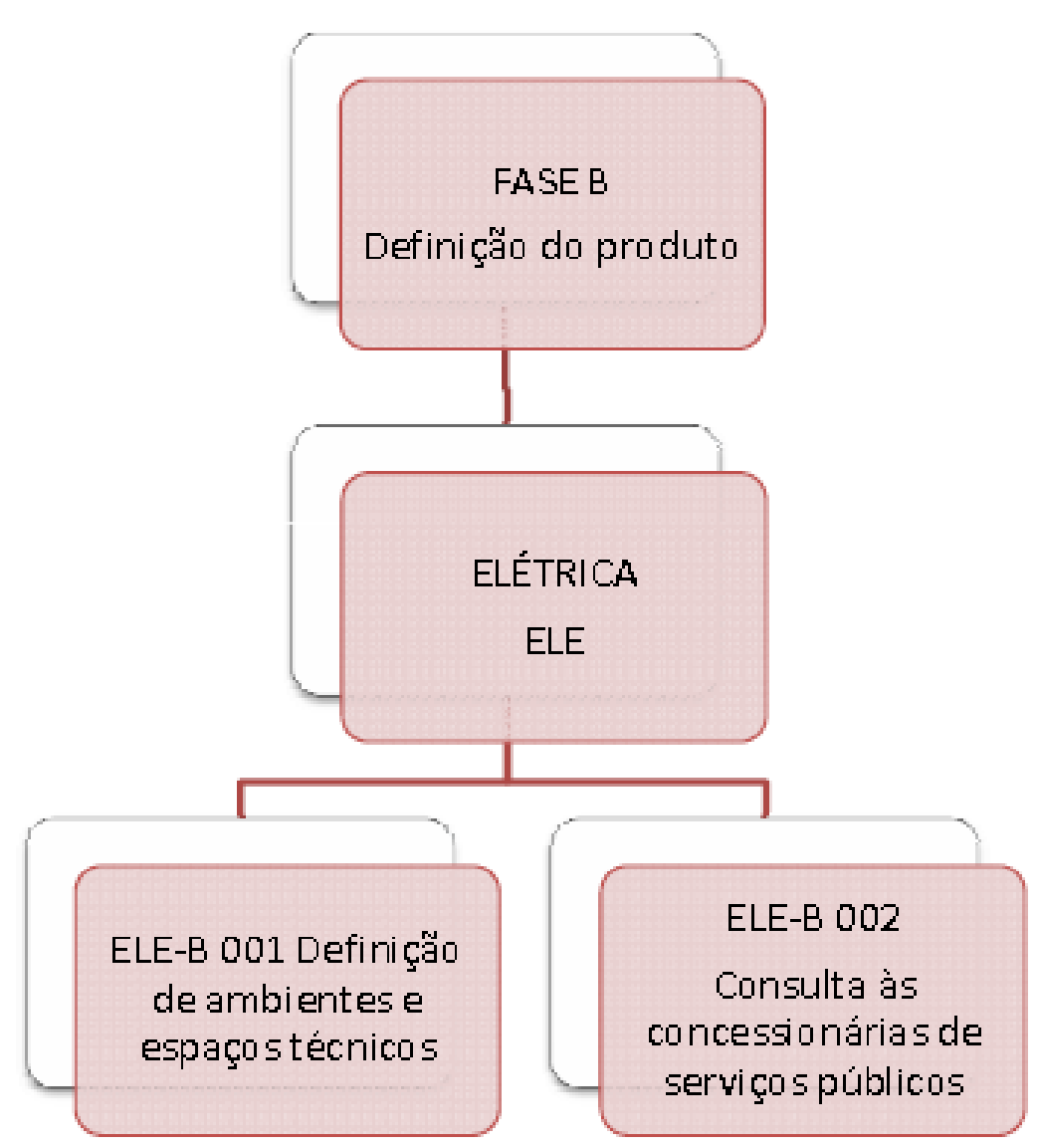

Figura 61: EAP para elétrica fase $B$ 


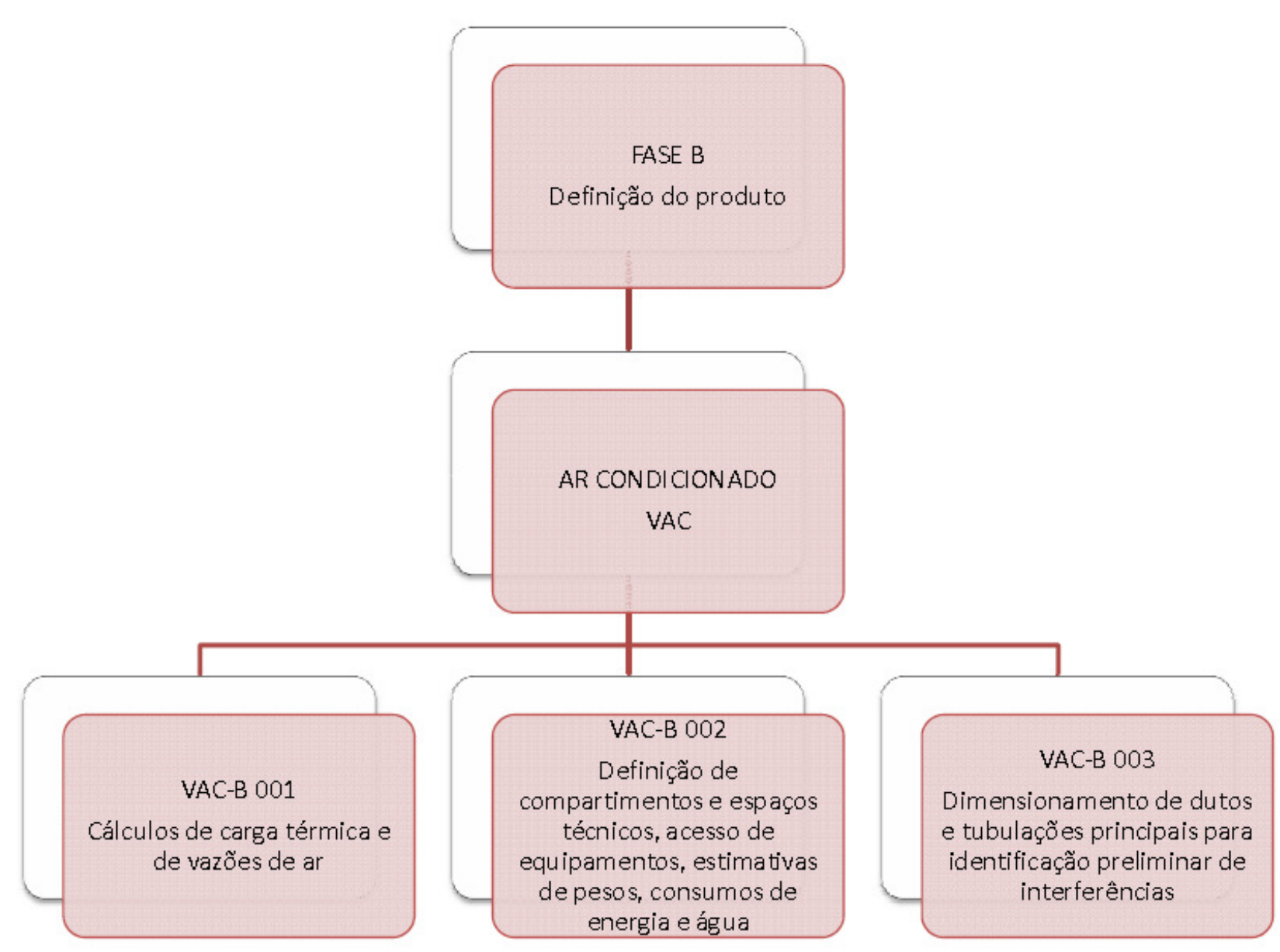

Figura 62: EAP para ar condicionado fase B 


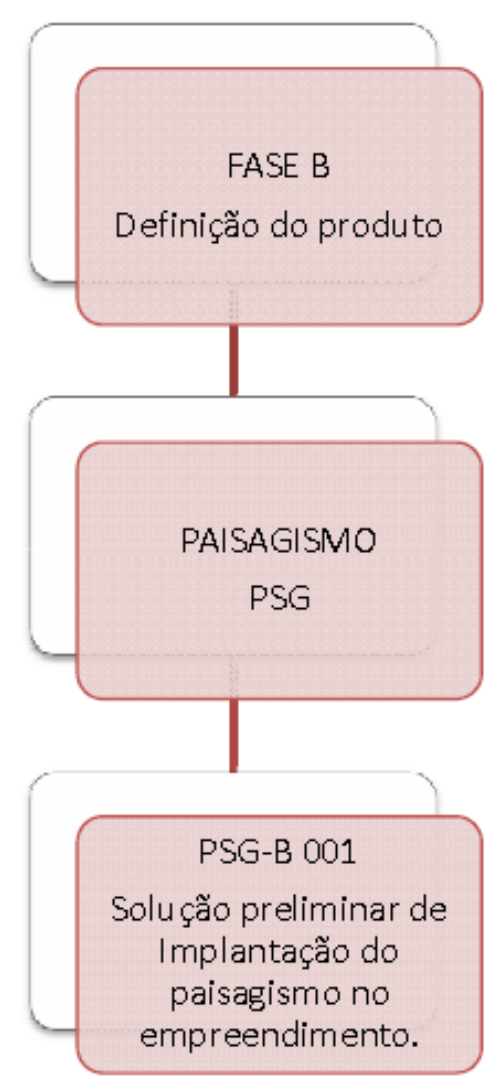

Figura 63: EAP para paisagismo fase B 


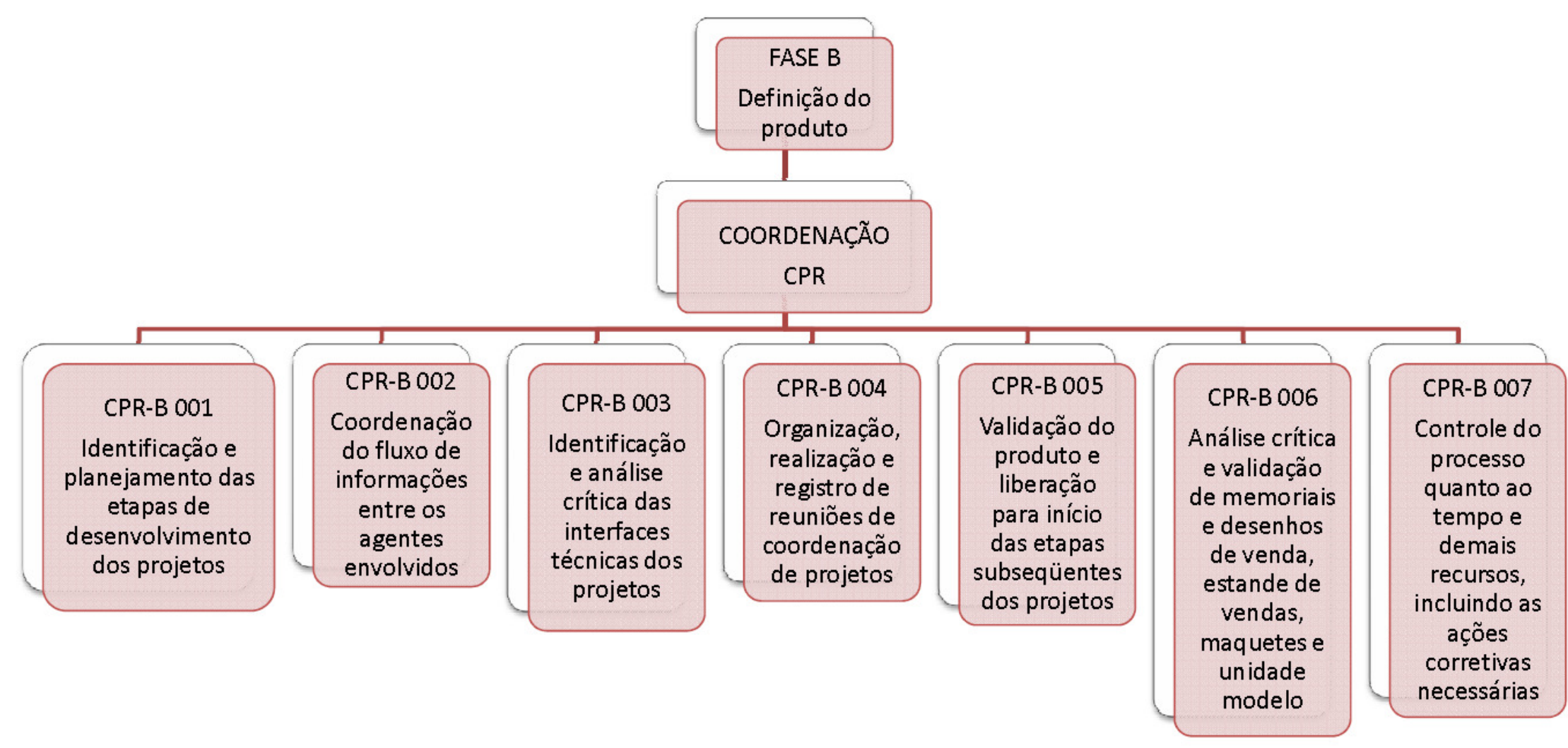

Figura 64: EAP para coordenação fase B 


\section{Fase C}

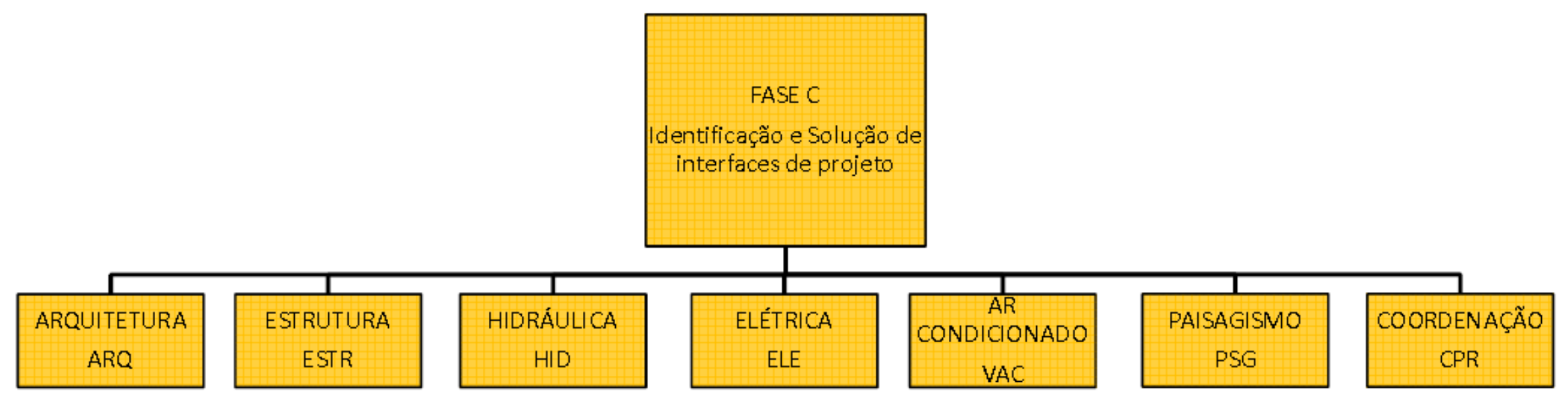

Figura 65: EAP conforme disciplinas para a fase $\mathrm{C}$ 


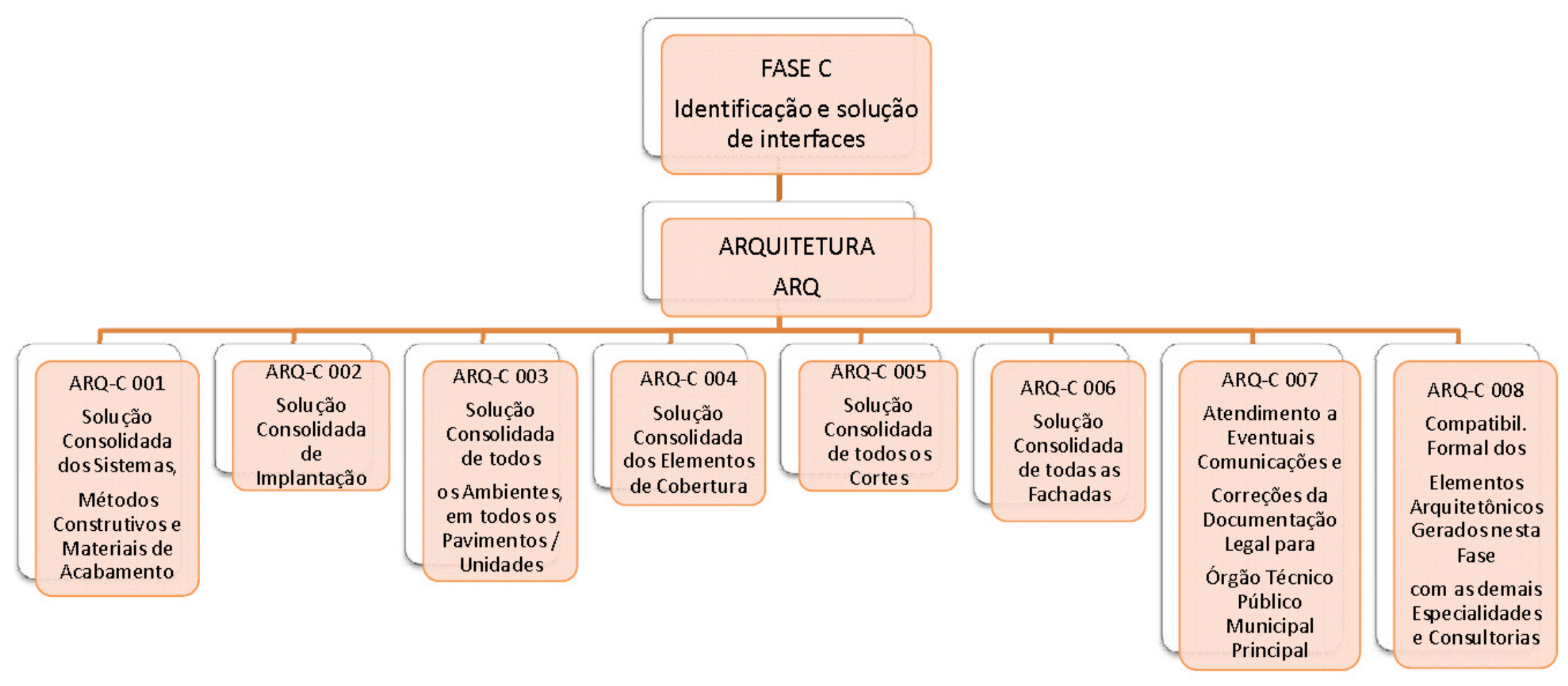

Figura 66: EAP para arquitetura fase $C$ 


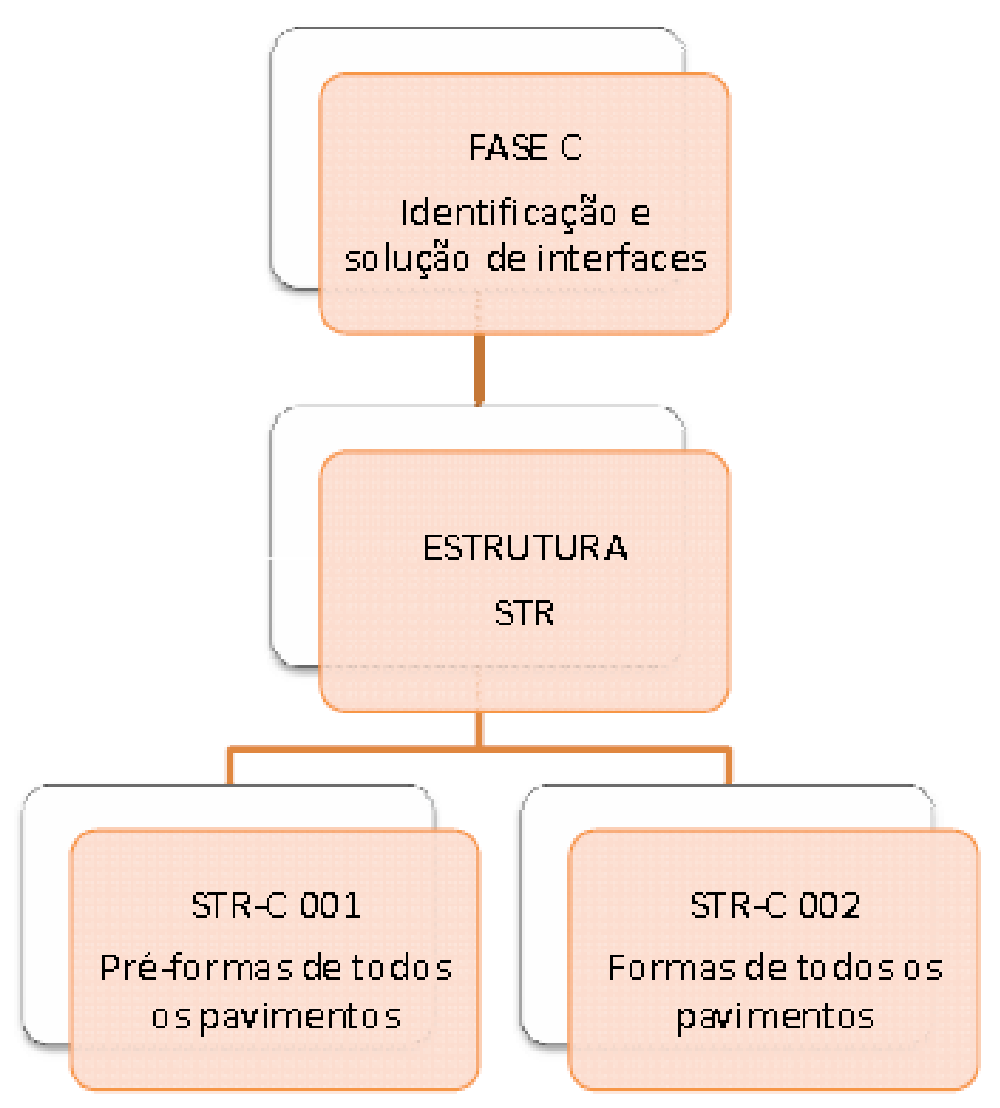

Figura 67: EAP para estrutura fase $C$ 


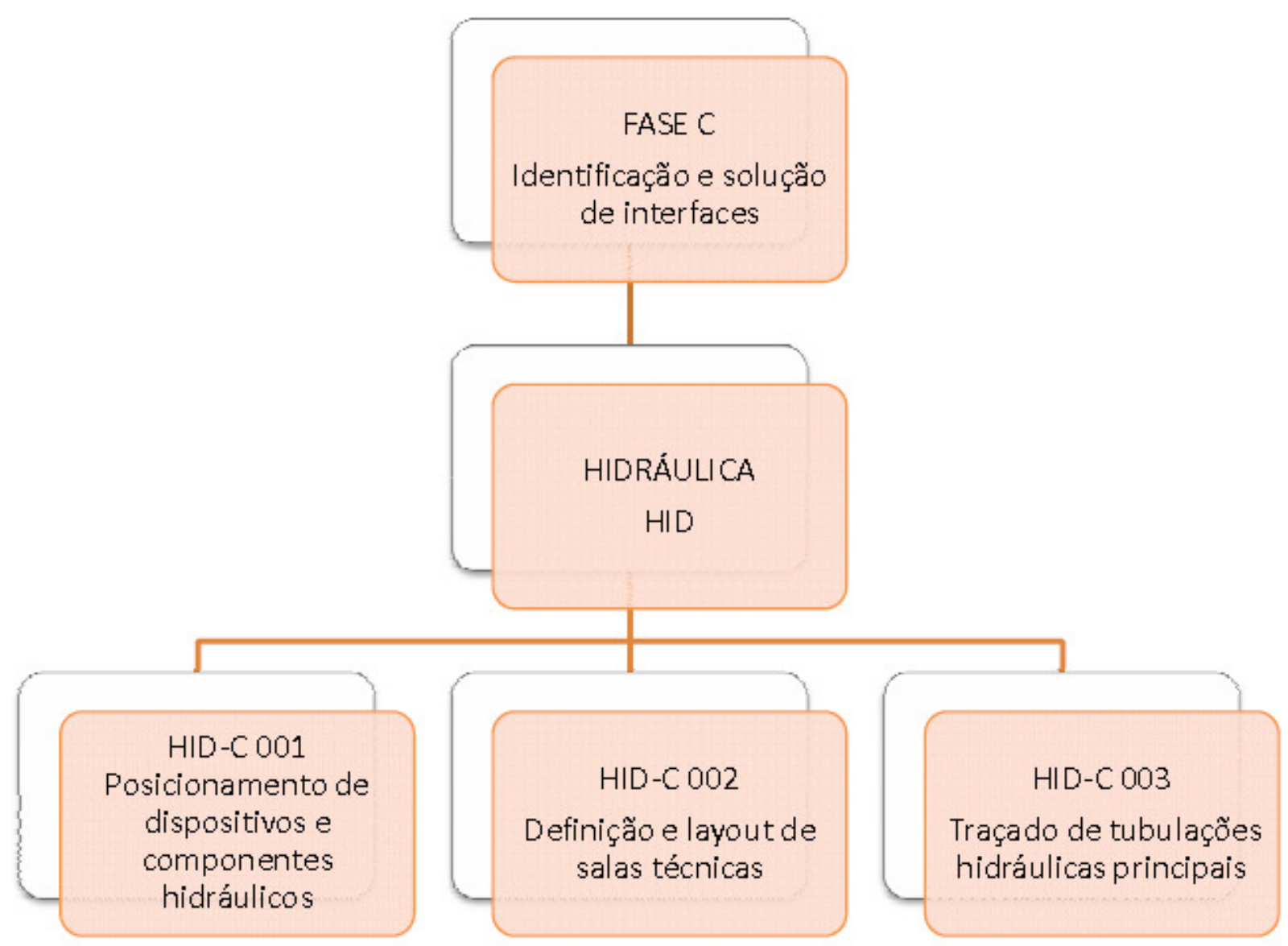

Figura 68: EAP para hidráulica fase $\mathrm{C}$ 


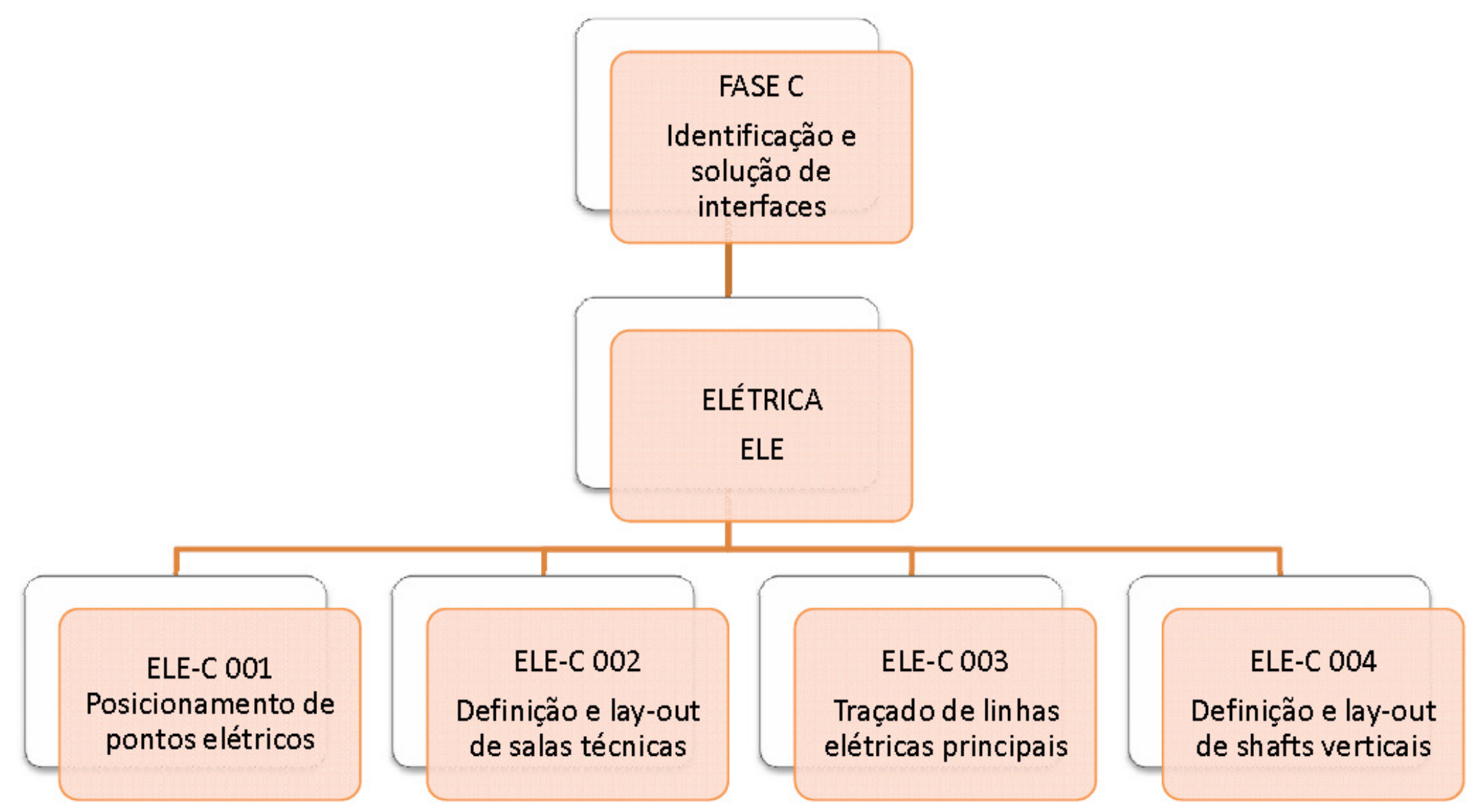

Figura 69: EAP para elétrica fase $C$ 


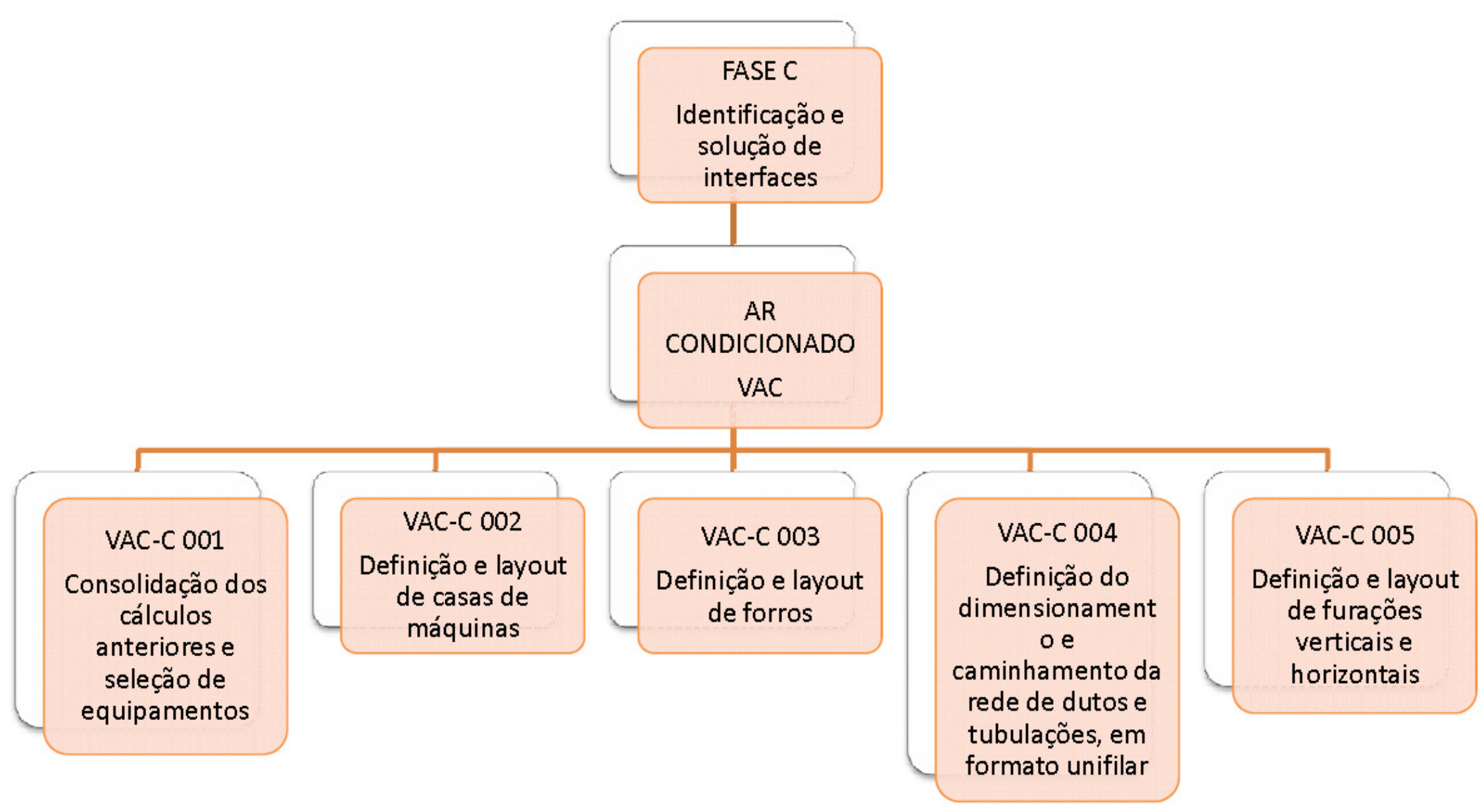

Figura 70: EAP para ar condicionado fase $\mathrm{C}$ 


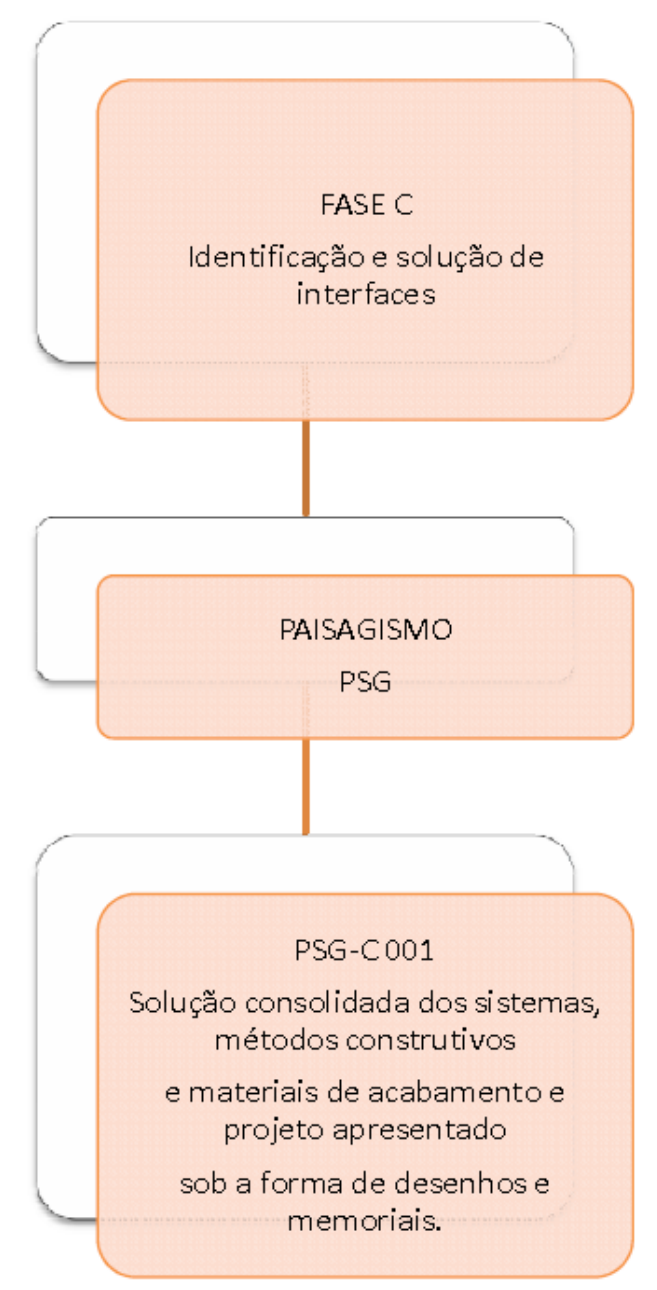

Figura 71: EAP para paisagismo fase $\mathrm{C}$ 


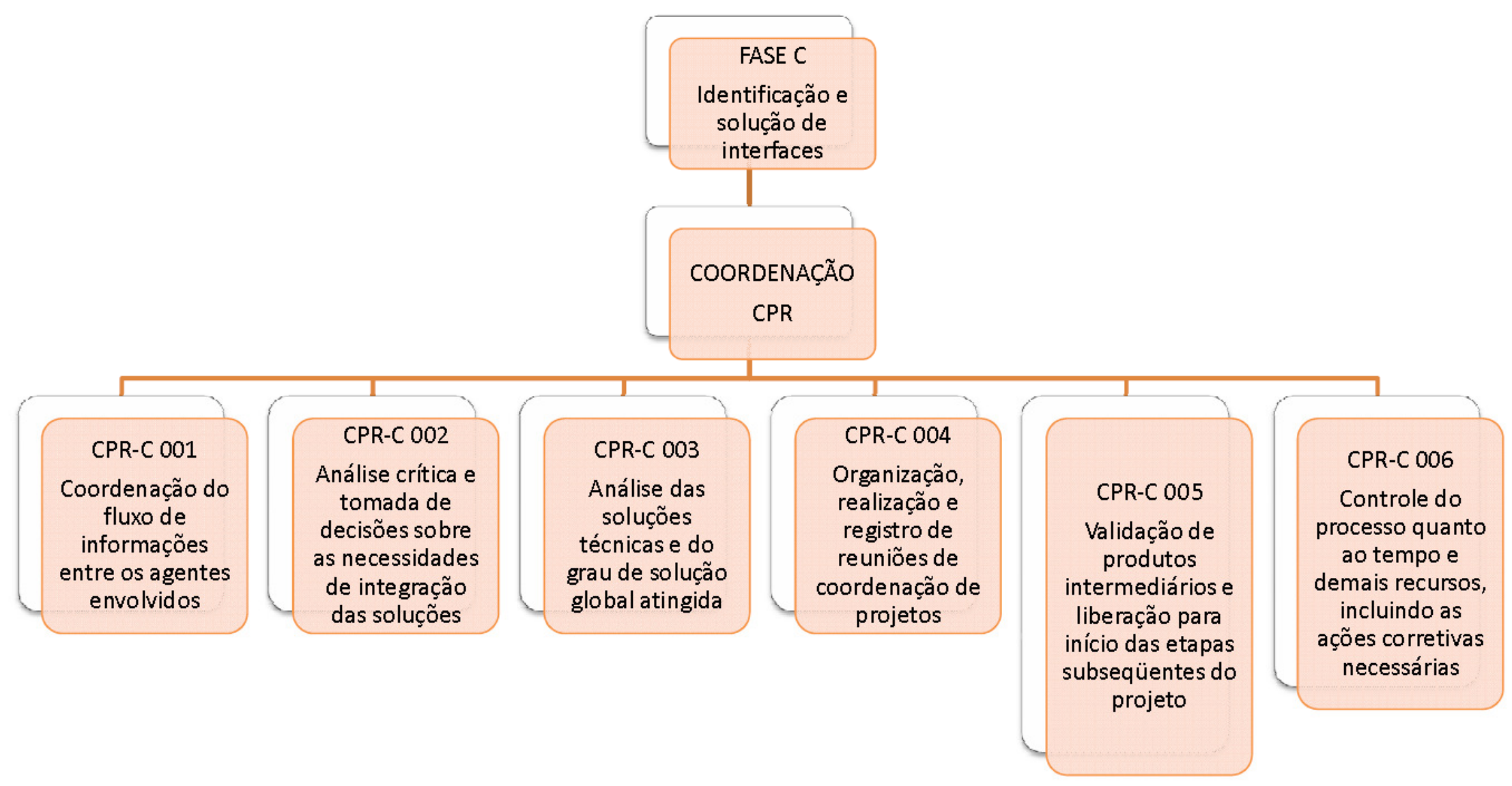

Figura 72: EAP para coordenação fase $C$ 


\section{Fase D}

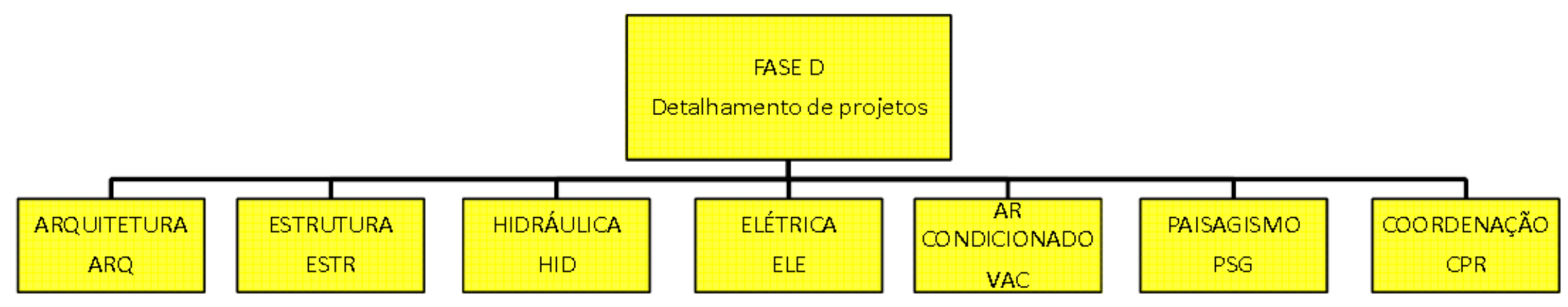

Figura 73: EAP conforme disciplinas para a fase $D$ 


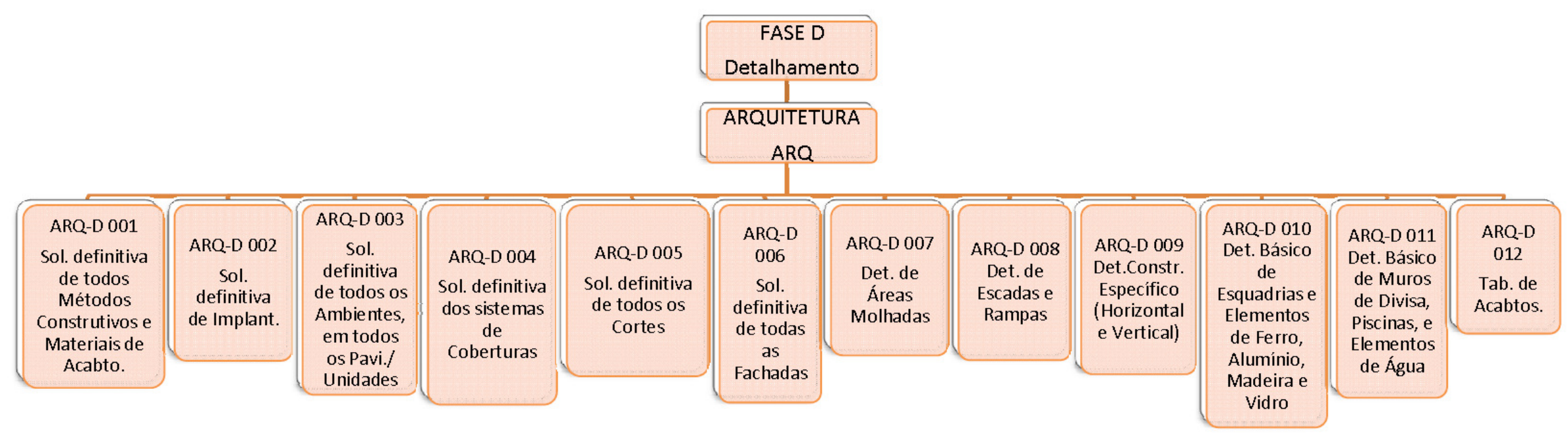

Figura 74: EAP para arquitetura fase $D$ 


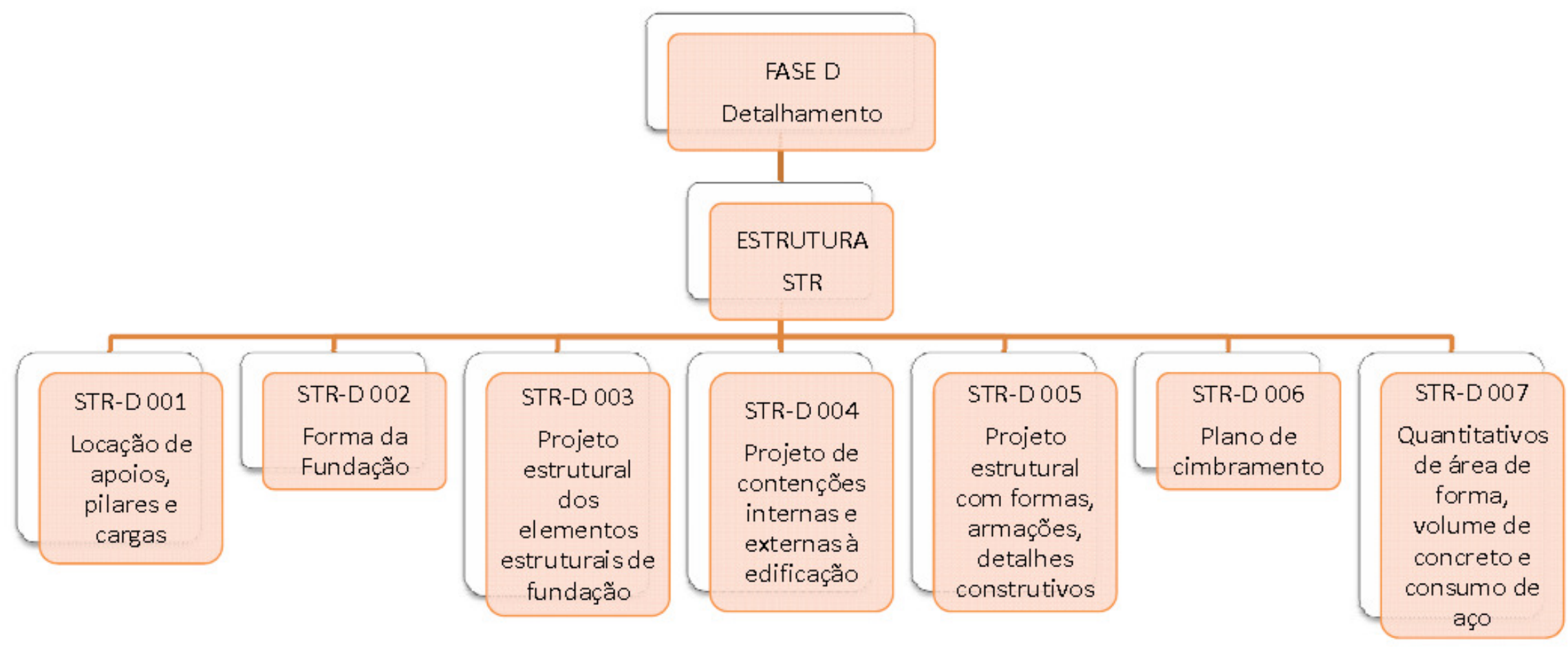

Figura 75: EAP para estrutura fase $D$ 


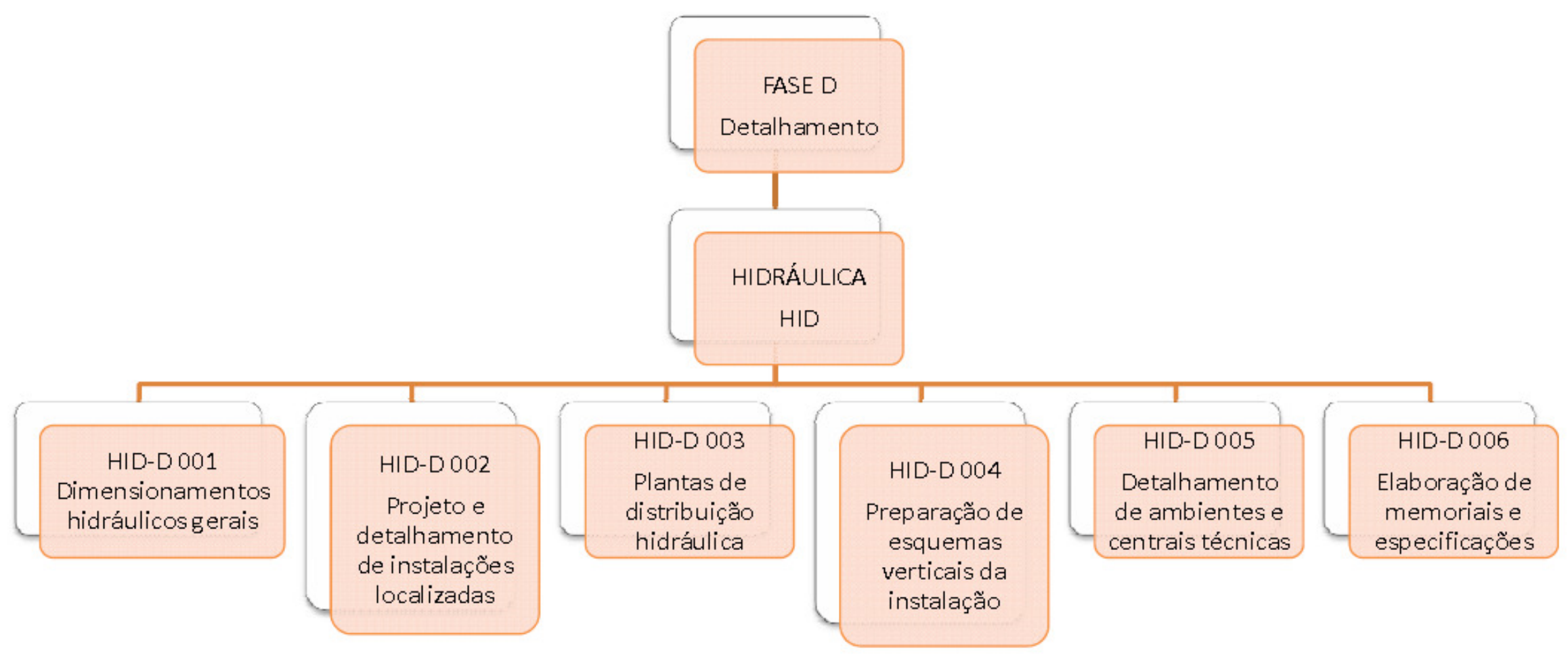

Figura 76: EAP para hidráulica fase $D$ 


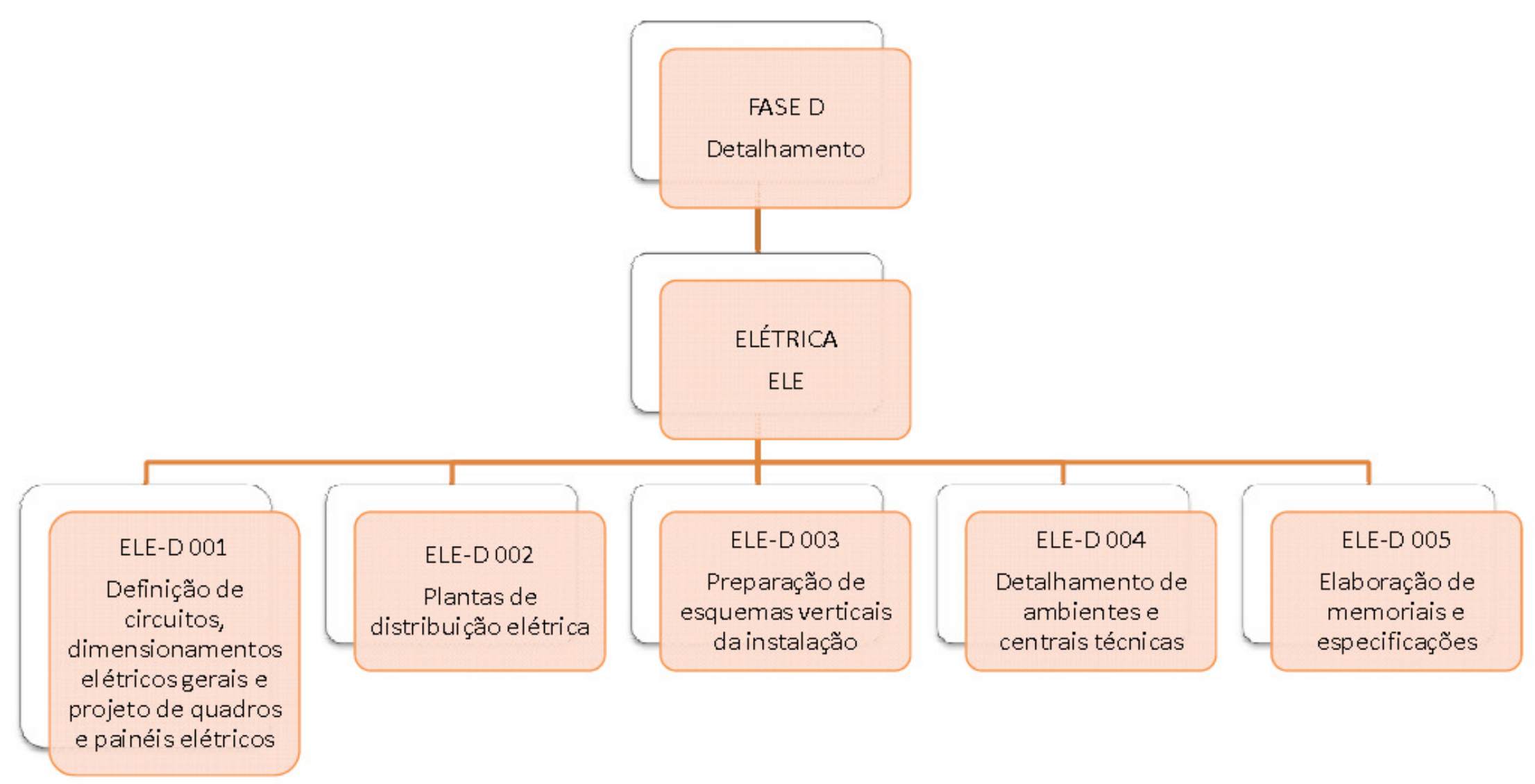

Figura 77: EAP para elétrica fase $D$ 


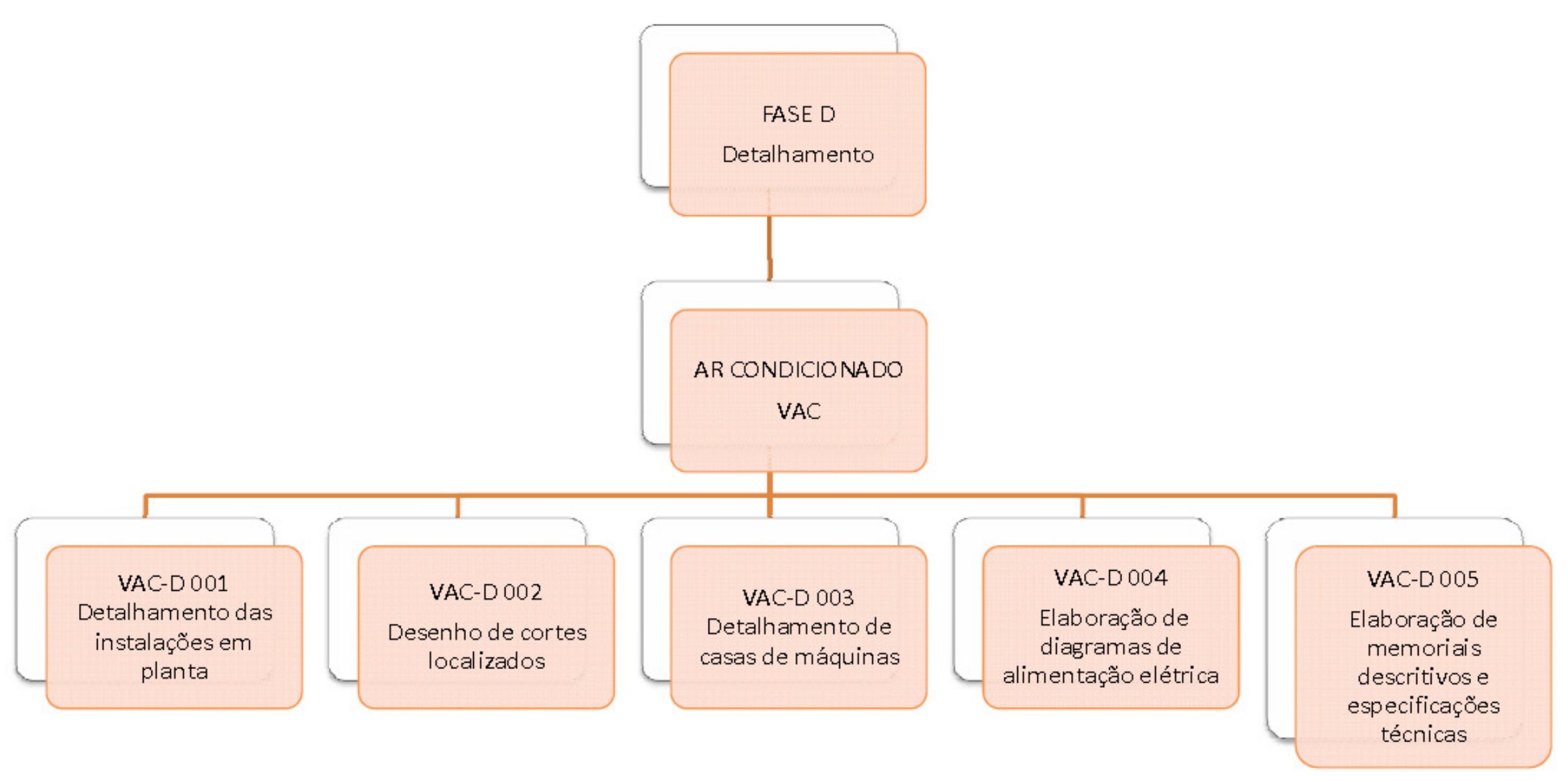

Figura 78: EAP para ar condicionado fase D 


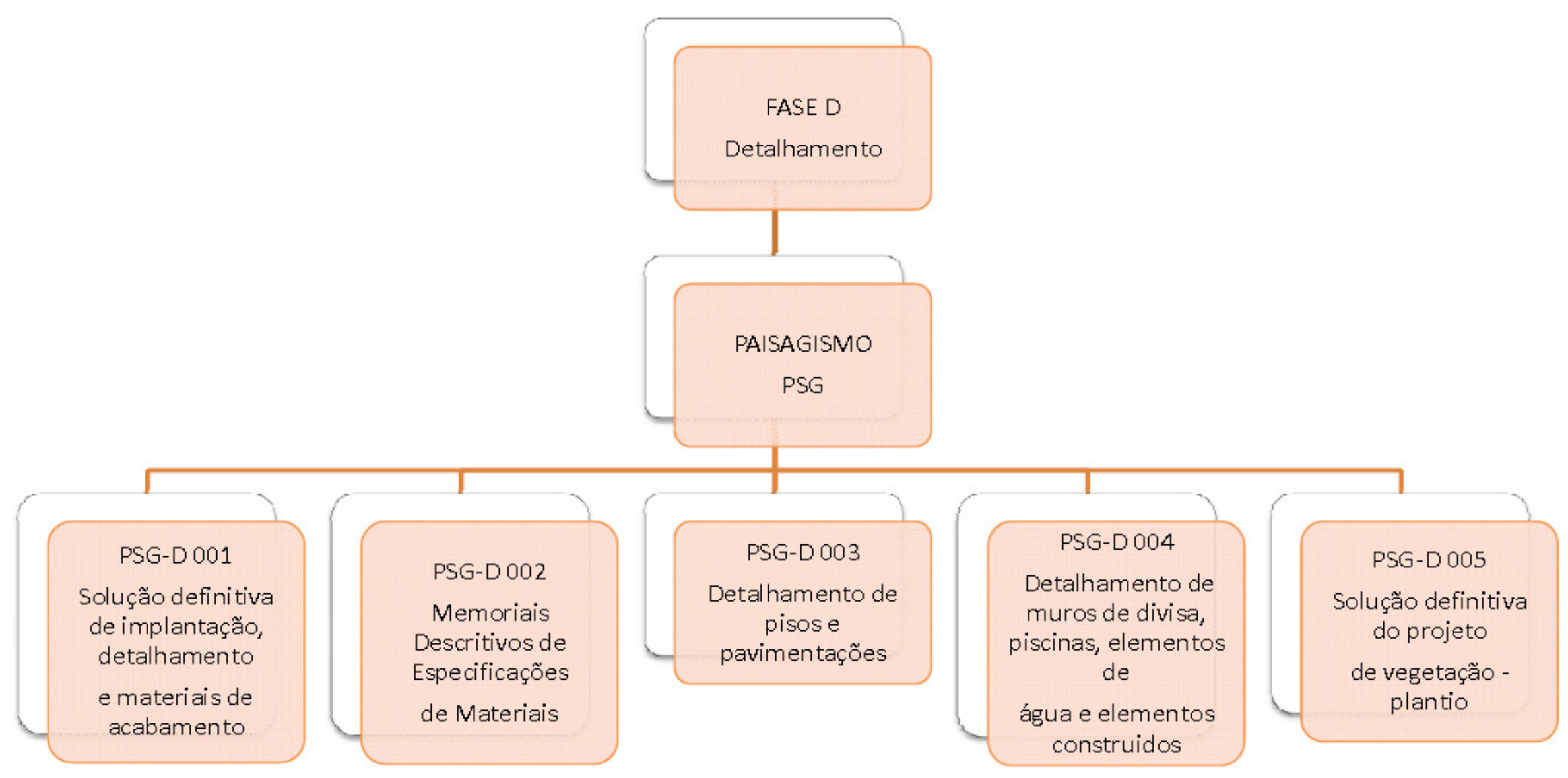

Figura 79: EAP para paisagismo fase $D$ 


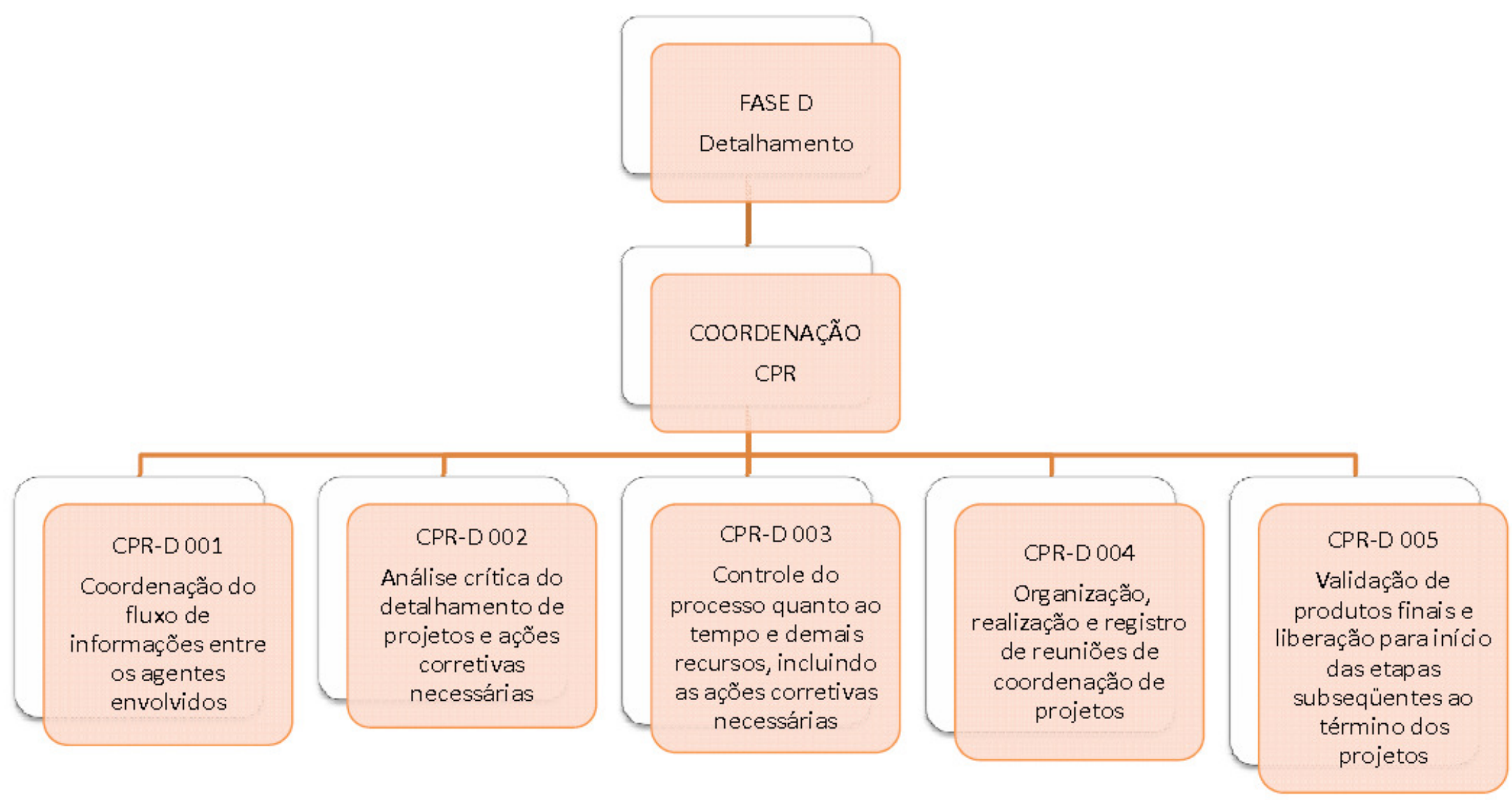

Figura 80: EAP para coordenação fase D 


\section{APÊNDICE C - Tabela de dependência de informações}

Neste apêndice serão apresentadas as tabelas de dependência de informações fases $B, C$ e D para uma melhor compreensão do desenvolvimento do trabalho. 


\section{Fase B}

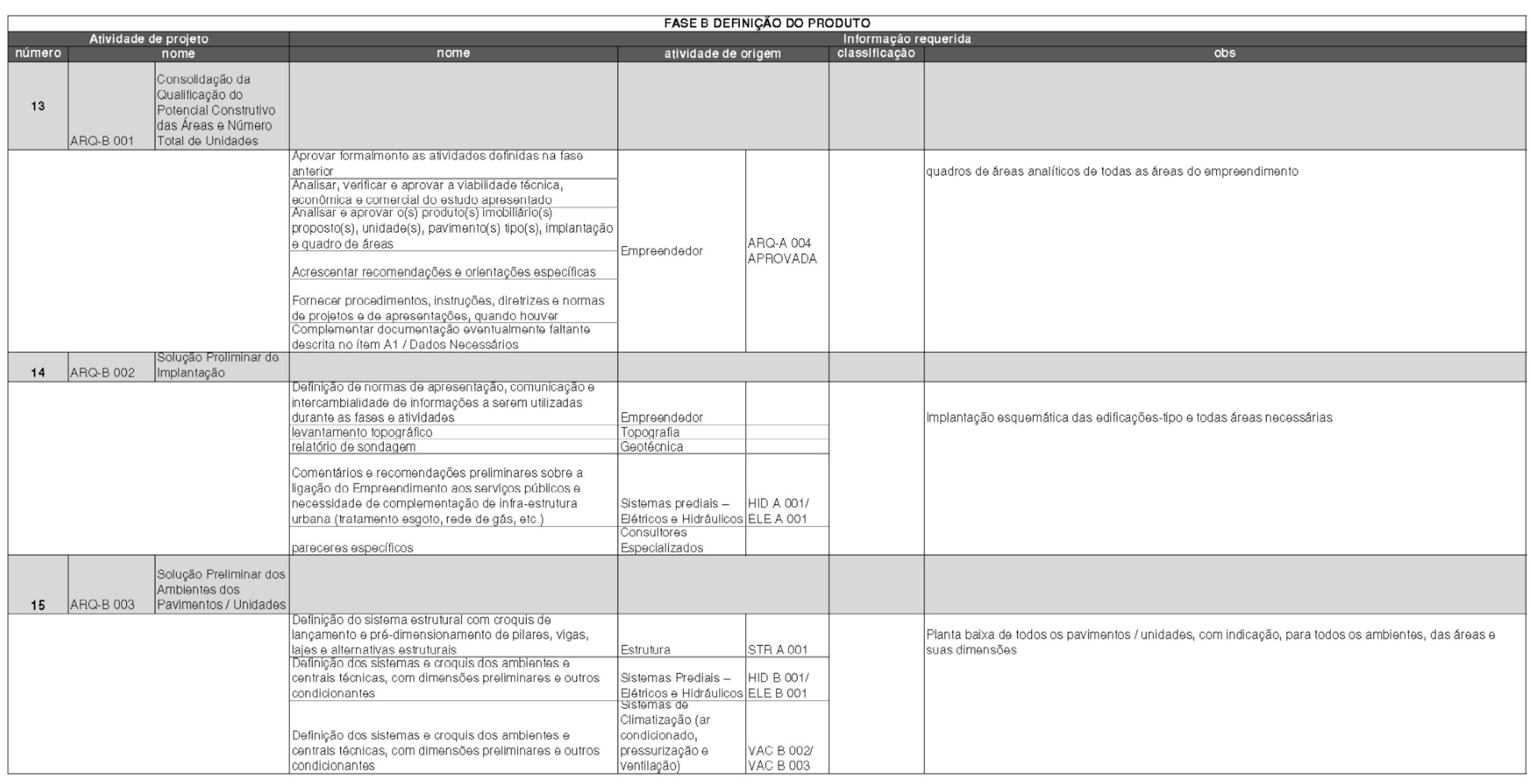




\begin{tabular}{|c|c|c|c|c|c|c|}
\hline \multirow[t]{4}{*}{16} & ARQ-B 004 & $\begin{array}{l}\text { Soluçąo Prelliminar dos } \\
\text { Elementos de } \\
\text { Cobertura }\end{array}$ & & & & \\
\hline & & & 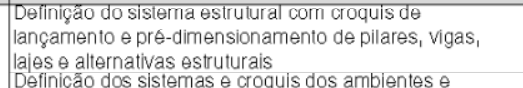 & Estrutura & STR A 001 & \multirow[t]{3}{*}{ Planta balixa dos elementos de cobertura } \\
\hline & & & $\begin{array}{l}\text { centrais tecnicas, com dimensốes prelliminares } \theta \text { outros } \\
\text { condidionantes }\end{array}$ & $\begin{array}{l}\text { Sistemas Prediais - } \\
\text { Elétricose Hidráulicos }\end{array}$ & $\begin{array}{l}\text { HID B } 001 / \\
\text { ELEB } 001\end{array}$ & \\
\hline & & & $\begin{array}{l}\text { Defininizão dos sistemas } \theta \text { croquis dos ambientes } \theta \\
\text { centrais técnicas, com dimensôes preliminares } \theta \text { outros } \\
\text { condicionantes }\end{array}$ & 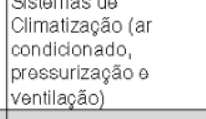 & $\begin{array}{l}\text { VAC B } 002 / \\
\text { VAC B 003 }\end{array}$ & \\
\hline \multirow[t]{4}{*}{17} & $A R Q-B 005$ & $\begin{array}{l}\text { Soluçăo Prelliminar dos } \\
\text { Cortes }\end{array}$ & & & & \\
\hline & & & 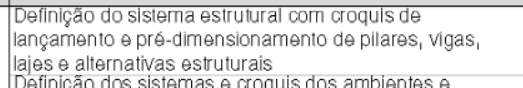 & Estrutura & STRA A001 & \multirow[t]{3}{*}{$\begin{array}{l}\text { Cortes } \theta \text { / ou seçễes Iongitudinais } \theta / \text { ou transversais preliminares de todos os pavimentos, indicando } \\
\text { todos os niveis e alturas (internas } \theta \text { externas) em relaçâa a referência adotada }\end{array}$} \\
\hline & & & $\begin{array}{l}\text { Uenthigaio désicas, com dimensôes preliminares e outros } \\
\text { contralis tionantes }\end{array}$ & $\begin{array}{l}\text { Sistemas Prediais - } \\
\text { Elétricose Hidráulicos } \\
\text { Sisiemas de }\end{array}$ & $\begin{array}{l}\text { HID B 001/ } \\
\text { ELE B 001 }\end{array}$ & \\
\hline & & & $\begin{array}{l}\text { Defininizão dos sistemas } \theta \text { croquis dos ambientes } \theta \\
\text { centrais técnicas, com dimensões preliminares e outros } \\
\text { condicionantes }\end{array}$ & 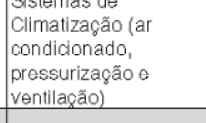 & $\begin{array}{l}\text { VAC B } 0021 \\
\text { VAC B } 003\end{array}$ & \\
\hline \multirow[t]{4}{*}{18} & ARQ-B 006 & $\begin{array}{l}\text { Soluçăo Prellminar das } \\
\text { Fachadas }\end{array}$ & & & & \\
\hline & & & 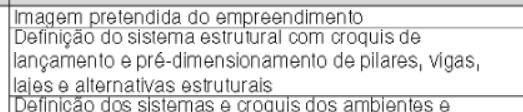 & $\begin{array}{l}\text { Empreendedor } \\
\text { Estrutura }\end{array}$ & STRA 001 & \multirow[t]{3}{*}{ Fachadas, de todas as edificą̧̋̋es, indicando os elementos que a(s) compōe(m) } \\
\hline & & & $\begin{array}{l}\text { centrais técnicas, com dimensôes preliminares } \theta \text { outros } \\
\text { condicionantes }\end{array}$ & $\begin{array}{l}\text { Sistemas Prediais - } \\
\text { Elétricose Hidráulicos }\end{array}$ & $\begin{array}{l}\text { HID B 001/ } \\
\text { ELEB B 001 }\end{array}$ & \\
\hline & & & $\begin{array}{l}\text { Definificão dos sistemas } \theta \text { croquis dos ambientes } \theta \\
\text { centrais técnicas, com dimensôes preliminares } \theta \text { outros } \\
\text { condicionantes }\end{array}$ & $\begin{array}{l}\text { Sistemas de } \\
\text { Climatizacãão (ar } \\
\text { condicionado, } \\
\text { pressurizacăo } \\
\text { ventilação) }\end{array}$ & $\begin{array}{l}\text { VAC B O02/ } \\
\text { VAC B O03 }\end{array}$ & \\
\hline \multirow[t]{3}{*}{19} & ARQ-B 007 & $\begin{array}{l}\text { Soluģao Prellminar dos } \\
\text { Sistemas, Métodose } \\
\text { Materials de } \\
\text { Acabamento }\end{array}$ & & & & \\
\hline & & & $\begin{array}{l}\text { tens essenciais aprovados } \theta \text { definidos nas atividades } \\
\text { anteriores }\end{array}$ & \multirow[b]{2}{*}{ Empreandedor } & \multirow{2}{*}{ 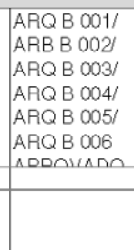 } & \multirow[t]{2}{*}{ Relatório com a conceituaçăo geral dos sistemas, métodos construlivos e materiais de acabamento } \\
\hline & & & 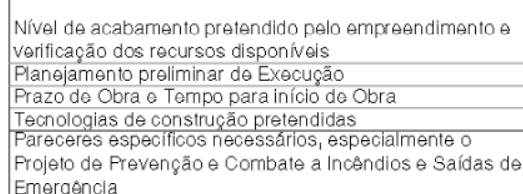 & & & \\
\hline
\end{tabular}




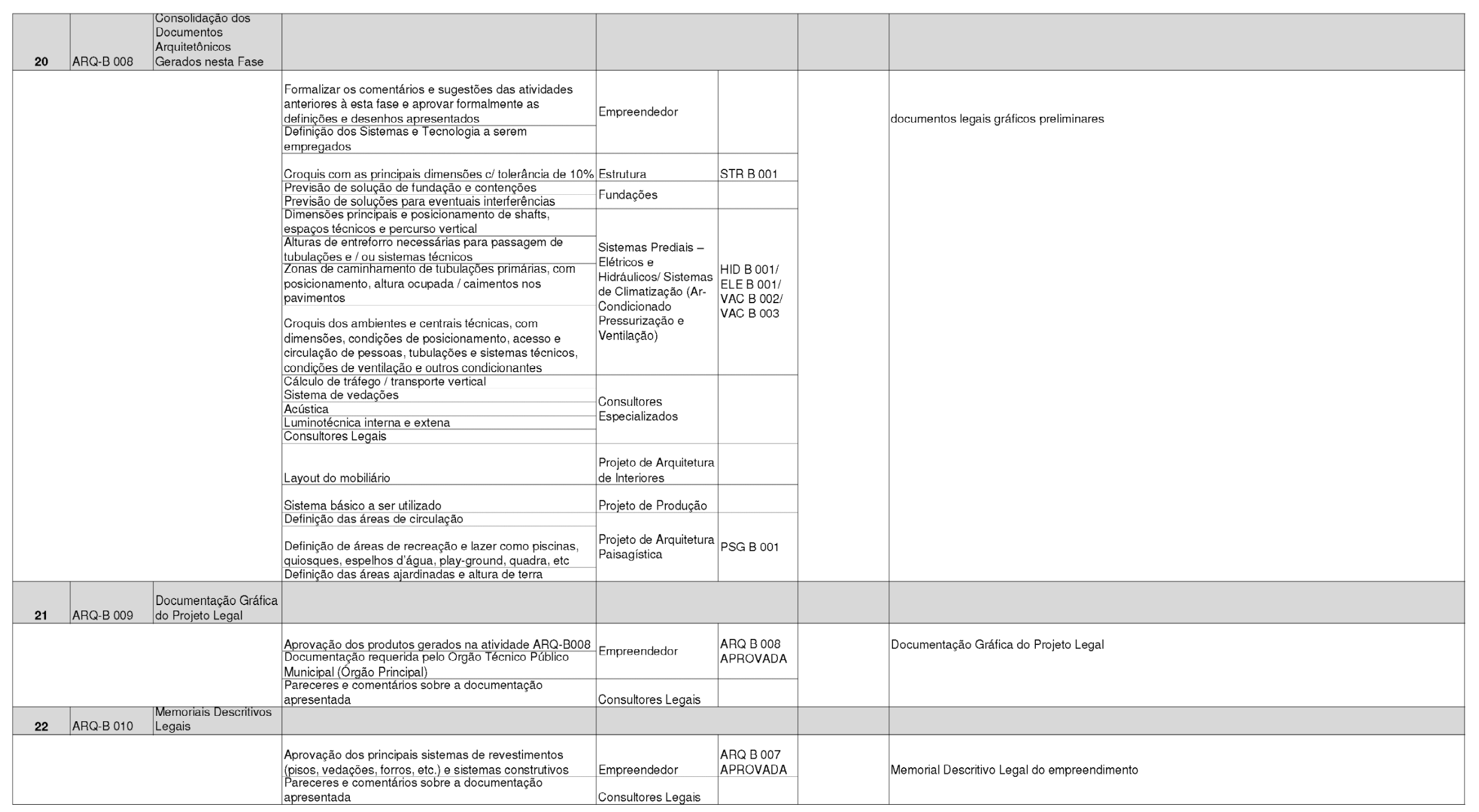




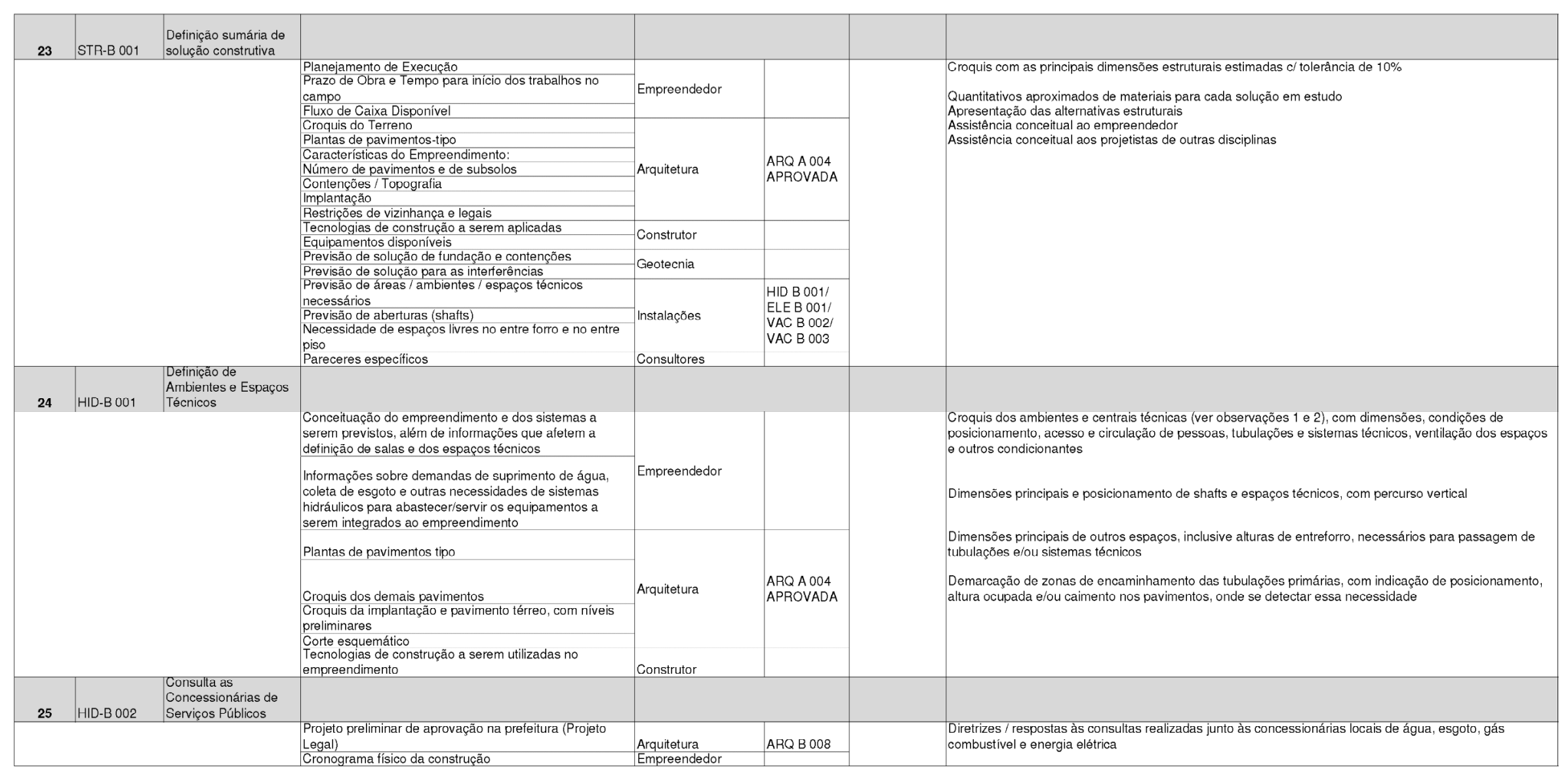




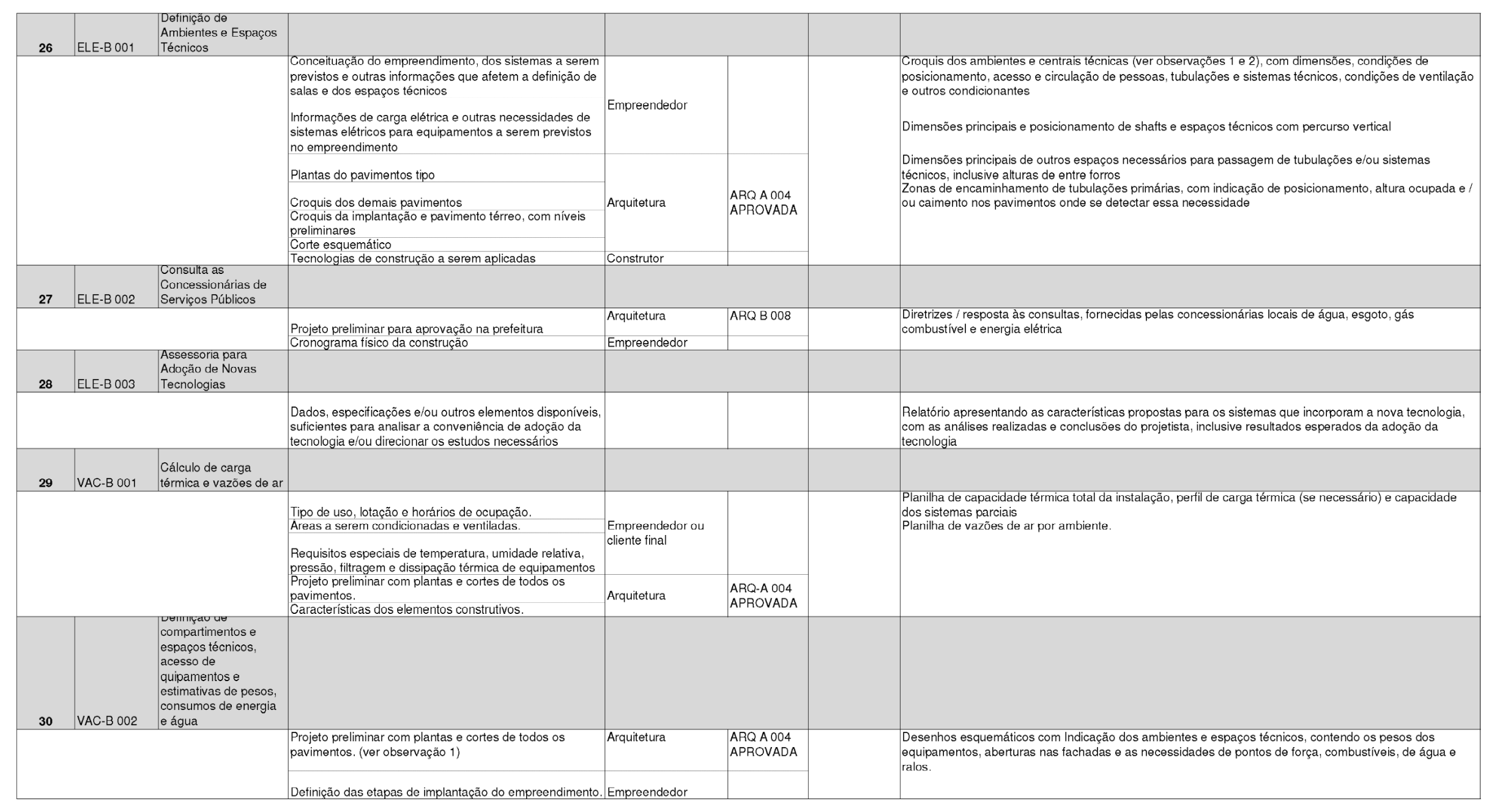




\begin{tabular}{|c|c|c|c|c|c|c|}
\hline 31 & VAC-B 003 & $\begin{array}{l}\text { Dimensionamento e } \\
\text { caminhamento das } \\
\text { redes de dutose } \\
\text { tubulaçôs principais }\end{array}$ & & & & \\
\hline \multirow[b]{3}{*}{32} & & \multirow[b]{3}{*}{$\begin{array}{l}\text { Soluẹáo proliminar do } \\
\text { Implantaçâo do } \\
\text { paisagismo no } \\
\text { empreendimento }\end{array}$} & $\begin{array}{l}\text { Projeto preliminar com plantas e cortes de todos os } \\
\text { pavimentos. }\end{array}$ & Arquitetura & $\begin{array}{l}\text { ARQ A } 004 \\
\text { APROVADA }\end{array}$ & \multirow[t]{3}{*}{$\begin{array}{l}\text { Desenhos esquemáticos com a indicação dos espaços ocupados pelas redes de dutos e tubulaçōes, } \\
\text { visando fornecer dados para compatibilizar os espaços com as demais instalaçōes. }\end{array}$} \\
\hline & & & Lançamento preliminar de formas. & \multirow{2}{*}{\multicolumn{2}{|c|}{ STRA001 }} & \\
\hline & PSG-B U01 & & & & & \\
\hline & & & Aprovaçäo da fase anterior & Empreendedor & & \multirow{7}{*}{ 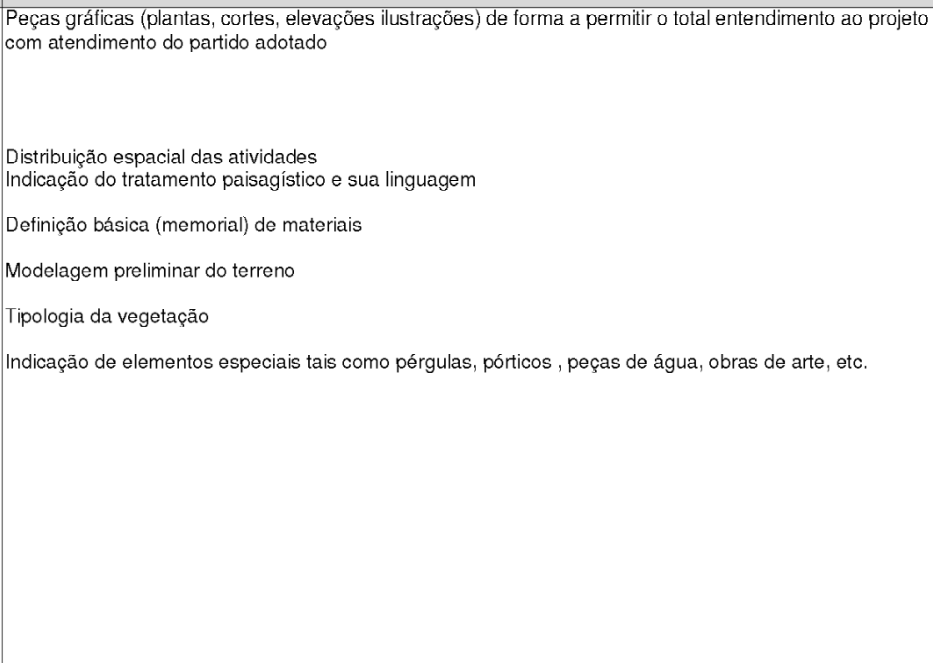 } \\
\hline & & & $\begin{array}{l}\text { Definição de normas de apresentação, comunicação o } \\
\text { fluxo de informaçües a serem utilizadas durante as fases } \\
\text { e atvidades, caso näo haja coordenação esta tareta } \\
\text { caberá ao empreendedor. }\end{array}$ & Coordenador & & \\
\hline & & & $\begin{array}{l}\text { Estudo preliminar e/ou anteprojeto } \\
\text { Restriçós Legais (́́rea verde e área permeável } \\
\text { necessárias para o projeto) }\end{array}$ & Arquitetura & $\begin{array}{l}\text { ARQ A OO4 } \\
\text { APROVADA }\end{array}$ & \\
\hline & & & $\begin{array}{l}\text { Proieto de terraplenagem (geométrico) quando pertinente } \\
\text { Levantamentuo Planialtimétrico Complementiação do do } \\
\text { levantamento planialtimátrico sc nocossário. }\end{array}$ & \multirow[b]{2}{*}{ Levantamentos } & & \\
\hline & & & 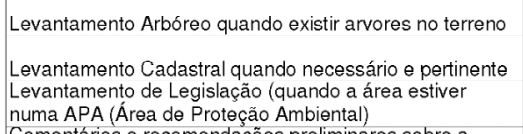 & & & \\
\hline & & & 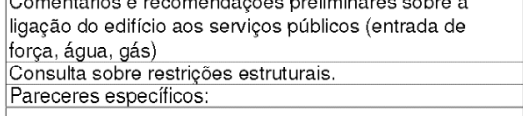 & \multirow[t]{2}{*}{$\begin{array}{l}\text { Sistemas prediais } \\
\text { Estrutura }\end{array}$} & \multirow[t]{2}{*}{$\begin{array}{l}\text { HID A 001/ } \\
\text { ELEA } 001 \\
\text { STR A OU1 }\end{array}$} & \\
\hline & & & $\begin{array}{l}\text { Agrônomo, consultor de piscina, consultor esportivo, } \\
\text { drenagem, vendas, biólogo, engenheiro de tráfego, } \\
\text { impermeabilizacão, ar condicionado, automacão etc.. }\end{array}$ & & & \\
\hline
\end{tabular}

Tabela 9: Tabela de dependência de informações fase B 


\section{Fase C}

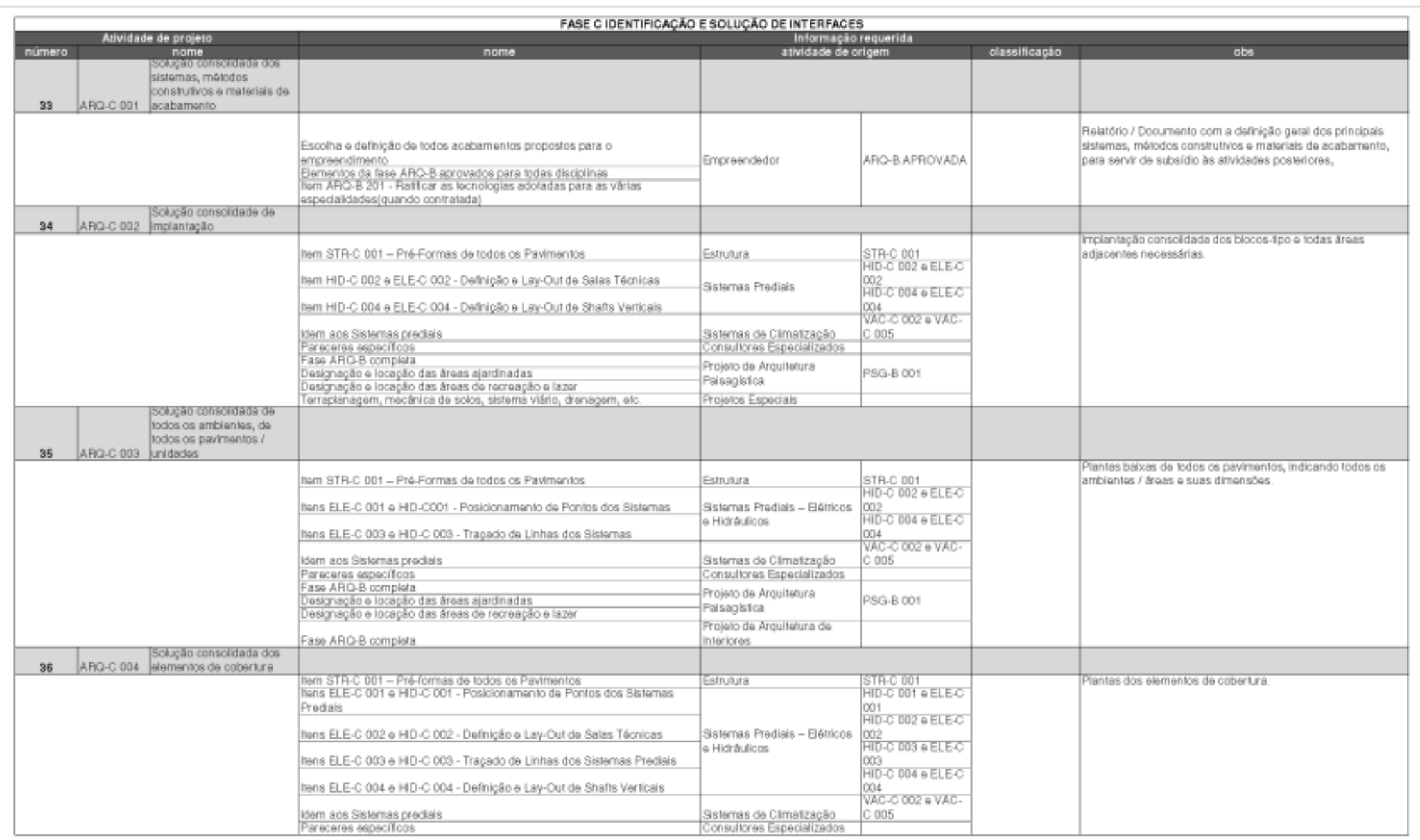




\begin{tabular}{|c|c|c|c|c|c|}
\hline \multirow[t]{9}{*}{37} & \begin{tabular}{|l|l|} 
ARQ-C 005 & $\begin{array}{l}\text { Soluęăo consolidada d } \\
\text { todos os cortes }\end{array}$ \\
\end{tabular} & & & & \\
\hline & & Leem STR-C 001 - Pré-tormas de todos os pavimentos & \multirow{5}{*}{$\begin{array}{l}\text { Sistemas Prediais - Elátricos } \\
\text { e Hidráulicos }\end{array}$} & \multirow{5}{*}{$\begin{array}{l}\text { STR-C } 001 \\
\text { ELE-C } 001 \text { e HID-C } \\
001 \\
\text { ELE-C } 002 \text { e HID-C } \\
002 \\
\text { ELE-C } 003 \text { e HID-C } \\
003 \\
\text { ELE-C } 004 \text { e HID-C } \\
004\end{array}$} & \multirow[t]{8}{*}{ 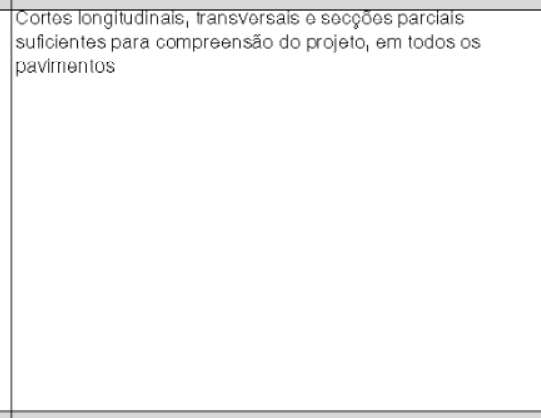 } \\
\hline & & Itens ELE-C 001 e HID-C 001-Posiclonamento de pontos dos sistemas & & & \\
\hline & & Itens ELE-C $002 \theta$ HID-C 002-Definilgãa $\theta$ Lay-out de Salas Técnicas & & & \\
\hline & & thens ELE-C 003 a HID-C 003-Traq̧ado de Linhas dos Sistemas Predials & & & \\
\hline & & 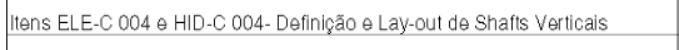 & & & \\
\hline & & & \multirow{3}{*}{ 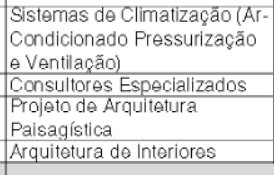 } & $\begin{array}{l}\text { VAC-C } 001 \text { a VAC- } \\
\text { C } 005\end{array}$ & \\
\hline & & Pareceres especificos & & & \\
\hline & & $\begin{array}{l}\text { Fase ARQ-B completa } \\
\text { Fase ARQ-B completa }\end{array}$ & & PSG B 001 & \\
\hline \multirow[t]{8}{*}{38} & \begin{tabular}{|l|l|} 
ARQ-C 006 & $\begin{array}{l}\text { Solugăa consolidada de } \\
\text { todas as Fachadas }\end{array}$ \\
\end{tabular} & & & & \\
\hline & & Lem STR-C 001 - Pré-formas de todos os pavimentos & 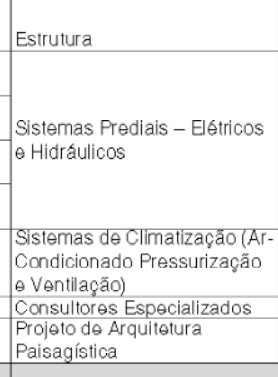 & \multirow{5}{*}{ 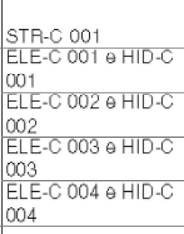 } & \multirow{7}{*}{ 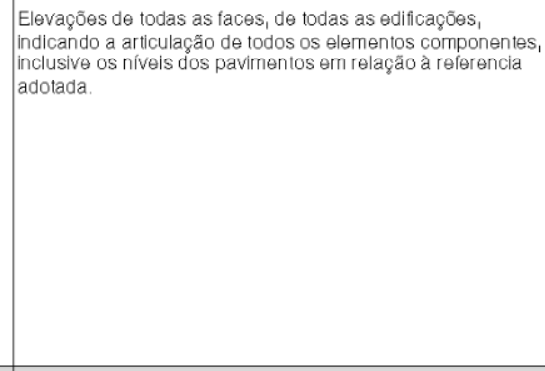 } \\
\hline & & Itens ELE-C 001 e HID-C 001-Posicionamento de pontos dos sistemas & \multirow{6}{*}{$\begin{array}{l}\text { Sistemas Prediais - Elétricos } \\
\text { e Hidráulicos } \\
\\
\text { Sistemas de Climatização (Ar- } \\
\text { Condicionado Pressurizaçăo } \\
\text { e Ventllą̧äo) } \\
\text { Consultores Especializados } \\
\text { Projelo do Arquitatura } \\
\text { Paisagistica }\end{array}$} & & \\
\hline & & Ltens ELE-C $002 \theta$ HID-C 002-Definifyão $\theta$ Lay-out de Salas Técnicas & & & \\
\hline & & Ltens ELE-C 003 e HID-C 003-Traçado de Linhas dos Sistemas Prediais & & & \\
\hline & & Itens ELE-C 004 \& HID-C 004-Definição e Lay-out de Shaffts Verticais & & & \\
\hline & & $\begin{array}{l}\text { Idem aos sistemas prediais } \\
\text { Pareceres específicos }\end{array}$ & & $\begin{array}{l}\text { VAC-C } 001 \text { a VAC- } \\
\text { C } 005\end{array}$ & \\
\hline & & Fase ARQ-B completa & & PSG-B 001 & \\
\hline \multirow[t]{2}{*}{39} & 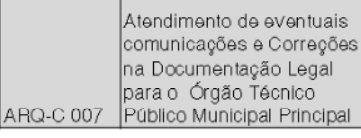 & & & & \\
\hline & & 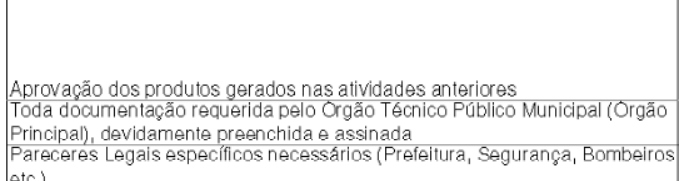 & Empreandedor & $\begin{array}{l}\text { ARQ-C 001 a ARQ- } \\
\text { C 006 APROVADA }\end{array}$ & 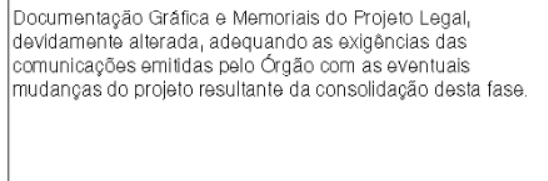 \\
\hline
\end{tabular}




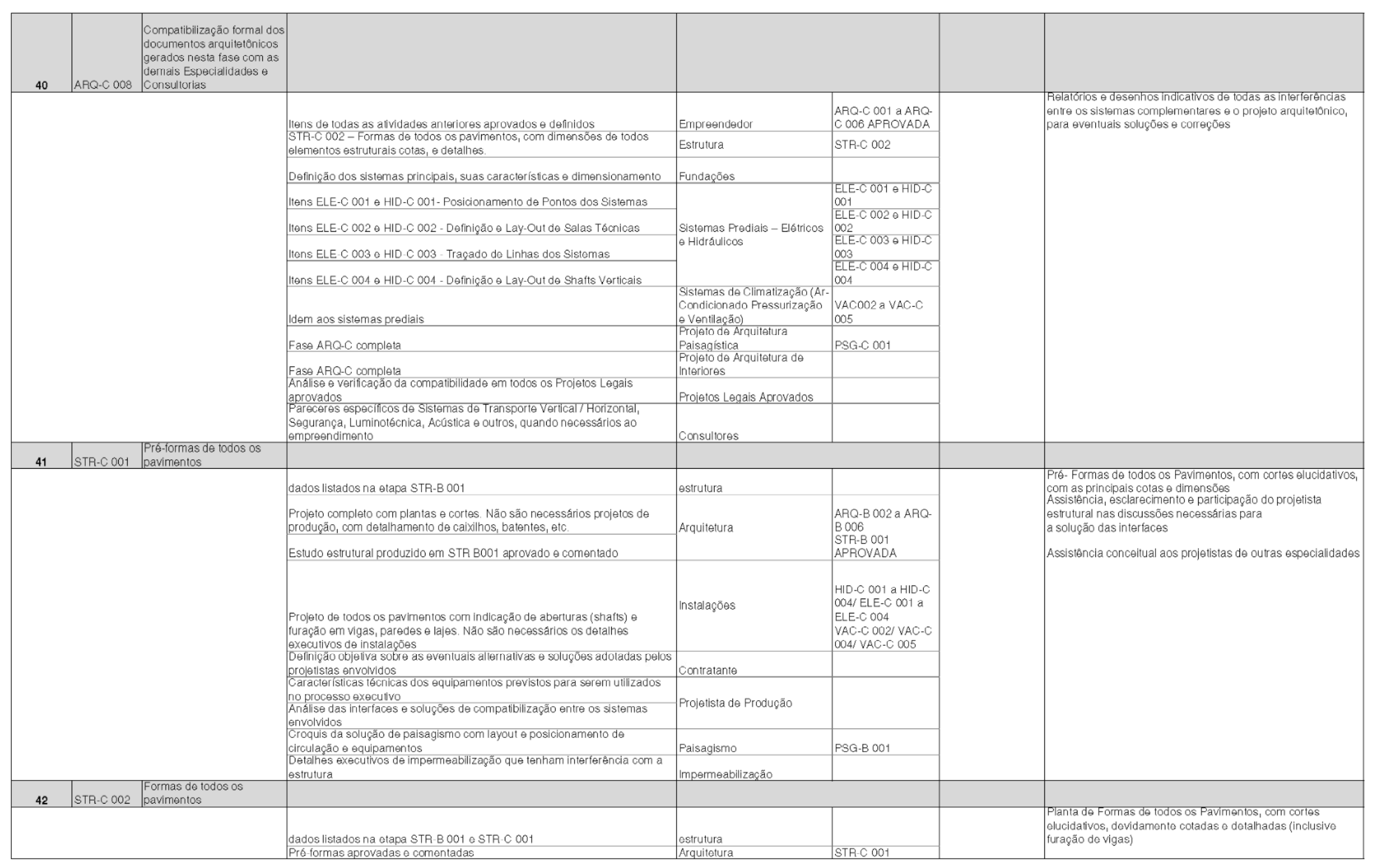




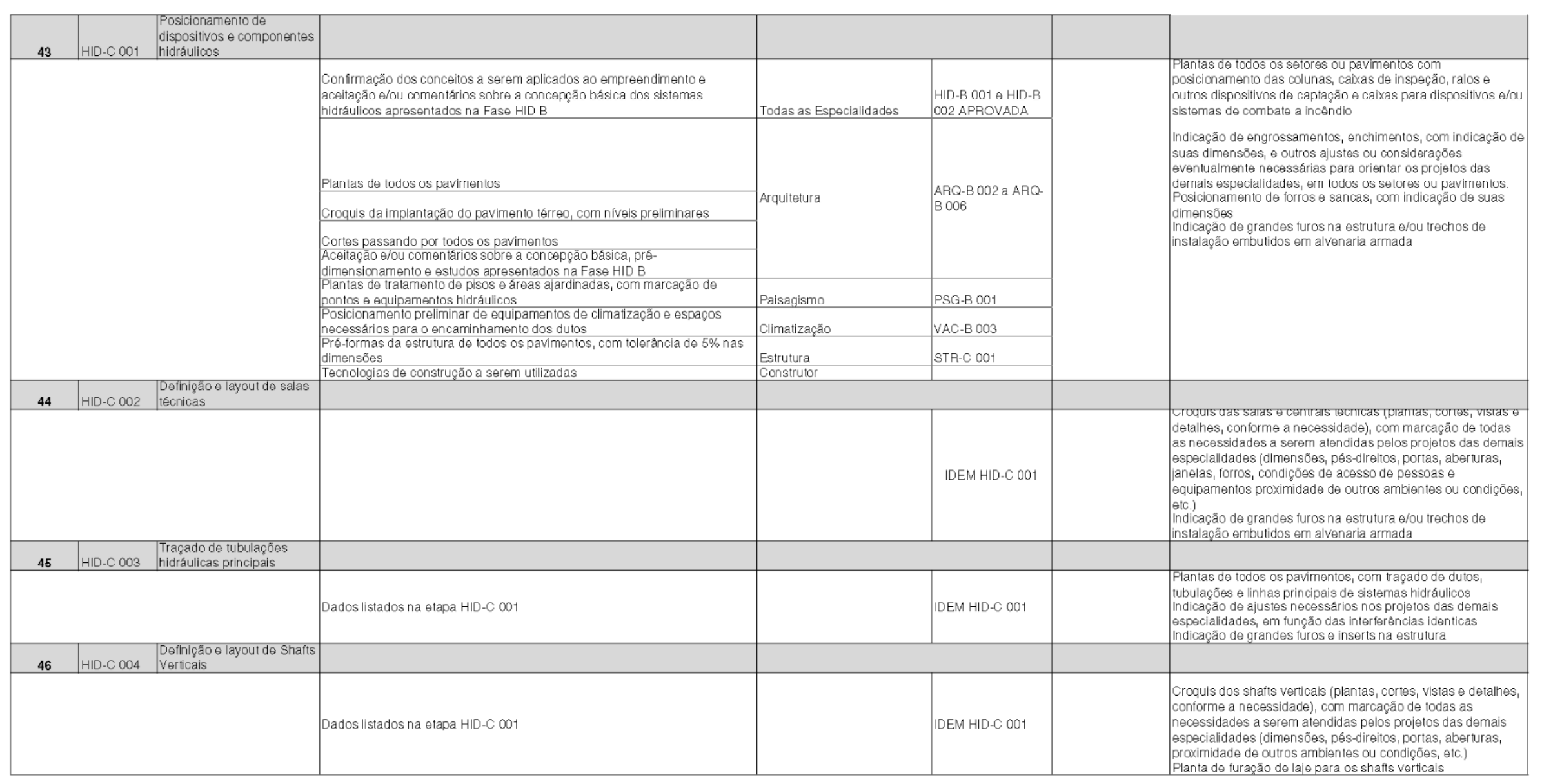




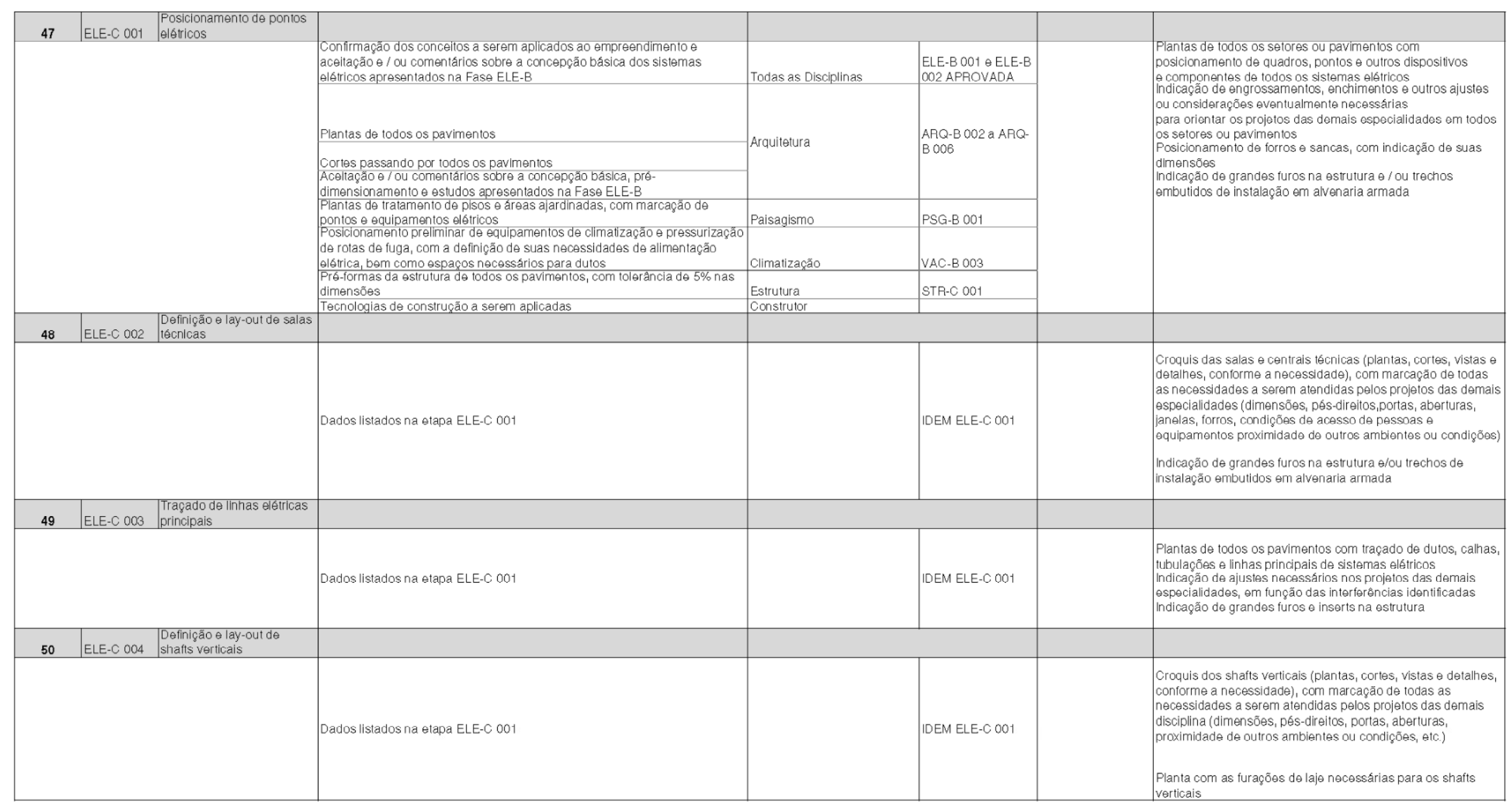




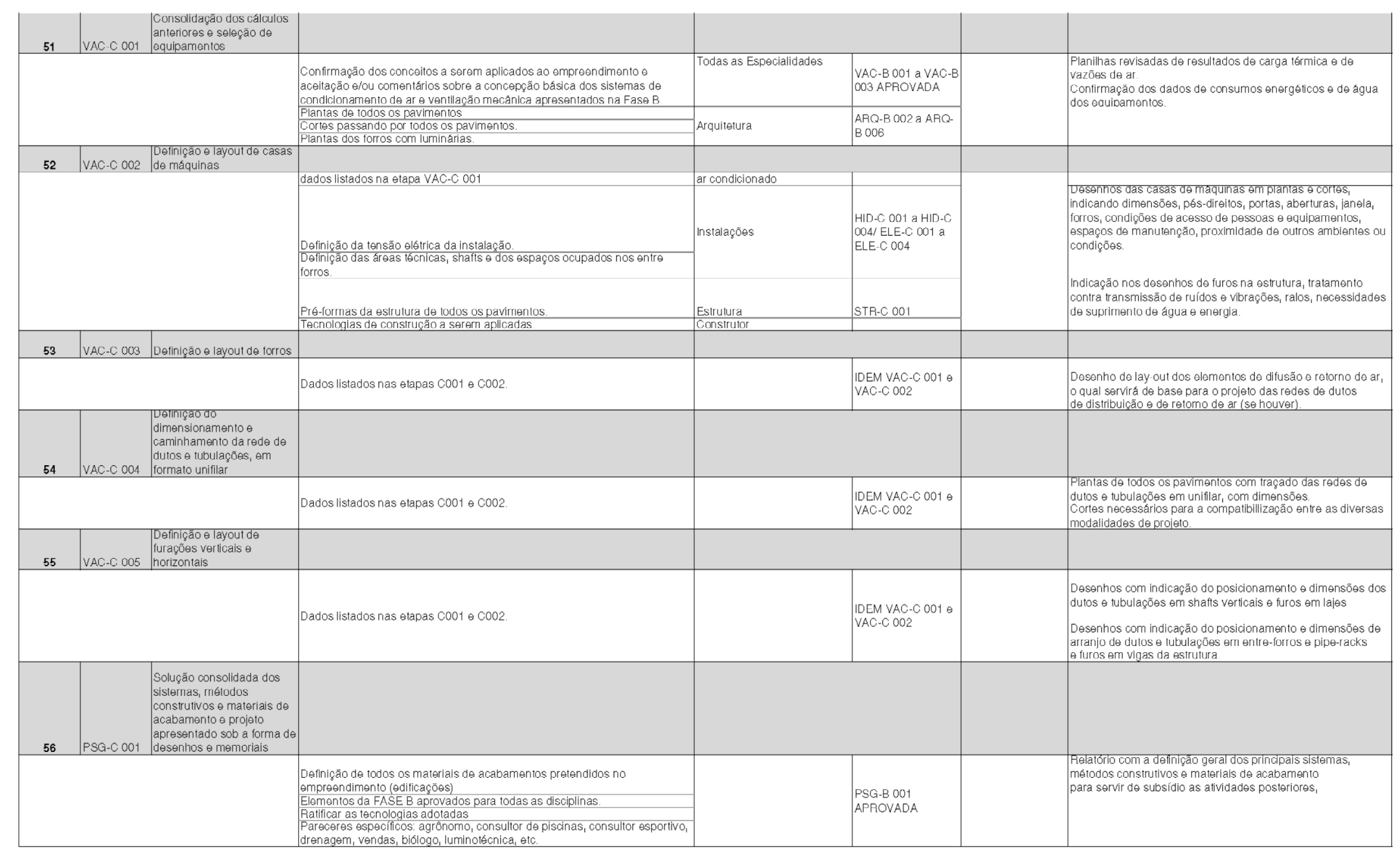

Tabela 10: Tabela de dependência de informações fase C 


\section{Fase D}

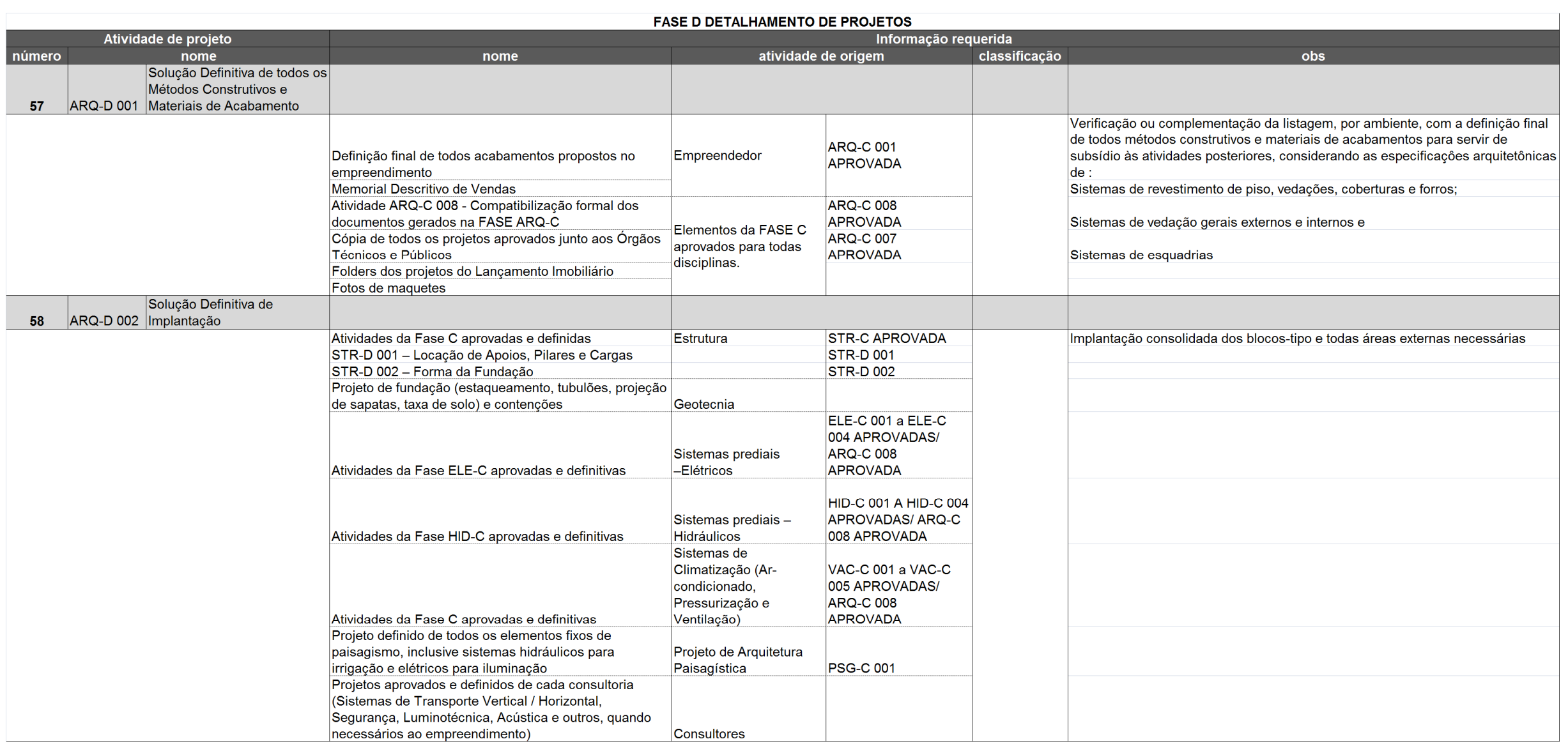




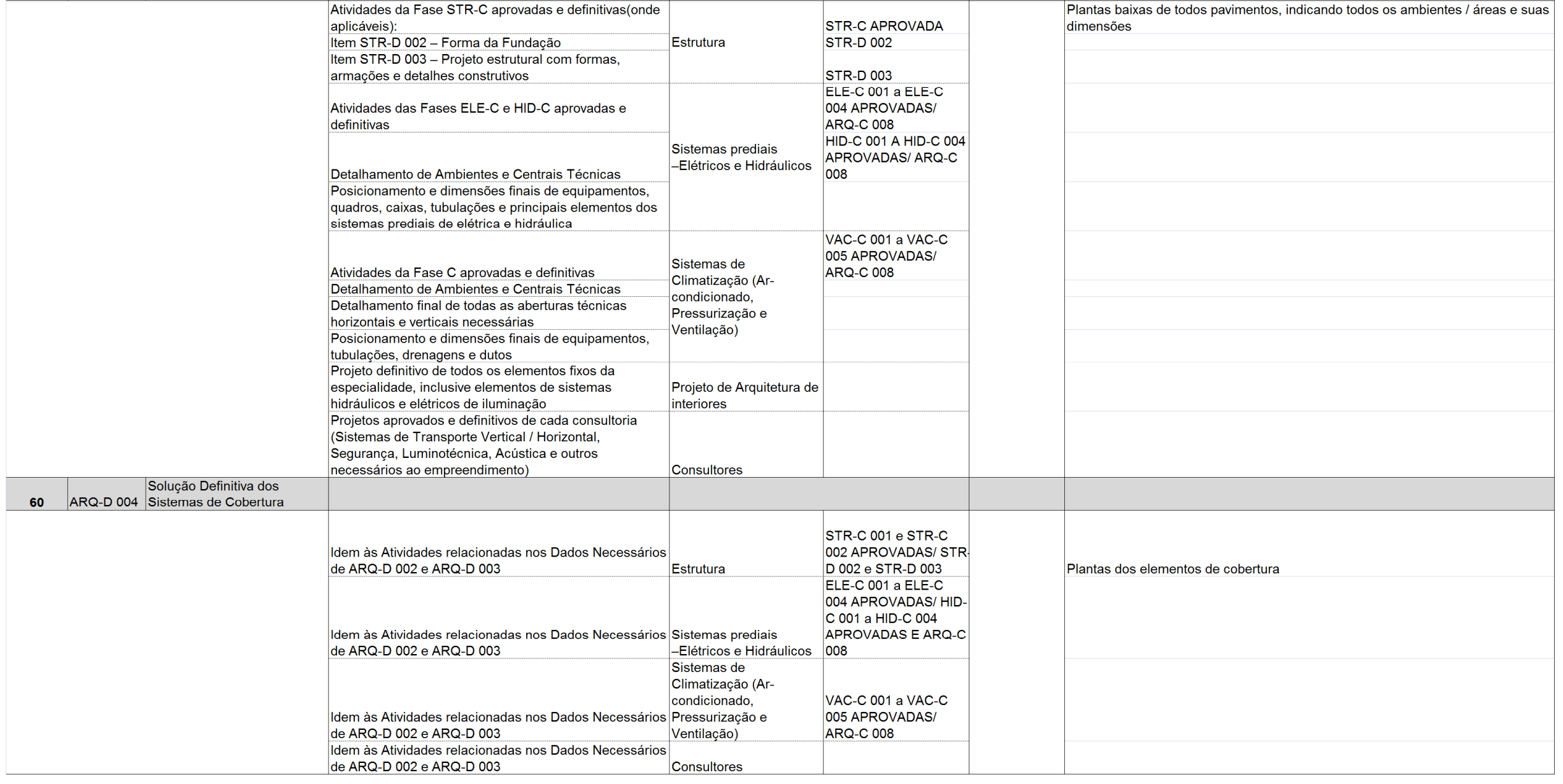




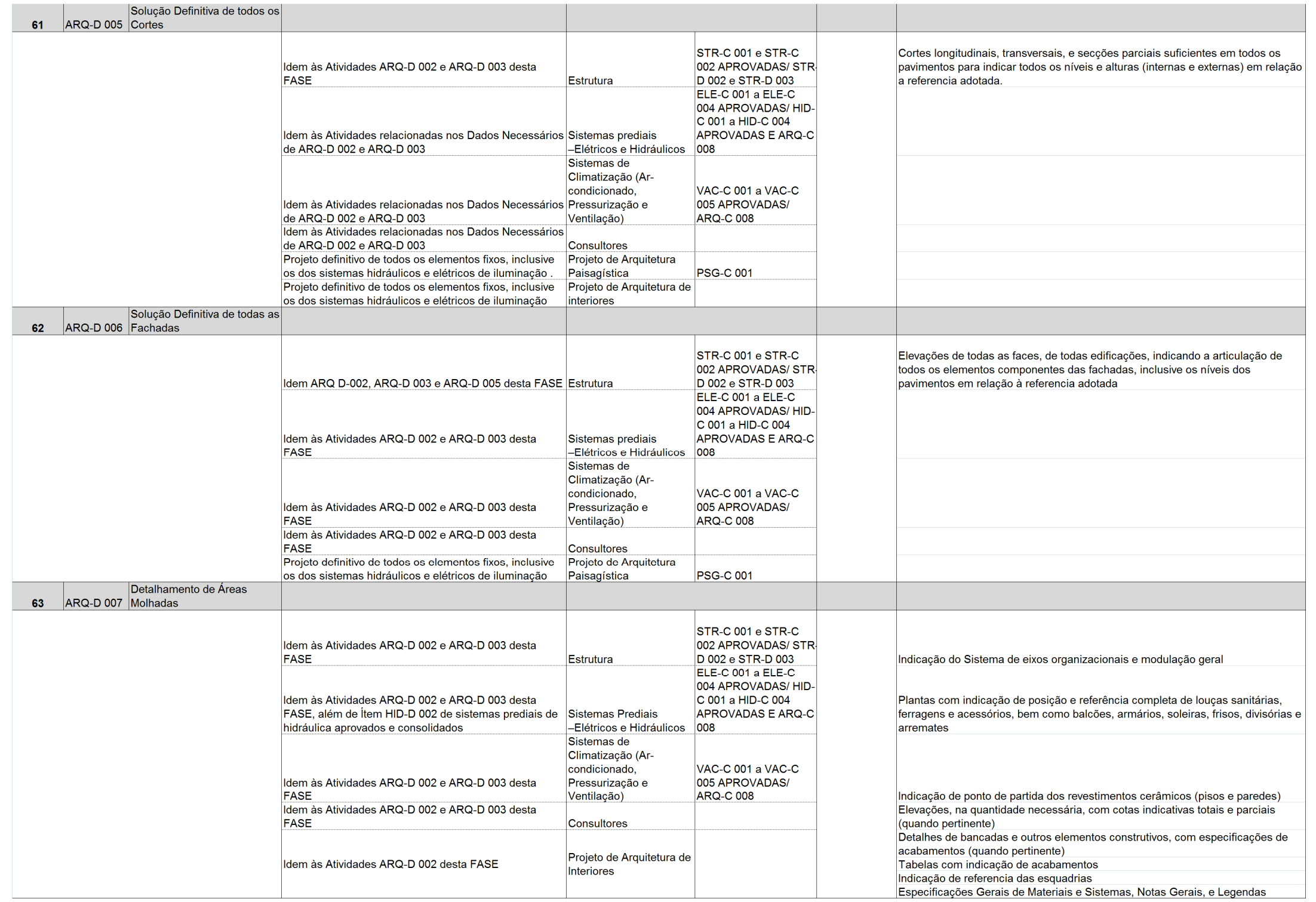




\begin{tabular}{|c|c|c|c|c|c|c|}
\hline \multirow[t]{2}{*}{64} & ARQ-D 008 & $\begin{array}{l}\text { Detalhamento de Escadas e } \\
\text { Rampas }\end{array}$ & & & & \multirow[b]{2}{*}{$\begin{array}{l}\text { Indicação do Sistema de eixos organizacionais e modulação geral } \\
\text { Planta baixa com dimensionamento de pisos e patamares } \\
\text { Representação, e quantificação completa de corrimão e numeração de pisos e } \\
\text { espelhos } \\
\text { Indicaçãõo do sentido de SUBIDA de escadas e rampas } \\
\text { Indicąão de início e fim de corrimãos } \\
\text { Indicacão de abertura de PCF e sua interferência na circulação } \\
\text { Cortes na quantidade necessária, com cotas indicativas dos níveis, altura de } \\
\text { espellho, corrimão e outros } \\
\text { Detalhes especificos, de acordo com o projeto } \\
\text { Tabelas com indicação de acabamentos } \\
\text { Indicação de referência das esquadrias } \\
\text { Especificações Gerais de Materiais e Sistemas, Notas Gerais, e Legendas }\end{array}$} \\
\hline & & & $\begin{array}{l}\text { Todas as Atividades listadas anteriormente } \\
\text { Todas as Atividades listadas anteriormente } \\
\text { Todas às Atividades listadas anteriormente } \\
\text { Todas às Atividades listadas anteriormente } \\
\text { Idem às Atividades ARQ-D } 002 \text { desta FASE }\end{array}$ & $\begin{array}{l}\text { Estrutura } \\
\text { Sistemas Prediais } \\
\text {-Elétricos e Hidráulicos } \\
\text { Sistemas de } \\
\text { Climatização (Ar- } \\
\text { condicionado, } \\
\text { Pressurização e } \\
\text { Ventilacaâo) } \\
\text { Consultores } \\
\\
\text { Projeto de Arquitetura de } \\
\text { Interiores }\end{array}$ & $\begin{array}{l}\text { STR-C } 001 \text { e STR-C } \\
\text { O02 APROVADAS/ STR- } \\
\text { D } 002 \text { e STR-D 003 } \\
\text { ELE-C } 001 \text { a ELE-C } \\
004 \text { APROVADAS/ HID- } \\
\text { C } 001 \text { a HID-C } 004 \\
\text { APROVADAS E ARQ-C } \\
008 \\
\\
\text { VAC-C } 001 \text { a VAC-C } \\
\text { 005 APROVADAS/ } \\
\text { ARQ-C } 008\end{array}$ & \\
\hline \multirow[t]{3}{*}{65} & ARQ-D 009 & $\begin{array}{l}\text { Detalhamento Construtivo / } \\
\text { Especifico (Horizontal e } \\
\text { Vertical) }\end{array}$ & & & & \\
\hline & & & $\begin{array}{l}\text { Todas as Atividades listadas anteriormente } \\
\text { Todas as Atividades listadas anteriormente }\end{array}$ & $\begin{array}{l}\text { Sistemas Prediais } \\
\text {-Elétricos e Hidráulicos } \\
\text { Sistemas de } \\
\text { Climatização (Ar- } \\
\text { condicionado, } \\
\text { Pressurização e } \\
\text { Ventilação) } \\
\end{array}$ & $\begin{array}{l}\text { STR-C } 001 \text { e STR-C } \\
002 \text { APROVADAS/ STR- } \\
\text { D } 002 \text { e STR-D } 003 \\
\text { ELE-C } 001 \text { a ELE-C } \\
\text { O04 APROVADAS/ HID- } \\
\text { C 0 } 01 \text { a HID-C } 004 \\
\text { APROVADAS E ARQ-C } \\
008 \\
\\
\text { VAC-C } 001 \text { a VAC-C } \\
\text { O05 APROVADAS/ } \\
\text { ARQ-C } 008\end{array}$ & $\begin{array}{l}\text { Desenhos complementares em escalas ampliadas, necessários à melhor } \\
\text { compreensão e execução da obra }\end{array}$ \\
\hline & & & Todas as Atividades listadas anteriormente & Consultores & & $\begin{array}{l}\text { Desenhos complementares de arremates de madeira (soleiras, peitoris, rodapés } \\
\text { ou revestimentos) } \\
\text { Desenhos complementares de arremates de elementos (esquadrias, escadas, } \\
\text { rampas com alvenarias e estruturas) } \\
\text { Desenhos complementares de arremates das alvenarias ou de outros elementos } \\
\text { de vedação com estruturas } \\
\text { Desenhos complementares de finalização de acabamentos de equipamentos com } \\
\text { todos os elementos da construção } \\
\text { Especificaçōes Gerais de Materiais e Sistemas, Notas Gerais, e Legendas }\end{array}$ \\
\hline
\end{tabular}




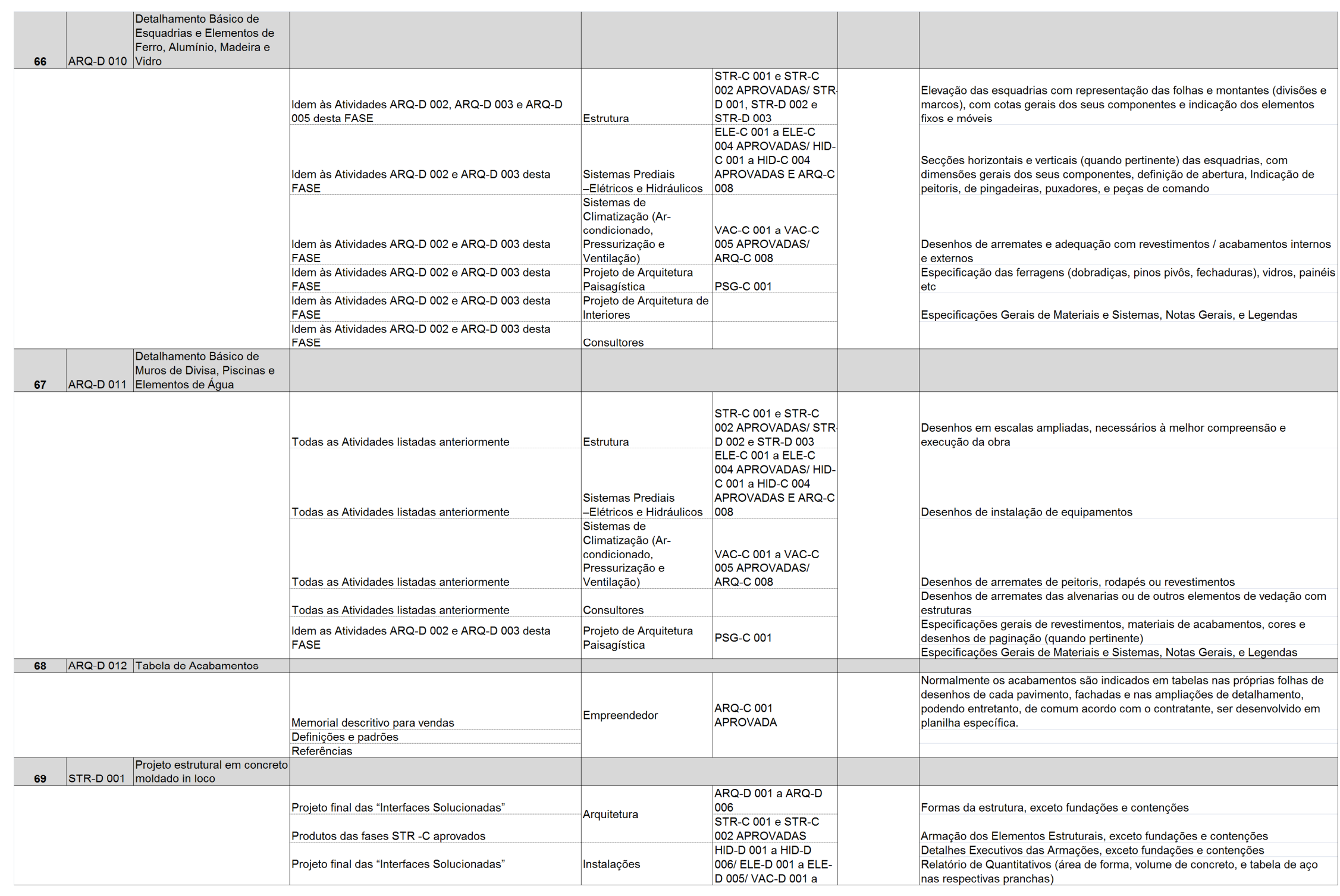




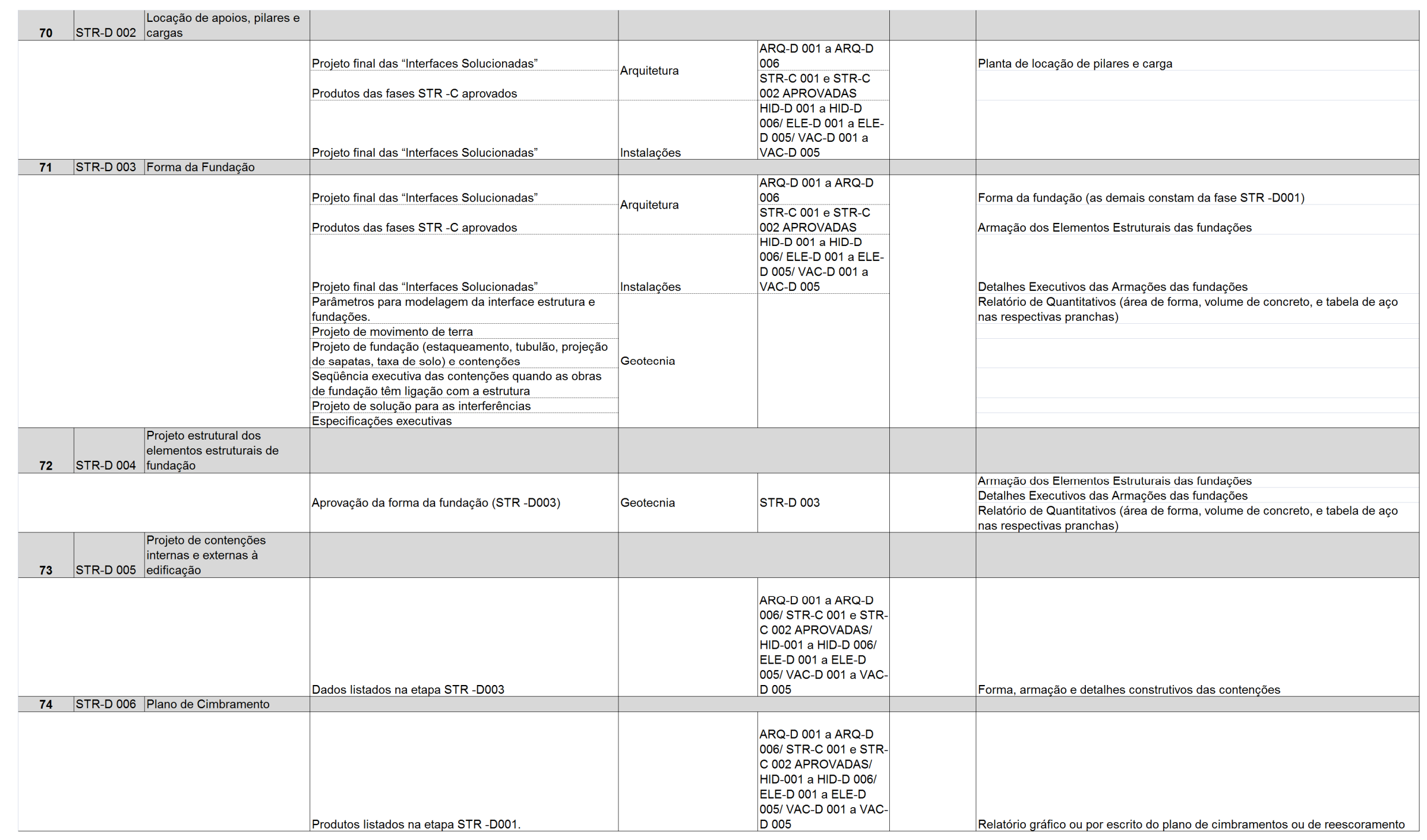




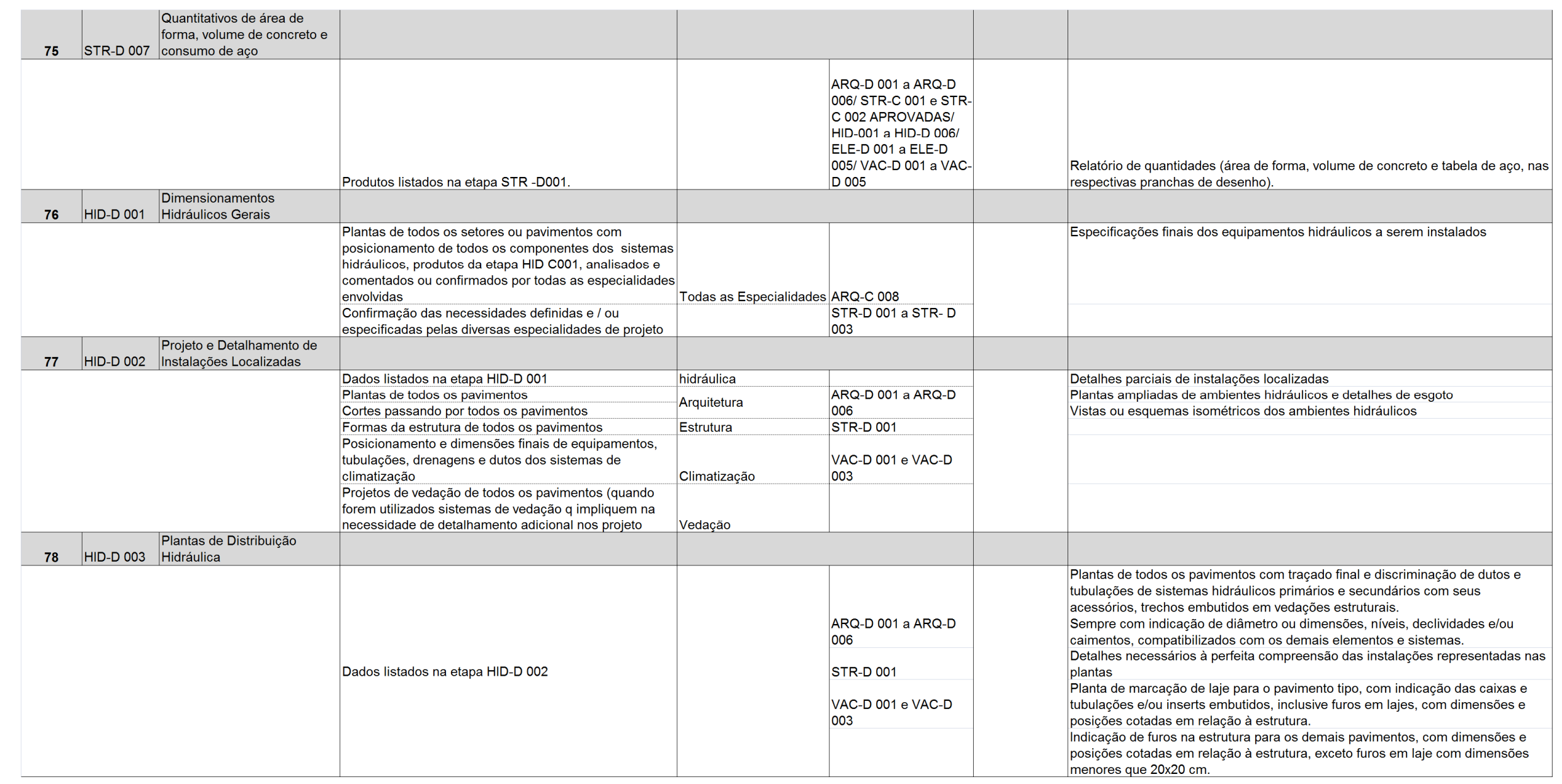




\begin{tabular}{|c|c|c|c|c|c|c|}
\hline 79 & HID-D 004 & $\begin{array}{l}\text { Preparação de Esquemas } \\
\text { Verticais da Instalação }\end{array}$ & & & & \\
\hline & & & Dados listados na etapa HID-D 002 & & $\begin{array}{l}\text { ARQ-D } 001 \text { a ARQ-D } \\
\text { O06/ STR-D 001/ VAC- } \\
\text { D } 001 \text { e VAC-D } 003\end{array}$ & $\begin{array}{l}\text { Esquemas verticais de distribuição para os diversos sistemas hidrálicos, } \\
\text { incluindo a discriminação de acessórios, com indicação de diâmetros, dimensões } \\
\text { e niveis, sempre compatibilizados com as plantas correspondentes } \\
\text { Detalhes necessários à perfeita compreensão da instalação representada nos } \\
\text { esquemas verticais }\end{array}$ \\
\hline \multirow[t]{2}{*}{80} & HIID-D 005 & $\begin{array}{l}\text { Detallamento de Ambientes e } \\
\text { Centrais Técnicas }\end{array}$ & & & & \\
\hline & & & Dados listados na etapa HID-D 002 & & $\begin{array}{l}\text { ARQ-D } 001 \text { a ARQ-D } \\
\text { 006/ STR-D D 001/ VAC- } \\
\text { D } 001 \text { e VAC-D } 003\end{array}$ & $\begin{array}{l}\text { Plantas, cortes, vistas, detalhes de montagem, incluindo o posicionamento e } \\
\text { discriminação de equipamentos, dutos, tubulacōes e seus acessórios, com } \\
\text { indicação de diâmetros ou dimensões, niveis e caimentos, sempre } \\
\text { compatibilizados com as plantas e esquemas correspondentes }\end{array}$ \\
\hline \multirow[t]{7}{*}{81} & HID-D 006 & $\begin{array}{l}\text { Elaboração de Memoriais e } \\
\text { Especificaçōes }\end{array}$ & & & & \\
\hline & & & $\begin{array}{l}\text { Plantas de todos os setores ou pavimentos, com } \\
\text { posicionamento de todos os componentes dos sistemas } \\
\text { hidráulicos, produtos da etapa HDD Co01, analisados e } \\
\text { comentados (ou confirmados) por todas as demais } \\
\text { especialidades de projeto envolvidas. } \\
\text { Confirmação de atendimento, pelos sistemas } \\
\text { hidráulicos, das necessidades definidas e/ou } \\
\text { especificadas pelas diversas especialidades de projeto }\end{array}$ & Todas as Especialidades & S ARQ-C 008 & Memoriais descritivos abrangendo todos os sistemas hidráulicos projetados \\
\hline & & & $\begin{array}{l}\text { Informaçōes sobre as modalidades de contratação e } \\
\text { gerenciamento especificas a serem adotadas }\end{array}$ & $\begin{array}{l}\text { Empreendedor e/ou } \\
\text { Construtor }\end{array}$ & & $\begin{array}{l}\text { Especificaçōes de serviços e recomendaçōes técnicas e administrativas para uso } \\
\text { e aplicaçâo das informaços contidas no projeto }\end{array}$ \\
\hline & & & $\begin{array}{l}\text { Plantas de todos os pavimentos } \\
\text { Cortes passando por todos os pavimentos }\end{array}$ & Arquitetura & $\begin{array}{l}\text { ARQ-D } 001 \text { a ARQ-D } \\
006\end{array}$ & $\begin{array}{l}\text { Especificacãão de todos os materiais e equipamentos a serem utilizados na } \\
\text { instalaçâ, com respectivos memoriais }\end{array}$ \\
\hline & & & Formas da estrutura de todos os pavimentos & Estrutura & STR-D 001 & \\
\hline & & & $\begin{array}{l}\text { Posicionamento e dimensōes finais de equipamentos, } \\
\text { tubulaçōes, drenagens e dutos dos sistemas de } \\
\text { climatizacâão }\end{array}$ & Climatização & $\begin{array}{l}\text { VAC-D } 001 \text { e VAC-D } \\
003\end{array}$ & \\
\hline & & & $\begin{array}{l}\text { Projetos de vedação de todos os pavimentos (quando } \\
\text { forem utilizados sistemas de vedacão que impliquem a } \\
\text { necessidade de detalhamento adicional nos projetos }\end{array}$ & Vedação & & \\
\hline \multirow[t]{4}{*}{82} & ELE-D 001 & $\begin{array}{l}\text { Definição de Circuitos, } \\
\text { Dimensionamentos Elétricos } \\
\text { Gerais e Projeto de Quadros } \\
\text { e Painéis Elétricos }\end{array}$ & & & & \\
\hline & & & $\begin{array}{l}\text { Plantas de todos os setores ou pavimentos com } \\
\text { posicionamento de quadros, pontos e outros dispositivos } \\
\text { e componentes de todos os sistemas elétricos, produtos } \\
\text { da etapa ELE COO1, analisados e comentados e } / \text { ou } \\
\text { confirmados por todas as especialidades de projeto } \\
\text { envolvidas }\end{array}$ & \multirow[t]{3}{*}{ Todas as Disciplinas } & \multirow{3}{*}{$\begin{array}{l}\text { ARQ-C } 008 \\
\text { STR-D } 001 \text { a STR- D } \\
003\end{array}$} & Especificaçôes finais de equipamentos elétricos da instalação \\
\hline & & & \multirow[b]{2}{*}{$\begin{array}{l}\text { Confirmação das necessidades de alimentação elétrica } \\
\text { dos equipamentos definidos e / ou especifica pelas } \\
\text { diversas especialidades de projeto }\end{array}$} & & & Diagramas unifilares gerais do sistema de energia elétrica \\
\hline & & & & & & $\begin{array}{l}\text { Tabelas de alimentadores } \\
\text { Diagramas elétricos e especificação de quadros e painéis elétricos de } \\
\text { distribuição, força e comando, inclusive definição das dimensões e especificação } \\
\text { dos seus componentes }\end{array}$ \\
\hline
\end{tabular}




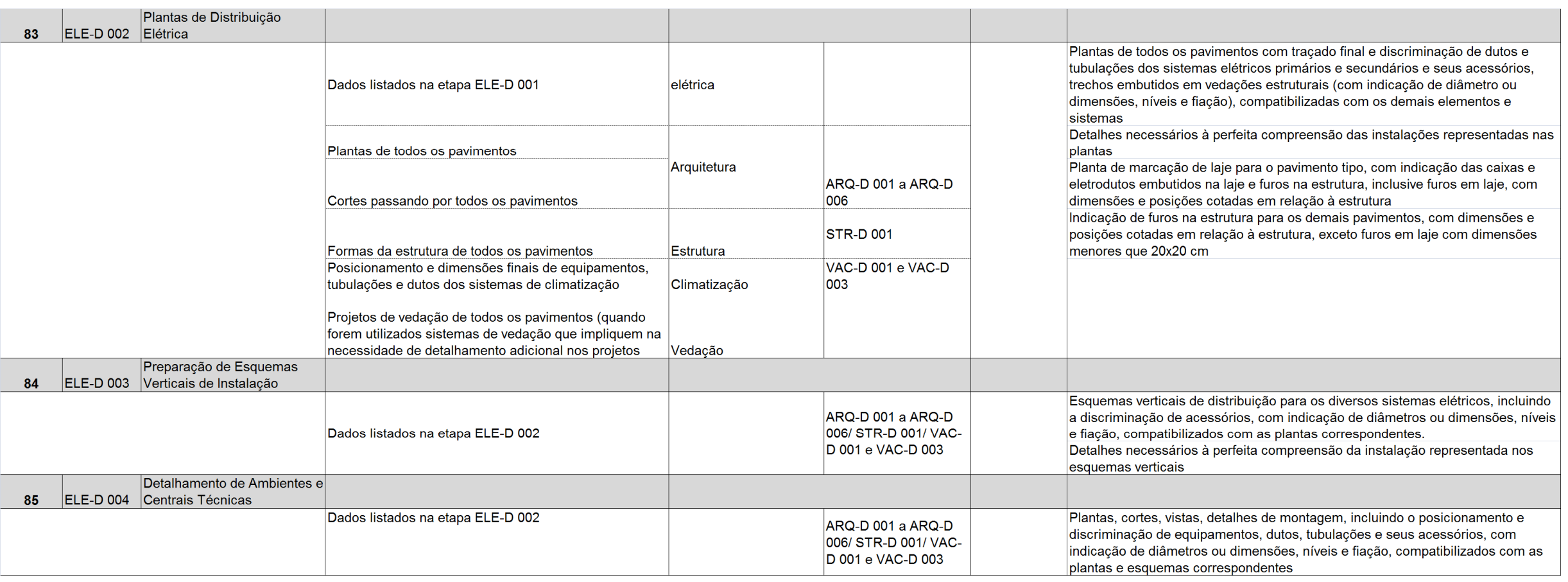




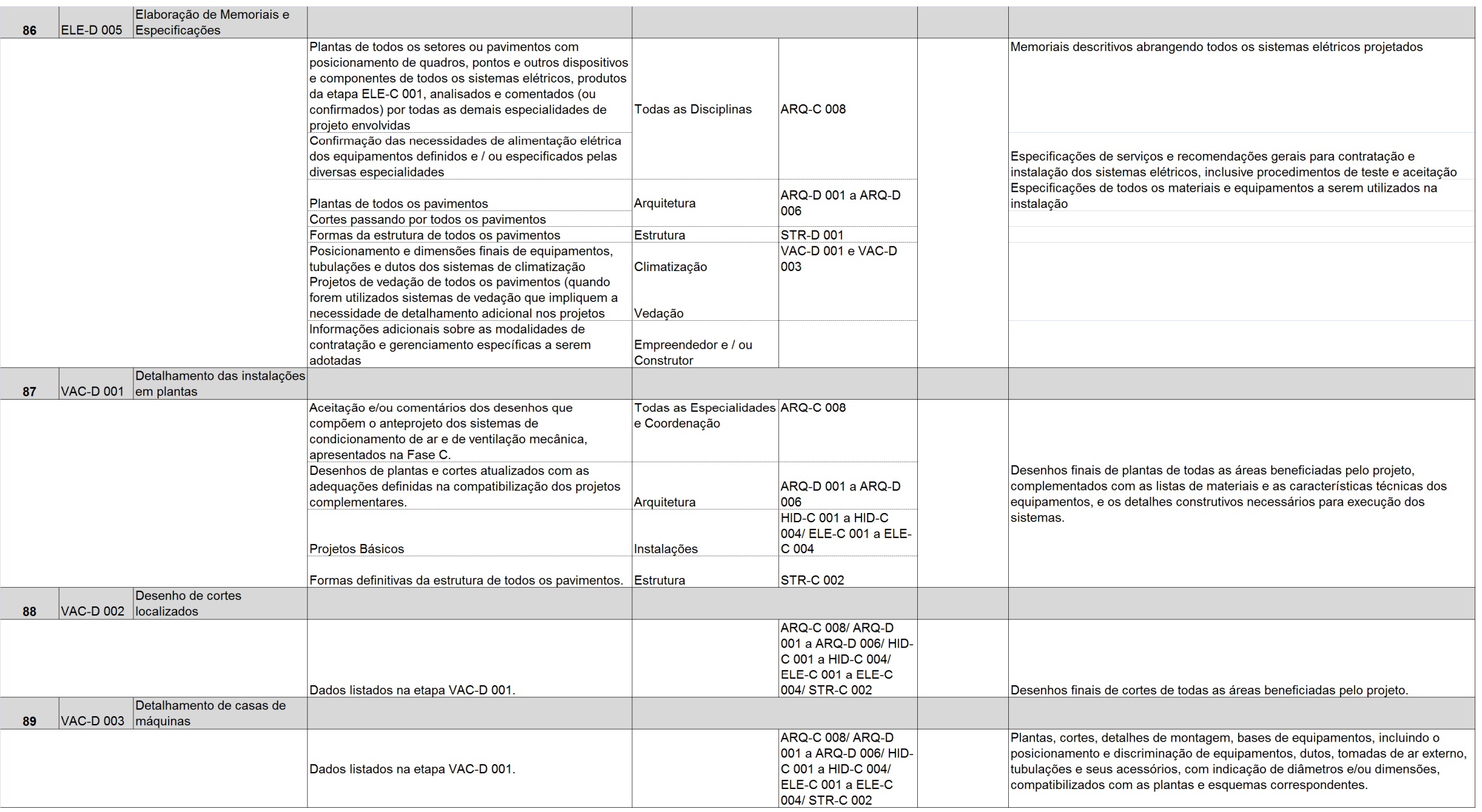




\begin{tabular}{|c|c|c|c|c|c|c|}
\hline 90 & VAC-D 004 & $\begin{array}{l}\text { Elaboração de diagramas de } \\
\text { alimentação elétrica }\end{array}$ & & & & \\
\hline & & & Dados listados na etapa VAC-D 001. & & $\begin{array}{l}\text { ARQ-C 008/ ARQ-D } \\
001 \text { a ARQ-D 006/ HID- } \\
\text { C } 001 \text { a HID-C 004/ } \\
\text { ELE-C } 001 \text { a ELE-C } \\
004 / \text { STR-C } 002\end{array}$ & $\begin{array}{l}\text { Diagramas elétricos unifilares, indicando as capacidades de cada circuito e todos } \\
\text { os dispositivos de proteção, medição e manobra. }\end{array}$ \\
\hline \multirow[t]{3}{*}{91} & VAC-D 005 & $\begin{array}{l}\text { Elaboracąão de memoriais } \\
\text { descritivos e especificaçōes } \\
\text { técnicas }\end{array}$ & & & & \\
\hline & & & \multirow{3}{*}{$\begin{array}{l}\text { Projeto Executivo completo e aprovado. } \\
\text { Informaçōes adicionais sobre as modalidades de } \\
\text { contratacacão e gerenciamento especificas a serem } \\
\text { adotadas. }\end{array}$} & $\begin{array}{l}\text { Ventilação e Ar } \\
\text { Condicionado }\end{array}$ & $\begin{array}{l}\text { VAC-D } 001 \text { a VAC-D } \\
\text { O04 APROVADOS }\end{array}$ & \multirow{3}{*}{$\begin{array}{l}\text { Memoriais descritivos da instalação. } \\
\text { Especificacãoes de execuçãoo, ensaios de desempenho e entrega dos sistemas. } \\
\text { Especificações de fornecimento para os materiais e equipamentos selecionados, } \\
\text { e respectivos testes de fábrica, a serem requeridos. }\end{array}$} \\
\hline & & & & $\begin{array}{l}\text { Empreendedor e/ou } \\
\text { Construtor }\end{array}$ & & \\
\hline \multirow[t]{7}{*}{92} & PSG-D 001 & $\begin{array}{l}\text { Solução definitiva de } \\
\text { implantação, detalhamento e } \\
\text { materiais de acabamento. }\end{array}$ & & & & \\
\hline & & & $\begin{array}{l}\text { Definição final de todos acabamentos propostos no } \\
\text { empreendimento. }\end{array}$ & \multirow[t]{2}{*}{$\begin{array}{l}\text { Empreendedor/Contratan } \\
\text { te/Gestor }\end{array}$} & \multirow[t]{2}{*}{$\begin{array}{l}\text { ARQ-C/ STR-C/ HID-CI } \\
\text { ELE-C/ VAC-C/ PSG-C } \\
\text { APROVADAS }\end{array}$} & \multirow[t]{6}{*}{$\begin{array}{l}\text { Desenhos em número e nas escalas convenientes e adequadas para a total } \\
\text { compreensão do projeto e a implantação do mesmo. Será composto no minimo } \\
\text { de plantas (com indicação do modelado no terreno, cotas de nivel, especificação } \\
\text { dos materiais e distribuição dos equipamentos, soluções de drenagem, pontos de } \\
\text { água e luz), cortes e detalhes construtivos }\end{array}$} \\
\hline & & & Elementos da FASE $C$ aprovados para todas disciplinas. & & & \\
\hline & & & $\begin{array}{l}\text { Projeto de implantação das edificacões } \\
\text { Atividades da Fase C aprovados e definitivos. }\end{array}$ & \begin{tabular}{|l} 
Arquitetura \\
Estrutura
\end{tabular} & $\begin{array}{l}\text { ARQ-D } 002 \\
\text { STR-C APROVADA }\end{array}$ & \\
\hline & & & Atividades da Fase $\mathrm{C}$ aprovados e definitivos. & Instalações elétricas & ELE-C APROVADA & \\
\hline & & & Atividades da Fase $C$ aprovados e definitivos. & Instalaçōes hidráulicas & HID-C APROVADA & \\
\hline & & & $\begin{array}{l}\text { Projetos aprovados e definitivos de cada consultoria } \\
\text { (sequranca. luminotécnica, etc.) }\end{array}$ & Consultores & & \\
\hline \multirow{2}{*}{93} & PSG-D 002 & $\begin{array}{l}\text { Memoriais Descritivos de } \\
\text { Especificacōes de materiais }\end{array}$ & & & & \\
\hline & & & $\begin{array}{l}\text { Todas as atividades produzidas e consolidadas nesta } \\
\text { fase, analisadas, comentadas e validadas por todas as } \\
\text { disciplinas envolvidas. }\end{array}$ & Todas as Disciplinas & $\begin{array}{l}\text { PSG-D } 001 \text { a PSG-D } \\
\text { O05 APROVADAS }\end{array}$ & \multirow[t]{2}{*}{$\begin{array}{l}\text { Especificacãão de materiais e sevicicos com as recomendaçōes técnicas para uso } \\
\text { e aplicaçăo das informaçōes contidas no projeto. }\end{array}$} \\
\hline \multirow[t]{6}{*}{94} & PSG-D 003 & $\begin{array}{l}\text { Detalhamento de pisos e } \\
\text { pavimentaçōes }\end{array}$ & & & & \\
\hline & & & $\begin{array}{l}\text { Definição final de todos acabamentos propostos no } \\
\text { empreendimento. }\end{array}$ & $\begin{array}{l}\text { Empreendedor / } \\
\text { Contratante / Gestor }\end{array}$ & $\begin{array}{l}\text { ARQ-C/ STR-C/ HID-C/ } \\
\text { ELE-C/ VAC-C/ PSG-C } \\
\text { APROVADAS }\end{array}$ & \multirow{5}{*}{ 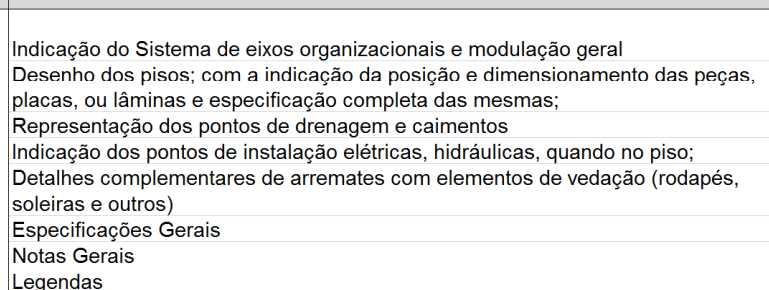 } \\
\hline & & & $\begin{array}{l}\text { Elementos da FASE C aprovados para todas disciplinas. } \\
\text { Projeto de implantação das edificaçōes } \\
\text { Atividades da Fase C aprovados e definitivos: }\end{array}$ & $\begin{array}{l}\text { Arquitetura } \\
\text { Estrutura }\end{array}$ & $\begin{array}{l}\text { ARQ-D } 002 \\
\text { STR-C APROVADA }\end{array}$ & \\
\hline & & & Atividades da Fase $C$ aprovados e definitivos. & Instalações elétricas & ELE-C APROVADA & \\
\hline & & & Atividades da Fase $\mathrm{C}$ aprovados e definitivos. & Instalaçč̄es hidráulicas & HID-C APROVADA & \\
\hline & & & $\begin{array}{l}\text { Projetos aprovados e definitivos de cada consultoria } \\
\text { (segurança, luminotécnica, etc.). }\end{array}$ & Consultores & & \\
\hline
\end{tabular}




\begin{tabular}{|c|c|c|c|c|c|c|}
\hline \multirow[t]{7}{*}{95} & PSG-D 004 & $\begin{array}{l}\text { Detalhamento de muros de } \\
\text { divisa, piscinas, elementos de } \\
\text { água e elementos } \\
\text { construidos. }\end{array}$ & & & & \\
\hline & & & $\begin{array}{l}\text { Definição final de todos acabamentos propostos no } \\
\text { empreendimento. }\end{array}$ & $\begin{array}{l}\text { Empreendedor/Contratan } \\
\text { te/Gestor }\end{array}$ & $\begin{array}{l}\text { ARQ-C/ STR-C/ HID-C/ } \\
\text { ELE-C/ VAC-C/ PSG-C }\end{array}$ & \multirow{6}{*}{$\begin{array}{l}\text { Desenhos cotados em escalas ampliadas, necessários à melhor compreensão e } \\
\text { execução da obra } \\
\text { Desenhos cotados de instalação de equipamentos } \\
\text { Desenhos cotados de arremates de peitoris, rodapés ou revestimentos; } \\
\text { Desenhos cotados de arremates das alvenarias ou de outros elementos de } \\
\text { vedação com estruturas; } \\
\text { Especificaçôos gerais } \\
\text { Notas Gerais } \\
\text { Legendas }\end{array}$} \\
\hline & & & $\begin{array}{l}\text { Elementos da FASE C aprovados para todas disciplinas. } \\
\text { Proieto de }\end{array}$ & & $\begin{array}{ll}\text { ARROVADAS } \\
\text { ARO-D } 002\end{array}$ & \\
\hline & & & & & & \\
\hline & & & Atividades da Fase $C$ aprovados e definitivos: & Estrutura & STR-C APROVADA & \\
\hline & & & $\begin{array}{l}\text { Atvidades da Fase } C \text { aprovados e detinitivos. } \\
\text { Atividades da Fase Caprovados e definitivos. }\end{array}$ & $\begin{array}{l}\text { Instaláçoes elertricas } \\
\text { Instalacõos hidrúlicas } \\
\end{array}$ & $\begin{array}{l}\text { ELE-C APROVADA } \\
\text { HID-C APROVADA }\end{array}$ & \\
\hline & & & $\begin{array}{l}\begin{array}{l}\text { Projetos aprovados e definitivos de cada consultoria } \\
\text { (segurança, luminotécnica, etc.). }\end{array} \\
\text {. }\end{array}$ & Consultores & & \\
\hline \multirow[t]{2}{*}{96} & PSG-D 005 & $\begin{array}{l}\text { Solução definitiva do projeto } \\
\text { de vegetação - plantio }\end{array}$ & & & & \\
\hline & & & $\begin{array}{l}\text { Produtos das fases PSG-D-001 a PSG-D-004 } \\
\text { aprovados. }\end{array}$ & & $\begin{array}{l}\text { PSG-D001 a PSG-D } \\
\text { O04 APROVADOS }\end{array}$ & Plantas de veqetacão \\
\hline
\end{tabular}

Tabela 11: Tabela de dependência de informações fase D 